\title{
Mapping and fine-mapping of genetic factors affecting bovine milk composition
}

\section{Sandrine Isolde Duchemin}

Acta Universitatis Agriculturae Sueciae Doctoral Thesis No. 2016:39

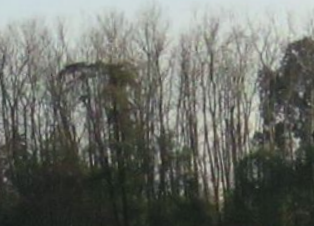

(n)

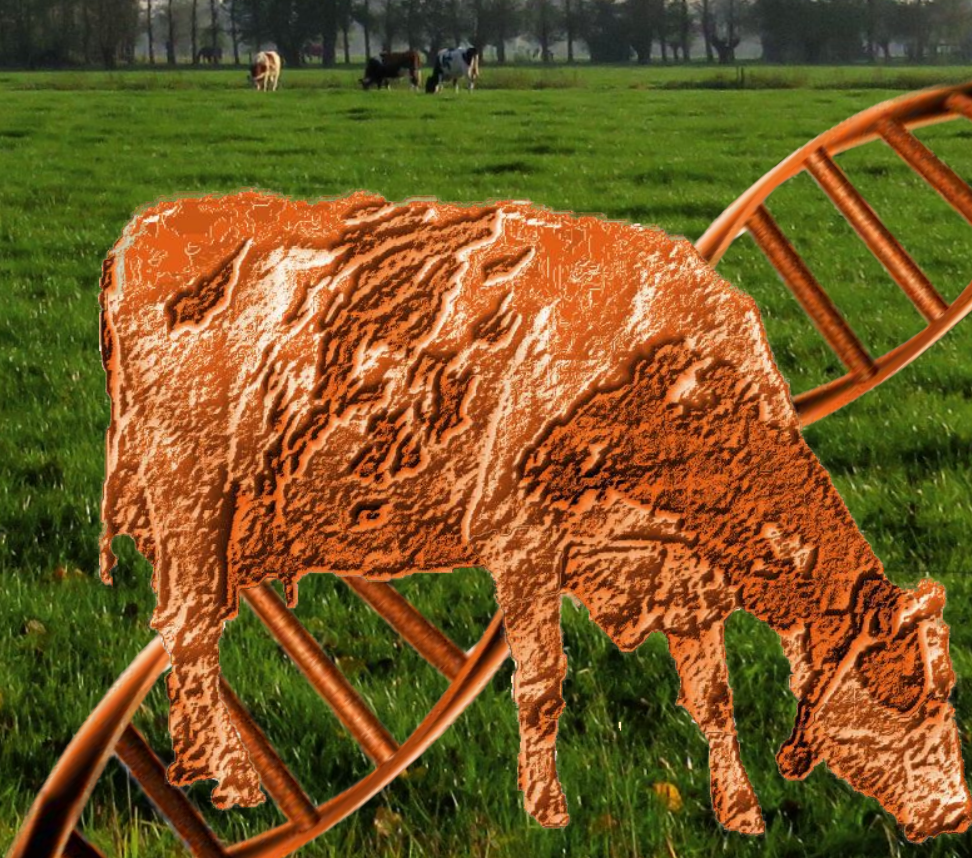

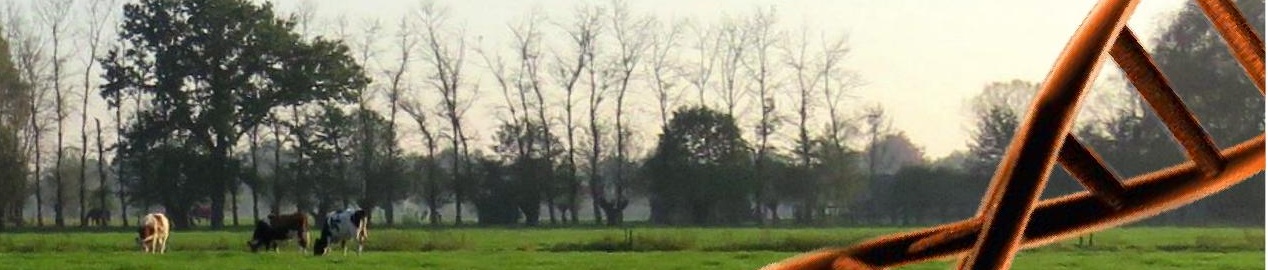

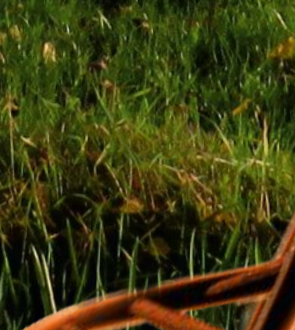




\section{Propositions}

1. Imputation is the limiting factor for detection of rare-variant quantitative trait loci in traditional genome-wide association studies.

(this thesis)

2. Good annotation of the cattle genome is crucial for gene discovery. (this thesis)

3. The real CRISPR/Cas9 revolution is the editing of human somatic cells, not the editing of human germ-line cells.

4. Diseases in animals as dynamic events are best modelled, diagnosed and treated by veterinarians.

5. Women who accept a gender quota are in fact agreeing they are less than men.

6. In science sand grains from publications build up to mountains of knowledge.

Propositions belonging to the thesis, entitled:

"Mapping and fine-mapping of genetic factors affecting bovine milk composition"

Sandrine Isolde Duchemin

Wageningen, 30 May 2016 


\section{Mapping and fine-mapping of genetic factors affecting bovine milk composition}




\section{Thesis committee}

\section{Promotors}

Prof. Dr. ir. J.A.M. van Arendonk

Professor of Animal Breeding and Genetics

Wageningen University

\section{Co-promotor}

Dr. ir. H. Bovenhuis

Associate professor, Animal Breeding and Genomics Centre

Wageningen University

Dr. ir. M.H.P.W. Visker

Researcher, Animal Breeding and Genomics Centre

Wageningen University

Dr. ir. W.F. Fikse

Senior researcher, Department of Animal Breeding and Genetics

Swedish University of Agricultural Sciences

\section{Other members (assessment committee)}

Prof. Dr. E.J.M. Feskens, Wageningen University

Prof. Dr. A.C.M. van Hooijdonk, Wageningen University

Prof. Dr. L. Andersson-Eklund, Swedish University of Agricultural Sciences, Sweden

Dr. D. Boichard, National Institute for Agricultural Research (INRA), France

The research presented in this doctoral thesis was conducted under the joint auspices of the Swedish University of Agricultural Sciences and the Graduate School Wageningen Institute of Animal Sciences of Wageningen University and is part of the Erasmus Mundus Joint Doctorate program "EGS-ABG". 


\title{
Mapping and fine-mapping of genetic factors affecting bovine milk composition
}

\author{
Sandrine Isolde Duchemin
}
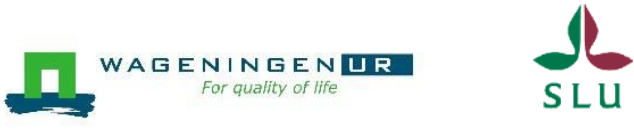

S LU

\author{
ACTA UNIVERSITATIS AGRICULTURAE SUECIAE \\ DOCTORAL THESIS № 2016:39
}

\section{Thesis}

submitted in fulfillment of the requirements for the degree of doctor from

Swedish University of Agricultural Sciences

by the authority of the Board of the Faculty of Veterinary Medicine and

Animal Science and from

Wageningen University

by the authority of the Rector Magnificus, Prof. Dr. A.P.J. Mol,

in the presence of the

Thesis Committee appointed by the Academic Board of Wageningen University and the Board of the Faculty of Veterinary Medicine and Animal Science at the Swedish University of Agricultural Sciences

to be defended in public on Monday May 30, 2016

at 4.00 p.m. in the Aula of Wageningen University 
ISSN 1652-6880

ISBN (print version) 978-91-576-8580-3

ISBN (electronic version) 978-91-576-8581-0

ISBN 978-94-6257-730-5

DOI: $10.18174 / 370103$

Duchemin, S.I.

Mapping and fine-mapping of genetic factors affecting bovine milk composition.

Joint PhD thesis, Swedish University of Agricultural Sciences, Uppsala, Sweden and Wageningen University, the Netherlands (2016)

With references, with summary in English 


\begin{abstract}
Duchemin, S.I. (2016). Mapping and fine-mapping of genetic factors affecting bovine milk composition. Joint PhD thesis, between Swedish University of Agricultural Sciences, Sweden and Wageningen University, the Netherlands
\end{abstract}

Bovine milk is an important source of nutrients in Western diets. Unraveling the genetic background of bovine milk composition by finding genes associated with milk-fat composition and non-coagulation of milk were the main goals of this thesis.

In Chapter 1, a brief description of phenotypes and genotypes used throughout the thesis is given. In Chapter 2, I calculated the genetic parameters for winter and summer milk-fat composition from $\sim 2,000$ Holstein-Friesian cows, and concluded that most of the fatty acids (FA) can be treated as genetically the same trait. The main differences between milk-fat composition between winter and summer milk samples are most likely due to differences in diets. In Chapter 3, I performed genome-wide association studies (GWAS) with imputed 777,000 single nucleotide polymorphism (SNP) genotypes. I targeted a quantitative trait locus (QTL) region on Bos taurus autosome (BTA) 17 previously identified with 50,000 SNP genotypes, and identified a region covering 5 mega-base pairs on BTA17 that explained a large proportion of the genetic variation in de novo synthesized milk FA. In Chapter 4, the availability of whole-genome sequences of keys ancestors of our population of cows allowed to fine-mapped BTA17 with imputed sequences. The resolution of the 5 mega base-pairs region substantially improved, which allowed the identification of the LA ribonucleoprotein domain family, member 1B (LARP1B) gene as the most likely candidate gene associated with de novo synthesized milk FA on BTA17. The LARP1B gene has not been associated with milk-fat composition before. In Chapter 5, I explored the genetic background of non-coagulation of bovine milk. I performed a GWAS with 777,000 SNP genotypes in 382 Swedish Red cows, and identified a region covering 7 mega base-pairs on BTA18 strongly associated with noncoagulation of milk. This region was further characterized by means of fine-mapping with imputed sequences. In addition, haplotypes were built, genetically differentiated by means of a phylogenetic tree, and tested in phenotype-genotype association studies. As a result, I identified the vacuolar protein sorting 35 homolog, mRNA (VPS35) gene, as candidate. The VPS35 gene has not been associated to milk composition before. In Chapter 6, the general discussion is presented. I start discussing the challenges with respect to high-density genotypes for gene discovery, and I continue discussing future possibilities to expand gene discovery studies, with which I propose some alternatives to identify causal variants underlying complex traits in cattle. 



\section{For my family}

"Flatter me, and I may not believe you.

Criticize me, and I may not like you.

Ignore me, and I may not forgive you.

Encourage me, and I will not forget you.

Love me and I may be forced to love you."

William Arthur Ward, writer, 1921-1994. 



\section{Table of Contents}

$5 \quad$ Abstract

$7 \quad$ Prologue

$11 \quad 1-$ General Introduction

212 - Genetic correlation between composition of bovine milk fat in winter and summer, and DGAT1 and SCD1 by season interactions

493 - A quantitative trait locus on Bos taurus autosome 17 explains a large proportion of the genetic variation in de novo synthesized milk fatty acids

734 - Fine-mapping of Bos taurus autosome 17 using imputed sequences for associations with de novo synthesized fatty acids in bovine milk

995 - Identification of QTL on chromosome 18 associated with noncoagulating milk in Swedish Red cows

1416 -General Discussion

163 Summary

169 Training and Education

175 Curriculum vitae

181 Acknowledgements

189 Colophon 

1

General Introduction 



\subsection{Milk}

Milk has fascinated mankind since the beginning of the ages. A clear example of this fascination is the Milky Way galaxy, which contains our Planet Earth. The Milky Way galaxy has its roots in the Greek-Roman Mythology. The word galaxy originates from galas, which is a synonym for milk in Greek language. According to the Mythology, the Milky Way galaxy was "drops of milk" spelt by goddess Hera, when breastfeeding Hercules, the bastard son of Zeus (Larousse encyclopedia, 2015). "The origin of the Milky Way" has been immortalized by the renaissance artist Jacopo Tintoretto circa 1575-1580 (National Gallery, London, UK; Figure 1.1), and the "Birth of the Milky Way" by the Flemish artist Peter Paul Rubens in 1637 (Museo del Prado, Madrid, Spain). In many civilizations, the Milky Way galaxy has been used as a metaphor for a splash of milk in the dark skies of our Universe. Essentially, this metaphor is a way of expressing the importance of milk for mankind. It is so important that from the very beginning of life, an infant receives milk as the primary source of nutrients.

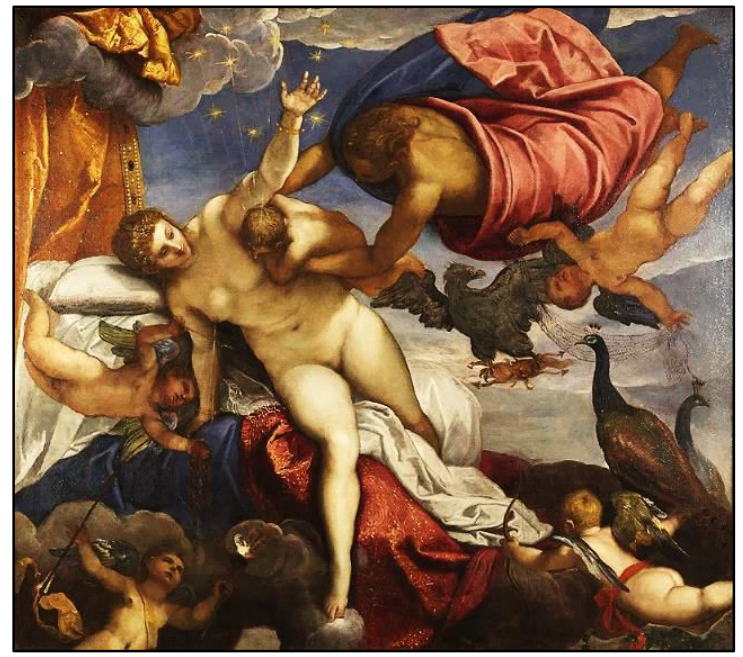

Figure 1.1 - "The origin of the Milky Way" by Jacopo Tintoretto circa 1575-1580 (exposed in the National Gallery, London, UK)

The fascination exerted by Universe on mankind is understandable. By contemplating stars, mankind loses notion of time allowing deeper lessons to be learnt. When G. Galilei (in: Galilei and Van Helden, 1989) first observed the Milky Way galaxy through his telescope in 1610 , he discovered that it was formed by many smaller groups of stars. Following the steps of G. Galilei (in: Galilei and Van Helden, 1989) a deeper look into the splash of milk in the dark skies might give us insights 
into the composition of milk. The splash might represent the fluid part of milk. The small groups of stars composing this splash might represent the main components in milk, such as proteins and fatty acids. The interstellar dust accompanying these stars might represent the minerals in milk. In just a few instants, the composition of milk is described as an (scientific) idea that has been transmitted throughout centuries by a simple metaphor.

Metaphors with our Universe do not stop at the Milky Way galaxy. Mankind named constellations after species of animals (e.g., Taurus, Aries, and Pisces), just like cave men have represented wild animals in their cave drawings. From stone-age to modern times, domestication of animals has been one of the drivers for men's transition from hunters to farmers. During this process, the role of cattle was undeniable. By domesticating cows, mankind preserved through time important resources, such as the genetic variation of bovine species. The preservation of this genetic variation has important consequences for the current technological development of mankind. It is so important that from the beginning of every life, genetic variation will determine the future of all species.

By using metaphors, such as Milky Way galaxy and names of constellations, mankind transmitted more than just a simple image from cave to modern men. As intrinsic parts of the Milky Way galaxy, cave and modern men would be united forever as one student. For mankind, these metaphors have engraved in our collective memories a deep respect for our Planet Earth and its scarce resources. Resources beyond genetic variation have been translated. In our modern times, this deep respect is taught by uniting human needs (milk as a nutrient) and animal resources (genes affecting bovine milk composition) through Animal Breeding and Genetics.

The scope of my thesis was to investigate the genetic background of bovine milk composition. More specifically, my thesis focuses on the composition of milk-fat, and on non-coagulation of milk.

\subsection{Milk-fat composition}

Bovine milk fat is an important source of energy for mankind. The main bioactive lipids in bovine milk are fatty acids (FA). According to Jensen (2002), bovine milk-fat is composed of more than 400 individual FA, most occurring in amounts less than $1 \%$. The individual FA in bovine milk-fat are organized in chain of carbons that vary in length from 4 to 22 carbons. According to their chain-lengths, these individual FA 
are grouped as short-chain (C4:0 - C12:0), medium-chain (C14:0 - C16:0) and longchain (C18:0 - C22:0) FA. In addition, individual FA can be either saturated or unsaturated. FA are saturated when a carbon is connected by a single bond to an adjacent carbon in the chain, and FA are unsaturated when a carbon is connected to an adjacent carbon in the chain by double or triple bonds. Differences in FA regarding their saturation are shown in Figure 1.2.
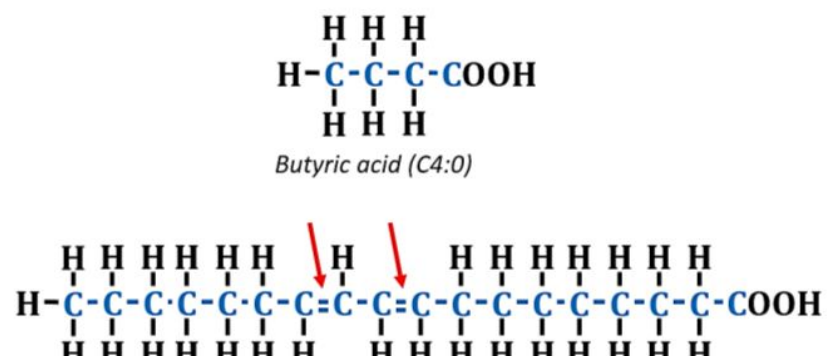

H H H H H H H H H H H H H H H H

Conjugated linoleic acid

(CLA cis9, trans11)

Figure 1.2 - Representation of fatty acids (FA). Butyric acid representing saturated FA, and conjugated linoleic acid representing unsaturated FA. Arrows in red point out the double bonds between adjacent carbons.

The biosynthesis of milk-fat occurs in the mammary gland of a cow. Individual FA in the mammary gland arise from circulating blood lipids and de novo synthesis. Circulating blood lipids originate from the feed of the cow or from the cow's body fat. Through the de novo synthesis, FA are elongated from precursors by adding C2:0. These precursors can be either acetate $(C 2: 0)$, propionate $(C 3: 0)$ or butyrate $(C 4: 0)$. C2:0 and C3:0 originate from lipids in circulating blood, while C4:0 may either originate from blood lipids or the de novo synthesis itself (e.g., Craninx et al., 2008). Depending on the precursor, FA synthesized de novo may terminate at either C16:0 or C17:0. It is assumed that de novo synthesis produces the short-chain FA, C14:0 and $50 \%$ of $\mathrm{C} 16: 0$ in milk, whereas the remaining $50 \%$ of $\mathrm{C} 16: 0$ and the long-chain FA come from the lipids in circulating blood.

FA in bovine milk are relevant for human health. According to Calder et al. (2015), FA are essential for the well-being of humans, and they have important biological activities regarding the cell and tissue metabolism, as well as responsiveness to hormones and other signals in human cells. Stoop et al. (2008) indicated that FA in bovine milk are heritable, with heritability estimates between 0.22 and 0.71 . These heritability estimates suggest that milk-fat composition can be improved by 
breeding. In addition, Tzompa-Sosa et al. (2014) showed that increases in long-chain saturated FA can influence the thermal properties of milk-fat, which can lead to important changes in the quality of milk-fat derived products. Moreover, breeding could be used to reduce the concentration of certain FA in bovine milk-fat. For instance, low concentrations of $\mathrm{C} 16: 0$ in bovine milk-fat would best meet infant requirements regarding the consumption of milk-fat derived products (e.g., TzompaSosa et al., 2014). Therefore, increasing the biological knowledge regarding bovine milk-fat composition can be of great interest to the dairy industry.

\subsection{Non-coagulation of milk}

In addition to FA, bovine milk is an important source of proteins for mankind. The main proteins in bovine milk are the caseins, which account for almost $80 \%$ of the

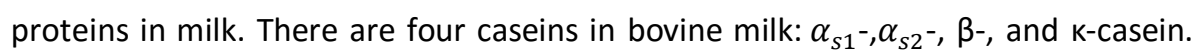
Most of these caseins are organized in micelles. These micelles are not soluble in water and can precipitate in the presence of rennet. This property is used in cheese production to induce coagulation of milk. In 2013, almost $30 \%$ of the total production of bovine milk in Sweden was destined to cheese production (LRF Dairy Sweden, 2015).

Besides the caseins, whey proteins account for the remaining $20 \%$ of the proteins in milk, of which $\beta$-lactoglobubin and $\alpha$-lactalbumin are the most important ones. The whey proteins are considered by-products of cheese production. In contrast to caseins, whey proteins are soluble in water, and can only be denatured by heat. When heated, whey proteins can produce products such as ricotta and whey butter.

It is economically relevant for the cheese industry to reduce time and losses while producing cheese. In this sense, if caseins in bovine milk do not coagulate after rennet addition, the entire chain of cheese production is delayed, generating losses for this industry. Consequently, non-coagulation of milk can be considered as a new phenotype that accounts for the needs of the cheese industry. Non-coagulation (NC) of milk is prevalent among several dairy cattle breeds, such as Swedish Red, Finnish Ayrshire, Holstein-Friesian, and Italian Brown Swiss, to name a few (e.g., Frederiksen et al., 2011; Cecchinato et al., 2011, Gustavsson et al., 2014). The prevalence of NC milk varies among these breeds ranging from $4 \%$ in Italian Brown Swiss (Cecchinato et al., 2009) up to $13 \%$ in Finnish Ayrshires (Ikonen et al., 2004). A recent study reported the prevalence of NC milk at $18 \%$ in the Swedish Red cows (Gustavsson et al., 2014). 


\subsection{Genomic regions influencing bovine milk composition}

Many genomic regions of the cattle genome have been associated with milk composition. While many of these genomic regions have not been studied in detail yet, some genes have been associated with milk-fat composition and noncoagulation of milk.

For bovine milk-fat composition, the main identified genes are: diacylglycerol Oacyltransferase 1 (DGAT1) located on Bos taurus autosome (BTA) 14, stearoyl-CoA desaturase 1 (SCD1) located on BTA26, acyl-CoA synthase short-chain family member 2 (ACSS2) located on BTA13, fatty acid synthase (FASN) located on BTA19, and 1-Acylglycerol-3-Phosphate O-Acyltransferase 6 (AGPAT6) located on BTA27. The association of the DGAT1 and SCD1 genes with milk-fat composition has been studied e.g., by Schennink et al. $(2007,2008)$. The association of the ACSS2, FASN and AGPAT6 genes with milk-fat composition has have been studied e.g., by Bouwman et al. (2011) and LittleJohn et al. (2014). The involvement of each of these genes occurs at different stages in the synthesis of milk-fat in the mammary gland of a cow: intracellular FA activation (ACSS2), fatty acid synthesis (FASN), unsaturation of FA (SCD1), and triacylglycerol synthesis (AGPAT6, DGAT1).

For bovine milk protein composition, the six major proteins in milk are encoded on

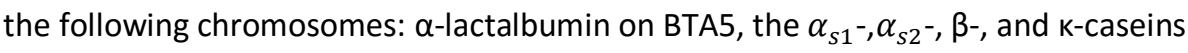
on BTA6, and $\beta$-lactoglobubin on BTA11. However, other chromosomal regions have been associated with milk protein composition (Schopen et al., 2011). These chromosomal regions encoding milk proteins seem to influence milk coagulation properties including non-coagulation of milk. Studies by Jensen et al. (2012) and by Gregersen et al. (2015) suggest that poor- and non-coagulation of milk are influenced by the milk protein variants of the k-casein gene. In contrast, study by Tyrisevä et al. (2008) and Gregersen et al. (2015) revealed that non-coagulation of milk can be influenced by other parts of the cattle genome too.

Promising genomic regions across the cattle genome in association with the desired trait can be identified with genetic markers. It is expected that associations with FA or non-coagulation of milk can be targeted to smaller chromosomal regions with sequences as compared to other panels of genetic markers, such as 50,000 (50k) and 777,000 (777k) single nucleotide polymorphism (SNP) markers. Sequences should contain all of the causal variants (Meuwissen and Goddard, 2010) that are believed 
to be associated with the studied phenotype. The use of sequences for association studies has been enabled by the availability of an increasing number of sequenced animals (bulls and cows) from projects like the 1000Bull Genome Consortium (Daetwyler et al., 2014).

\subsection{Aim and outline of this thesis}

The present thesis aims at unraveling the genetic background of bovine milk composition by finding genes associated with milk-fat composition and noncoagulation of milk in targeted chromosomal regions. Throughout this thesis, there is a consistent increase in the number of genotypes analyzed, which have been useful to increase the resolution of some interesting genomic regions associated with bovine milk composition. In Chapter 2, we calculated the genetic correlations between the composition of bovine milk fat in winter and summer, and DGAT1 and $S C D 1$ by season interactions. The conclusions of this work were further explored in Chapters 3 and 4. In Chapter 3, a quantitative trait locus on Bos taurus autosome (BTA) 17 explaining a large proportion of the genetic variation in de novo synthesized milk FA is mapped. In Chapter 4, we fine-mapped this QTL associated with de novo synthesized milk FA on BTA17 using imputed sequences. In Chapter 5, a similar finemapping methodology was used for the identification of a QTL on BTA18 associated with non-coagulation of milk in Swedish Red cows. In Chapter 6, challenges regarding the substantial increase in the number of genotypes used in this thesis, and the future possibilities to expand gene discovery are discussed.

\subsection{References}

Bouwman, A. C., Bovenhuis, H., Visker, M. H. P. W., and van Arendonk, J. A. M. 2011. Genome-wide association of milk fatty acids in Dutch dairy cattle. BMC Genetics 12:43.

Calder, P. C. 2015. Functional roles of fatty acids and their effects on human health. J Parenter Enteral Nutr, 39.1: 18S-32S.

Cecchinato, A., De Marchi, M., Gallo, L., Bittante, G., and Carnier, P. 2009. Midinfrared spectroscopy predictions as indicator traits in breeding programs for enhanced coagulation properties of milk. J Dairy Sci 92, 5304-5313.

Cecchinato, A., Penasa, M., De Marchi, M., Gallo, L., Bittante, G., and Carnier, P. 2011. Genetic parameters of coagulation properties, milk yield, quality, and acidity: estimated using coagulating milk and noncoagulating information in Brown Swiss and Holstein cows. J Dairy Sci 94, 4205-4213. 
Craninx, M., A. Steen, H. Van Laar, T. Van Nespen, J. Martin-Tereso, B. De Baets, and V. Fievez. 2008. Effect of lactation stage on the odd- and branched-chain milk fatty acids of dairy cattle under grazing and indoor conditions. J. Dairy Sci. 91:26622677.

Daetwyler, H.D., Capitan, A., Pausch, H., Stothard, P., van Binsbergen, R., Brondum, R.F., Liao, X., Djari, A., Rodriguez, S.C., Grohs, C., Esquerre, D., Bouchez, O., Rossignol, M-N., Klopp, C., Rocha, D., Fritz, S., Eggen, A., Bowman, P.J., Coote, D. Chamberlain, A.J., Anderson, C., VanTassell, C.P., Hulsegge, I., Goddard, M.E., Guldbrandtsen, B., Lund, M.S., Veerkamp, R.F., Boichard, D.A., Fries, R., and Hayes, B. J. 2014. Whole-genome sequencing of 234 bulls facilitates mapping of monogenic and complex traits in cattle. Nat Genet 46, 858-865.

Frederiksen, P. D., Andersen, K. K., Hammershøj, M., Poulsen, H. D., Sørensen, J., Bakman, M., Qvist, K.B., and Larsen, L.B. 2011. Composition and effect of blending of noncoagulating, poorly coagulating, and well-coagulating bovine milk from individual Danish Holstein cows. J Dairy Sci 94, 4787-4799.

Galilei, G., and Van Helden, A. 1989.Sidereus Nuncius, or the sidereal messenger. Chicago: University of Chicago Press.

Gustavsson, F., Glantz, M., Poulsen, N. A., Wadsö, L., Stålhammar, H., Andrén, A., Lindmark-Månsson, H., Larsen, L.B., Paulsson, M., and Fikse, W. F. 2014. Genetic parameters for rennet- and acid-induced coagulation properties in milk from Swedish Red dairy cows. J Dairy Sci 97, 5219-5229.

Gregersen, V. R., Gustavsson, F., Glantz, M., Christensen, O. F., Stålhammar, H., Andrén, A., Lindmark-Månsson, H., Poulsen, N. A., Larsen, L.B., Paulsson, M., and Bendixen, C. 2015. Bovine chromosomal regions affecting rheological traits in rennet-induced skim milk gels. J Dairy Sci 98, 1261-1272.

Ikonen, T., Morri, S., Tyrisevä, A-M., Ruottinen, O., and Ojala, M. 2004. Genetic and phenotypic correlations between milk coagulation properties, milk production traits, somatic cell count, casein content, and pH of milk. J Dairy Sci 87, 458-467.

Jensen, R. G. 2002. The composition of bovine milk lipids: January 1995 to December 2000. J. Dairy Sci. 85:295-350.

Jensen, H. B., Poulsen, N. A., Andersen, K. K., Hammershøj, M., Poulsen, H. D., and Larsen, L. B. 2012. Distinct composition of bovine milk from Jersey and HolsteinFriesian cows with good, poor, or noncoagulation properties as reflected in protein genetic variants and isoforms. J Dairy Sci 95, 6905-17.

Larousse Encyclopedia. 2015. http://www.larousse.fr/encyclopedie, accessed on Nov 3rd, 2015.

Littlejohn, M.D., Tiplady, K., Lopdell, T., Law, T. A., Scott, A., Harland, C., Sherlock, R., Henty, K., Obolonkin, V.,Lehnert, K., MacGibbon, A., Spelman, R. J., Davis, S. R., and 
Snell, R. G. 2014. Expression variants of the lipogenic AGPAT6 gene affect diverse milk composition phenotypes in Bos taurus. PLoS ONE 9: e85757.

LRF Dairy Sweden. 2015. http://www.Irf.se/globalassets/dokument/omIrf/branscher/Irf-mjolk/statistik/milk_key_figures_sweden.pdf , accessed on Nov 3rd, 2015.

Meuwissen, T., and Goddard, M. 2010. Accurate prediction of genetic values for complex traits by whole-genome resequencing. Genetics 185, 623-631.

Rubens, P. P. 1637. Birth of the Milky Way. Museo del Prado, Madrid, Spain.

Schennink, A., Stoop, W. M., Visker, M. H. P. W., Heck, J. , Bovenhuis, H., Van Der Poel, J., van Valenberg, H., and van Arendonk, J. A. M. 2007. DGAT1 underlies large genetic variation in milk-fat composition of dairy cows. Anim. Genet. 38:467-473.

Schennink, A., J. M. L. Heck, H. Bovenhuis, M. H. P. W. Visker, H. J. F. van Valenberg, and J. A. M. van Arendonk. 2008. Milk fatty acid unsaturation: genetic parameters and effects of Stearoyl-CoA Desaturase (SCD1) and Acyl CoA: Diacylglycerol Acyltransferase 1 (DGAT1). J. Dairy Sci. 91:2135-2143.

Schopen, G.C., Visker, M. H. P. W., Koks, P. D., Mullaart, E., van Arendonk, J. A. M., and Bovenhuis, H. 2011. Whole-genome association study for milk protein composition in dairy cattle. J Dairy Sci 94: 3148-3158.

Stoop, W. M., van Arendonk, J. A. M., Heck, J. M. L.,van Valenberg, H. J. F., and Bovenhuis, H. 2008. Genetic parameters for major milk fatty acids and milk production traits of Dutch Holstein-Friesians. J Dairy Sci. 91:385-394.

Tintoretto, J. (circa 1575-1580). Origins of the Milky Way. National Gallery, London, UK.

Tyrisevä, A. M., Elo, K., Kuusipuro, A., Vilva, V., Jänönen, I., Karjalainen, H., Ikonen, T., Ojala, M. 2008. Chromosomal regions underlying noncoagulation of milk in Finnish Ayrshire cows. Genetics 180, 1211-1220

Tzompa-Sosa, D. A., van Aken, G. A., van Hooijdonk, A. C. M., and van Valenberg, H. J. F. 2014. Influence of C16: 0 and long-chain saturated fatty acids on normal variation of bovine milk fat triacylglycerol structure. J Dairy Sci 97:4542-4551. 


\section{2}

\section{Genetic correlation between composition of bovine milk fat in winter and summer, and DGAT 1 and SCD1 by season interactions}

S. Duchemin ${ }^{1,2}$, H. Bovenhuis ${ }^{1}$, W. M. Stoop ${ }^{1}$, A. C. Bouwman ${ }^{1}$, J. A. M. van Arendonk $^{1}$, M. H. P. W. Visker ${ }^{1}$

${ }^{1}$ Animal Breeding and Genomics Centre, Wageningen University, PO Box 338, 6700 $\mathrm{AH}$ Wageningen, the Netherlands; ${ }^{2}$ Department of Animal Breeding and Genetics, Swedish University of Agricultural Sciences, Uppsala, Sweden 


\begin{abstract}
Milk fat composition shows substantial seasonal variation, most of which is probably caused by differences in the feeding of dairy cows. The present study aimed to know whether milk fat composition in winter is genetically the same trait as milk fat composition in summer. For this purpose, we estimated heritabilities, genetic correlations, effects of acyl-CoA: diacylglycerol acyltransferase1 (DGAT1) K232A and stearoyl-CoA desaturase1 (SCD1) A293V polymorphisms for milk fat composition in winter and summer, and tested for genotype by season interactions of DGAT1 K232A and SCD1 A293V polymorphisms. Milk samples were obtained from 2,001 first lactation Dutch Holstein Friesian cows, most of which with records in both winter and summer. Summer milk contained higher amounts of unsaturated fatty acids (FA) and lower amounts of saturated FA compared to winter milk. Heritability estimates were comparable between seasons: moderate to high for short and medium chain FA (0.33 to 0.74$)$ and moderate for long chain FA (0.19 to 0.43$)$ in both seasons. Genetic correlations between winter and summer milk were high, indicating that milk fat composition in winter and in summer can largely be considered as genetically the same trait. DGAT1 K232A and SCD1 A293V polymorphisms effects were similar across seasons for most FA. DGAT1 232A allele in winter as well as in summer milk samples was negatively associated with most FA with less than 18 carbons, SFA, SFA to UFA, and C10 to C16 unsaturation indices, and was positively associated with C14:0, unsaturated C18, UFA, and C18 and CLA unsaturation indices. SCD1 293V allele in winter as well as in summer milk samples was negatively associated with C18:0, C10:1 to C14:1cis-9, C18:1trans-11, and C10 to C14 unsaturation indices, and positively associated with $\mathrm{C} 8: 0$ to $\mathrm{C} 14: 0, \mathrm{C} 16: 1 \mathrm{cis}-9$, and C16 to CLA unsaturation indices. In addition, significant DGAT1 K232A by season interaction was found for some FA and SCD1 A293V by season interaction was only found for C18:1trans-11. These interactions were due to scaling of genotype effects.
\end{abstract}

Key words: genetic correlation, seasonal variation, DGAT1, SCD1 


\subsection{Introduction}

Milk is an important source of lipids, proteins, vitamins and minerals in many Western human diets. Among the milk produced by the main dairy species (e.g., cows, goats and sheep), bovine milk is economically the most important. Bovine milk fat contains essential nutrients including fat soluble vitamins and bio-active lipids (German \& Dillard, 2006) and is pointed out by FAO (2008) as being the main source of saturated fatty acids (SFA) in human diets.

Genetic factors can influence milk fat composition, and its genetic variation has been reported in previous studies (e.g., Soyeurt et al., 2006; Schennink et al., 2007). Stoop et al. (2008) concluded that short and medium chain fatty acids (FA) synthesized de novo are more affected by genetic factors than long chain FA that originate from the cow's diet or from mobilization of body fat (Chilliard et al., 2000; Palmquist, 2006). Moreover, polymorphisms in DGAT1 and $S C D 1$ genes have been recognized as having large effects on milk fat composition (Moioli et al., 2007; Schennink et al., 2007; 2008).

In addition, nutrition of dairy cows can considerably alter milk fat composition (e.g., Palmquist et al., 1993; Lock \& Bauman, 2004; Chilliard et al., 2007). It is well established that feeding dairy cows with polyunsaturated fatty acids (PUFA) that originate from forages results in a reduction of de novo synthesized FA and in an increase of long chain FA in milk fat (e.g., Chilliard et al., 2001; Bauman and Griinari, 2003). Furthermore, there are indications that nutrition affects mammary lipogenic gene expression (Bernard et al., 2008; Mach et al., 2011).

Substantial seasonal variation in milk fat composition has been found in European countries (Precht and Molketin, 2000; Thorsdottir et al., 2004; Heck et al., 2009). The main cause for this seasonal variation seems to be the differences in diets: in winter cows in Northern Europe are usually kept inside and fed silage whereas in summer cows are mainly on pasture and fed with fresh grass. These considerable differences in diets might affect the genetic background of milk fat composition. However, at present no information is available of possible genotype by season interaction on milk fat composition. Therefore, our aim was to study whether winter milk fat composition is genetically the same trait as summer milk fat composition. For this purpose, we estimated heritabilities, genetic correlations, effects of DGAT1 K232A and SCD1 A293V polymorphisms for milk fat composition in winter and summer, and 
tested for genotype by season interactions of DGAT1 K232A and SCD1 A293V polymorphisms.

\subsection{Materials and methods}

This study is part of the Dutch Milk Genomics Initiative, which was initiated to identify opportunities to change milk composition through breeding. Based on data collected in this project, heritability estimates for milk fat composition based on winter milk samples have been published by Stoop et al. (2008) and effects of polymorphisms in the DGAT1 and SCD1 genes on milk fat composition based on winter samples have been published by Schennink et al. $(2007 ; 2008)$. In the present study, heritability estimates for milk fat composition in winter and summer were obtained using a bivariate approach. Furthermore, to test whether winter milk fat composition is genetically the same trait as summer milk fat composition, we estimated genetic correlations between milk fat composition in winter and summer and, more specifically, we tested for DGAT1 and SCD1 by season interactions.

\subsubsection{Animals}

Data were available on 2,001 first lactation Holstein Friesian cows from 398 commercial herds in the Netherlands. Winter records were available from 1,905 cows, with each cow between 63 and 282 days in lactation. Summer records were available from 1,795 cows, with each cow between 97 and 335 days in lactation. A total of 1,699 cows had both a winter and a summer record, 206 animals had only a winter milk sample and 96 animals had only a summer sample. Details about the experimental design can be found in Stoop et al. (2008). In total 3,700 records on milk fat composition were available.

\subsubsection{Phenotypes}

One milk sample of $500 \mathrm{~mL}$ per cow per season was collected during morning milking between February and March 2005 ("winter") and between May and June 2005 ("summer"). Sample bottles contained sodium azide $(0.03 \mathrm{w} / \mathrm{w} \%)$ for conservation. Fat percentage (fat\%) was measured by infrared spectroscopy using a MilkoScan FT6000 (Foss Electric, Hillerod, Denmark) at the Milk Control Station (Qlip, Zutphen, the Netherlands). Milk fat composition was measured by gas chromatography (GC) at the COKZ laboratory (Qlip, Leudsen, the Netherlands), as described by Schennink et al. (2007). The fatty acids were identified and quantified by comparing the methyl ester chromatograms of the milk fat samples with the chromatograms of pure FA 
methyl ester standards (Stoop et al., 2008), and were measured as weight proportion of total fat (\%w/w). In this study, results are shown for individual FA: C4:0 to C18:0, C10:1 to C18:1cis-9, C18:1trans-11, C18:2cis-9,trans-11 (CLA), C18:2cis-9,12 and $\mathrm{C} 18: 3$ cis-9,12,15. For $\mathrm{C} 10: 1$ and $\mathrm{C} 12: 1$, it could not be ascertained, if the cis-double bond occurred at the carbon 9 position. Because of coelution associated with the GC extraction method, C14:1cis-9 represents the sum of C14:1cis-9 and C15:0iso, and C18:1cis-9 represents the sum of C18:1cis-9 and C18:1trans-12. The groups of saturated FA (SFA), unsaturated FA (UFA) and the ratio SFA to UFA are described in Table 2.1. SFA and UFA sum to approximately $94 \% \mathrm{w} / \mathrm{w}$ of total fat.

Table 2.1 - Trait definition: groups of fatty acids

\begin{tabular}{|c|c|}
\hline Group & Content \\
\hline SFA & $\begin{array}{l}\text { C4:0, C5:0, C6:0, C7:0, C8:0, C9:0, C10:0, C11:0, C12:0, C13:0, C14:0, } \\
\text { C15:0, C16:0, C17:0 and C18:0. }\end{array}$ \\
\hline SFA to UFA & $\begin{array}{l}\mathrm{C} 10: 1, \mathrm{C} 12: 1, \mathrm{C} 14: 1 \text { cis-91, C16:1cis-9, C18:1trans-4-82, C18:1trans-9, } \\
\mathrm{C} 18: 1 \text { trans-11, C18:1cis-93, C18:1cis-11, C18:2cis-9,12, C18:2cis- } \\
\text { 9,trans-11 (CLA) and C18:3cis-9,12,15. } \\
\text { saturated to unsaturated FA ratio. }\end{array}$ \\
\hline \multicolumn{2}{|c|}{$\begin{array}{l}{ }^{1} \mathrm{C} 14: 1 \text { cis-9 due to coelution associated with the GC extraction method represents the sum of } \mathrm{C} 14: 1 \text { cis- } 9 \\
\text { and } \mathrm{C} 15 \text { iso. } \\
{ }^{2} \mathrm{C} 18: 1 \text { trans-4-8 due to coelution associated with the GC extraction method represent the sum of } \\
\mathrm{C} 18: 1 \text { trans- } 4 \text {, } \mathrm{C} 18: 1 \text { trans-5, } \mathrm{C} 18: 1 \text { trans- } 6, \mathrm{C} 18: 1 \text { trans- } 7 \text { and } \mathrm{C} 18: 1 \text { trans-8. } \\
{ }^{3} \mathrm{C} 18: 1 \text { cis-9 due to coelution associated with the GC extraction method represents the sum of } \mathrm{C} 18: 1 \text { cis-9 } \\
\text { and } \mathrm{C} 18: 1 \text { trans- } 12 \text {. }\end{array}$} \\
\hline
\end{tabular}

Fatty acid unsaturation indices were defined as described by Kelsey et al. (2003):

$$
\frac{\text { unsaturated cis-9 }}{\text { unsaturated cis-9+saturated }} * 100 \text {, e.g., C14index }=\frac{c 14: 1 \text { cis-9 }}{c 14: 1 \text { cis-9+c14:0 }} * 100
$$

Indices were calculated for the following product and substrate pairs: C10:1 and C10:0 (C10index); C12:1 and C12:0 (C12index); C14:1cis-9 and C14:0 (C14index); C16:1cis-9 and C16:0 (C16index); C18:1cis-9 and C18:0 (C18index); CLA and C18:1trans-11 (CLAindex).

\subsubsection{Genotypes}

Blood samples for DNA isolation were collected between April and June 2005. Genotyping of the DGAT1 K232A polymorphism was performed with a TaqMan ${ }^{\circ}$ allelic discrimination assay (Applied Biosystems, Foster city, CA), according to Schennink et al. (2007). For the DGAT1 K232A polymorphism 1,692 animals were 
genotyped, whereas for 103 animals no genotypes were available either because no DNA was available $(N=92)$ or because the genotyping was ambiguous $(N=11)$. Genotypes for the SCD1 A293V polymorphism were assayed with the SNaPshot ${ }^{\circ}$ single base primer extension method (Applied Biosystems, Foster city, CA), according to Schennink et al. (2008). For the SCD1 A293V polymorphism 1,637 animals were genotyped, whereas for 158 animals no genotypes were available either because no DNA was available $(\mathrm{N}=92$ ) or the sample was genotyped ambiguously $(\mathrm{N}=66)$.

\subsubsection{Statistical Analyses}

Variance and covariance components were estimated by bivariate analyses between a trait in winter and the same trait in summer milk samples using an animal model in ASReml (Gilmour et al., 2002), as described by Stoop et al. (2008):

$$
\begin{aligned}
& y_{i j k l m n}=\mu+b_{1} * \operatorname{dim}_{i j k l m n}+b_{2} * e^{-0.05 * \operatorname{dim}_{i j k l m n}}+b_{3} * a f c_{i j k l m n}+b_{4} * \\
& {\text { af } c_{i j k l m n}^{2}}^{2} \operatorname{season~}_{k}+\operatorname{scode}_{l}+\operatorname{herd}_{m}+a_{n}+e_{i j k l m n}
\end{aligned}
$$

where $y_{i j k l m n}$ is the dependent variable; $\mu$ is the overall mean; $b_{1}$ and $b_{2}$ are the regression coefficients relative to $\operatorname{dim}_{i j k l m n}$; $\operatorname{dim}_{i j k l m n}$ is the covariate describing the effect of days in milk, modeled with a Wilmink curve (Wilmink, 1987); $b_{3}$ and $b_{4}$ are the regression coefficients relative to $a f c_{i j k l m n} ; a f c_{i j k l m n}$ is the covariate describing the effect of age at first calving; season $n_{k}$ is the fixed effect of calving season (June August 2004, September - November 2004, or December 2004 - February 2005); scode, is the fixed effect accounting for differences in genetic level between groups of proven bull daughters and young bull daughters; herd $d_{m}$ is the random effect of herd; $a_{n}$ is the random additive genetic effect of animal; and $e_{i j k l m n}$ is the random residual effect.

The variance-covariance structure of [1] was defined as: $\operatorname{Var}\left(a_{n}\right)=\mathbf{A} \sigma_{a}^{2}$, where $\mathbf{A}$ is the matrix of additive genetic relationships between individuals and $\sigma_{a}^{2}$ is the additive genetic variance; $\operatorname{Var}\left(\operatorname{herd}_{m}\right)=\mathbf{I} \sigma_{\text {herd }}^{2}$, where $\mathbf{I}$ is the identity matrix and $\sigma_{\text {herd }}^{2}$ is the herd variance and $\operatorname{Var}\left(e_{i}\right)=\mathbf{I} \sigma_{e}^{2}$, where $I$ is the identity matrix and $\sigma_{e}^{2}$ is the residual variance.

Intraherd heritability was calculated (Heringstad et al., 2006) to make heritability estimates comparable with other studies that considered the effect of herd as fixed, and was defined as: $h^{2}=\frac{\sigma_{a}^{2}}{\sigma_{a}^{2}+\sigma_{e}^{2}}$ 
The fraction of variance due to herd reflects the relative importance of herd effects such as feed and management practices, and was defined as: herd $=\frac{\sigma_{\text {herd }}^{2}}{\sigma_{a}^{2}+\sigma_{\text {herd }}^{2}+\sigma_{e}^{2}}$.

Phenotypic, genetic, herd and residual correlations between a trait in winter and the same trait in summer milk samples were calculated as: $r=\frac{\sigma_{T w, T s}}{\sqrt{\left(\sigma_{\left.T w^{*} \sigma_{T S}^{2}\right)}^{2}\right.}}$, where $\sigma_{T w, T s}=$ covariance between the same trait measured in winter and summer milk samples; $\sigma_{T w}^{2}=$ variance of the trait in winter samples and $\sigma_{T S}^{2}=$ variance of the trait in summer samples. The genetic correlation between a trait measured in two different environments can be used to assess genotype by environment interaction (e.g. Falconer and Mackay, 1996). We followed this approach to assess whether milk fat composition in winter and summer milk is genetically the same trait. Significance of genetic correlations was based on the likelihood ratio test, in which the likelihood of the full model was compared to the likelihood of a model with restricted genetic correlation of 0.995 . A value of 0.995 was chosen because restricting the genetic correlation to 1 leads to singularity. Significance of the likelihood ratio test was based on a Chi-Square distribution with one degree of freedom.

Model [1] was extended with a fixed genotype effect to estimate effects of DGAT1 (KK, KA or AA genotypes) or SCD1 (AA, AV or VV genotypes), and to estimate DGAT1 or $S C D 1$ by season interactions. Animals with missing genotypes were assigned to a separate genotype class. Missing genotypes appeared to be randomly distributed across other effects in the model.

\subsection{Results}

\subsubsection{Milk-fat composition in winter and summer}

Phenotypic means for fat composition in winter and summer milk samples are shown in Table 2.2. In summer milk, short chain FA (C4:0 to C12:0) contributed $13.67 \%$ to total fat, medium chain FA (C14:0 and C16:0) contributed $40.32 \%$ and $\mathrm{C} 18: 0$ contributed $9.88 \%$. Among the unsaturated C18 FA, the largest fraction was C18:1 cis9 (20.56\%). Fat\% was slightly higher in winter (4.36) as compared to summer milk (4.26; $\mathrm{P}=2.4 \mathrm{e}-5)$. The largest differences in summer compared to winter milk were a $3.42 \% \mathrm{w} / \mathrm{w}$ decrease in $\mathrm{C} 16: 0(\mathrm{P}<0.001)$, a $2.38 \% \mathrm{w} / \mathrm{w}$ increase in $\mathrm{C} 18: 1$ cis-9 $(\mathrm{P}<0.001)$ and a $1.16 \% \mathrm{w} / \mathrm{w}$ increase in $\mathrm{C} 18: 0(\mathrm{P}<0.001)$. Furthermore, relatively large increases could also be seen for C18:1trans-11 $(+0.45 \% \mathrm{w} / \mathrm{w}), \mathrm{CLA}(+0.17 \% \mathrm{w} / \mathrm{w})$ and C18:3cis$9,12,15(+0.07 \% \mathrm{w} / \mathrm{w} ; \mathrm{P}<0.001)$. In addition, a $3.39 \% \mathrm{w} / \mathrm{w}$ decrease in SFA and a 
$3.00 \% \mathrm{w} / \mathrm{w}$ increase in UFA were observed $(\mathrm{P}<0.001)$. Among unsaturation indices, increases for C14index $(+0.49 \% \mathrm{w} / \mathrm{w})$ and C16index $(+0.37 \% \mathrm{w} / \mathrm{w})$, and a decrease in CLAindex $(2.10 \% \mathrm{w} / \mathrm{w})$ were seen in summer compared to winter milk $(\mathrm{P}<0.001)$. Standard deviations of unadjusted FA were on average $20 \%$ larger in summer than in winter milk.

\subsubsection{Heritability estimates and variance components}

Heritability $\left(h^{2}\right)$, the fraction of variance due to herd (herd), and the ratios of phenotypic, genetic and herd variances for milk fat composition in winter and summer are shown in Table 2.3. In winter milk, moderate to high heritability estimates were found for fat\%, short chain FA (C4:0 to C12:0), medium chain FA (C14:0 and C16:0), C12:1, C16:1cis-9, CLA, and C12 to C18 unsaturation indices. In summer milk, moderate to high heritability estimates were found for fat\%, short chain FA (C4:0 to C12:0), medium chain FA (C14:0 and C16:0), C10:1 to C18:1 cis-9, and $\mathrm{C} 10$ to $\mathrm{C} 14$ unsaturation indices. In general, heritability estimates for winter and summer milk were very similar.

Fraction of variance due to herd (herd) in winter milk was moderate to high for C12:0, and most unsaturated C18 FA. Herd in summer milk was moderate to high for C12:0, C16:0, unsaturated C18 FA, and groups of FA. In general, herd was higher in summer compared to winter milk for most FA, groups of FA, and all unsaturation indices.

Differences in $h^{2}$ and herd for milk fat composition between winter and summer can either be the result of changes in additive genetic, herd or residual variance. Therefore, we also compared the magnitude of the individual variance components in winter and in summer milk. In summer, $\sigma_{a}^{2}$ was considerably higher for C18:1trans11 and CLA compared to winter milk. For most FA, $\sigma_{\text {herd }}^{2}$ was substantially higher in summer compared to winter milk, especially for C18:1trans-11, CLA, and SFA.

\subsubsection{Correlations between milk-fat composition in winter and summer}

The phenotypic, genetic, herd and residual correlations between winter and summer milk fat composition are shown in Table 2.4. The phenotypic correlations ranged from 0.29 for C18:1trans-11 to 0.69 for C18:2cis-9,12 and C14index, indicating that phenotypic correlation between winter and summer milk for individual FA is in the same order of magnitude as the phenotypic correlation for fat\% (0.63). Genetic 
correlations were higher than 0.90 for most FA and unsaturation indices. For C8:0 (0.93), C10:0 (0.95), C14:0 (0.94), C16:0 (0.76), C18:1trans-11 (0.70), CLA (0.80), C18:3cis-9,12,15 (0.79), SFA (0.77), UFA (0.82) and SFA to UFA (0.79), genetic correlations were significantly different from $1(P<0.05)$. Herd correlations were lower than 0.42 (C6:0) for most FA, groups of FA and unsaturation indices, except for herd correlations of 0.54 for $\mathrm{C} 12: 0$ and 0.76 for $\mathrm{C} 18: 2$ cis-9,12.

\subsubsection{DGAT 1 effects on milk-fat composition}

Estimated effects for DGAT1 K232A polymorphism on milk fat composition in winter and summer milk samples are shown in Table 2.5. The 232A allele was associated with lower fat\% in both winter and summer milk. In winter as well as in summer milk, the $232 \mathrm{~A}$ allele was negatively associated with most FA with less than 18 carbons, SFA, SFA to UFA, and C10 to C16 unsaturation indices, and was positively associated with C14:0, unsaturated C18, UFA, and C18 and CLA unsaturation indices. In general, effects of DGAT1 K232A polymorphism were very similar in winter and in summer milk.

Significant DGAT1 by season interaction was found for C4:0 to C14:0, C16:1cis-9, C18:1cis-9, CLA, C18:3cis-9,12,15, SFA, UFA, and C14 and C16 unsaturation indices (P $\leq 0.05)$. Significant DGAT1 by season interactions seem to be due to scaling rather than re-ranking: genotype effects in both seasons were in the same direction but of a different magnitude. Figure 2.1 shows an example of scaling of the genotype effects on C18:1cis-9.

\subsubsection{SCD1 effects on milk-fat composition}

Estimated effects for SCD1 A293V polymorphism on milk fat composition in winter and summer milk samples are shown in Table 2.6. SCD1 A293V polymorphism had no significant effects on fat\% in winter as well as in summer milk. In winter milk, the 293V allele was negatively associated with C18:0, C10:1 to C14:1cis-9, C18:1trans$11, \mathrm{C} 18: 3$ cis-9,12,15, and C10 to C14 unsaturation indices, and positively associated with $\mathrm{C} 8: 0$ to $\mathrm{C} 14: 0, \mathrm{C} 16: 1$ cis-9, CLA, and C16 to CLA unsaturation indices. In summer milk, the 293V allele was negatively associated with C18:0, C10:1 to C14:1cis-9, C18:1trans-11, CLA, and C10 to C14 unsaturation indices, and positively associated with $\mathrm{C} 8: 0$ to $\mathrm{C} 14: 0, \mathrm{C} 16: 1$ cis-9, $\mathrm{C} 18: 3$ cis-9,12,15, and C16 to CLA unsaturation indices. In general, effects of SCD1 A293V polymorphism were very similar in winter and in summer milk. Significant $S C D 1$ by season interaction was found only for $\mathrm{C} 18$ :1trans-11 ( $\mathrm{P}=0.03)$. The 293V allele was negatively associated with $\mathrm{C} 18: 1$ trans11 and this negative effect was larger in summer than in winter milk (Figure 2.2). 


\subsection{Discussion}

Heritability estimates for fat composition in winter and summer milk were very similar, and estimates of winter milk are comparable with results published by Stoop et al. (2008), which are based on univariate analyses. Intraherd heritability estimates in our study are higher than estimates reported by others (Renner and Kosmack, 1974; Karijord et al., 1982, Soyeurt et al., 2008). This might be because these studies used different methods to measure FA, or studied different breeds.

Genetic correlations between winter and summer milk were high for all FA, indicating that milk fat composition in winter and in summer can be largely considered as genetically the same trait. Effects of DGAT1 K232A and SCD1 A293V polymorphisms on milk fat composition in winter and in summer were similar and their effects in summer milk confirm the results of Schennink et al. $(2007 ; 2008)$ for winter milk. The results also showed several differences between winter and summer milk, which will be discussed in more detail.

\subsubsection{Effects of season on milk-fat composition}

Summer milk contained larger proportions of $\mathrm{C} 18: 0$ and unsaturated $\mathrm{C} 18$, and smaller proportions of short and medium chain FA compared to winter milk, which is in agreement with literature (Palmquist et al., 1993; Soyeurt et al., 2008; Heck et al., 2009). Differences between winter and summer milk fat in our study could be partly due to differences in lactation stage, as cows in summer were on average 80 days later in lactation than in winter (247 versus 167 days). Effects of lactation stage were accounted for in the statistical analysis and are known to be relatively small (Kelsey et al., 2003; Stoop et al., 2008). Therefore, we expect that it has not influenced our results. 
Table 2.2 - Phenotypic mean \pm standard deviation for fat\%, individual fatty acids, groups of fatty acids and unsaturation indices based on 1,905 winter milk samples and 1,795 summer milk samples.

\begin{tabular}{|c|c|c|c|}
\hline Trait & Winter ${ }^{1}$ & Summer & $-\log (P)^{2}$ \\
\hline \multicolumn{4}{|l|}{ Milk production trait } \\
\hline Fat $\%$ & $4.36 \pm 0.70$ & $4.26 \pm 0.73$ & $4.6^{* * *}$ \\
\hline \multicolumn{4}{|l|}{ Individual fatty acids ${ }^{3}$} \\
\hline $\mathrm{C} 4: 0$ & $3.50 \pm 0.27$ & $3.52 \pm 0.35$ & $1.3^{\text {ns }}$ \\
\hline $\mathrm{C} 6: 0$ & $2.22 \pm 0.17$ & $2.17 \pm 0.21$ & $15.0^{* * *}$ \\
\hline $\mathrm{C} 8: 0$ & $1.37 \pm 0.14$ & $1.32 \pm 0.17$ & $22.0^{* * *}$ \\
\hline $\mathrm{C} 10: 0$ & $3.03 \pm 0.43$ & $2.87 \pm 0.46$ & $26.6 * * *$ \\
\hline $\mathrm{C} 12: 0$ & $4.11 \pm 0.69$ & $3.79 \pm 0.73$ & $40.9 * * *$ \\
\hline $\mathrm{C} 14: 0$ & $11.61 \pm 0.92$ & $11.15 \pm 1.06$ & $43.2^{* * *}$ \\
\hline $\mathrm{C} 16: 0$ & $32.59 \pm 2.83$ & $29.17 \pm 3.50$ & $203.8^{* * *}$ \\
\hline $\mathrm{C} 18: 0$ & $8.72 \pm 1.42$ & $9.88 \pm 1.77$ & $99.3 * * *$ \\
\hline $\mathrm{C} 10: 1$ & $0.37 \pm 0.07$ & $0.35 \pm 0.07$ & $17.7^{* * *}$ \\
\hline $\mathrm{C} 12: 1$ & $0.12 \pm 0.03$ & $0.11 \pm 0.03$ & $23.7^{* * *}$ \\
\hline C14:1cis-9 & $1.36 \pm 0.26$ & $1.38 \pm 0.28$ & $1.6^{*}$ \\
\hline C16:1cis-9 & $1.45 \pm 0.32$ & $1.40 \pm 0.30$ & $6.0 * * *$ \\
\hline C18:1cis-9 & $18.18 \pm 2.04$ & $20.56 \pm 2.80$ & $170.4^{* * *}$ \\
\hline C18:1trans-11 & $0.78 \pm 0.22$ & $1.23 \pm 0.61$ & $174.3^{* * *}$ \\
\hline C18:2cis-9,trans-11 (CLA) & $0.39 \pm 0.11$ & $0.56 \pm 0.28$ & $120.4^{* * *}$ \\
\hline C18:2cis-9,12 & $1.20 \pm 0.29$ & $1.12 \pm 0.25$ & $16.7^{* * *}$ \\
\hline C18:3cis-9,12,15 & $0.42 \pm 0.11$ & $0.49 \pm 0.16$ & $59.8 * * *$ \\
\hline \multicolumn{4}{|l|}{ Groups of fatty acids ${ }^{3}$} \\
\hline SFA & $69.08 \pm 2.80$ & $65.69 \pm 4.02$ & $162.1 * * *$ \\
\hline UFA & $25.03 \pm 2.42$ & $28.03 \pm 3.39$ & $158.5^{* * *}$ \\
\hline SFA / UFA & $2.79 \pm 0.37$ & $2.39 \pm 0.43$ & $159.7^{* * *}$ \\
\hline \multicolumn{4}{|l|}{ Unsaturation indices 4} \\
\hline C10 index & $10.89 \pm 1.91$ & $11.00 \pm 1.82$ & $1.1^{\mathrm{ns}}$ \\
\hline C12 index & $2.74 \pm 0.54$ & $2.76 \pm 0.56$ & $0.6^{\text {ns }}$ \\
\hline C14 index & $10.51 \pm 1.84$ & $11.00 \pm 1.84$ & $15.1^{* * *}$ \\
\hline C16 index & $4.24 \pm 0.82$ & $4.61 \pm 0.92$ & $36.4^{* * *}$ \\
\hline C18 index & $67.62 \pm 3.74$ & $67.60 \pm 3.89$ & $0.1^{\mathrm{ns}}$ \\
\hline CLA index & $33.72 \pm 4.06$ & $31.62 \pm 3.96$ & $57.0 * * *$ \\
\hline
\end{tabular}

${ }^{1}$ Data based on winter milk samples for fat\%, C4:0 to C18:0, C18:1cis-9, C18:1trans-11, CLA, C18:2cis-9,12, C18:3cis-9,12,15, and SFA to UFA have been published by Stoop et al. (2008).

${ }^{2}$ Significance levels were assessed by a t-test considering winter and summer milk samples as independent traits, and $-\log (P)$ represent the $-\log (P$-values $)$ of the difference between seasons, where ${ }^{*}$ P -value $<0.001, * * P$-value $<0.01, * P$-value $\leq 0.05$ and $n s=$ non-significant, i.e., $\mathrm{P}>0.05$.

${ }^{3}$ Expressed in \% $\mathrm{w} / \mathrm{w}$.

${ }^{4}$ Unsaturation indices calculated as unsaturated/(unsaturated + saturated) $\times 100$. 
Table 2.3 - Heritability $\left(h^{2}\right)$, fraction of variance due to herd $($ herd $)$, phenotypic $\left(\sigma_{p}^{2}\right)$, genetic $\left(\sigma_{a}^{2}\right)$ and herd $\left(\sigma_{\text {herd }}^{2}\right)$ variances and ratios of phenotypic, genetic and herd variances for fat\%, individual fatty acids, groups of fatty acids and unsaturation indices based on 1,905 winter milk samples and 1,795 summer milk samples

\begin{tabular}{|c|c|c|c|c|c|c|c|c|c|c|}
\hline Trait & $\begin{array}{c}h^{2} \\
\text { winter }^{1} \\
\end{array}$ & $\begin{array}{l}h^{2} \\
\text { summer }^{1}\end{array}$ & $\begin{array}{l}\text { herd } \\
\text { winter }^{2}\end{array}$ & $\begin{array}{l}\text { herd } \\
\text { summer }^{2}\end{array}$ & $\begin{array}{c}\sigma_{p}^{2} \\
\text { summer }^{3} \\
\end{array}$ & $\begin{array}{c}\sigma_{a}^{2} \\
\text { summer }\end{array}$ & $\begin{array}{c}\sigma_{\text {herd }}^{2} \\
\text { summer }\end{array}$ & $\begin{array}{l}\sigma_{p}^{2} \text { summer/ } \\
\sigma_{p}^{2} \text { winter }^{3} \\
\end{array}$ & $\begin{array}{l}\sigma_{a}^{2} \text { summer/ } \\
\sigma_{a}^{2} \text { winter } \\
\end{array}$ & $\begin{array}{l}\sigma_{\text {herd }}^{2} \text { summer/ } \\
\sigma_{\text {herd }}^{2} \text { winter } \\
\end{array}$ \\
\hline \multicolumn{11}{|l|}{ Milk production trait } \\
\hline Fat $\%$ & 0.57 & 0.63 & 0.06 & 0.11 & 0.58 & 0.33 & 0.06 & 1.12 & 1.16 & 1.92 \\
\hline \multicolumn{11}{|l|}{ Individual fatty acids } \\
\hline C4:0 & 0.43 & 0.38 & 0.16 & 0.24 & 0.13 & 0.04 & 0.03 & 1.63 & 1.29 & 2.39 \\
\hline C6:0 & 0.48 & 0.41 & 0.16 & 0.18 & 0.04 & 0.01 & 0.01 & 1.56 & 1.29 & 1.80 \\
\hline C8:0 & 0.62 & 0.41 & 0.20 & 0.19 & 0.03 & 0.01 & 0.01 & 1.42 & 0.96 & 1.35 \\
\hline $\mathrm{C} 10: 0$ & 0.74 & 0.55 & 0.23 & 0.19 & 0.22 & 0.10 & 0.04 & 1.11 & 0.88 & 0.90 \\
\hline $\mathrm{C} 12: 0$ & 0.64 & 0.51 & 0.43 & 0.40 & 0.55 & 0.17 & 0.22 & 1.10 & 1.16 & 1.92 \\
\hline C14:0 & 0.58 & 0.51 & 0.17 & 0.34 & 1.15 & 0.39 & 0.39 & 1.29 & 0.90 & 2.55 \\
\hline C16:0 & 0.37 & 0.36 & 0.30 & 0.51 & 12.40 & 2.23 & 6.28 & 1.51 & 1.06 & 2.58 \\
\hline C18:0 & 0.24 & 0.19 & 0.19 & 0.30 & 3.15 & 0.41 & 0.95 & 1.59 & 1.07 & 2.56 \\
\hline C10:1 & 0.33 & 0.47 & 0.10 & 0.25 & $5.11 \mathrm{E}-3$ & $1.80 \mathrm{E}-3$ & $1.29 \mathrm{E}-3$ & 1.15 & 1.36 & 2.87 \\
\hline C12:1 & 0.37 & 0.48 & 0.21 & 0.30 & $0.95 \mathrm{E}-3$ & $0.32 \mathrm{E}-3$ & $0.29 E-3$ & 1.21 & 1.39 & 1.77 \\
\hline C14:1cis-9 & 0.33 & 0.46 & 0.07 & 0.15 & 0.08 & 0.03 & 0.01 & 1.23 & 1.54 & 2.72 \\
\hline C16:1cis-9 & 0.42 & 0.39 & 0.07 & 0.09 & 0.09 & 0.03 & 0.01 & 0.90 & 0.80 & 1.29 \\
\hline C18:1cis-9 & 0.27 & 0.37 & 0.29 & 0.35 & 7.79 & 1.88 & 2.69 & 1.86 & 2.30 & 2.26 \\
\hline C18:1trans-11 & 0.29 & 0.20 & 0.58 & 0.64 & 0.38 & 0.03 & 0.25 & 8.28 & 4.91 & 9.10 \\
\hline C18:2cis-9,trans11(CLA) & 0.43 & 0.28 & 0.51 & 0.58 & 0.08 & 0.01 & 0.05 & 6.09 & 3.32 & 7.02 \\
\hline C18:2cis-9,12 & 0.20 & 0.23 & 0.50 & 0.57 & 0.07 & 0.01 & 0.04 & 0.82 & 0.84 & 0.93 \\
\hline C18:3cis-9,12,15 & 0.26 & 0.22 & 0.64 & 0.63 & $25.94 \mathrm{E}-3$ & $2.15 \mathrm{E}-3$ & $16.30 \mathrm{E}-3$ & 2.19 & 1.96 & 2.14 \\
\hline
\end{tabular}


(continuation)

\begin{tabular}{|c|c|c|c|c|c|c|c|c|c|c|}
\hline Trait & $\begin{array}{c}h^{2} \\
\text { winter }^{1}\end{array}$ & $\begin{array}{l}h^{2} \\
\text { summer }^{1}\end{array}$ & $\begin{array}{l}\text { herd } \\
\text { winter }^{2}\end{array}$ & $\begin{array}{l}\text { herd } \\
\text { summer }\end{array}$ & $\begin{array}{c}\sigma_{p}^{2} \\
\text { summer }^{3} \\
\end{array}$ & $\begin{array}{c}\sigma_{a}^{2} \\
\text { summer }\end{array}$ & $\begin{array}{c}\sigma_{\text {herd }}^{2} \\
\text { summer }\end{array}$ & $\begin{array}{l}\sigma_{p}^{2} \text { summer/ } \\
\sigma_{p}^{2} \text { winter }^{3}\end{array}$ & $\begin{array}{l}\sigma_{a}^{2} \text { summer/ } \\
\sigma_{a}^{2} \text { winter }\end{array}$ & $\begin{array}{l}\sigma_{\text {herd }}^{2} \text { summer } \\
\sigma_{\text {herd }}^{2} \text { winter }\end{array}$ \\
\hline \multicolumn{11}{|c|}{ Groups of fatty acids } \\
\hline SFA & 0.30 & 0.34 & 0.29 & 0.44 & 15.88 & 3.06 & 6.94 & 2.00 & 1.83 & 3.02 \\
\hline UFA & 0.30 & 0.32 & 0.29 & 0.40 & 11.34 & 2.20 & 4.55 & 1.93 & 1.78 & 2.66 \\
\hline SFA to UFA & 0.29 & 0.31 & 0.29 & 0.42 & 0.18 & 0.03 & 0.08 & 1.33 & 1.14 & 1.91 \\
\hline \multicolumn{11}{|c|}{ Unsaturation indices } \\
\hline C10 index & 0.31 & 0.43 & 0.06 & 0.13 & 3.29 & 1.22 & 0.44 & 0.94 & 1.21 & 1.98 \\
\hline C12 index & 0.36 & 0.51 & 0.06 & 0.15 & 0.31 & 0.14 & 0.05 & 1.12 & 1.44 & 2.82 \\
\hline C14 index & 0.44 & 0.52 & 0.06 & 0.07 & 3.36 & 1.64 & 0.22 & 1.05 & 1.25 & 1.08 \\
\hline C16 index & 0.48 & 0.33 & 0.06 & 0.13 & 0.89 & 0.26 & 0.12 & 1.28 & 0.83 & 2.68 \\
\hline C18 index & 0.35 & 0.31 & 0.06 & 0.11 & 15.38 & 4.18 & 1.72 & 1.09 & 0.89 & 2.17 \\
\hline CLA index & 0.26 & 0.25 & 0.08 & 0.17 & 16.03 & 3.39 & 2.69 & 0.96 & 0.85 & 2.00 \\
\hline
\end{tabular}

${ }^{1} h^{2}=\sigma_{a}^{2} /\left(\sigma_{a}^{2}+\sigma_{e}^{2}\right)$. Standard errors between 0.01 and 0.12

${ }^{2}$ herd $=\sigma_{\text {herd }}^{2} /\left(\sigma_{a}^{2}+\sigma_{\text {herd }}^{2}+\sigma_{e}^{2}\right)$. Standard errors between 0.02 and 0.08

${ }^{3} \sigma_{p}^{2}=\sigma_{a}^{2}+\sigma_{\text {herd }}^{2}+\sigma_{e}^{2}$. 
Seasonal variation in milk fat composition seems to be the result of pasture grazing of dairy cows in summer compared to winter (Precht and Molketin, 2000; Thorsdottir et al., 2004). Grazing or availability of fresh cut grass in summer will result in a different dietary supply of FA, because fresh cut grass contains more PUFA than conserved forages which are affected by decreases in the leaf/stem ratio during the maturation period (Dewhurst et al., 2001). It is well known that supply of PUFA through the diet of dairy cows decreases de novo synthesized FA and increases long chain FA in milk fat (e.g., Chilliard et al., 2001; Agenas et al, 2002; Bernard et al, 2008). Therefore, our observation that summer milk had higher amounts of long chain FA and lower amounts of de novo synthesized FA compared to winter milk is probably because about $50 \%$ of the cows in our experiment had access to pasture in summer ( 3.5 to 24 hours/day), whereas all cows were kept indoors in winter.

Differences in dietary supply of FA between winter and summer are also reflected by our relatively low herd correlations between milk fat composition in winter and summer milk. This suggests that effect of herd, of which diet is part, on milk fat composition is not constant over the year. This might be related to the considerably higher herd variances in summer compared to winter milk found in our results. Variation due to herd might be due to several factors, however, differences in feeding regimes between and within herds play a major role. Larger herd variances in summer are most likely due to larger differences in feeding strategies between herds as well as within a herd: apparently the quantity and composition of forages, either fresh or conserved, varies more between herds and within a herd in summer compared to winter.

In contrast, herd correlations found in our study for C12:0 and for C18:2 cis-9,12 were higher than for other FA, probably because the supply of these FA on a herd were relatively constant during the year. Most concentrate feed supplied to Dutch dairy cows have high concentration of $\mathrm{C} 12: 0$, due to the presence of ingredients such as palm kernel expeller (47\%) and extracted coconut (48\%) both rich in $\mathrm{C} 12: 0$ (Grummer, 1991; Heck et al., 2009). The high herd correlation for C12:0 might be because on a herd the same type of concentrate is fed to cows in both winter and summer. C18:2cis-9,12 is one of the major PUFA found in maize silage (Chilliard et al., 2001, Khanal et al., 2008). The high herd correlation for this FA suggest that herds that feed maize silage do this in winter as well as in summer. 
Table 2.4 Phenotypic $\left(r_{p}\right)$, genetic $\left(r_{a}\right)$, herd $\left(r_{\text {herd }}\right)$, and residual $\left(r_{e}\right)$ correlations (SE in parentheses) for fat\%, individual fatty acids, groups of fatty acids and unsaturation indices between 1,905 winter milk samples and 1,795 summer milk samples.

\begin{tabular}{|c|c|c|c|c|}
\hline Trait & $r_{p}$ & $r_{a}^{\mathbf{1}}$ & $r_{\text {herd }}$ & $r_{e}$ \\
\hline \multicolumn{5}{|l|}{ Milk production trait } \\
\hline Fat $\%$ & $0.63(0.02)$ & $0.99(0.04)^{\mathrm{ns}}$ & $0.19(0.15)$ & $0.40(0.09)$ \\
\hline \multicolumn{5}{|l|}{ Individual fatty acids } \\
\hline $\mathrm{C} 4: 0$ & $0.48(0.02)$ & $0.94(0.06)^{\mathrm{ns}}$ & $0.31(0.08)$ & $0.25(0.09)$ \\
\hline C6:0 & $0.55(0.02)$ & $0.95(0.05)^{\mathrm{ns}}$ & $0.42(0.08)$ & $0.29(0.09)$ \\
\hline C8:0 & $0.52(0.02)$ & $0.93(0.05)^{*}$ & $0.40(0.08)$ & $0.16(0.14)$ \\
\hline C10:0 & $0.56(0.02)$ & $0.95(0.03)^{*}$ & $0.41(0.07)$ & $-0.03(0.26)$ \\
\hline C12:0 & $0.54(0.02)$ & $0.98(0.03)^{\mathrm{ns}}$ & $0.54(0.05)$ & $-0.06(0.21)$ \\
\hline C14:0 & $0.52(0.02)$ & $0.94(0.04)^{*}$ & $0.37(0.07)$ & $0.14(0.15)$ \\
\hline $\mathrm{C} 16: 0$ & $0.42(0.03)$ & $0.76(0.11)^{* *}$ & $0.21(0.06)$ & $0.47(0.07)$ \\
\hline C18:0 & $0.45(0.02)$ & $0.90(0.10)^{\mathrm{ns}}$ & $0.26(0.08)$ & $0.41(0.05)$ \\
\hline C10:1 & $0.44(0.02)$ & $0.99(0.04)^{\mathrm{ns}}$ & $0.31(0.10)$ & $0.15(0.10)$ \\
\hline C12:1 & $0.49(0.02)$ & $1.00(0.03)^{\mathrm{ns}}$ & $0.37(0.07)$ & $0.21(0.10)$ \\
\hline C14:1cis-9 & $0.61(0.02)$ & $1.00(0.02)^{\mathrm{ns}}$ & $0.16(0.14)$ & $0.46(0.06)$ \\
\hline C16:1cis-9 & $0.67(0.02)$ & $0.97(0.03)^{\mathrm{ns}}$ & $0.19(0.17)$ & $0.53(0.06)$ \\
\hline C18:1cis-9 & $0.41(0.03)$ & $0.91(0.08)^{\mathrm{ns}}$ & $0.19(0.07)$ & $0.33(0.07)$ \\
\hline C18:1trans-11 & $0.29(0.03)$ & $0.70(0.17)^{* *}$ & $0.26(0.05)$ & $0.22(0.07)$ \\
\hline C18:2cis-9, trans-11 (CLA) & $0.36(0.03)$ & $0.80(0.11)^{* *}$ & $0.30(0.05)$ & $0.25(0.08)$ \\
\hline C18:2cis-9,12 & $0.69(0.02)$ & $0.96(0.07)^{\mathrm{ns}}$ & $0.76(0.03)$ & $0.52(0.04)$ \\
\hline C18:3cis-9,12,15 & $0.44(0.03)$ & $0.79(0.13)^{* *}$ & $0.41(0.05)$ & $0.40(0.05)$ \\
\hline \multicolumn{5}{|l|}{ Groups of fatty acids } \\
\hline SFA & $0.42(0.03)$ & $0.77(0.11)^{* *}$ & $0.23(0.07)$ & $0.42(0.06)$ \\
\hline UFA & $0.40(0.03)$ & $0.82(0.10)^{*}$ & $0.17(0.07)$ & $0.38(0.06)$ \\
\hline SFA to UFA & $0.40(0.03)$ & $0.79(0.11)^{* *}$ & $0.17(0.07)$ & $0.42(0.06)$ \\
\hline \multicolumn{5}{|l|}{ Unsaturation indices } \\
\hline C10 index & $0.55(0.02)$ & $0.97(0.09)^{\mathrm{ns}}$ & $0.16(0.15)$ & $0.53(0.03)$ \\
\hline C12 index & $0.58(0.02)$ & $1.00(0.02)^{\mathrm{ns}}$ & $0.05(0.16)$ & $0.39(0.08)$ \\
\hline C14 index & $0.69(0.02)$ & $0.99(0.02)^{\mathrm{ns}}$ & $0.15(0.20)$ & $0.50(0.07)$ \\
\hline C16 index & $0.62(0.02)$ & $0.93(0.05)^{\mathrm{ns}}$ & $0.22(0.15)$ & $0.50(0.06)$ \\
\hline C18 index & $0.60(0.02)$ & $0.99(0.03)^{\mathrm{ns}}$ & $0.30(0.16)$ & $0.45(0.05)$ \\
\hline CLA index & $0.56(0.02)$ & $0.97(0.04)^{\mathrm{ns}}$ & $0.23(0.13)$ & $0.49(0.04)$ \\
\hline
\end{tabular}

${ }^{1}$ Supercripts indicate whether the genetic correlation differs significantly from 0.995, where ${ }^{*}$ P-value $<0.01, *$ P-value $\leq 0.05$ and $n s=$ non-significant, i.e., $\mathrm{P}>0.05$ 
Table 2.5 Effects of the DGAT1 K232A polymorphism (SE in parentheses) on fat\%, individual fatty acids, groups of fatty acids and unsaturation indices based on 1,905 winter milk samples and 1,795 summer milk samples

\begin{tabular}{|c|c|c|c|c|c|c|c|}
\hline \multirow{4}{*}{ Trait } & \multirow{4}{*}{$\begin{array}{c}-\log (\mathrm{P}) \\
\text { DGAT1 X } \\
\text { season } \\
\text { interaction }{ }^{1}\end{array}$} & \multirow{2}{*}{\multicolumn{3}{|c|}{ Winter }} & \multirow{2}{*}{\multicolumn{3}{|c|}{ Summer }} \\
\hline & & & & & & & \\
\hline & & $\mathrm{KA}^{2}$ & $A A^{3}$ & & $\mathrm{KA}^{2}$ & $A A^{3}$ & \\
\hline & & $(\mathrm{N}=829)$ & $(\mathrm{N}=644)$ & $-\log (P)^{4}$ & $(N=773)$ & $(N=592)$ & $-\log (P)^{4}$ \\
\hline \multicolumn{8}{|l|}{ Milk production trait } \\
\hline Fat $\%$ & $1.2^{\mathrm{ns}}$ & $-0.46(0.04)$ & $-0.99(0.04)$ & $126.9 * * *$ & $-0.46(0.04)$ & $-0.95(0.05)$ & $126.8^{* * *}$ \\
\hline \multicolumn{8}{|l|}{ Individual fatty acids } \\
\hline $\mathrm{C} 4: 0$ & $1.5^{*}$ & $-0.01(0.02)$ & $0.01(0.02)$ & $0.3^{\text {ns }}$ & $0.01(0.02)$ & $0.00(0.02)$ & $0.2^{\mathrm{ns}}$ \\
\hline $\mathrm{C} 6: 0$ & $5.1^{* * *}$ & $-0.02(0.01)$ & $-0.06(0.01)$ & $13.4^{* * *}$ & $-0.04(0.01)$ & $-0.12(0.01)$ & $14.1 * * *$ \\
\hline $\mathrm{C} 8: 0$ & $5.0 * * *$ & $0.00(0.01)$ & $-0.03(0.01)$ & $9.2^{* * *}$ & $-0.02(0.01)$ & $-0.08(0.01)$ & $10.0^{* * *}$ \\
\hline $\mathrm{C} 10: 0$ & $5.1 * * *$ & $0.07(0.03)$ & $0.02(0.03)$ & $3.2 * * *$ & $-0.03(0.03)$ & $-0.14(0.03)$ & $3.7 * * *$ \\
\hline $\mathrm{C} 12: 0$ & $2.7^{* *}$ & $0.13(0.04)$ & $0.10(0.04)$ & $1.0^{\mathrm{ns}}$ & $-0.01(0.04)$ & $-0.07(0.04)$ & $1.0^{\text {ns }}$ \\
\hline $\mathrm{C} 14: 0$ & $4.0^{* * *}$ & $0.44(0.06)$ & $0.80(0.06)$ & $33.4^{* * *}$ & $0.30(0.07)$ & $0.52(0.07)$ & $32.6^{* * *}$ \\
\hline $\mathrm{C} 16: 0$ & $0.1^{\mathrm{ns}}$ & $-1.05(0.16)$ & $-2.56(0.17)$ & $65.0^{* * *}$ & $-1.14(0.17)$ & $-2.63(0.18)$ & $65.6^{* * *}$ \\
\hline C18:0 & $0.0^{\mathrm{ns}}$ & $-0.16(0.09)$ & $-0.07(0.10)$ & $0.7^{\mathrm{ns}}$ & $-0.16(0.11)$ & $-0.11(0.12)$ & $0.7^{\mathrm{ns}}$ \\
\hline $\mathrm{C} 10: 1$ & $0.7^{\mathrm{ns}}$ & $0.00(0.00)$ & $-0.02(0.00)$ & $8.4^{* * *}$ & $-0.01(0.00)$ & $-0.03(0.00)$ & $8.9^{* * *}$ \\
\hline C12:1 & $1.0^{\mathrm{ns}}$ & $\begin{array}{c}0.23 \mathrm{E}-3 \\
(1.76 \mathrm{E}-3)\end{array}$ & $\begin{array}{c}-4.88 \mathrm{E}-3(1.89 \mathrm{E}- \\
3)\end{array}$ & $3.0 * * *$ & $\begin{array}{c}-3.85 \mathrm{E}-3(1.82 \mathrm{E}- \\
3)\end{array}$ & $\begin{array}{l}-6.59 \mathrm{E}-3 \\
(1.97 \mathrm{E}-3)\end{array}$ & $3.0^{* * *}$ \\
\hline C14:1cis-9 & $0.3^{\text {ns }}$ & $-0.01(0.020$ & $-0.04(0.02)$ & $1.3^{*}$ & $-0.03(0.02)$ & $-0.04(0.02)$ & $1.3^{*}$ \\
\hline C16:1cis-9 & $1.9^{*}$ & $-0.14(0.02)$ & $-0.32(0.02)$ & $53.2^{* * *}$ & $-0.12(0.02)$ & $-0.27(0.02)$ & $53.7 * * *$ \\
\hline C18:1cis-9 & $2.6^{* *}$ & $0.66(0.12)$ & $1.73(0.13)$ & $61.0 * * *$ & $1.01(0.15)$ & $2.34(0.16)$ & $62.8^{* * *}$ \\
\hline C18:1trans-11 & $0.4^{\mathrm{ns}}$ & $-0.01(0.01)$ & $0.03(0.01)$ & $3.5^{* * *}$ & $0.02(0.03)$ & $0.05(0.03)$ & $3.9^{* * *}$ \\
\hline $\begin{array}{l}\text { C18:2cis-9, trans-11 } \\
\text { (CLA) }\end{array}$ & $2.3^{* *}$ & $0.02(0.01)$ & $0.05(0.01)$ & $16.0^{* * *}$ & $0.04(0.01)$ & $0.09(0.01)$ & $15.2^{* * *}$ \\
\hline C18:2cis-9,12 & $0.4^{\mathrm{ns}}$ & $0.06(0.01)$ & $0.13(0.02)$ & $28.2^{* * *}$ & $0.07(0.01)$ & $0.15(0.01)$ & $29.0 * * *$ \\
\hline C18:3cis-9,12,15 & $1.3^{*}$ & $0.01(0.00)$ & $0.04(0.01)$ & $23.5^{* * *}$ & $0.01(0.01)$ & $0.06(0.01)$ & $22.8^{* * *}$ \\
\hline
\end{tabular}




\begin{tabular}{|c|c|c|c|c|c|c|c|}
\hline \multirow[b]{2}{*}{ Trait } & \multirow{2}{*}{$\begin{array}{c}\log (\mathrm{P}) \\
\text { DGAT1 } \mathrm{X} \\
\text { season } \\
\text { interaction }^{1} \\
\end{array}$} & \multicolumn{3}{|c|}{ Winter } & \multicolumn{3}{|c|}{ Summer } \\
\hline & & $\begin{array}{c}\mathrm{KA}{ }^{2} \\
(\mathrm{~N}=829)\end{array}$ & $\begin{array}{c}A A^{3} \\
(N=644)\end{array}$ & $-\log (P)^{4}$ & $\begin{array}{c}K A^{2} \\
(N=773)\end{array}$ & $\begin{array}{c}A A^{3} \\
(N=592)\end{array}$ & $-\log (P)^{4}$ \\
\hline \multicolumn{8}{|c|}{ Groups of fatty acids } \\
\hline SFA & $2.8^{* *}$ & $-0.72(0.17)$ & $-2.00(0.18)$ & $44.3^{* * *}$ & $-1.20(0.21)$ & $-2.84(0.22)$ & $46.6 * * *$ \\
\hline UFA & $3.0^{* *}$ & $0.62(0.14)$ & $1.68(0.15)$ & $42.4^{* * *}$ & $1.04(0.18)$ & $2.43(0.19)$ & $44.7^{* * *}$ \\
\hline SFA / UFA & $0.4^{\mathrm{ns}}$ & $-0.11(0.02)$ & $-0.26(0.02)$ & $44.8^{* * *}$ & $-0.14(0.02)$ & $-0.30(0.02)$ & $46.2^{* * *}$ \\
\hline \multicolumn{8}{|c|}{ Unsaturation indices } \\
\hline C10 index & $1.1^{\mathrm{ns}}$ & $-0.31(0.12)$ & $-0.55(0.13)$ & $2.3^{* *}$ & $-0.20(0.12)$ & $-0.26(0.13)$ & $2.0^{* *}$ \\
\hline C12 index & $1.1^{\mathrm{ns}}$ & $-0.09(0.03)$ & $-0.20(0.04)$ & $5.5^{* * *}$ & $-0.09(0.04)$ & $-0.13(0.04)$ & $5.3^{* * *}$ \\
\hline C14 index & $1.4^{*}$ & $-0.49(0.11)$ & $-0.98(0.12)$ & $12.8^{* * *}$ & $-0.47(0.12)$ & $-0.75(0.13)$ & $12.6^{* * *}$ \\
\hline C16 index & $1.8^{*}$ & $-0.26(0.05)$ & $-0.58(0.06)$ & $21.2 * * *$ & $-0.20(0.06)$ & $-0.41(0.07)$ & $21.7^{* * *}$ \\
\hline C18 index & $0.6^{\mathrm{ns}}$ & $1.18(0.24)$ & $2.23(0.26)$ & $23.5^{* * *}$ & $1.40(0.25)$ & $2.71(0.27)$ & $23.3^{* * *}$ \\
\hline CLA index & $0.7^{\mathrm{ns}}$ & $1.09(0.27)$ & $1.82(0.29)$ & $15.0^{* * *}$ & $1.27(0.26)$ & $2.36(0.28)$ & $15.3^{* * *}$ \\
\hline
\end{tabular}

${ }^{1}$ - $\log (\mathrm{P})$ DGAT1 $\mathrm{x}$ season interaction represents $-\log (\mathrm{P}$-values) of the interaction between DGAT1 genotypes in winter milk samples and DGAT1 genotypes in summer milk samples, where ${ }^{* *}{ }^{*} \mathrm{P}$-value $<0.001,{ }^{* * P}$-value $<0.01,{ }^{*} \mathrm{P}$-value $\leq 0.05$ and ns=non-significant, i.e., $\mathrm{P}>0.05$.

${ }^{2}$ Estimated contrast of KA - KK genotypes, where KK is set to zero, obtained using model [1] extended with DGAT1 K232A as a fixed genotype effect. ${ }^{3}$ Estimated contrast of AA - KK genotypes, where KK is set to zero, obtained using model [1] extended with DGAT1 K232A as a fixed genotype effect. ${ }^{4}$ Significance levels are represented by -log (P-values) of the effects of DGAT1 K232A polymorphism in winter and summer milk samples, respectively. Nominal P-values are reported. 
Table 2.6 Effects of the SCD1 A293V polymorphism (SE in parentheses) on fat\%, individual fatty acids, groups of fatty acids and unsaturation indices based on 1,905 winter milk samples and 1,795 summer milk samples.

\begin{tabular}{|c|c|c|c|c|c|c|c|}
\hline \multirow[b]{3}{*}{ Trait } & \multirow{3}{*}{$\begin{array}{c}-\log (\mathrm{P}) \text { SCD1 } \mathrm{x} \\
\text { season } \\
\text { interaction }^{1}\end{array}$} & \multirow{2}{*}{\multicolumn{3}{|c|}{ Winter }} & \multirow{2}{*}{\multicolumn{3}{|c|}{ Summer }} \\
\hline & & & & & & & \\
\hline & & $\begin{array}{c}V^{2} \\
(\mathrm{~N}=689)\end{array}$ & $\begin{array}{c}\mathrm{VV}^{3} \\
(\mathrm{~N}=117)\end{array}$ & $-\log (P)^{4}$ & $\begin{array}{c}V^{2} \\
(N=653)\end{array}$ & $\begin{array}{c}\mathrm{VV}^{3} \\
(\mathrm{~N}=103)\end{array}$ & $-\log (P)^{4}$ \\
\hline \multicolumn{8}{|l|}{ Milk production trait } \\
\hline Fat $\%$ & $0.7^{\mathrm{ns}}$ & $0.00(0.03)$ & $0.05(0.07)$ & $0.1^{\mathrm{ns}}$ & $-0.02(0.04)$ & $0.04(0.07)$ & $0.1^{\text {ns }}$ \\
\hline \multicolumn{8}{|l|}{ Individual fatty acids } \\
\hline $\mathrm{C} 4: 0$ & $0.5^{\mathrm{ns}}$ & $-0.02(0.01)$ & $0.01(0.03)$ & $1.1^{\mathrm{ns}}$ & $-0.01(0.02)$ & $0.05(0.03)$ & $1.1^{\mathrm{ns}}$ \\
\hline C6:0 & $0.7^{\mathrm{ns}}$ & $0.01(0.01)$ & $0.02(0.02)$ & $1.0^{\mathrm{ns}}$ & $0.01(0.01)$ & $0.06(0.02)$ & $0.7^{\mathrm{ns}}$ \\
\hline C10:0 & $0.3^{\text {ns }}$ & $0.10(0.02)$ & $0.15(0.04)$ & $8.1^{* * *}$ & $0.09(0.02)$ & $0.20(0.04)$ & $7.5^{* * *}$ \\
\hline $\mathrm{C} 12: 0$ & $0.1^{\text {ns }}$ & $0.09(0.03)$ & $0.14(0.06)$ & $2.3^{* *}$ & $0.05(0.03)$ & $0.13(0.06)$ & $2.3^{* *}$ \\
\hline $\mathrm{C} 14: 0$ & $0.9^{\text {ns }}$ & $0.22(0.04)$ & $0.40(0.09)$ & $6.5^{* * *}$ & $0.13(0.05)$ & $0.30(0.09)$ & $6.5^{* * *}$ \\
\hline C16:0 & $0.6^{\mathrm{ns}}$ & $-0.14(0.13)$ & $-0.26(0.25)$ & $0.4^{\mathrm{ns}}$ & $-0.12(0.13)$ & $0.22(0.27)$ & $0.3^{\text {ns }}$ \\
\hline C18:0 & $0.3^{\text {ns }}$ & $-0.29(0.07)$ & $-0.43(0.13)$ & $5.5^{* * *}$ & $-0.24(0.08)$ & $-0.64(0.16)$ & $6.0 * * *$ \\
\hline C10:1 & $0.5^{\mathrm{ns}}$ & $-0.03(0.00)$ & $-0.06(0.01)$ & $42.7^{* * *}$ & $-0.03(0.00)$ & $-0.05(0.01)$ & $42.9 * * *$ \\
\hline C12:1 & $0.0^{\text {ns }}$ & $-0.01(0.00)$ & $-0.02(0.00)$ & $25.0 * * *$ & $-0.01(0.00)$ & $-0.02(0.00)$ & $24.1 * * *$ \\
\hline C16:1cis-9 & $0.2^{\mathrm{ns}}$ & $0.16(0.02)$ & $0.34(0.03)$ & $47.6 * * *$ & $0.15(0.01)$ & $0.35(0.03)$ & $48.4^{* * *}$ \\
\hline C18:1cis-9 & $0.5^{\mathrm{ns}}$ & $0.09(0.09)$ & $0.20(0.18)$ & $0.3^{\text {ns }}$ & $0.17(0.12)$ & $-0.04(0.24)$ & $0.4^{\mathrm{ns}}$ \\
\hline C18:1trans-11 & $1.6^{*}$ & $-0.01(0.01)$ & $-0.04(0.02)$ & $2.1^{* *}$ & $-0.07(0.02)$ & $-0.11(0.04)$ & $2.3^{* *}$ \\
\hline C18:2cis-9,trans-11(CLA) & $0.4^{\mathrm{ns}}$ & $0.02(0.00)$ & $0.02(0.01)$ & $2.5^{* *}$ & $-0.07(0.02)$ & $-0.11(0.04)$ & $1.7^{*}$ \\
\hline C18:2cis-9,12 & $0.4^{\mathrm{ns}}$ & $0.01(0.01)$ & $-0.02(0.02)$ & $0.9^{\text {ns }}$ & $0.01(0.01)$ & $-0.04(0.02)$ & $1.4^{*}$ \\
\hline C18:3cis-9,12,15 & $1.1^{\mathrm{ns}}$ & $0.01(0.00)$ & $-0.01(0.01)$ & $1.5^{*}$ & $0.02(0.01)$ & $0.00(0.01)$ & $2.2^{* *}$ \\
\hline
\end{tabular}


(continuation)

\begin{tabular}{|c|c|c|c|c|c|c|c|}
\hline \multirow[b]{2}{*}{ Trait } & \multirow{2}{*}{$\begin{array}{c}-\log (\mathrm{P}) \operatorname{SCD} 1 \mathrm{x} \\
\text { season } \\
\text { interaction }^{1}\end{array}$} & \multicolumn{3}{|c|}{ Winter } & \multicolumn{3}{|c|}{ Summer } \\
\hline & & $\begin{array}{c}V^{2} \\
(N=689)\end{array}$ & $\begin{array}{c}\mathrm{VV}^{3} \\
(\mathrm{~N}=117)\end{array}$ & $-\log (P)^{4}$ & $\begin{array}{c}V^{2} \\
(N=653)\end{array}$ & $\begin{array}{c}\mathrm{VV}^{3} \\
(\mathrm{~N}=103)\end{array}$ & $-\log (P)^{4}$ \\
\hline \multicolumn{8}{|c|}{ Groups of fatty acids } \\
\hline SFA & $0.2^{\mathrm{ns}}$ & $-0.02(0.13)$ & $0.05(0.25)$ & $0.0^{\text {ns }}$ & $-0.06(0.16)$ & $0.29(0.32)$ & $0.0^{\mathrm{ns}}$ \\
\hline UFA & $0.5^{\mathrm{ns}}$ & $0.04(0.11)$ & $0.08(0.22)$ & $0.0^{\text {ns }}$ & $0.07(0.14)$ & $-0.21(0.28)$ & $0.1^{\mathrm{ns}}$ \\
\hline SFA to UFA & $0.3^{\text {ns }}$ & $-0.01(0.02)$ & $-0.01(0.03)$ & $0.0^{\text {ns }}$ & $0.00(0.02)$ & $0.03(0.03)$ & $0.0^{\text {ns }}$ \\
\hline \multicolumn{8}{|c|}{ Unsaturation indices } \\
\hline C10 index & $0.1^{\mathrm{ns}}$ & $-1.18(0.09)$ & $-2.15(0.17)$ & $70.8 * * *$ & $-1.11(0.08)$ & $-2.11(0.17)$ & $69.2 * * *$ \\
\hline C12 index & $0.0^{\text {ns }}$ & $-0.29(0.02)$ & $-0.55(0.05)$ & $51.5^{* * *}$ & $-0.29(0.03)$ & $-0.53(0.05)$ & $50.8^{* * *}$ \\
\hline C14 index & $0.0^{\text {ns }}$ & $-1.34(0.08)$ & $-2.59(0.16)$ & $98.4 * * *$ & $-1.31(0.08)$ & $-2.59(0.16)$ & $97.0 * * *$ \\
\hline C16 index & $0.2^{\mathrm{ns}}$ & $0.47(0.04)$ & $0.98(0.08)$ & $56.7^{* * *}$ & $0.49(0.04)$ & $1.05(0.09)$ & $58.7^{* * *}$ \\
\hline C18 index & $0.1^{\text {ns }}$ & $0.85(0.19)$ & $1.51(0.37)$ & $6.6 * * *$ & $0.75(0.20)$ & $1.47(0.39)$ & $7.0 * * *$ \\
\hline CLA index & $0.3^{\text {ns }}$ & $1.29(0.20)$ & $2.43(0.40)$ & $14.3^{* * *}$ & $1.14(0.20)$ & $2.13(0.39)$ & $15.0 * * *$ \\
\hline
\end{tabular}

1- $\log (\mathrm{P})$ SCD1 x season interaction represents $-\log (\mathrm{P}$-values) of the interaction between SCD1 genotypes in winter milk samples and SCD1 genotypes in summer milk samples, where $* * * \mathrm{P}$-value $<0.001, * * \mathrm{P}$-value $<0.01,{ }^{*} \mathrm{P}$-value $\leq 0.05$ and ns=non-significant, i.e., $\mathrm{P}>0.05$.

${ }^{2}$ Estimated contrast of VA - AA genotypes, where AA is set to zero, obtained using model [1] extended with SCD1 A293V as a fixed genotype effect. ${ }^{3}$ Estimated contrast of VV - AA genotypes, where AA is set to zero, obtained using model [1] extended with SCD1 A293V as a fixed genotype effect.

${ }^{4}$ Significance levels are represented by -log (P-values) of the effects of SCD1 A293V polymorphism in winter and summer milk samples, respectively. Nominal P-values are reported. 
It is well established that the supply of FA reaching the mammary gland of a cow for milk fat synthesis can be indirectly affected by processes that occur in the rumen known to convert PUFA into SFA (e.g., Chilliard et al., 2001, Jenkins et al., 2008). These processes are dependent on many factors that include: quantity and composition of microbiota (Haarfoot \& Hazlewood, 1997; Lock \& Bauman, 2004), the proportion of forages and concentrates in a cow's diet (Dewhurst et al., 2006) and the source of the PUFA supplied to dairy cows (Sterk et al., 2011). Therefore, part of the observed differences in milk fat composition between winter and summer milk can also be attributed to dietary effects on processes in the rumen, which are known to affect the amounts of C18:1trans-11 and CLA reaching the mammary gland of a cow (Mach et al., 2011).

\subsubsection{Effects of polymorphisms in DGAT1 and in SCD1}

Some studies indicate that nutrition affects mammary expression of lipogenic genes (Bernard et al., 2008; Mach et al., 2011). Therefore, effects of polymorphisms in DGAT1 and SCD1 on milk fat composition might differ between winter and summer. In the present study, significant DGAT1 by season interactions were found on many FA, and SCD1 by season interaction was found only on C18:1trans-11. However, estimated genotype effects suggest that these interactions are due to scaling rather than to re-ranking (Figures 2.1 and 2.2). High genetic correlations between milk fat composition in winter and summer as well as similar genotypic effects in winter and summer support the idea that mainly the same genes are involved in milk fat composition in winter and in summer.

DGAT 1. Is the gene encoding acyl-CoA: diacylglycerol acyltransferase1 (DGAT1; EC: 2.3.1.20), which is an enzyme responsible for the fixation of $F A$ to the third position of triacylglycerol (TAG) (Cases et al., 1998; Palmquist, 2006; Yen et al., 2008). The K232A polymorphism causes an amino acid change (Lysine > Alanine at position 232 of the protein) that might alter the activity or specificity of the enzyme. In our study, the DGAT1 232A allele was associated with a lower milk fat\%, which agrees with previous research (e. g., Grisart et al., 2002; Winter et al., 2002; Thaller et al., 2003). DGAT1 shows a preference to esterify short chain and UFA to the third position of a TAG (Kinsella, 1976; Morand et al., 1998; Mistry and Medrano, 2002). In winter, the DGAT1 232A allele was negatively associated with most FA with less than 18 carbons and was positively associated with all unsaturated C18. In summer milk, higher amounts of UFA were found compared to winter milk. This larger supply seems to increase the effect of the DGAT1 K232A polymorphism, especially for UFA for which 


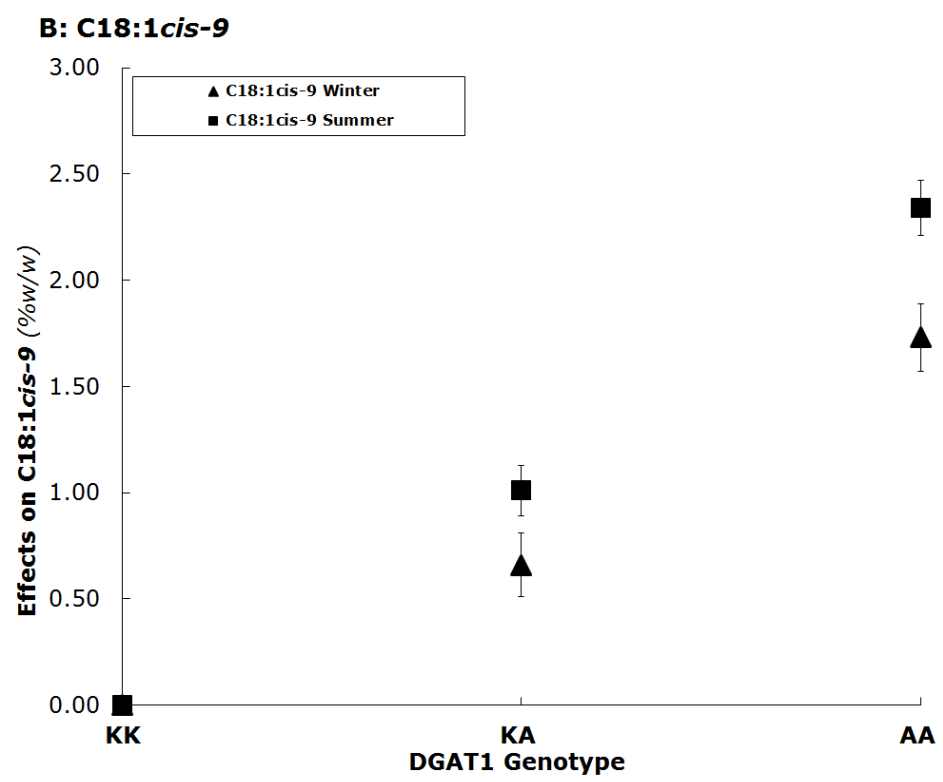

Figure 2.1 Estimated effects of DGAT1 K232A polymorphism in winter and summer samples represented by the contrasts of AA-KK and KA-KK genotypes, where KK is set to zero. These contrasts illustrate the significant DGAT1 K232A by season interaction on C18:1cis-9. SE are shown as error bars.

it has preference, because the effects of DGAT1 232A allele on most unsaturated C18 and UFA were larger in summer compared to winter milk and resulted in DGAT1 by season interaction.

SCD1. Is the gene encoding stearoyl-CoA desaturase1 (SCD1; EC: 1.14.19.1) and the A293V polymorphism causes an amino acid change (Alanine > Valine at position 293 of the protein) which might affect the catalytic function of the enzyme, responsible for the insertion of a cis-double bond between carbon 9 and 10 of a FA (Pereira et al., 2003). In the present study, SCD1 A293V polymorphism had no significant effects on fat\%. These results are in line with Schennink et al. (2008).

Unsaturation indices have been suggested as indicators to indirectly measure the desaturation activity of the SCD1 enzyme (e.g., Peterson et al., 2002). In both winter and summer, high means for C18 and CLA unsaturation indices (Table2.2) indicate that $\mathrm{C} 18: 0$ and $\mathrm{C} 18: 1$ trans-11 are unsaturated to a higher extent than $\mathrm{C} 10: 0, \mathrm{C} 12: 0$, C14:0 and C16:0. These results are in line with Enoch et al. (1976) who suggest that $S C D 1$ has preferences in unsaturating longer chain FA. In addition, the SCD1 293V 


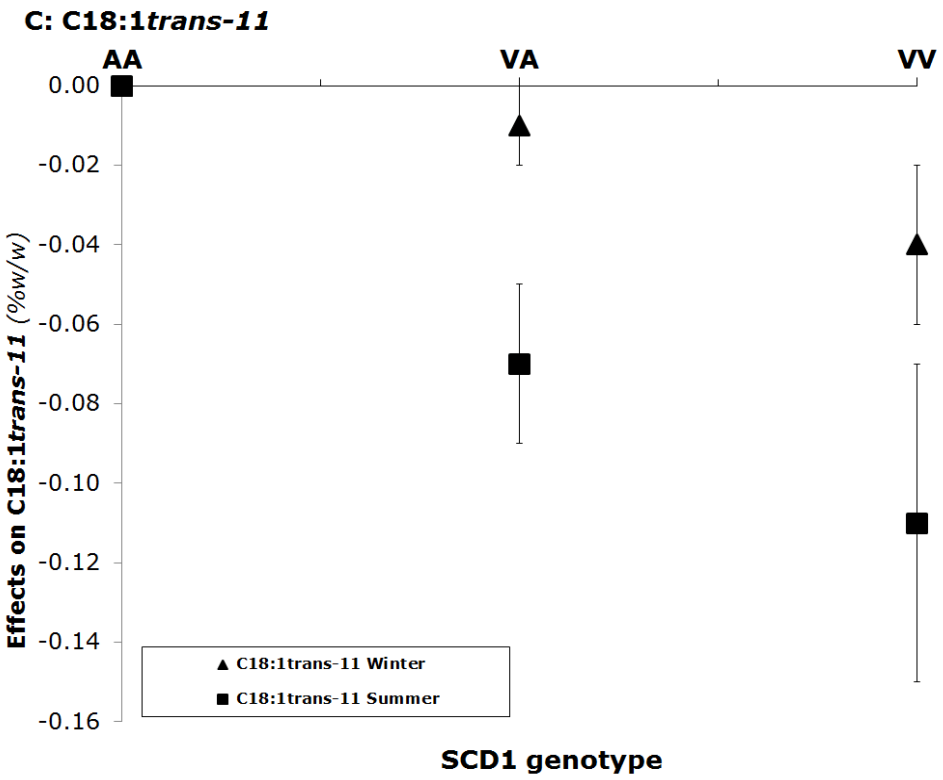

Figure 2.2 Estimated effects of SCD1 A293V polymorphism in winter and summer samples represented by the contrasts of VV-AA and VA-AA genotypes, where AA is set to zero. These contrasts illustrate the significant SCD1 A293V by season interaction on C18:1trans-11. SE are shown as error bars.

allele was positively associated with C16 to CLA indices compared to the SCD1 293A allele in both winter and summer (Table 2.6). These associations suggest that the SCD1 293V allele might have a higher affinity or specificity to unsaturate longer chain FA (e.g., C18:0 or C18:1trans-11) than other available FA (e.g., C10:0 or C14:0).

\subsection{Conclusions}

Milk fat composition in winter and in summer can be largely considered as genetically the same trait, because of the very high genetic correlations found between winter and summer milk fat composition. Differences in milk fat composition between winter and summer can probably be attributed to differences in the diets of cows between the two seasons rather than to genetic differences. Effects of DGAT1 K232A and SCD1 A293V polymorphisms on fat composition are similar in winter and in summer milk. Significant DGAT1 and SCD1 by season interactions were found for some fatty acids, and these interactions seem to be due to scaling of the genotype effects. 


\subsection{Acknowledgements}

This study is part of the Dutch Milk Genomics Initiative, funded by Wageningen University, NZO (Dutch Dairy Association, Zoetermeer, the Netherlands), Cooperative Cattle Improvement organization CRV (Arnhem, the Netherlands), and the Dutch technology foundation STW (Utrecht, the Netherlands). The authors thank the owners of the herds for their help in collecting the data. The first author expresses her gratitude for having benefitted from academic and financial support of the Erasmus Mundus program "European Master in Animal Breeding and Genetics (EM$A B G)$ ", and the Koepon Foundation.

\subsection{References}

Agenäs, S., K. Holtenius, M. Griinari, and E. Burstedt. 2002. Effects of turnout to pasture and dietary fat supplementation on milk fat composition and Conjugated Linoleic Acid in dairy cows. Acta Agric. Scand. A Anim. Sci. 52:25-33.

Bauman, D. E., and J. M. Griinari. 2003. Nutritional regulation of milk fat synthesis. Annual Review of Nutrition 23:203-227.

Bernard, L., C. Leroux, and Y. Chilliard. 2008. Expression and nutritional regulation of lipogenic genes in the ruminant lactating mammary gland. Bioactive components of milk. Pages 67-108. Vol. 606. Z. Bösze, ed. Springer, New York, USA.

Cases, S., S. J. Smith, Y.-W. Zheng, H. M. Myers, S. R. Lear, E. Sande, S. Novak, C. Collins, C. B. Welch, A. J. Lusis, S. K. Erickson, and R. V. Farese. 1998. Identification of a gene encoding an acyl CoA:diacylglycerol acyltransferase, a key enzyme in triacylglycerol synthesis. Proc. Natl. Acad. Sci. USA 95:13018-13023.

Chilliard, Y., A. Ferlay, R. M. Mansbridge, and M. Doreau. 2000. Ruminant milk fat plasticity: nutritional control of saturated, polyunsaturated, trans and conjugated fatty acids. Ann. Zootech. 49:181-205.

Chilliard, Y., A. Ferlay, and M. Doreau. 2001. Effect of different types of forages, animal fat or marine oils in cow's diet on milk fat secretion and composition, especially conjugated linoleic acid (CLA) and polyunsaturated fatty acids. Livest. Prod. Sci. 70:31-48.

Chilliard, Y., F. Glasser, A. Ferlay, L. Bernard, J. Rouel, and M. Doreau. 2007. Diet, rumen biohydrogenation and nutritional quality of cow and goat milk fat. Eur. J. Lipid Sci. Technol. 109:828-855. 
Dewhurst, R. J., N. D. Scollan, S. J. Youell, J. K. S. Tweed, and M. O. Humphreys. 2001. Influence of species, cutting date and cutting interval on the fatty acid composition of grasses. Grass for. Sci. 56:69-74.

Dewhurst, R. J., K. J. Shingfield, M. R. F. Lee, and N. D. Scollan. 2006. Increasing the concentrations of beneficial polyunsaturated fatty acids in milk produced by dairy cows in high-forage systems. Anim. Feed Sci. Technol. 131:168-206.

Enoch, H. G., A. Catala, and. P. Strittmatter. 1976. Mechanism of rat liver microsomal stearol-CoA desaturase. Studies of the substrate specificity, enzyme-substrate interactions, and the function of lipid. J. Biol. Chem. 251:5095-5103.

Falconer, D. S., and T. F. C. Mackay. 1996. Introduction to Quantitative Genetics. Correlated characters: genotype-environment interaction. Pages 321-325. Fourth edition, ed. Longman Greens, Harlow, Essex, UK.

FAO. 2008. Fats and fatty acids in human nutrition - Report of an expert consultation. in Food and Nutrition Paper. Vol. 91. Food and Agriculture Organization of the United Nations (FAO), Geneva.

German, J. B., and C. J. Dillard. 2006. Composition, Structure and Absorption of Milk Lipids: A Source of Energy, Fat-Soluble Nutrients and Bioactive Molecules. Crit. Rev. Food Sci. 46:57-92.

Gilmour, A. R., Gogel, B. J., Cullis, B. R., and R. Thompson. 2002. ASReml User Guide Release 2.0. Hemel Hempstead, HP1 1ES, UK.

Grisart, B., W. Coppieters, F. Fanir, L. Karim, C. Ford, P. Berzi, N. Cambisano, M. Mni, S. Reid, P. Simon, R. Spelman, M. Georges, and R. Snell. 2002. Positional candidate cloning of a QTL in dairy cattle: identification of a missense mutation in the bovine DGAT1 gene with major effect on milk yield and composition. Genome Res. 12:222-231.

Grummer, R. R. 1991. Effect of Feed on the Composition of Milk Fat. J. Dairy Sci. 74:3244-3257.

Harfoot, C. G., and G. P. Hazlewood. 1997. Lipid in the rumen. Pages 382-426 in Rumen Microbial Ecosystem. 2nd ed. B. A. Professional, ed. P.N. Hobson and C. S. Stewart, London, UK.

Heck, J. M. L., H. J. F. van Valenberg, J. Dijkstra, and A. C. M. van Hooijdonk. 2009. Seasonal variation in the Dutch bovine raw milk composition. J. Dairy Sci. 92:47454755.

Heringstad, B., D. Gianola, Y. M. Chang, J. Ødegård, and G. Klemetsdal. 2006. Genetic associations between clinical mastitis and somatic cell score in early first-lactation cows. J. Dairy Sci. 89:2236-2244. 
Jenkins, T. C., R. J. Wallace, P. J. Moate, and E. E. Mosley. 2008. Board-invited review: Recent advances in biohydrogenation of unsaturated fatty acids within the rumen microbial ecosystem. J. Anim. Sci. 86:397-412.

Karijord, $\varnothing$., N. Standal, and O. Syrstad. 1982. Sources of variation in composition of milk fat. Z. Tierz. Züchtungsbio. 99:81-93.

Kelsey, J. A., B. A. Corl, R. J. Collier, and D. E. Bauman. 2003. The effect of breed, parity, and stage of lactation on conjugated linoleic acid (CLA) in milk fat from dairy cows. J. Dairy Sci. 86:2588-2597.

Khanal, R. C., T. R. Dhiman, and R. L. Boman. 2008. Changes in fatty acid composition of milk from lactating dairy cows during transition to and from pasture. Livest. Sci. 114:164-175.

Kinsella, J. E. 1976. Monoacyl-sn-glycerol 3-phosphate acyltransferase specificity in bovine mammary microsomes. Lipids 11:680-684.

Lock, A. L. and D. E. Bauman. 2004. Modifying milk fat composition of dairy cows to enhance fatty acids beneficial to human health. Lipids 39:1197-1206.

Mach, N., A. A. A. Jacobs, L. Kruijt, J. van Baal, and M. A. Smits. 2011. Alteration of gene expression in mammary gland tissue of dairy cows in response to dietary unsaturated fatty acids. Animal 5:1217-1230.

Mistry, D. H. and J. F. Medrano. 2002. Cloning and localization of the bovine and ovine Lysophosphatidic Acid Acyltransferase (LPAAT) genes that codes for an enzyme involved in triglyceride biosynthesis. J. Dairy Sci. 85:28-35.

Moioli, B., G. Contarini, A. Avalli, G. Catillo, L. Orru, G. De Matteis, G. Masoero, and F. Napolitano. 2007. Short communication: Effect of stearoyl-coenzyme A desaturase polymorphism on fatty acid composition of milk. J. Dairy Sci. 90:35533558.

Morand, L. Z., J. N. Morand, R. Matson, and J. B. German. 1998. Effect of insulin and prolactin on acyltransferase activities in MAC-T bovine mammary cells. J. Dairy Sci. 81:100-106.

Palmquist, D. L. 2006. Milk fat: origin of fatty acids and influence of nutritional factors thereon. Pages 43-92 in Advanced Dairy Chemistry: Lipids. Vol. 2. Springer, ed. P. F. Fox, P. L. H. McSweeney, New York, USA.

Palmquist, D. L., A. Denise Beaulieu, and D. M. Barbano. 1993. Feed and animal factors influencing milk fat composition. J. Dairy Sci. 76:1753-1771.

Pereira, S. L., A. E. Leonard, and P. Mukerji. 2003. Recent advances in the study of fatty acid desaturases from animals and lower eukaryotes. Prostaglandins Leukot. Essent. Fatty Acids 68:97-106. 
Peterson, D. G., J. A. Kelsey, and D. E. Bauman. 2002. Analysis of variation in cis-9, trans-11 conjugated linoleic acid (CLA) in milk fat of dairy cows. J. Dairy Sci. 85:2164-2172.

Precht, J., and D. Molketin. 2000. Frequency distributions of conjugated linoleic acid and trans fatty acids in European milk fats. Milchwissenschaft 55:687-691.

Renner, E., and U. Kosmack. 1974. Genetische aspekte zur fettsaürenzusammensetzung des milchfettes. Züchtungskunde 46:217-226.

Schennink, A., W. M. Stoop, M. H. P. W. Visker, J. M. L. Heck, H. Bovenhuis, J. J. Van Der Poel, H. J. F. Van Valenberg, and J. A. M. Van Arendonk. 2007. DGAT1 underlies large genetic variation in milk-fat composition of dairy cows. Anim. Genet. 38:467473.

Schennink, A., J. M. L. Heck, H. Bovenhuis, M. H. P. W. Visker, H. J. F. van Valenberg, and J. A. M. van Arendonk. 2008. Milk fatty acid unsaturation: genetic parameters and effects of Stearoyl-CoA Desaturase (SCD1) and Acyl CoA: Diacylglycerol Acyltransferase 1 (DGAT1). J. Dairy Sci. 91:2135-2143.

Soyeurt, H., P. Dardenne, A. Gillon, C. Croquet, S. Vanderick, P. Mayeres, C. Bertozzi, and N. Gengler. 2006. Variation in fatty acid contents of milk and milk fat within and across breeds. J. Dairy Sci. 89:4858-4865.

Soyeurt, H., P. Dardenne, F. Dehareng, C. Bastin, and N. Gengler. 2008. Genetic parameters of saturated and monounsaturated fatty acid content and the ratio of saturated to unsaturated fatty acids in bovine milk. J. Dairy Sci. 91:3611-3626.

Sterk, A.-R. 2011. Ruminant fatty acid metabolism. PhD thesis. Wageningen University, Wageningen, the Netherlands.

Stoop, W. M., J. A. M. van Arendonk, J. M. L. Heck, H. J. F. van Valenberg, and H. Bovenhuis. 2008. Genetic parameters for major milk fatty acids and milk production traits of Dutch Holstein-Friesians. J. Dairy Sci. 91:385-394.

Thaller, G., W. Krämer, A. Winter, B. Kaupe, G. Erhardt, and R. Fries. 2003. Effects of DGAT1 variants on milk production traits in German cattle breeds. J. Anim. Sci. 81:1911-1918.

Thorsdottir, I., J. Hill, and A. Ramel. 2004. Short communication: Seasonal variation in cis-9, trans-11 conjugated linoleic acid content in milk fat from Nordic countries. J. Dairy Sci. 87:2800-2802.

Wilmink, J. B. M. 1987. Adjustment of test-day milk, fat and protein yield for age, season and stage of lactation. Livest. Prod. Sci. 16:335-348.

Winter, A., W. Krämer, F. A. O. Werner, S. Kollers, S. Kata, G. Durstewitz, J. Buitkamp, J. E. Womack, G. Thaller, and R. Fries. 2002. Association of a lysine-232/alanine polymorphism in a bovine gene encoding acyl-CoA:diacylglycerol acyltransferase 
(DGAT1) with variation at a quantitative trait locus for milk fat content. Proc. Natl. Acad. Sci. USA 99:9300-9305.

Yen, C.-L. E., S. J. Stone, S. Koliwad, C. Harris, and R. V. Farese. 2008. Thematic Review Series: Glycerolipids. DGAT enzymes and triacylglycerol biosynthesis. J. Lipid Res. 49:2283-2301. 



\section{A quantitative trait locus on Bos taurus autosome 17 explains a large proportion of the genetic variation in de novo synthesized milk fatty acids}

S. I. Duchemin ${ }^{1,2}$, M. H. P. W. Visker ${ }^{1}$, J. A. M. Van Arendonk ${ }^{1}$, H. Bovenhuis ${ }^{1}$

${ }^{1}$ Animal Breeding and Genomics Centre, Wageningen University, PO Box 338, 6700 $\mathrm{AH}$ Wageningen, the Netherlands; ${ }^{2}$ Department of Animal Breeding and Genetics, Swedish University of Agricultural Sciences, Uppsala, Sweden 


\section{Abstract}

A genomic region associated with milk fatty acid (FA) composition has been detected on Bos Taurus Autosome (BTA) 17 based on 50k SNP genotypes. The aim of our study was to fine-map BTA17 with imputed 777k single nucleotide polymorphism (SNP) genotypes in order to identify candidate genes associated with milk FA composition. Phenotypes consisted of gas chromatography measurements of 14 FA based on winter and summer milk samples. Phenotypes and genotypes were available on 1,640 animals in winter milk, and on 1,581 animals in summer milk samples. SingleSNP analyses showed that several SNP in a region located between 29.0 and 34.0 mega base-pairs were in strong association with $\mathrm{C} 6: 0, \mathrm{C} 8: 0$, and $\mathrm{C} 10: 0$. This region was further characterized based on haplotypes. In summer milk samples, for example, these haplotypes explained almost $10 \%$ of the genetic variance in C6:0, $9 \%$ in $\mathrm{C} 8: 0,3.5 \%$ in $\mathrm{C} 10: 0,1.8 \%$ in $\mathrm{C} 12: 0$, and $0.9 \%$ in $\mathrm{C} 14: 0$. Two groups of haplotypes with distinct predicted effects could be defined, suggesting the presence of one causal variant. Predicted haplotype effects tended to increase from C6:0 to C14:0, however, the proportion of genetic variance explained by the haplotypes tended to decrease from $\mathrm{C} 6: 0$ to $\mathrm{C} 14: 0$. This is an indication that the quantitative trait locus (QTL) region is either involved in the elongation process or in early termination of de novo synthesized FA. Although many genes are present in this QTL region, most of these genes on BTA17 have not been characterized yet. The strongest association was found close to the progesterone receptor membrane component 2 (PGRMC2) gene. This gene has not been associated to milk FA composition. Therefore, no clear candidate gene associated with milk FA composition could be identified for this QTL.

Key words: milk fatty acid composition, dairy cattle, candidate genes, high-density genotyping. 


\subsection{Introduction}

Bovine milk-fat is composed of more than 400 different fatty acids (FA), many of which are still un-identified (Jensen, 2002). FA may differ in the number of carbons and this difference can be related to the origin of the FA. Most short-chain FA are FA of less than 12 carbons that are mainly elongated from acetate by de novo synthesis in the mammary gland of a cow (e.g., Palmquist, 2006). Medium-chain FA are FA of 14 and 16 carbons and, while C14:0 mainly originates from de novo synthesis, C16:0 originates from two sources: approximately $50 \%$ from de novo synthesis and $50 \%$ from the diet of a cow. Most long-chain FA are FA of 18 or more carbons that mainly originate from the cow's diet, or from body fat mobilization (e.g., Chilliard et al., 2000). In addition to differences in the number of carbons, FA may also differ in their degree of saturation. On average, more than $70 \%$ of the identified FA in milk consist of saturated FA, and the remaining consist of unsaturated FA.

Variation in the content of several FA in milk is affected by genetic factors. Stoop et al. (2008) reported that individual milk FA have heritability estimates that range from 0.22 to 0.71 . Some well characterized genes are recognized as having large effects on milk-fat and FA composition, such as acyl-CoA: diacylglycerol acyltransferase1 (DGAT1) located on BTA14, and stearoyl-CoA desaturase1 (SCD1) located on BTA26 (e.g., Schennink et al., 2007, Schennink et al., 2008). In addition, several regions of the bovine genome have been identified as having effects on milk-fat and FA composition but have not been characterized yet (e.g., Bouwman et al, 2012). By fine-mapping these regions, it is possible to identify candidate genes (Ishii et al., 2013) associated with milk FA composition. Further insights into the biosynthesis of milk-fat and FA are relevant if the aim is to change milk FA composition by means of breeding (Boichard and Brochard, 2012) or feeding strategies.

Fine-mapping allows to refine genomic regions by testing a large number of single nucleotide polymorphism (SNP) that are likely associated with a quantitative trait locus (QTL) (Hinds et al., 2005). Recently, a genomic region associated with shortchain FA in milk has been detected on BTA17 (Bouwman et al., 2012). However, no candidate gene or causal variant has been identified so far. The aim of our study was to fine-map BTA17 with imputed 777k SNP genotypes in order to identify candidate genes associated with milk FA composition. 


\subsection{Material and Methods}

This study is part of the Dutch Milk Genomics Initiative that aims at exploring the possibilities to modify milk FA composition through breeding. Bouwman et al. (2012) performed a genome-wide association study (GWAS) using 50k SNP genotypes based on milk FA composition of winter and summer milk samples. In the present study, we re-analyzed the same phenotypes, and fine-mapped BTA17 using imputed $777 \mathrm{k}$ SNP genotypes.

\subsubsection{Animals and phenotypes}

Morning milk samples of $500 \mathrm{~mL}$ per cow were retrieved from 2,001 first-lactation Holstein-Friesian cows from 398 herds throughout the Netherlands. At least three cows per herd were sampled in two distinct seasons: February-March 2005 (which will be referred to as "Winter" samples) and May-June 2005 (which will be referred to as "Summer" samples). The milk samples were taken from the same cows during the same lactation. Some cows sampled in winter were no longer lactating when summer milk samples were taken. Additional cows were sampled from the same herds to guarantee milk samples from at least three cows per herd. A total of 1,905 cows had phenotypic records in the winter, with each cow lactating between 63 and 282 days (see Stoop et al., 2008). A total of 1,795 cows had phenotypic records in the summer, with each cow lactating between 97 and 335 days (see Duchemin et al, 2013). About $50 \%$ of the cows in our experiment had access to pasture in summer ( 3.5 to $24 \mathrm{~h} / \mathrm{d}$ ), whereas all cows were kept indoors and fed silage in winter. Further details about the experimental design can be found in Stoop et al. (2008).

Milk FA composition was measured by gas chromatography at the COKZ laboratory (Qlip, Leudsen, Netherlands). Milk-fat was extracted from the milk samples, and fatty acid methyl esters were prepared from fat fractions, as described by Schennink et al. (2007). The FA were identified and quantified by comparing the methyl ester chromatograms of the milk fat samples with the chromatograms of pure FA methyl ester standards (Stoop et al., 2008). FA included in this study were measured as weight proportion of total fat (\%wt/wt) and are described in Table 3.1. In addition, an indicator of de novo synthesized milk FA was created by combining C6:0 through $\mathrm{C} 14: 0$ individual FA in the index referred to as "C6:0-C14:0" (Table 3.2). 


\subsubsection{Genotypes and imputation}

A blood sample from each cow and semen from each bull were used to extract DNA. The DNA of 55 sires and 1,813 daughters belonging to our experimental population was genotyped with a 50k SNP chip. This chip was designed by CRV (Arnhem, Netherlands), and was used to genotype the animals with the Infinium assay (Illumina, San Diego, CA).

A reference population of 1,333 animals belonging to CRV and including the 55 sires with offsprings in our data was additionally genotyped with a 777k SNP chip (Illumina, San Diego, CA). This information on the reference population was used to impute the genotypes of our experimental population from 50k to 777k SNP. This imputation was done using Beagle version 3.2.2 (Browning and Browning, 2009), and resulted in a total of 1,736 animals being imputed to $777 \mathrm{k}$ SNP. From these 1,736 animals, 12 animals were excluded because of pedigree inconsistencies and, subsequently, three animals were excluded because their herds no longer met the requirement of a minimum of three animals sampled per herd. As a consequence, 1,721 animals with imputed 777k SNP genotypes were available for this study. Imputation of BTA17 increased the number of SNP genotypes from 1,562 (i.e., 50k) to 22,240 (i.e., $777 \mathrm{k}$ ). The positions of the imputed SNP were based on the bovine genome assembly UMD 3.1. (Zimin et al., 2009)

\subsubsection{Fine-mapping of BTA17}

The fine-mapping of BTA17 was performed separately for winter and summer milk samples by using imputed 777k SNP genotypes and the 14 FA described in Table 3.1. For each season, animals were included in the analyses if both phenotypic and genotypic data were available. Therefore, a total of 1,640 animals were available for winter milk, and a total of 1,581 animals were available for summer milk samples.

Single SNP analyses were performed using the following animal model:

$$
\begin{aligned}
& y_{i j k l m n o}=\mu+b_{1} * \operatorname{dim}_{i}+b_{2} * e^{-0.05 * \operatorname{dim}_{i}}+b_{3} * a f c_{j}+b_{4} * a f c_{j}^{2}+ \\
& \text { season }_{k}+\operatorname{scode}_{l}+S N P_{m}+\operatorname{herd}_{n}+a_{o}+e_{i j k l m n o}(1)
\end{aligned}
$$

where $y_{i j k l m n o}$ is the dependent variable; $\mu$ is the overall mean; $b 1$ and $b 2$ are the regression coefficients related to $\operatorname{dim}_{i} ; \operatorname{dim}_{i}$ is the covariate describing the effect of days in milk, modeled with a Wilmink curve (Wilmink, 1987); b3 and b4 are the regression coefficients related to $a f c_{j} ; a f c_{j}$ is the covariate describing the effect of age at first calving; season ${ }_{k}$ is the fixed effect of calving season (June - August 2004, 
September - November 2004, or December 2004 - February 2005); scode $_{l}$ is the fixed effect accounting for differences in genetic level between groups of proven bull daughters and young bull daughters; $S N P_{m}$ is the fixed effect of SNP genotype ; her $d_{n}$ is the random effect of herd, and is assumed to be distributed as $\sim N\left(0, I \sigma_{\text {herd }}^{2}\right)$, for which $\mathbf{I}$ is the identity matrix, and is the herd variance; $a_{o}$ is the random additive genetic effect of animal, and is assumed to be distributed as $\sim N\left(0, \mathbf{A} \sigma_{a}^{2}\right)$, where $\mathbf{A}$ is the additive genetic relationships matrix which consisted of 12,548 animals, and $\sigma_{a}^{2}$ is the additive genetic variance; and $e_{i j k l m n o}$ is the random residual effect, and is assumed to be distributed as $\sim \mathrm{N}\left(0, \mathbf{I} \sigma_{e}^{2}\right)$, for which $\mathrm{I}$ is the identity matrix, and $\sigma_{e}^{2}$ is the residual variance.

Additive genetic and herd variances were estimated without the inclusion of SNP information, and the resulting estimates were fixed within model (1).

Heritability estimates were calculated from univariate analyses based on model (1) without the inclusion of SNP effects as follows: $h^{2}=\frac{\sigma_{a}^{2}}{\sigma_{a}^{2}+\sigma_{e}^{2}}$. Analyses were performed separately for winter and summer milk samples. All statistical analyses were performed using ASReml 3.0 (Gilmour et al., 2009).

\subsubsection{Construction of haplotypes}

Haplotypes were constructed to further characterize a genomic region on BTA17, and these were constructed separately for winter and summer milk samples. This construction started with the identification of promising SNP by single SNP analyses using model (1). The SNP with the highest significance was defined as "QTagSNP1". Subsequently, we corrected for the effect of QTagSNP1, by including QTagSNP1 as a fixed effect in model (1). This correction allowed to run a second round of single SNP analyses, and to retrieve remaining significant SNP. After this second round of analyses, if another SNP still was significant, it was defined as "QTagSNP2". In these analyses, a SNP was considered to be still significant if $-\log _{10}(P$-value $) \geq 3$. Next, we corrected for the effects of QTagSNP2 in the model already extended with QTagSNP1, by further including QTagSNP2 as a fixed effect. This methodology was repeated until no additional significant SNP were retrieved. Linkage disequilibrium (LD) was estimated as $r^{2}$ between all the identified QTagSNP using PLINK version 1.07 (Purcell et al., 2007). After the identification of QTagSNP, haplotypes were constructed based on the identified QTagSNP. 
Effects of haplotypes were estimated with the following animal model:

$$
\begin{aligned}
& y_{i j k \operatorname{lnpqr}}=\mu+b_{1} * \operatorname{dim}_{i}+b_{2} * e^{-0.05 * \operatorname{dim}_{i}}+b_{3} * a f c_{j}+b_{4} * a f c_{j}^{2}+ \\
& \text { season }_{k}+\text { scode }_{l}+\text { haplo }_{p}+\text { haplo2 }_{q}+\text { herd }_{n}+a_{r}^{*}+e_{i j k l n p q r}(2)
\end{aligned}
$$

where variables are as previously described for model (1), and: haplo $1_{\mathrm{p}}$ is the random effect of the first haplotype; haplo $2_{q}$ is the random effect of the second haplotype, and they are both assumed to be distributed as $N \sim\left(0, \mathbf{I} \sigma_{\text {haplo }}^{2}\right)$, for which $\mathbf{I}$ is the identity matrix, and $\sigma_{\text {haplo }}^{2}$ is the haplotype variance. The first and second haplotypes were jointly used to estimate one haplotype variance $\left(\sigma_{\text {haplo }}^{2}\right)$ and one effect for each haplotype. This was achieved by combining the design matrices of both haplotypes in ASReml. $a_{r}^{*}$ is the random additive genetic effect of animal estimated without the inclusion of haplotypes, and is assumed to be distributed as $N \sim\left(0, \mathbf{A} \sigma_{a^{*}}^{2}\right)$, for which $\mathbf{A}$ is the additive genetic relationships matrix which consisted of 12,548 animals, and $\sigma_{a^{*}}^{2}$ is the additive genetic variance that remains after accounting for haplotype effects. The total additive genetic variance was defined as: $\sigma_{a}^{2}=\sigma_{a^{*}}^{2}+$ $\sigma_{\text {haplo }}^{2}$. The fraction of genetic variance explained by haplotypes was defined as: $\sigma_{\text {haplo }}^{2} / \sigma_{a}^{2}$.

Additionally, we tested whether predicted haplotype effects differed from each other. Significance levels of the differences between predicted effects of haplotypes were assessed using Student's t-tests, as implemented in ASReml. The predicted effect of a haplotype was considered significantly different from another haplotype if $\mathrm{P}$-value $\leq 0.05$.

\subsection{Results}

\subsubsection{Phenotypic means and heritability estimates}

Phenotypic means and heritability estimates for milk FA composition in winter and summer milk samples are shown in Table 3.1. Winter milk had higher contents of short-chain FA than summer milk samples (14.2\% vs. $13.7 \%)$, higher contents of medium-chain FA ( $44.2 \%$ vs. $40.4 \%$ ), and lower contents of long-chain FA, such as C18:0 (8.7\% vs. 9.9\%) and cis-9 C18:1 (18,2\% vs. 20.5\%). Phenotypic variances were higher in summer as compared to winter milk samples, but genetic variances were similar in both seasons. A detailed discussion on differences between winter and summer milk samples can be found in our previous study (Duchemin et al., 2013). 
Table 3.1 Phenotypic means (SD), and heritability estimates $\left(h^{2}\right)^{1}$ for individual fatty acids (FA) based on 1,640 winter milk samples and 1,581 summer milk samples

\begin{tabular}{|c|c|c|c|c|}
\hline \multirow[b]{2}{*}{ Individual FA (\% wt/wt) } & \multicolumn{2}{|l|}{ Winter } & \multicolumn{2}{|l|}{ Summer } \\
\hline & Mean (SD) & $h^{2}$ & Mean (SD) & $h^{2}$ \\
\hline \multicolumn{5}{|l|}{ Saturated FA: } \\
\hline $\mathrm{C} 4: 0$ & $3.51(0.27)$ & 0.47 & $3.52(0.35)$ & 0.41 \\
\hline C6:0 & $2.23(0.16)$ & 0.46 & $2.17(0.21)$ & 0.39 \\
\hline C8:0 & $1.36(0.14)$ & 0.59 & $1.32(0.17)$ & 0.35 \\
\hline C10:0 & $3.02(0.43)$ & 0.73 & $2.87(0.45)$ & 0.48 \\
\hline C12:0 & $4.12(0.70)$ & 0.62 & $3.79(0.72)$ & 0.48 \\
\hline C14:0 & $11.62(0.92)$ & 0.62 & $11.16(1.05)$ & 0.54 \\
\hline C16:0 & $32.62(2.84)$ & 0.47 & $29.20(3.49)$ & 0.40 \\
\hline C18:0 & $8.71(1.39)$ & 0.28 & $9.86(1.77)$ & 0.19 \\
\hline \multicolumn{5}{|l|}{ Unsaturated FA: } \\
\hline $\mathrm{C} 10: 1^{2}$ & $0.37(0.07)$ & 0.35 & $0.35(0.07)$ & 0.50 \\
\hline $\mathrm{C} 12: 1^{2}$ & $0.12(0.03)$ & 0.38 & $0.11(0.03)$ & 0.47 \\
\hline cis-9 C14:133 & $1.36(0.25)$ & 0.35 & $1.38(0.28)$ & 0.43 \\
\hline cis-9 C16:1 & $1.45(0.32)$ & 0.44 & $1.40(0.30)$ & 0.38 \\
\hline cis-9 C18:14 & $18.18(2.05)$ & 0.22 & $20.53(2.76)$ & 0.35 \\
\hline cis-9, trans-11 C18:2 (CLA) & $0.39(0.11)$ & 0.55 & $0.56(0.27)$ & 0.27 \\
\hline
\end{tabular}

${ }^{1} h^{2}=\sigma_{a}^{2} /\left(\sigma_{a}^{2}+\sigma_{e}^{2}\right)$, where $h^{2}$ is the heritability estimate, $\sigma_{a}^{2}$ is the additive genetic variance and $\sigma_{e}^{2}$ is the residual variance; SE between 0.01 and 0.12 for winter samples, and between 0.02 and 0.08 for summer samples.

${ }^{2}$ For $\mathrm{C} 10: 1$ and $\mathrm{C} 12: 1$, the cis double bond could not be ascertained at the carbon 9 position. ${ }^{3}$ cis-9 C14:1 represents the sum of cis-9 C14:1 and iso C15 due to co-elution associated with the gas chromatography (GC) extraction method.

${ }^{4}$ cis-9 C18:1 represents the sum of cis-9 C18:1 and trans-12 C18:1 due to co-elution associated with the GC extraction method.

\subsubsection{Fine-mapping of BTA17}

Results of the fine-mapping of BTA17 for winter and summer milk samples are shown in Additional File 1. For both seasons, we analyzed the associations between 22,240 imputed SNP and each of the 14 FA. In a region between 29.0 and 34.0 mega base-

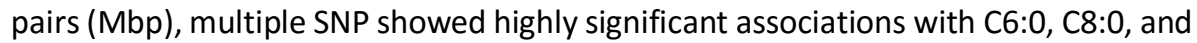
C10:0. Moreover, multiple SNP showed associations both in winter and summer milk samples (Additional file 1). Previously, Bouwman et al. (2012) identified associations of multiple regions on BTA17 with C6:0, C8:0, C10:0, C14:1, and C16:1. Detailed analyses in the current study focused on the region between 29.0 and $34.0 \mathrm{Mbp}$ 
because here the strongest and most consistent associations were found across winter and summer milk samples.

Figure 3.1A illustrates the strongest associations found with the imputed $777 \mathrm{k}$ SNP genotypes for $\mathrm{C} 8: 0$ in summer milk samples. Additionally in Figure 3.1A, these associations were overlaid with the associations found by Bouwman et al. (2012) using 50k SNP genotypes, which was mainly the same data as used in the current study. Within the marked region (figure 3.1A), 10 significant SNP were found with the 50k SNP whereas 83 significant SNP were found with the imputed 777k SNP. The most significant SNP identified based on the imputed $777 \mathrm{k}$ SNP $\left(-\log _{10}(\mathrm{P}\right.$-value $)=$ 7.93) was not present on the 50k SNP array. The most significant SNP identified based on the 50k SNP genotypes was less significant $\left(-\log _{10}(P\right.$-value $)=6.21$; Bouwman et al., 2012) than the most significant SNP identified in the present study. The location of the QTL could be refined to the genomic region located between 29.0 and $34.0 \mathrm{Mbp}$ on BTA17 (figure 3.1A). Figure 3.1B shows the results of the associations for five FA in summer milk samples for this region.

\subsubsection{Construction of haplotypes}

The construction of haplotypes was based on the identified QTagSNP in the finemapping of BTA17. These SNP, QTagSNP1 and QTagSNP2, were different for winter and summer milk samples. For winter milk samples, QTagSNP1 was BovineHD1700008470 (rs109426433) located at $29.92 \mathrm{Mbp}$, and with minor allele frequency (MAF) of 0.47. QTagSNP1 was associated with C6:0 $\left(-\log _{10}(\mathrm{P}\right.$-value $)=$ 4.90), $\mathrm{C} 8: 0\left(-\log _{10}(\mathrm{P}\right.$-value $\left.)=6.28\right), \mathrm{C} 10: 0\left(-\log _{10}(\mathrm{P}\right.$-value $\left.)=4.03\right)$ and $\mathrm{C} 12: 0\left(-\log _{10}(\mathrm{P}-\right.$ value $=1.33$ ). QTagSNP2 was BovineHD1700009150 (rs135934524) located at 32.90 $\mathrm{Mbp}$, with MAF of 0.44. QTagSNP2 was associated with $\mathrm{C6:0}\left(-\log _{10}(\mathrm{P}\right.$-value $\left.)=2.76\right)$, C8:0 $\left(-\log _{10}(\mathrm{P}\right.$-value $\left.)=3.27\right)$, and C10:0 $\left(-\log _{10}(\mathrm{P}\right.$-value $\left.)=2.24\right)$. QTagSNP1 and QTagSNP2 showed the strongest associations with C8:0. LD between QTagSNP1 and QTagSNP2 was $r^{2}=0.04$.

For summer milk samples, QTagSNP1 was BovineHD1700008490 (rs109290136) located at $30.08 \mathrm{Mbp}$ (Figure 3.1B), with MAF of 0.44. QTagSNP1 was associated with C6:0 $(-\log 10(P$-value $)=6.82), C 8: 0(-\log 10(P$-value $)=7.93), C 10: 0(-\log 10(P-$ value $)=$ 6.13) and $C 12: 0(-\log 10(P$-value $)=3.35)$. QTagSNP2 was BovineHD1700008967 (rs135465158) located at 32.17 Mbp (Figure 3.1C), with MAF of 0.14. QTagSNP2 was associated with $\mathrm{C6}: 0 \quad(-\log 10(\mathrm{P}$-value $)=2.82), \mathrm{C} 8: 0(-\log 10(\mathrm{P}$-value $)=3.19)$, and C10:0 (- $\log 10(P$-value $)=1.84)$. QTagSNP1 and QTagSNP2 showed the strongest associations with C8:0. LD between QTagSNP1 and QTagSNP2 was $r^{2}=0.07$. LD 
between QTagSNP1 and all other markers in the fine-mapped region as well as significance of association with C8:0 is represented in Additional File 3.2 - figure A. LD between QTagSNP2 and all other markers in the fine-mapped region as well as significance of association with C8:0 is represented in Additional file 3.2 - figure B. LD between QtagSNP1 for winter milk samples and QtagSNP1 for summer milk samples was $r^{2}=0.56$; LD among other combinations of QTagSNP based on winter or on summer milk samples was low $\left(r^{2}<0.10\right)$. For both winter and summer milk samples, two QTagSNP were identified. These two QTagSNP were used for haplotype construction, and this construction resulted in four haplotypes. As QTagSNP were not the same in winter and in summer milk samples, different haplotypes were constructed for both seasons.

\subsubsection{Predicted effects of haplotypes}

Predicted effects of haplotypes are shown in Table 3.2. For winter samples, frequencies of haplotypes were 0.33 for $A-A, 0.21$ for $A-G, 0.12$ for $C-A$, and 0.35 for C-G. While A-A haplotypes were associated with higher contents of C6:0, C8:0, C10:0, $\mathrm{C} 12: 0, \mathrm{C} 14: 0$ and the index C6:0-C14:0, C-G haplotypes were associated with lower contents of these FA and index. The absolute difference between one copy of the most contrasting haplotypes (A-A and C-G) was 0.040 for $\mathrm{C} 6: 0,0.039$ for $\mathrm{C} 8: 0,0.090$ for $\mathrm{C} 10: 0,0.054$ for $\mathrm{C} 12: 0,0.065$ for $\mathrm{C} 14: 0$, and 0.239 for the index $\mathrm{C} 6: 0-\mathrm{C} 14: 0$. The fraction of genetic variance explained by haplotypes was $2.7 \%$ for $\mathrm{C} 6: 0,2.8 \%$ for $\mathrm{C} 8: 0,1.4 \%$ for $\mathrm{C} 10: 0,0.5 \%$ for $\mathrm{C} 12: 0,0.3 \%$ for $\mathrm{C} 14: 0$, and $0.7 \%$ for the index $\mathrm{C} 6: 0-$ C14:0. Effects of the C-A haplotype did not differ from effects of the A-G haplotype

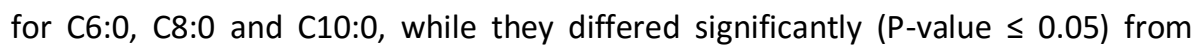
effects of the $C-G$ haplotype for $\mathrm{C} 8: 0$. These results suggest that there are two groups of haplotypes with distinct effects (A-A, and A-G/C-A/C-G) for C6:0 and C10:0, and there are three groups of haplotypes with distinct effects (A-A, C-G, and $A-G / C-A)$ for C8:0.

For summer samples, frequencies of haplotypes were 0.44 for $A-G, 0.12$ for $A-A, 0.01$ for $C-A$, and 0.42 for $C-G$. While $C-G$ haplotypes were associated with higher contents of $\mathrm{C} 6: 0, \mathrm{C} 8: 0, \mathrm{C} 10: 0, \mathrm{C} 12: 0, \mathrm{C} 14: 0$, and the index $\mathrm{C} 6: 0-\mathrm{C} 14: 0, \mathrm{~A}-\mathrm{G}$ haplotypes were associated with lower contents of these $F A$ and index. The absolute difference between one copy of the most contrasting haplotypes ( $C-G$ and $A-G$ ) was 0.048 for $\mathrm{C} 6: 0,0.043$ for $\mathrm{C} 8: 0,0.102$ for $\mathrm{C} 10: 0,0.101$ for $\mathrm{C} 12: 0,0.106$ for $\mathrm{C} 14: 0$, and 0.495 for the index $\mathrm{C} 6: 0-\mathrm{C} 14: 0$. The fraction of genetic variance explained by haplotypes was $0.3 \%$ for $\mathrm{C} 4: 0,9.7 \%$ for $\mathrm{C} 6: 0,9 \%$ for $\mathrm{C} 8: 0,3.5 \%$ for $\mathrm{C} 10: 0,1.8 \%$ for $\mathrm{C} 12: 0,0.9 \%$ for $\mathrm{C} 14: 0$, and $5.0 \%$ for the index $\mathrm{C} 6: 0-\mathrm{C} 14: 0$. 
In summer samples, predicted effects of the $A-G$ haplotype differed significantly ( $P$ value $\leq$ 0.05; table 3.2) from effects of A-A, C-G and C-A haplotypes for C6:0, C8:0,

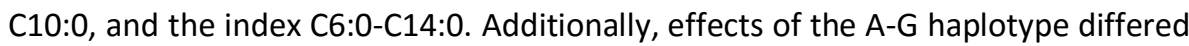
significantly ( $P$-value $\leq 0.05$ ) from effects of the $C-G$ haplotype for C12:0, and C14:0. Effects of the C-G haplotype did not differ from the effects of C-A and A-A haplotypes for any of the traits. These results suggest that there are two groups of haplotypes with distinct effects (A-G, and A-A/C-A/C-G) for C6:0, C8:0, C10:0, C12:0, C14:0, and the index $\mathrm{C6}: 0-\mathrm{C} 14: 0$.

\subsection{Discussion}

In the present study, we refined the location of a QTL first described by Bouwman et al. (2012). This QTL seems to influence multiple de novo synthesized FA. We finemapped BTA17 by using imputed 777k SNP genotypes, and by using winter and summer milk FA composition. To further characterize the effects associated with this genomic region, we constructed haplotypes for each season.

\subsubsection{Fine-mapping of BTA17}

The fine-mapping of BTA17 combined high-density SNP genotyping with imputation. Imputation was based on a large reference population genotyped with 777k SNP. Additionally, the 55 sires belonging to our experimental population were genotyped with both 50k and 777k SNP. Our experimental population, which is composed of the daughters of the 55 sires, was imputed from 50k to 777k SNP genotypes using Beagle (Browning and Browning, 2009). The estimated error of this imputation was below 1\%. Pausch et al. (2013) showed that imputation to high-density genotypes largely depends on the size of the reference population. An imputation accuracy of about $\sim 99 \%$ can be obtained when a reference population of more than 400 animals is used (Pausch et al., 2013). This is in line with the imputation accuracy obtained in the current study. When imputation accuracy is high, GWAS based on imputed genotypes can assist in fine-mapping because imputation provides a high-resolution view of an associated region, and increases the chance that a causal SNP can be directly identified (Marchini and Howie, 2010). In the present study, the number of SNP increased by at least 10 times with the imputation of BTA17 from 50k to 777k SNP genotypes. 

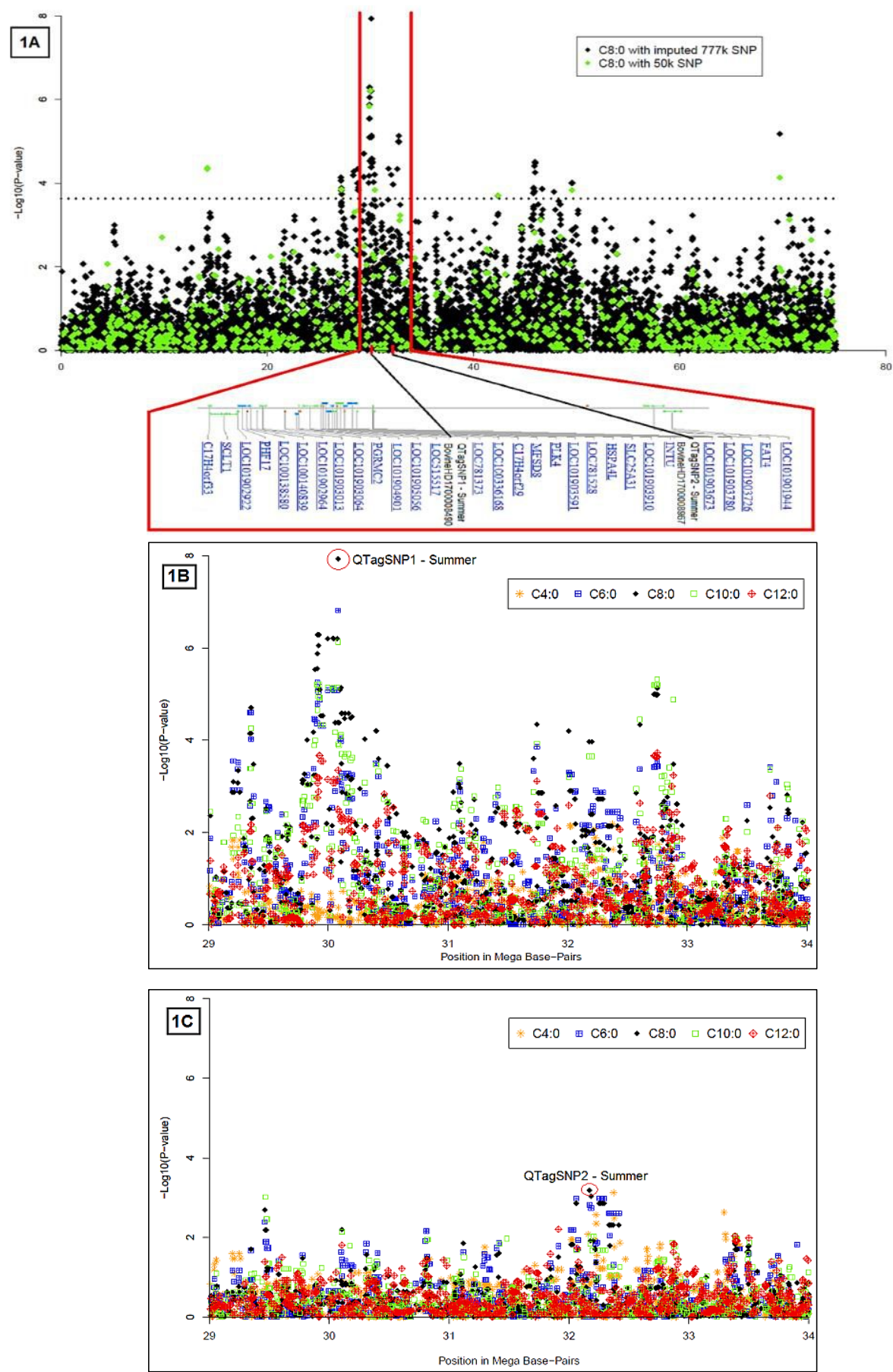
Figure 3.1. (A) Fine-mapping of BTA17 for $\mathrm{C} 8: 0$ in summer milk samples showing genome-wide association of imputed $777 \mathrm{k}(777,000)$ SNP overlaid with genome-wide association of $50 \mathrm{k}$ $(50,000)$ SNP genotypes done by Bouwman et al. (2012). The black dotted line is the genomewide significance level based on 50k SNP genotypes at a false discovery rate of $0.05\left[-\log _{10}(P\right.$ value $)=3.63$. A list of candidate genes was added as well as an indication of the location of SNP, with the highest significance referred to QTagSNP1 and the SNP with the second highest significance referred to QTagSNP2. (B) Fine-mapping of candidate region from 29.0 to 34.0 Mbp associated with $\mathrm{C} 4: 0$ to $\mathrm{C} 12: 0$ on BTA17 (results represent summer samples only). Circle indicates QTagSNP1. (C) Fine-mapping of candidate region on BTA17 after the correction for QTagSNP1 (results represent summer samples only). Circle indicates QTagSNP2.

GWAS by Bouwman et al. (2012) with 50k SNP genotypes identified a QTL associated with milk FA composition on BTA17. By fine-mapping BTA17 with the imputed $777 \mathrm{k}$ SNP genotypes, additional SNP were found to be significantly associated with milk FA, and these were more significant than the SNP found by Bouwman et al. (2012). In addition, multiple FA showed associations with the same genomic region on BTA17, both in winter and in summer milk samples (Additional File 1). We focused on the strongest and most consistent associations found in both winter and summer milk samples. These associations were identified in this region located between 29$34 \mathrm{Mbp}$. Additional analyses in which we extended the region (26- $34 \mathrm{Mbp}$ ) showed results that were comparable to the ones presented in this paper.

Within this genomic region, summer milk showed more pronounced associations than winter milk samples. Duchemin et al. (2013) reported strong genetic correlations between winter and summer milk-fat composition of de novo synthesized FA (e.g., 0.95 for C6:0, 0.93 for C8:0, and 0.95 for C10:0). These strong genetic correlations suggest that de novo FA in winter and in summer milk are genetically the same trait. In addition, GWAS by Bouwman et al. (2012) showed that many genomic regions associated with milk FA in winter milk could be confirmed in summer milk samples (e.g., BTA17). Therefore, it is likely that milk FA composition is influenced by similar groups of genes. When studying the effects of DGAT1 polymorphism on milk-fat composition in winter and summer milk samples, Duchemin et al. (2013) concluded that genotypic effects were in the same direction, but some of the genotypic effects were larger in summer as compared to winter. 
Table 3.2 Predicted effects of haplotypes (frequency given in parenthesis after each haplotype) for de novo synthesized milk fatty acids based on 1,640 winter milk samples and 1,581 summer milk samples.

\begin{tabular}{|c|c|c|c|c|c|}
\hline \multirow{2}{*}{ Trait } & \multicolumn{4}{|c|}{ Winter milk samples } & \multirow{2}{*}{$\begin{array}{l}\sigma_{\text {haplo }}^{2} / \sigma_{\mathrm{a}}^{2} \\
(\%)^{1}\end{array}$} \\
\hline & A-A (0.33) & A-G (0.21) & C-A (0.12) & C-G (0.35) & \\
\hline C4:0 & $0.000 \pm 0.000^{\mathrm{a}}$ & $0.000 \pm 0.000^{a}$ & $0.000 \pm 0.000^{a}$ & $0.000 \pm 0.000^{a}$ & $0.0 \%$ \\
\hline C6:0 & $0.021 \pm 0.010^{\mathrm{a}}$ & $0.002 \pm 0.010^{b}$ & $-0.004 \pm 0.011^{b c}$ & $-0.019 \pm 0.010^{c}$ & $2.7 \%$ \\
\hline C8:0 & $0.020 \pm 0.009^{a}$ & $0.002 \pm 0.009^{b}$ & $-0.002 \pm 0.010^{b}$ & $-0.019 \pm 0.009 c$ & $2.8 \%$ \\
\hline $\mathrm{C} 10: 0$ & $0.045 \pm 0.023^{a}$ & $0.005 \pm 0.023^{b}$ & $-0.005 \pm 0.025^{b c}$ & $-0.045 \pm 0.023^{c}$ & $1.4 \%$ \\
\hline C12:0 & $0.026 \pm 0.020^{a}$ & $0.004 \pm 0.020^{\mathrm{ab}}$ & $0.001 \pm 0.022^{\mathrm{ab}}$ & $-0.028 \pm 0.020^{b}$ & $0.5 \%$ \\
\hline C14:0 & $0.037 \pm 0.028^{a}$ & $0.003 \pm 0.028^{\mathrm{ab}}$ & $-0.012 \pm 0.031^{\mathrm{ab}}$ & $-0.028 \pm 0.028^{b}$ & $0.3 \%$ \\
\hline \multirow[t]{3}{*}{$\mathrm{C} 6: 0-\mathrm{C} 14: 0$} & $0.106 \pm 0.084^{a}$ & $0.027 \pm 0.085^{\mathrm{ab}}$ & $0.000 \pm 0.091^{\mathrm{ab}}$ & $-0.133 \pm 0.084^{b}$ & $0.7 \%$ \\
\hline & \multicolumn{4}{|c|}{ Summer milk samples } & \\
\hline & A-G (0.44) & A-A (0.12) & C-A (0.01) & C-G (0.42) & \\
\hline $\mathrm{C} 4: 0$ & $-0.009 \pm 0.009^{a}$ & $0.002 \pm 0.010^{\mathrm{a}}$ & $0.006 \pm 0.011^{a}$ & $0.000 \pm 0.009^{a}$ & $0.3 \%$ \\
\hline C6:0 & $-0.043 \pm 0.021^{a}$ & $-0.009 \pm 0.022^{b}$ & $0.046 \pm 0.027^{c}$ & $0.005 \pm 0.021^{b c}$ & $9.7 \%$ \\
\hline C8:0 & $-0.035 \pm 0.016^{a}$ & $-0.003 \pm 0.017^{b}$ & $0.030 \pm 0.021^{b}$ & $0.008 \pm 0.016^{b}$ & $9.0 \%$ \\
\hline C10:0 & $-0.068 \pm 0.031^{a}$ & $0.003 \pm 0.033^{b}$ & $0.030 \pm 0.043^{b}$ & $0.034 \pm 0.032^{\mathrm{b}}$ & $3.5 \%$ \\
\hline C12:0 & $-0.049 \pm 0.032^{a}$ & $0.003 \pm 0.035^{\mathrm{ab}}$ & $-0.006 \pm 0.045^{\mathrm{ab}}$ & $0.052 \pm 0.033^{b}$ & $1.8 \%$ \\
\hline C14:0 & $-0.055 \pm 0.039^{a}$ & $0.004 \pm 0.044^{\mathrm{ab}}$ & $0.000 \pm 0.054^{\mathrm{ab}}$ & $0.051 \pm 0.041^{b}$ & $0.9 \%$ \\
\hline $\mathrm{C} 6: 0-\mathrm{C} 14: 0$ & $-0.329 \pm 0.168^{a}$ & $-0.050 \pm 0.180^{b}$ & $0.213 \pm 0.237^{b}$ & $0.166 \pm 0.172^{\mathrm{b}}$ & $5.0 \%$ \\
\hline
\end{tabular}

a-c For each trait (i.e., within a row), different letters indicate a significant difference between haplotypes at $P \leq 0.05$, using Student's t-test. ${ }^{1} \sigma_{a}^{2}=\sigma_{a^{*}}^{2}+\sigma_{\text {haplo, }}^{2}$, where $\sigma_{a}^{2}$ is the total additive genetic variance, $\sigma_{a^{*}}^{2}$ is the additive genetic variance that remains after accounting for haplotype effects, and $\sigma_{\text {haplo }}^{2}$ is the haplotype variance 
Duchemin et al. (2013) concluded that differences between winter and summer milkfat composition were likely due to differences in the diets of the cows, and that the effects of DGAT1 were scaled. This scaling resulted in significant DGAT1 by season interaction, especially for short-chain FA (C4:0 to C14:0). In the present study, similar scaling effects might explain the more pronounced associations found in summer as compared to winter milk samples.

\subsubsection{Construction of haplotypes}

Haplotypes were constructed by first retrieving the most significant SNP within the fine-mapped region. This SNP, QTagSNP1, was associated with C8:0. Most of the variation in the region was explained by QTagSNP1, but not all. The remaining variation was accounted for by QTagSNP2 (results shown for summer samples, Figure 3.1B and 3.1C). After adjusting for both QTagSNP, no other significant SNP was found. Based on the two QTagSNP, a total of four haplotypes were constructed. In summer milk samples, these haplotypes explained almost $10 \%$ of the genetic variance in $\mathrm{C} 6: 0,9 \%$ in $\mathrm{C} 8: 0,3.5 \%$ in $\mathrm{C} 10: 0,1.8 \%$ in $\mathrm{C} 12: 0$, and $0.9 \%$ in $\mathrm{C} 14: 0$ (Table 3.2). When these FA were combined into an index, haplotypes explained $5 \%$ of the genetic variance in de novo synthesized milk FA (C6:0-C14:0; Table 3.2). After testing for differences between these haplotypes, we concluded that estimated effects in summer milk for three out of four haplotypes did not differ from each other. Therefore, our four haplotypes could be divided in two groups with distinct effects on C6:0, C8:0, C10:0, C12:0, C14:0, and the index C6:0-C14:0: A-G versus the remaining haplotypes. The existence of two groups of haplotypes with distinct effects can be explained by one causal variant, i.e., one QTL. However, we cannot exclude the presence of multiple causal variants in strong LD.

The QTL region is associated with multiple de novo synthesized FA. The de novo synthesis occurs within the mammary gland of a cow, and is a process that elongates precursors by adding $\mathrm{C} 2: 0$. These precursors originate from blood lipids and can be either acetate (C2:0), propionate $(\mathrm{C} 3: 0)$ or butyrate $(\mathrm{C} 4: 0)$. Butyrate in milk may originate from de novo synthesis or directly from $\beta$-hydroxybutyrate derived from the blood (e.g., Craninx et al., 2008). Depending on the precursor, the elongation process ends either at C16:0 or at C17:0. Results of the current study show that predicted effects of haplotypes increase from C6:0 to C14:0, however, the proportion of genetic variance explained by haplotypes decreases from C6:0 to C14:0. This increase of haplotype effects tends to be more pronounced in summer than in winter milk samples (Table 3.2). These results suggest that our candidate gene is involved in the elongation of FA or the early termination of this process 
(Barber et al., 1997), and it might be up-regulated in summer as compared to winter milk samples.

Interestingly, in other species, such as humans, macaques and pigs, this genomic region is highly conserved. Further, in dairy cattle breeds, two studies suggested that this region on BTA17 contains signatures of selection: Qanbari et al. (2011) identified signatures of selection in a region close to the progesterone receptor membrane component 2 (PGRMC2 at 29.8Mb) gene; and Stella et al. (2010) in a region close to the sprout homolog1, antagonist of FGF signaling (Drosophila) (SPRY1 at 34.7 Mbp) gene. Possibly this genomic region is related to a highly conserved evolutionary mechanism.

\subsubsection{Candidate genes}

Information on candidate genes possibly associated with de novo synthesized FA was retrieved from the National Center for Biotechnology Information (NCBI) website. The QTL region on BTA17 contains 29 genes, but 18 of these genes have not been characterized yet Between QTagSNP1 and QTagSNP2 in summer samples, there are 11 genes of which five have been characterized (Figure 3.1A).

The gene that has been characterized and is closest to the most significant association is PGRMC2, which is located between 29.87 and $29.89 \mathrm{Mbp}$. This gene belongs to the Superfamily cytochrome b5-like heme/steroid binding domain. This Superfamily is involved in the fatty acid metabolic process, and oxido-reductase activity. In humans, this gene has been associated with breast adenocarcinoma (Causey et al., 2011), and it was pointed out as a regulator of cytochrome P450 enzyme activity (Wendler and Wehling, 2013). By sequencing the mRNA found in milk fat layer, Lemay et al. (2013) showed that PGRMC2 is expressed in humans throughout the lactation, which included colostrum, transitional and mature milk. In cattle, PGRMC2 has been associated with fertility. Kowalik et al. (2013) showed that expression of PGRMC2 mRNA in the bovine endometrium was higher in the first trimester of pregnant cows as compared to cyclic animals. However, the translation of PGRMC2 mRNA in protein within the bovine endometrium was not different between cyclic and pregnant cows. In our study, cows in winter and summer sampling period were in a different stage of lactation (average of 166 days in winter and average of 247 days in summer samples), and probably at different stages of pregnancy. This might be a reason for the more pronounced associations found in summer milk samples. Therefore, we performed additional analyses in which we investigated interactions between stage of lactation and our QTagSNPs in both 
seasons. None of these interactions were significant (results not shown). Bionaz et al. (2012) showed that PGRMC2 is expressed during lactation in bovine mammary tissue. PGRMC2 has not been associated with milk FA composition in dairy cattle.

Of the genes located within our QTL region, Bionaz et al. (2012) showed that four other genes are highly expressed during lactation in bovine mammary tissue: UPF0462 protein C4orf33-like (LOC513251), sodium channel and clathrin linker 1 (SCLT1), la-related protein 1B-like (LOC515517), and chromosome 17 open reading frame, human C4orf29 (C17H4orf29). The location in Mbp for these genes is between 29.10-29.12 for LOC513251, between 29.12-29.35 for SCLT1, between 30.03-30.07 for LOC515517, and between 30.10-30.13 for C17H4orf29. By sequencing the mRNA found in milk fat layer, Lemay et al. (2013) showed in humans that C17h4orf33 (validated LOC513251 gene in humans), LARP1B (validated LOC515517 gene in humans), and $\mathbf{C 1 7 H 4 o r f 2 9}$ are expressed during all stages of lactation. These four genes have not yet been associated to milk FA composition.

In the present paper, we refined the location of a QTL, which is associated with multiple de novo synthesized milk FA, to a region between 29.0 and $34.0 \mathrm{Mbp}$ on BTA17. We characterized the effects associated with this region by constructing haplotypes, and identified candidate genes possibly related to this QTL.

\subsection{Conclusions}

The fine-mapping of BTA17 improved the location of a QTL associated with multiple de novo synthesized milk FA. In summer milk samples, this QTL region explained a large proportion of the genetic variance in these FA individually (e.g., 10\% in C6:0). When all de novo synthesized milk FA were combined into an index, this QTL region explained $5 \%$ of the genetic variance. This QTL region seems to be involved in either the elongation process of the de novo FA synthesis or in the early termination of this process. In addition, the effects of this QTL region are bigger in summer as compared to winter milk samples. Candidate genes associated with milk FA composition could not be clearly identified for this QTL because the QTL region on BTA17 is still being characterized. A characterized gene that might be of interest within the QTL region is PGRMC2. 


\subsection{Acknowledgements}

This study is part of the Dutch Milk Genomics Initiative, funded by Wageningen University, the Dutch Dairy Association (NZO), Cooperative Cattle Improvement Organization (CRV; Arnhem, the Netherlands), and the Dutch Technology Foundation (STW). We would like thank Chris Schrooten from CRV for the imputation of the 777k SNP genotypes. The first author currently benefits from a joint grant from the European Commission (within the framework of the Erasmus-Mundus joint doctorate "EGS-ABG") and Breed4Food (a public-private partnership in the domain of animal breeding and genomics and CRV). 


\subsection{Supplementary files}

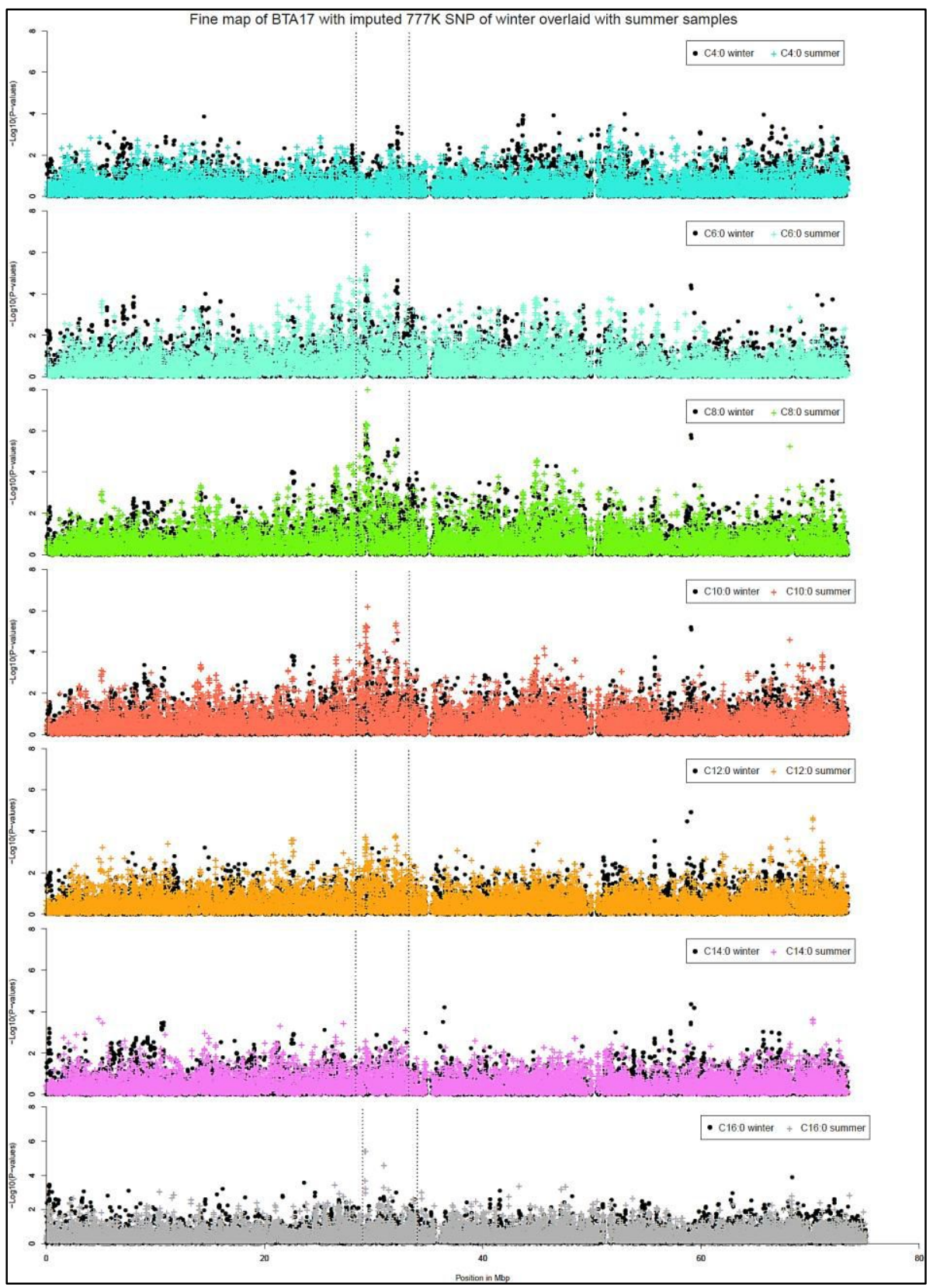




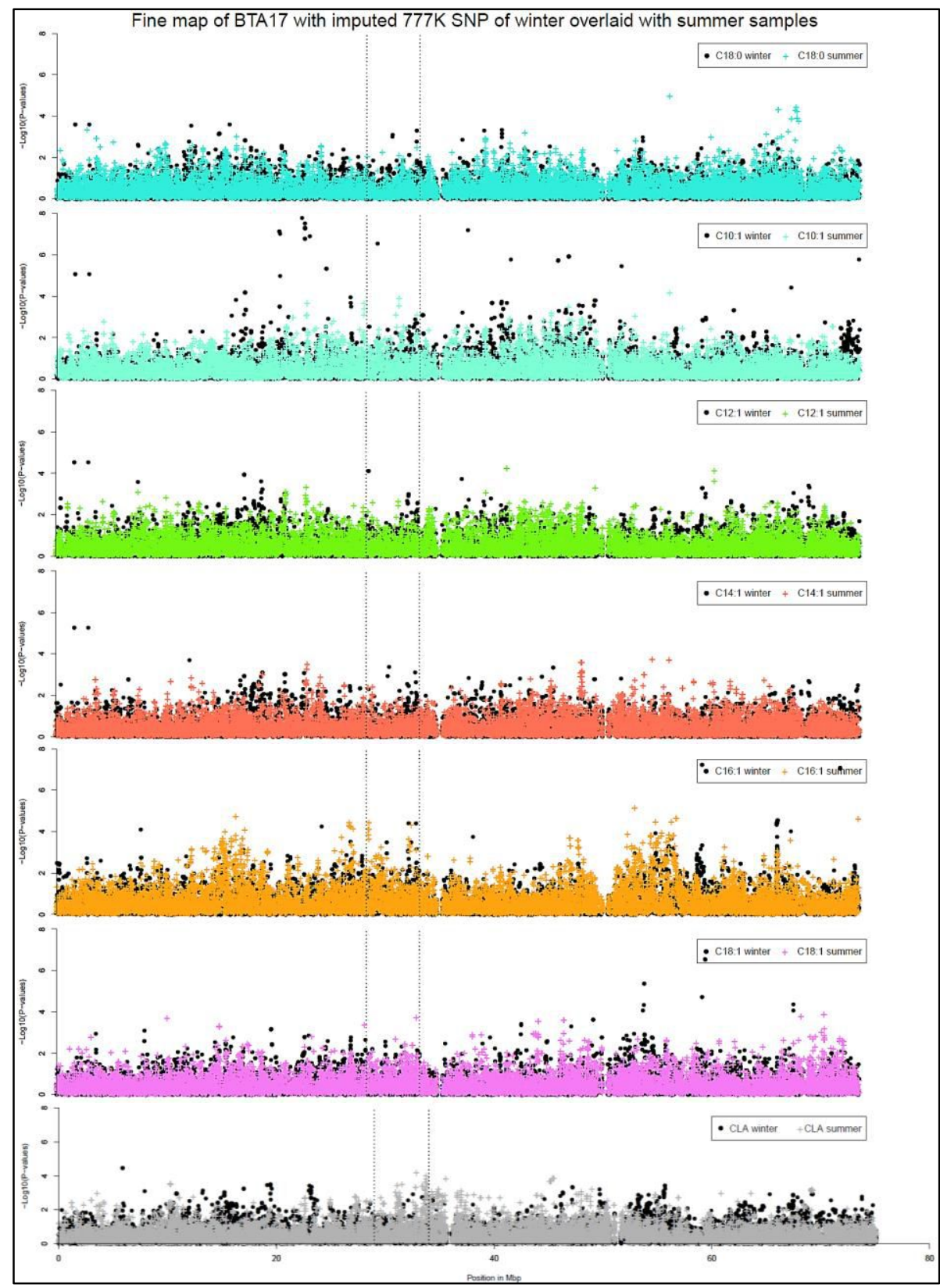

Supplementary Figure 3.1. Fine-mapping of BTA17 with imputed 777k SNP genotypes overlaid between winter and summer samples for 14 FA. The marked region between black dotted lines (29.0 to $34.0 \mathrm{Mbp}$ ) is the region we focused on to refine the location of the QTL. 

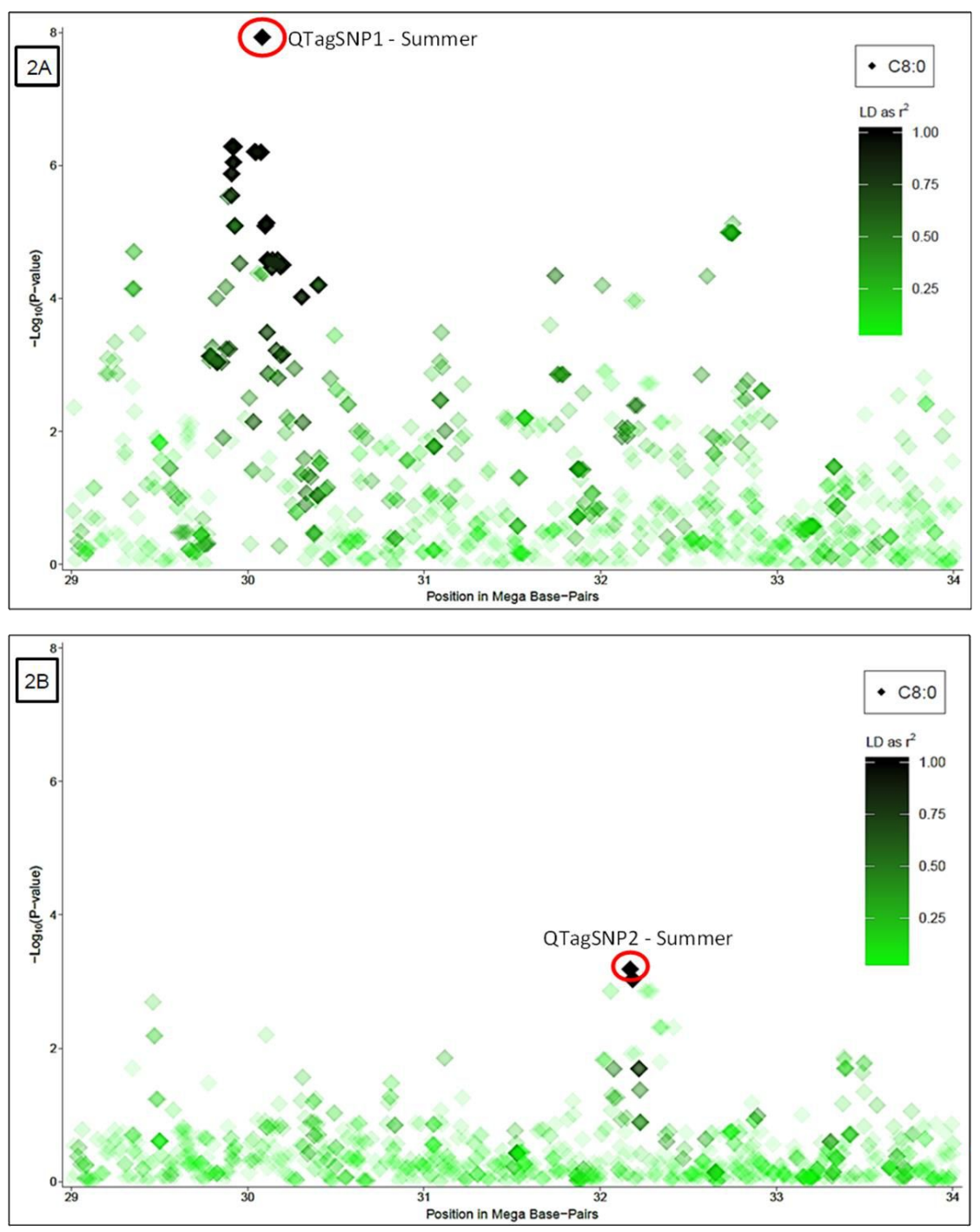

Supplementary Figure 3.2. (A) Fine-mapping of candidate region from 29.0 to $34.0 \mathrm{Mbp}$ associated with C8:0 on BTA17 (results represent summer samples only). Circle indicates QTagSNP1. Linkage disequilibrium (LD), measured as $r^{2}$, between QTagSNP1 and all other markers for the trait is represented as a gradient of colors. (B) Fine-mapping of candidate region associated with C8:0 on BTA17, after the correction for QTagSNP1 (results represent summer samples only). Circle indicates QTagSNP2. LD, measured as $r^{2}$, between QTagSNP2 and all other markers for the trait is represented as a gradient of colors. 


\subsection{References}

Barber, M. C., R. A. Clegg, M. T. Travers, and R. G. Vernon. 1997. Lipid metabolism in the lactating mammary gland. Biochim. Biophys. Acta. 1347:101-126

Bionaz, M., K. Periasamy, S. L. Rodriguez-Zas, W. L. Hurley, and J. J. Loor. 2012. A novel dynamic impact approach DIA for functional analysis of time-course omics studies: validation using the bovine mammary transcriptome. PLoS ONE.7: e32455

Boichard, D., and M. Brochard. 2012. New phenotypes for new breeding goals in dairy cattle. Animal. 6:544-550.

Bouwman, A., M. H. P. W. Visker, J. A. M. van Arendonk, and H. Bovenhuis. 2012. Genomic regions associated with bovine milk fatty acids in both summer and winter milk samples. BMC Genet. 13:93.

Browning, B. L., and S. R. Browning. 2009. A unified approach to genotype imputation and haplotype-phase inference for large data sets of trios and unrelated individuals. Am. J. Hum. Genet. 84:210-223.

Causey, M. W., L. J. Huston, D. M. Harold, C. J. Charaba, D. L. Ippolito, Z. S. Hoffer, T. A. Brown, and J. D. Stallings. 2011. Transcriptional analysis of novel hormone receptors PGRMC1 and PGRMC2 as potential biomarkers of breast adenocarcinoma staging. J. Surg. Res. 171:615-622.

Chilliard, Y., A. Ferlay, R. M. Mansbridge, and M. Doreau. 2000. Ruminant milk fat plasticity: Nutritional control of saturated, polyunsaturated, trans and conjugated fatty acids. Ann. Zootech. 49:181-206.

Duchemin, S., H. Bovenhuis, W. M. Stoop, A. C. Bouwman, J. A. M. van Arendonk, and M. H. P. W. Visker. 2013. Genetic correlation between composition of bovine milk fat in winter and summer, and DGAT1 and SCD1 by season interactions. J. Dairy Sci. 96:592-604.

Gilmour, A. R., B. Gogel, B. Cullis, and R. Thompson. 2009. ASReml user guide release 3.0. VSN International Ltd, Hemel Hempstead, UK.

Hinds, D. A., L. L. Stuve, G. B. Nilsen, E. Halperin, E. Eskin, D. G. Ballinger, K. A. Frazer, and D. R. Cox. 2005. Whole-genome patterns of common DNA variation in three human populations. Science. 307:1072-1079.

Ishii, A., K. Yamaji, Y. Uemoto, N. Sasago, E. Kobayashi, N. Kobayashi, T. Matsuhashi, S. Maruyama, H. Matsumoto, S. Sasazaki, and H. Mannen. 2013. Genome-wide association study for fatty acid composition in Japanese Black cattle. Anim. Sci. J. 84:675-682.

Jensen, R. G. 2002. The composition of bovine milk lipids: January 1995 to December 2000. J. Dairy Sci. 85:295-350. 
Kowalik, M. K., D. Slonina, R. Rekawiecki, and J. Kotwica. 2013. Expression of progesterone receptor membrane component (PGRMC) 1 and 2, serpine mRNA binding protein 1 (SERBP1) and nuclear progesterone receptor (PGR) in the bovine endometrium during the estrous cycle and the first trimester of pregnancy. Reprod. Biol. 13:15-23.

Lemay, D. G., O. A. Ballard, M. A. Hughes, A. L. Morrow, N. D. Horseman, and L. A. Nommsen-Rivers. 2013. RNA sequencing of the human milk fat layer transcriptome reveals distinct gene expression profiles at three stages of lactation. PLoS ONE 8:e67531.

Marchini, J., and B. Howie. 2010. Genotype imputation for genome-wide association studies. Nat. Rev. Genet. 11:499-511.

Palmquist, D. L. 2006. Milk fat: Origin of fatty acids and influence of nutritional factors thereon. Pages 43-92 in Advanced Dairy Chemistry: Lipids. Vol. 2. P. F. Fox and P. L. H. McSweeney, ed. Springer, New York, USA.

Pausch, H., B. Aigner, R. Emmerling, C. Edel, K.-U. Götz, and R. Fries. 2013. Imputation of high-density genotypes in the Fleckvieh cattle population. Genet. Sel. Evol. 45:3.

Purcell, S., B. Neale, K. Todd-Brown, L. Thomas, M. A. Ferreira, D. Bender, J. Maller, P. Sklar, P. I. De Bakker, and M. J. Daly. 2007. PLINK: a tool set for whole-genome association and population-based linkage analyses. Am. J. Hum. Genet. 81:559575.

Qanbari, S., D. Gianola, B. Hayes, F. Schenkel, S. Miller, S. Moore, G. Thaller, and H. Simianer. 2011. Application of site and haplotype-frequency based approaches for detecting selection signatures in cattle. BMC Genomics 12:318.

Schennink, A., J. M. L. Heck, H. Bovenhuis, M. H. P. W. Visker, H. J. F. van Valenberg, and J. A. M. van Arendonk. 2008. Milk fatty acid unsaturation: genetic parameters and effects of stearoyl-coa desaturase (SCD1) and acyl coa: diacylglycerol acyltransferase 1 (DGAT1). J. Dairy Sci. 91:2135-2143.

Schennink, A., W. Stoop, M. Visker, J. Heck, H. Bovenhuis, J. Van Der Poel, H. Van Valenberg, and J. Van Arendonk. 2007. DGAT1 underlies large genetic variation in milk-fat composition of dairy cows. Anim. Genet. 38:467-473.

Stella, A., P. Ajmone-Marsan, B. Lazzari, and P. Boettcher. 2010. Identification of selection signatures in cattle breeds selected for dairy production. Genetics. 185:1451-1461.

Stoop, W. M., J. A. M. van Arendonk, J. M. L. Heck, H. J. F. van Valenberg, and H. Bovenhuis. 2008. Genetic parameters for major milk fatty acids and milk production traits of Dutch Holstein-Friesians. J. Dairy Sci. 91:385-394. 
Wendler, A., and M. Wehling. 2013. PGRMC2, a yet uncharacterized protein with potential as tumor suppressor, migration inhibitor, and regulator of cytochrome P450 enzyme activity. Steroids.78:555-558.

Wilmink, J. B. M. 1987. Adjustment of test-day milk, fat and protein yield for age, season and stage of lactation. Livest. Prod. Sci. 16:335-348.

Zimin, A. V., A. L. Delcher, L. Florea, D. R. Kelley, M. C. Schatz, D. Puiu, F. Hanrahan, G. Pertea, C. P. Van Tassell, and T. S. Sonstegard. 2009. A whole-genome assembly of the domestic cow, Bos taurus. Genome Biol. 10:R42. 


\section{4}

\section{Fine-mapping of BTA17 using imputed sequences for associations with de novo synthesized fatty acids in bovine milk}

S. I. Duchemin ${ }^{1,2}$, H. Bovenhuis ${ }^{1}$, H-J. Megens ${ }^{1}$, J. A. M. Van Arendonk ${ }^{1}$, M. H. P. W. Visker ${ }^{1}$

${ }^{1}$ Animal Breeding and Genomics Centre, Wageningen University, PO Box 338, 6700 $\mathrm{AH}$ Wageningen, the Netherlands; ${ }^{2}$ Department of Animal Breeding and Genetics, Swedish University of Agricultural Sciences, Uppsala, Sweden

(Manuscript in preparation) 


\section{Abstract}

A genomic region associated with milk fatty acids on Bos taurus autosome (BTA) 17 has been discovered with 50,000 (50k) SNP and characterized with imputed 777,000 (777k) SNP genotypes. The aim of this study was to characterize this genomic region using imputed whole-genome sequences (WGS) and identify candidate genes associated with milk fatty acids (FA) composition on BTA17. Phenotypes and genotypes were available for 1,905 cows sampled in winter, and for 1,795 cows sampled in summer. Phenotypes consisted of gas chromatography measurements of 6 FA in winter and in summer milk samples. Genotypes consisted of imputed 777k SNP, and 89 sequenced founders of our population of cows. In addition, 450 WGS from the 1,000 bull genome consortium were available. Using 495 Holstein-Friesians sequences as reference population, we imputed the imputed 777k SNP genotyped cows to sequence level. Single-marker analyses were run with an animal model, and many significant associations with C6:0, C8:0, C10:0, C12:0 and C14:0 were identified. For example, for $\mathrm{C} 8: 0$, a total of 1,182 significant associations in winter milk samples, and a total of 1,943 significant associations in summer milk samples were identified. Similar results were identified for all 6 FA. For C8:0 in summer milk samples, the genomic region located between 29 and 34 mega base-pairs on BTA17 revealed a total of 608 significant associations. The most significant association ($\log _{10}(P$-value $\left.)=7.66\right)$ was found for 8 SNP in perfect linkage disequilibrium. After fitting one of these $8 \mathrm{SNP}$ as a fixed effect in the model, and re-running the singlemarker analyses, no further significant associations were found. In the QTL region located between 29 and 34 mega base-pairs, a total of 14 genes could be identified. Six out of the 8 SNP in perfect LD were located in the LA ribonucleoprotein domain family, member 1B (LARP1B) gene. This primary candidate gene has not been associated with milk-fat composition yet.

Key words: QTL, candidate genes, sequences, LARP1B 


\subsection{Introduction}

Bovine milk-fat is an important source of energy in human diets. The main bioactive lipids in bovine milk are fatty acids (FA). FA from bovine milk have important biological activities regarding the cell and tissue metabolism, as well as responsiveness to hormones and other signals in human cells (Calder, 2015). Previous studies on milk FA composition have indicated that amounts of individual FA in bovine milk are heritable (e.g., Duchemin et al., 2013). Heritability estimates range from 0.22 to 0.71 in Dutch Holstein-Friesian cows (Stoop et al., 2008). These findings suggested there is high genetic variability in the content of many individual FA in bovine milk.

Supporting these findings, polymorphisms in the acyl-CoA: diacylglycerol (DGAT1) and in the stearoyl-CoA desaturase1 (SCD1) genes have been associated with milk FA composition (e.g., Moioli et al, 2007; Schennink et al., 2007, 2008). In addition, Bouwman et al. (2012) identified many promising genomic regions associated with individual FA in bovine milk, when performing a genome-wide association study (GWAS) with 50,000 single-nucleotide polymorphism (SNP) genotypes. One of these regions located on Bos taurus autosome (BTA) 17 was fine-mapped with imputed 777,000 SNP (777k) genotypes, and significant associations with short-chain de novo synthesized FA have been identified (Duchemin et al., 2014). Furthermore, other studies have helped characterize BTA17. In Danish Holsteins, Buitenhuis et al. (2014) performed a GWAS identifying a QTL on BTA17 associated with conjugated linoleic acid (CLA). In Fleckvieh cattle breed, Pausch et al. (2012) performed a GWAS identifying a genomic region on BTA17 associated with supernumerary teats, and this genomic region has been associated with the absence of teats in Japanese Black cattle (Ihara et al., 2007). In Bubalus bubalis, Venturini et al. (2014) performed a GWAS on milk production traits and identified significant associations with milk production traits (i.e., milk yield, fat yield and protein yield) on BTA17 (note: BTA17 is used as a one-to-one correspondence to BBU17 in buffaloes). Despite the attempts to characterize BTA17 with a limited annotation of the cattle genome and genetic markers separated by more than 4 mega-base pairs in most cases, it is still difficult to identify the causal variants underlying the identified QTL.

With the advent of whole-genome sequences (WGS) in cattle, causal variants underlying QTL should be identified more easily with GWAS. WGS should contain the polymorphisms causing the genetic differences between individuals (Meuwissen and Goddard, 2010). To overcome the high-costs associated with WGS, Druet et al. 
(2014) proposed to sequence influential ancestors of a population, and impute the rest of this population to sequence level. A GWAS using imputed WGS was first implemented by Daetwyler et al. (2014). Their study successfully mapped previously identified QTL affecting milk production traits and curly coat in cattle. Therefore, GWAS using imputed WGS can be used successful in (fine) mapping complex traits.

GWAS by Bouwman et al. (2012) identified a QTL region on BTA17 influencing C6:0, C8:0 and C10:0 FA. This genomic region was further characterized by Duchemin et al. (2014), and their findings suggested that this QTL region influenced multiple short-chain FA (C6:0 to C12:0) in a similar location on BTA17. Although candidate genes have been suggested for this QTL region, no causal variant for this QTL has been identified yet. The aim of this study was to use imputed WGS to identify the causal variant underlying the QTL on BTA17 associated with multiple short-chain FA previously identified by Bouwman et al. (2012), and fine-mapped by Duchemin et al. (2014).

\subsection{Material and Methods}

\subsubsection{Animals and phenotypes}

Morning milk (500mL/cow) was sampled from 2,001 primiparous Holstein-Friesian cows belonging to 398 herds throughout the Netherlands. These samples were collected in two periods: February-March 2005 (referred to as winter samples) and May-June 2005 (referred to as summer samples). For each herd, most of the cows were sampled in both periods. However, some cows sampled in winter were no longer in lactation in summer. Consequently, additional cows were sampled in summer to ensure that at least 3 cows per herd were sampled in both periods. For winter milk samples, phenotypes were available on 1,905 cows, and their lactation stages ranged from 63 to $282 d$ (see Stoop et al., 2008). For summer milk samples, phenotypes were available on 1,795 cows, and their lactation stages ranged from 97 to 335d (see Duchemin et al., 2013). During the winter, all cows were kept indoors and fed silage, while in summer $50 \%$ of the cows could graze pasture ( 3.5 to $24 \mathrm{~h} / \mathrm{d}$ ). More information on the experimental design is available in Stoop et al. (2008).

Milk FA were measured by gas chromatography at the COKZ laboratory (Qlip, Leudsen, Netherlands). The milk FA included in this study were C4:0, C6:0, C8:0, $\mathrm{C} 10: 0, \mathrm{C} 12: 0$, and $\mathrm{C} 14: 0$, and they were expressed as weight proportion of total fat (\%wt/wt). For more information regarding phenotypes, see Stoop et al. (2008). 


\subsubsection{Genotypes and variant calling}

Blood from cows and semen from bulls were sampled to retrieve DNA for genotyping purposes. First, a total of 55 sires (founders) and 1,813 cows (experimental population) were genotyped with a 50k SNP chip designed by CRV (Arnhem, the Netherlands) with the Illumina Infinium array (Illumina Inc., San Diego, CA). Second, 777k SNP genotypes were imputed for the 1,813 cows, based on their 50k SNP genotypes and a reference population of 1,333 animals including the 55 founder sires genotyped with the 777k SNP chip (Illumina). See Duchemin et al., (2014) for details. The imputation resulted in 1,736 cows imputed to $777 \mathrm{k}$ SNP genotypes. From these 1,736 animals, some animals were removed from the data: 12 animals because of pedigree inconsistencies, and, subsequently, 3 animals that did not meet the criteria of a minimum of 3 animals sampled per herd. Therefore, 777K SNP genotypes were available for 1,721 cows. For BTA17, the target of the present study, the data consisted of a total of 22,240 imputed SNP genotypes for each of the 1,721 cows. Third, the 55 founder sires and 34 influential ancestors (grand-sires) of the experimental population (MGI) were sequenced. These 89 ancestors were sequenced with the HiSeq ${ }^{\circledR} 2000$ Sequencing System (Illumina Inc., San Diego, CA). All downstream analyses were performed according to the protocols described by Daetwyler et al., (2014). Multi-sample variant calling was done using the UnifiedGenotyper implemented in GATK, following the procedures as explained by Daetwyler et al., (2014). The resulting raw VCF files were filtered for exclusion of duplicates, resulting in 854,779 called sites for BTA17.

In addition, 450 WGS from Holstein-Friesian cows and bulls were available from Run5 of the 1000 Bull Genome Consortium (RUN5; Daetwyler et al., 2014). These 450 WGS included the re-sequenced 44 out of the 55 founder sires. All positions of the variants on sequences were aligned to the bovine genome assembly UMD3.1 (Zimin et al., 2009). SNP and indels at same base-pairs positions were excluded because of alignment and sequencing problems. For further details on alignment, variant calling and filtering, see Daewytler et al. (2014). For BTA17, a total of 1,157,678 sites were available for each of the 450 sequenced animals.

\subsubsection{Imputation}

We created a reference population containing both MGI and RUN5 WGS. This reference population consisted of imputing the 45 MGI WGS to the level of the 450 RUN5 WGS to equalize the number of sites. Comparison of called sites for BTA17 between the $45 \mathrm{MGI}$ and the 450 RUN5 WGS showed that 495,726 called sites 
overlapped, and 661,952 sites in the RUN5 WGS were not called in MGI WGS. These 661,952 sites were set to missing in the 45 MGI WGS and imputed based on the 450 RUN5 WGS. Imputation was done using Beagle version 4.0 (Browning and Browning, 2007). After imputation, the 45 MGI WGS were combined with the 450 RUN5 WGS, resulting in a reference population of 495 Holstein-Friesian animals with 1,157,678 sites for BTA17.

Inconsistencies between 777K SNP genotypes and WGS sites of the reference population were checked using the Conform-gt software (https://faculty.washington.edu/browning/conform-gt.html). Three hundred and eighty three SNP were inconsistent sites due to strand problems, and 1,481 SNP showed different positions between the 777k SNP genotypes and in the WGS. These inconsistencies were set to missing and imputed to WGS. All BTA17 WGS sites were imputed for the 1,721 cows with Beagle version 4.0 based on their imputed $777 \mathrm{~K}$ SNP genotypes and the reference population of 495 animals with WGS. The accuracy of imputation for each marker was provided by Beagle as the bi-allelic $r^{2}$ (AR2). Only polymorphic markers with an AR2 $\geq 0.8$ were retained for the remaining analyses.

\subsubsection{Fine-mapping of BTA17 with imputed sequences}

The fine-mapping of BTA17 with imputed sequences was performed in Asreml 4.0 (beta version, Gilmour et al., 2009), and consisted of two steps. For the first step, we ran single-variant analyses for each FA with all polymorphic variants imputed with an $A R 2 \geq 0.8$, using the following animal model:

$$
\begin{aligned}
y_{i j k l m n o}=\mu+b_{1} & \operatorname{dim}_{i j k l m n o}+b_{2} * e_{i}^{-0.05 * \operatorname{dim}_{i j k l m n o}}+b_{3} * a f c_{i j k l m n o}+b_{4} * a f c_{i j k l m n o}^{2} \\
& +\operatorname{season~}_{k}+\operatorname{scode}_{l}+\text { variant }_{m}+\operatorname{herd}_{n}+a_{o}+e_{i j k l m n o}
\end{aligned}
$$

where, $y_{i j k l m n o}$ is the phenotype; $b_{1}$ and $b_{2}$ are the regression coefficients regarding $\operatorname{dim}_{i j k l m n o} ; \operatorname{dim}_{i j k l m n o}$ is the fixed effect of days in milk modelled by a Wilmink's curve (Wilmink, 1987); $b_{3}$ and $b_{4}$ are the regression coefficients regarding af $c_{i j k l m n o}$; $a f c_{i j k l m n o}$ is the fixed effect of age at first calving; season $n_{k}$ is the fixed effect of calving season (June-August 2004, September-November 2004 or December 2004 - February 2005); scode $_{l}$ is the fixed effect accounting for genetic differences between groups of proven bull daughters and young bull daughters; variant $_{m}$ is the fixed effect of a variant; herd $_{m}$ is the random effect of herd assumed to be distributed as $N \sim\left(0, I \sigma_{\text {herd }}^{2}\right)$, where I is the identity matrix and $\sigma_{\text {herd }}^{2}$ is the herd variance; $a_{n}$ is the random additive genetic effect of animal 
assumed to be distributed as $N \sim\left(0, \boldsymbol{A} \sigma_{a}^{2}\right)$, where $\mathbf{A}$ is the additive relationship matrix based on 12,548 animals and $\sigma_{a}^{2}$ is the additive genetic variance; and $e_{i j k l m n}$ is the random residual effect assumed to be distributed as $N \sim\left(0, \boldsymbol{I} \sigma_{e}^{2}\right)$, where $\mathbf{I}$ is the identity matrix and $\sigma_{e}^{2}$ is the residual variance.

Variance components were estimated based on model [1] prior to the inclusion of information on genetic markers, and these variance component estimates were subsequently fixed within model [1].

The strongest association found in the first step was named as "TagSNP1". For the second step, TagSNP1 was added as a fixed effect in model [1], and single-variant analyses were re-run for each FA with all polymorphic variants imputed with an AR2 $\geq 0.8$.

Manhattan plots illustrating significance of associations were produced in $\mathrm{R}$ ( $\mathrm{R}$ Core Team, 2015). In addition, linkage disequilibrium (B) between TagSNP1 and all polymorphic SNP imputed with an AR2 $\geq 0.8$ was calculated using PLINK version 1.9 (Purcel et al., 2007).

\subsubsection{Candidate genes and causal variants}

Candidate genes were assessed with the online tool variant effect predictor (Ve!P; McLaren et al., 2010) available through Ensembl (http://www.ensembl.org). This tool determines the effects of SNP, insertions, deletions, copy number variants and structural variants on either genes, transcripts, proteins or regulatory regions.

\subsection{Results}

\subsubsection{Descriptive statistics}

The phenotypic means and heritability estimates for the 6 studied FA are presented in Table 4.1. In both samples, C14:0 was the most abundant FA. Heritability estimates were higher in winter milk samples in comparison with summer milk samples, especially for C8:0 and C10:0. Phenotypic means and heritability estimates of these 6 FA in winter and summer milk samples have been discussed in detail by Duchemin et al. (2013).

\subsubsection{Imputation}

To enable combining the MGI WGS with the RUN5 WGS into one reference population, the 661,952 sites that were not called in the 45 MGI WGS were imputed 

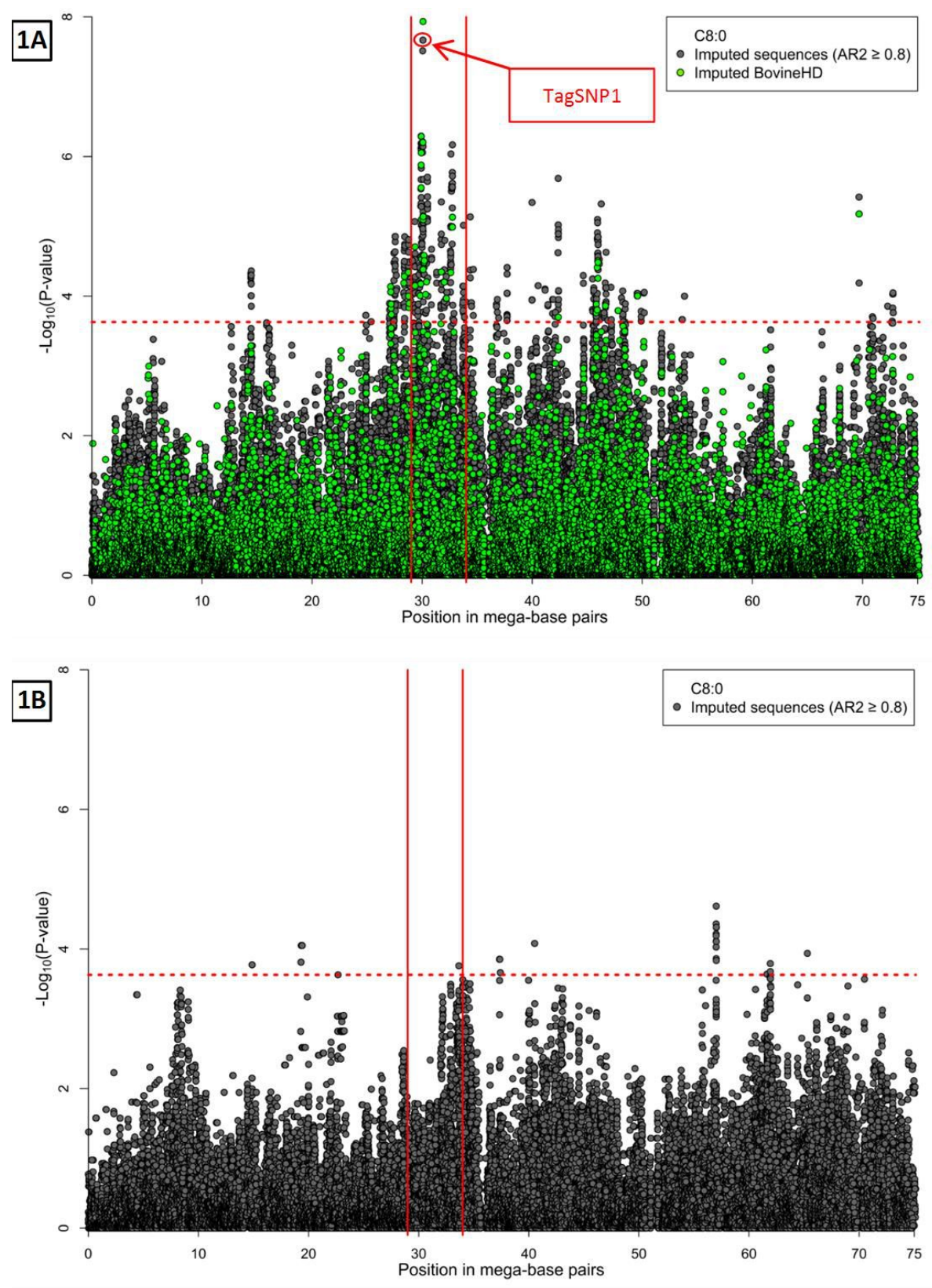

Figure 4.1 - (A) Fine-mapping of BTA17 for C8:0 in summer milk samples showing the genomewide association of imputed sequences with an accuracy of imputation (AR2) $\geq 0.8$ overlaid with imputed 777k $(777,000)$ SNP genotypes done by Duchemin et al. (2014). The red dotted line is the genome-wide significance level based on 50,000 SNP genotypes at a false discovery 
rate of $0.05\left[-\log _{10}(P\right.$-value $\left.)=3.63\right]$. The vertical red lines indicate the location of the QTL region previously identified by Duchemin et al. (2014). The SNP with the highest significance is referred to as TagSNP1. (B) Fine-mapping of BTA17 for C8:0 in summer milk samples showing the genome-wide association of imputed sequences with AR2 $\geq 0.8$ after correction for TagSNP1.

based on the 450 RUN5 WGS. The average accuracy of imputation for these 661,952 sites was equal to 0.97. Based on the reference population of 495 WGS, all 1,157,678 sites on BTA17 were imputed for the 1,721 cows. As Table 4.2 shows, $58.6 \%$ of these sites were monomorphic variants in our data set, and have been excluded from our analyses. The remaining $41.4 \%$ were polymorphic variants. From these $41.4 \%$ polymorphisms, a total of 356,044 (30.8\%) were imputed with AR2 $\geq 0.8$ (average accuracy $=0.96$ ). All polymorphisms imputed with AR2 $\geq 0.8$ were considered for our fine-mapping of BTA17 with imputed sequences.

\subsubsection{Fine-mapping of BTA17 with imputed sequences}

Associations were analyzed for each of the 6 FA separately for winter and summer milk samples. We analyzed these phenotypes for both samples combined with all 356,044 imputed sequence variants of BTA17 imputed with AR2 $\geq 08$ (supplementary figure 4.1 A, B, C and D). We focus on C8:0 because associations were found in a similar location for all 6 FA in both samples, and the strongest of these associations was identified with $\mathrm{C} 8: 0$. For $\mathrm{C} 8: 0$, an association was significant at $-\log _{10}(P$-value $)=$ 3.63. This threshold was defined by Bouwman et al. (2012), and corresponds to the genome-wide significance level based on the 50k SNP genotypes at a false discovery rate (FDR) of 5\%. For C8:0 in winter milk samples, we identified 1,182 significant associations on BTA17 at a $-\log _{10}(P$-value $)>3.63$.

For C8:0 in summer milk samples, we identified 1,943 significant associations on BTA17 (- $\log _{10}(P$-value) $>3.63)$. Of these significant associations, 608 were located within the previously defined QTL region (Duchemin et al., 2014) between 29 and 34 MBP (Figure 4.1A). A set of 8 SNP in perfect LD showed the strongest association with $\mathrm{C} 8: 0$ in summer milk samples at a $-\log _{10}(P$-value $)=7.66$. One of these 8 SNP was defined as TagSNP1. TagSNP1 (rs110127535) had a MAF of 0.44 and was imputed with an AR2 $=0.98$. TagSNP1 was added as fixed effect in model 1 , and associations were analyzed again between each of the 6 FA in both winter and summer samples and all 356,044 imputed sequence variants of BTA17 with AR2 $\geq$ 0.8 . No significant associations were found after adjusting for the TagSNP1 for any 
of the $6 \mathrm{FA}$ in winter or summer milk samples (Figure 4.1B, Supplementary figure 4.1B).

\subsubsection{Candidate genes}

The QTL region located between 29 and 34 MBP on BTA17 contains 14 genes based on the current annotation of the cattle genome (table 4.3). These 14 genes are: chromosome 4 open reading frame 33 (C4orf33) gene, sodium channel and clathrin linker 1 (SLCT1) gene; jade family PHD finger 1 (JADE1) gene; progesterone receptor membrane component 2 (PGRMC2) gene; LA ribonucleoprotein domain family, member 1B (LARP1B) gene; U2 spliceosomal RNA (U2) gene, the abhydrolase domain containing 18 (ABHD18 former C4orf29) gene; small nucleolar RNA SNORA42/SNORA80 family (SNORA42) gene; major facilitator superfamily domain containing 8 (MFSD8) gene, the polo-like kinase 4 (PLK4) gene; solute carrier family 25 member 31 (SLC25A31) gene; inturned planar cell polarity protein (INTU) gene; and FAT atypical cadherin 4 (FAT4) gene. In addition, Ve!P was used on the 608 variants including TagSNP1, and these variants were distributed as indicated in figure 4.2 .

Of the 8 SNP that showed the strongest association: 2 SNP were intergenic, 3 SNP were upstream gene variants of the $L A R P 1 B$ gene, and 3 SNP were intron variants in the $L A R P 1 B$ gene. The splice-region variant (rs110862734) is located at $29.94 \mathrm{MBP}$ in the $L A R P 1 B$ gene $\left[-\log _{10}(P\right.$-value) for association with $C 8: 0$ in summer milk $=6.18$; $L D$ with 8 most significantly associated SNP $=0.92]$.
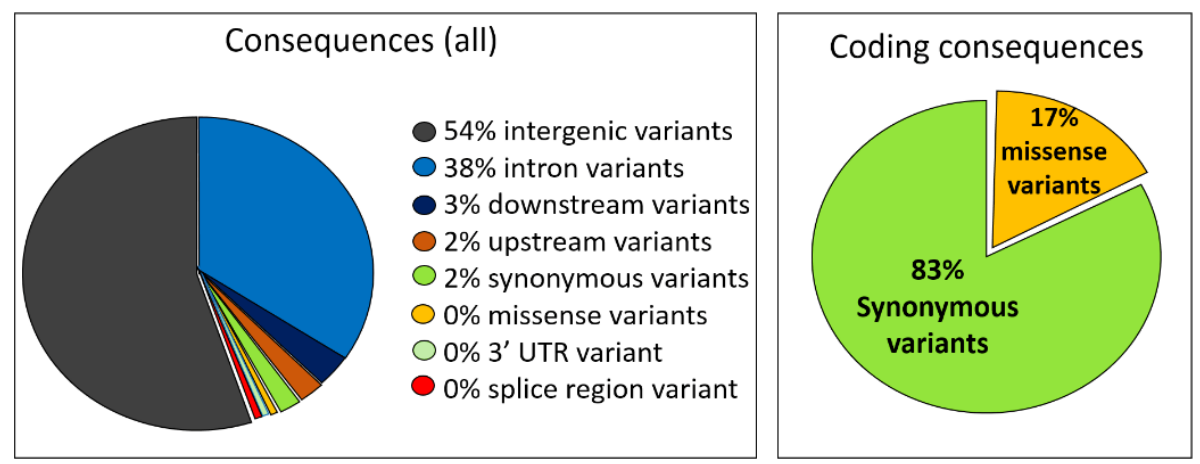

Figure 4.2 - Distribution of the 608 significant variants according to their functions and their coding consequences. 


\subsection{Discussion}

The fine-mapping of BTA17 was first performed by Duchemin et al. (2014), in which the de novo synthesized FA in winter and summer milk samples were analyzed with imputed 777k SNP genotypes. Their study identified two intergenic SNP associated with multiple FA in a QTL region located between 29 and 34 mega base-pairs on BTA17. In the present work, 6 of the FA studied by Duchemin et al. (2014) have been considered. Our goal was to identify the causal variant underlying this QTL region, and to characterize this QTL region with recent information on candidate genes.

\subsubsection{Fine-mapping of BTA17 with imputed sequences}

The fine-mapping of BTA17 with imputed sequences identified many significant associations with the 6 studied FA. In agreement with Duchemin et al. (2014), multiple FA showed strong signals at a similar location on BTA17. These multiple FA were the de novo synthesized FA in the mammary gland of a cow. It is assumed that de novo synthesis elongates FA by adding C2:0 to precursors, such as C2:0, C3:0 and $\mathrm{C} 4: 0$. Depending on which precursors, the elongation of FA is assumed to end at either $\mathrm{C} 16: 0$ or $\mathrm{C} 17: 0$. The origin of these precursors in the mammary gland of a cow varies: C2:0 and C3:0 are originated mainly from blood lipids, while C4:0 can either arise from blood lipids or be de novo synthesized (e.g., Craninx et al, 2008). In the present study, C4:0 does not seem to be influenced by this QTL region, while this QTL region seems to influence the other $5 \mathrm{FA}$. With imputed sequences, it was possible to observe that the QTL region does not only influences C6:0, C8:0 and C10:0, but also $\mathrm{C} 12: 0$ and $\mathrm{C} 14: 0$ (Supplementary file 1). Although the signals were weaker for C12:0 and C14:0, their signals overlap with the remaining FA in the QTL region for winter and summer milk samples (Supplementary file $1 \mathrm{~A}$ and $\mathrm{B}$ ).

Whole-genome sequences (WGS) should contain all of the causal variants underlying complex traits. On BTA17, the density of markers increased by more than 20 times from imputed 777k SNP genotypes to sequence level. With this increased density, more associations became significantly associated with the 6 studied FA: from less than 100 using imputed $777 \mathrm{k}$ SNP genotypes to more than a thousand with sequence data. For instance, 8 SNP were in perfect LD, and represent our strongest associations with C8:0 in summer milk samples. Duchemin et al. (2014) using imputed 777k SNP genotypes identified only one top SNP, and at a higher significance level than the eight SNP identified by this study. In the present study, we imputed to sequence level the already imputed 777k SNP genotypes. With sequence data, the extent of LD among SNP is conversed at 5-10kb in Bos Taurus breeds (e.g., 
Gibbs et al., 2009). According to Weiss and Terwilliger (2000), the distribution of LD shows stochastic variance, which tends to be highly skewed under certain conditions, as described by Terwilliger (2001). As a consequence, some parts of the genome will exhibit regions of long LD, while most SNP will exhibit less LD than predicted by lower density panels of genetic markers. If this is the case, it is possible that the imputation overestimated the extent of LD between genetic markers, and therefore, the effect of the top SNP with imputed 777k SNP is likely overestimated in comparison with sequence data. Other GWAS using imputed sequences have identified a considerable number of significant variants closely linked to each other (e.g., Daetwyler et al., 2014; Sahana et al., 2014). In addition, single-marker analyses assume that each marker contributes independently to the genetic variance. Taken together, these findings might explain why Duchemin et al. (2014) obtained better significance level for their top SNP than in the present study.

TagSNP1 seems to explain most of the genetic variation in a region distributed over almost 20 MBP on BTA17 (Figure 4.1B). The QTL region identified in the present study is wider than the 5 MBP QTL region narrowed by Duchemin et al. (2014). The present study confirms the multiple FA that were found associated with a similar QTL region and the strongest association that was found with C8:0, both by Duchemin et al. (2014). Study conducted by Govignon-Gion et al. (2014) found a QTL region on BTA17 associated with $\mathrm{C} 4: 0$ and $\mathrm{C} 6: 0$ when performing GWAS with imputed 500K SNP genotypes for three different breeds of dairy cattle. This QTL region was present in the three breeds, and the strongest associations were identified with C4:0. In our study, C4:0 in winter and summer milk samples was not significantly associated with our QTL region. The main difference between Govignon-Gion et al. (2014) and the present study is the method of measurement of fatty acids. Our 6 studied FA were measured by gas chromatography for both winter and summer milk samples, whereas the FA studied by Govignon-Gion et al. (2014) were measured by midinfrared spectrometry. This might explain the observed differences between the studies.

Previously for the same QTL region, Bouwman et al. (2012) identified 10 significant SNP with 50k SNP genotypes, and Duchemin et al. (2014) identified 83 significant SNP with imputed 777k SNP genotypes for C8:0 in summer samples. From the 50K to the imputed $777 \mathrm{k}$ SNP genotypes, there was no overlap of associations. From imputed $777 \mathrm{k}$ SNP to imputed sequences, 70 associations found by the imputed $777 \mathrm{k}$ SNP genotypes were also found among the 608 significant associations with imputed sequences. In addition, the 8 SNP include the strongest SNP ( $r$ 109290136) identified 
by Duchemin et al. (2014) with imputed 777k SNP genotypes. However, the significance of the top SNP in Duchemin et al. (2014) was higher [ $-\log _{10}(P$-value $)=$ 7.93] than the significance of the strongest SNP identified with imputed sequences (Figure 4.1A).

\subsubsection{Candidate genes}

Six of our eight strongest associations are located within the $L A R P 1 B$ gene. According to genecards (http://www.genecards.org/), the LARP1B gene encodes a protein containing domains found in the La related protein of Drosophila melanogaster. The LARP1 family was first described in Drosophila melanogaster (Chauvet et al., 2000), where the Drosophila $L A R P 1$ gene is required for spermatogenesis, embryogenesis and cell cycle progression (e.g., Ichihara et al., 2007). Study by Blagden et al. (2009) showed that the Drosophila $L A R P 1$ gene interacts with poly $A$ binding protein (PABP), and suggested that the phenotype observed in $L A R P 1$ mutants could be the result of defective mRNA translation or regulation. In Caenorhabditis elegans, the CeLARP1 gene was identified as an RNA-binding protein (Nykamp et al., 2008). In yeast, the mRNA-dependent LA-related proteins family (LARP1) when in association with SLF1 promotes copper detoxification (Schenk et al., 2012). In viruses, the LARP1B gene has the biological process of mitophagy in response to mitochondrial depolarization (Orvedahl et al., 2011). In Arabidopsis, the overexpression of the LARP1B gene causes a premature leaf yellowing phenotype, and leaf senescence (Zhang et al., 2012).

According to Stavraka and Blagden (2015), la related proteins family 1 (LARP1) genes in humans have two paralogues: $L A R P 1 A$ and $L A R P 1 B$. LARP1A (or simply LARP1) is positioned at chromosome 5q34, encoding 1096 amino acid proteins. LARP1B (or LARP2) is positioned at chromosome 4q28, encoding 914 amino acid proteins. According to Stavraka and Blagden (2015), LARP1A and LARP1B are similar (60\% homology and $73 \%$ of positivity). Burrows et al. (2010) showed that $L A R P 1 A$ is more abundant than $\angle A R P 1 B$, therefore $\angle A R P 1 B$ has been less studied. According to Uniprot (www.uniprot.org; accessed on 11/21/2015), the gene ontology regarding the molecular function of the LARP1B gene in humans is the poly(A) RNA binding, i.e., the very same as $L A R P 1 A$. Review by Bousquet-Antonelli, and Deragon (2009) suggested that members of the same family are functional homologs and/or share a common molecular mode of action on different RNA baits.

Interestingly, in mammalian cells, Tcherkezian et al. (2014) found that the LARP1A gene associates with the mTOR complex 1 (mTORC1) and is required for global protein synthesis as well as cell growth and proliferation. This implicates the LARP1A 
gene as an important regulator of cell growth and proliferation. Bionaz et al. (2012) reviewed the role of $m$ TORC1 relating it to the regulation of protein synthesis, particularly translation in the mammary tissue. Interestingly, mTORC1 was considered to be the missing link between nutrition and milk protein synthesis (Bionaz et al., 2012). According to Bionaz et al. (2012), insulin regulates the amount of translation of the $m T O R C$ pathway that will influence milk protein synthesis. Gomes and Blenis (2015) suggest that, through various mechanisms, mTORC1 stimulate mRNA translation, aerobic glycolysis, glutamine anaplerosis, lipid synthesis, the pentose phosphate and pyrimidine synthesis, thus producing the major components necessary for cell growth and proliferation. Although less studied as compared with the $L A R P 1 A$ gene, the $L A R P 1 B$ gene possess the same molecular function as $\angle A R P 1 A$ gene. We cannot exclude that the $L A R P 1 B$ might play a role regarding cell growth and proliferation in the mammary gland of a cow.

Furthermore, the $L A R P 1 B$ gene contains a splice-region variant. According to Sammeth et al. (2008) splice-region variants generate different mature transcripts from the same primary RNA sequence. Although no further information is available on the possible transcripts generated by the $\angle A R P 1 B$ gene, this gene is highly expressed in bovine mammary tissue (Bionaz et al., 2012), and it is expressed in all stages of lactation in humans (Lemay et al., 2013). Yet, the LARP1B gene has not been associated to milk FA composition or milk-fat synthesis.

Previously, the candidate gene identified by Duchemin et al. (2014) was the PGRMC2 gene. The PGRMC2 gene is still among the genes associated with the QTL region that influences multiple FA on BTA17 (Table 4.3). However, the PGRMC2 gene was assigned as the most likely candidate gene because it was the closest gene to the strongest association found by Duchemin et al. (2014). At that time, there were no associations found in the PGRMC2 gene. In addition, the identified LOC515517 was the gene closest to the strongest association on BTA17. However, because of limited annotation available on BTA17 at that time, LOC515517 was identified as a suggestive candidate gene while $P G R M C 2$ was suggested as primary candidate gene. Since then, LOC515517 has been annotated in the cattle genome as LARP1B gene.

\subsection{Conclusions}

The fine-mapping of BTA17 with imputed sequences identified a substantial number (in the thousands) of significant associations with de novo synthesized milk FA (C6:0 
to 14:0). With imputed sequences, the resolution of the QTL region influencing multiple milk FA improved compared to previous studies. The strongest associations were identified with C8:0 in summer milk samples. With imputed sequences, the number of candidate genes in this QTL region was reduced from 29 to 14 . Among these 14 candidate genes, 6 out of 8 SNP in strong LD were identified in the LARP1B gene. The $\angle A R P 1 B$ gene is expressed in bovine mammary tissue. Nonetheless, the $L A R P 1 B$ gene has not been associated with milk FA composition at present.

\subsection{References}

Bionaz, M., K. Periasamy, S. L. Rodriguez-Zas, W. L. Hurley, and J. J. Loor. 2012. A novel dynamic impact approach DIA for functional analysis of time-course omics studies: validation using the bovine mammary transcriptome. PLoS ONE.7: e32455

Bionaz, M., Hurley, W., and Loor, J. 2012. Milk protein synthesis in the lactating mammary gland: Insights from transcriptomics analyses.INTECH Open Access Publisher.

Blagden, S. P., Gatt, M. K., Archambault, V., Lada, K., Ichihara, K., Lilley, K. S. , Inoue, Y. H., and Glover, D. M. 2009.Drosophila Larp associates with poly(A)-binding protein and is required for male fertility and syncytial embryo development, Developmental Biology 334:186-197.

Bousquet-Antonelli, C., and Deragon, J. M. 2009. A comprehensive analysis of the Lamotif protein superfamily. RNA 15:750-764.

Bouwman, A., M. H. P. W. Visker, J. A. M. van Arendonk, and H. Bovenhuis. 2012. Genomic regions associated with bovine milk fatty acids in both summer and winter milk samples. BMC Genet. 13:93.

Browning, S. R., and Browning, B. L. (2007). Rapid and accurate haplotype phasing and missing-data inference for whole-genome association studies by use of localized haplotype clustering. Am J Hum Genet 81, 1084-1097.

Buitenhuis, B., Janss, L.L.G., Poulsen, N.A., Larsen, L.B., Larsen, M. K., and Sørensen, P. 2014. Genome-wide association and biological pathway analysis for milk-fat composition in Danish Holstein and Danish Jersey cattle. BMC Genomics 2014, 15:1112.

Burrows, C., Abd Latip, N., Lam, S.J., Carpenter, L., Sawicka, K., Tzolovsky, G., Gabra, H., Bushell, M., Glover, D.M., Willis, A. E., et al. 2010. The RNA binding protein Larp1 regulates cell division, apoptosis and cell migration. Nucleic Acids Res 38: 5542-5553.

Calder, P.C. 2015. Functional roles of fatty acids and their effects on human health. J Parenter Enteral Nutr, 39.1: 18S-32S. 
Chauvet, S., Maurel-Zaffran, C., Miassod, R., Jullien, N., Pradel, J., Aragnol, D. 2000. Dlarp, a new candidate Hox target in Drosophila whose orthologue in mouse is expressed at sites of epithelium/mesenchymal interactions. Dev Dyn 218: 401413.

Craninx, M., A. Steen, H. Van Laar, T. Van Nespen, J. Martin-Tereso, B. De Baets, and V. Fievez. 2008. Effect of lactation stage on the odd-and branched-chain milk fatty acids of dairy cattle under grazing and indoor conditions. J. Dairy Sci. 91:26622677.

Daetwyler, H.D., Capitan, A., Pausch, H., Stothard, P., van Binsbergen, R., Brondum, R.F., Liao, X., Djari, A., Rodriguez, S.C., Grohs, C., Esquerre, D., Bouchez, O., Rossignol, M-N., Klopp, C., Rocha, D., Fritz, S., Eggen, A., Bowman, P.J., Coote, D. Chamberlain, A.J., Anderson, C., VanTassell, C.P., Hulsegge, I., Goddard, M.E., Guldbrandtsen, B., Lund, M.S., Veerkamp, R.F., Boichard, D.A., Fries, R., and Hayes, B. J. 2014. Whole-genome sequencing of 234 bulls facilitates mapping of monogenic and complex traits in cattle. Nat Genet 46, 858-865.

Druet, T., Macleod, I. M., and Hayes, B. J. (2014). Toward genomic prediction from whole-genome sequence data: impact of sequencing design on genotype imputation and accuracy of predictions. Heredity (Edinb) 112, 39-47. doi:10.1038/hdy.2013.13.

Duchemin, S. I., H. Bovenhuis, W. M. Stoop, A. C. Bouwman, J. A. M. van Arendonk, and M. H. P. W. Visker. 2013. Genetic correlation between composition of bovine milk fat in winter and summer, and DGAT1 and SCD1 by season interactions. J. Dairy Sci. 96:592-604.

Duchemin, S. I., Visker, M.H.P.W., Van Arendonk, J.A.M., and Bovenhuis, H. 2014. A quantitative trait locus on Bos taurus autosome 17 explains a large proportion of the genetic variation in de novo synthesized milk fatty acids. J Dairy Sci 97: 72767285.

Gibbs, R. A., Taylor, J. F., Van Tassell, C.P., Barendse, W., Eversole, K. A., Gill, C. A., Green, R. D., Hamernik, D. L., Kappes, S. M., Lien, S., Matukumalli, L. K., Mcewan, J. C., Nazareth, L. V., Schnabel, R. D., Weinstock, G. M., Wheeler, D. A., AjmoneMarsan, P., Boettcher, P. J., Caetano, A. R., Garcia, J. F., Hanotte, O., Mariani, P., Skow, L. C., Sonstegard, T. S., Williams, J. L., Diallo, B., Hailemariam, L., Martinez, M. L., Morris, C. A., Silva, L. O. C., Spelman, R. J., Mulatu, W., Zhao, K., Abbey, C. A., Agaba, M., Araujo, F. R., Bunch, R. J., Burton, J., Gorni, C., Olivier, H., Harrison, B. E., Luff, B., Machado, M. A., Mwakaya, J., Plastow, G., Sim, W., Smith, T., Thomas, M. B., Valentini, A., Williams, P., Womack, J., Woolliams, J.A., Liu, Y., Qin, X., Worley, K. C., Gao, C., Jiang, H., Moore, S. S., Ren, Y., Song, X.-Z., Bustamante, C. D., Hernandez, R. D., Muzny, D. M., Patil, S., San Lucas, A., Fu, Q., Kent, M. P., Vega, 
R., Matukumalli, A., Mcwilliam, S., Sclep, G., Bryc, K., Choi, J., Gao, H., Grefenstette, J. J., Murdoch, B., Stella, A., Villa-Angulo, R., Wright, M., Aerts, J., Jann, O., Negrini, R., Goddard, M. E., Hayes, B. J., Bradley, D. G., Barbosa Da Silva, M., Lau, L.P. L., Liu, G. E., Lynn, D. J., Panzitta, F., Dodds, K. G. 2009. Genome-wide survey of SNP variation uncovers the genetic structure of cattle breeds. Science 324:528-32.

Gilmour, A. R., Gogel, B., Cullis, B., and Thompson, R. (2009). ASReml user guide, release 3.0. VSN International Ltd., Hemel Hempstead, UK.

Gomes,A. P., and Blenis, J. 2015. A nexus for cellular homeostasis: the interplay between metabolic and signal transduction pathways. Current opinion in biotechnology 34:110-117.

Govignon-Gion, A., Fritz, S., Larroque, H., Brochard, M., Chantry, C., Lahalle, F., and Boichard, D. 2014. QTL Detection for Milk Fatty Acids in French Dairy Cattle. In 10th World Congress on Genetics Applied to Livestock Production. Asas.

Ichihara, K., Shimizu, H., Taguchi, O., Yamaguchi, M., and Inoue, Y.H. 2007. A Drosophila orthologue of larp protein family is required for multiple processes in male meiosis. Cell Struct Funct 32: 89-100

Ihara, N., Watanabe, T., Sato, Y., Itoh, T., Suzuki, T., and Sugimoto, Y. 2007. Oligogenic transmission of abnormal teat patterning phenotype (ATPP) in cattle. Animal Genetics 38, 15-9.

Lemay, D. G., O. A. Ballard, M. A. Hughes, A. L. Morrow, N. D. Horseman, and L. A. Nommsen-Rivers. 2013. RNA sequencing of the human milk fat layer transcriptome reveals distinct gene expression profiles at three stages of lactation. PLoS ONE 8:e67531.

McLaren, W., Pritchard, B., Rios, D., Chen, Y., Flicek, P., and Cunningham, F. (2010). Deriving the consequences of genomic variants with the Ensembl API and SNP Effect Predictor. Bioinformatics 26, 2069-2070.

Meuwissen, T., and Goddard, M. 2010. Accurate prediction of genetic values for complex traits by whole-genome resequencing. Genetics 185, 623-631.

Moioli, B., G. Contarini, A. Avalli, G. Catillo, L. Orru, G. De Matteis, G. Masoero, and F. Napolitano. 2007. Short communication: Effect of stearoyl-coenzyme A desaturase polymorphism on fatty acid composition of milk. J. Dairy Sci. 90:35533558.

Nykamp, K., Lee, M. H., and Kimble, J. 2008. C. elegans La-related protein, LARP-1, localizes to germline $\mathrm{P}$ bodies and attenuates Ras-MAPK signaling during oogenesis. Rna 14: 1378-1389.

Orvedahl, A., Sumpter Jr, R., Xiao, G., Ng, A., Zou, Z., Tang, Y., Narimatsu, M., Gilpin, C., Sun, Q., Roth, M., Forst, C. V., Wrana, J. L., Zhang, Y. E., Luby-Phelps, K., Xavier, 
R. J., Xie, Y., and Levine, B. 2011. Image-based genome-wide siRNA screen identifies selective autophagy factors. Nature 480:113-117.

Pausch, H., Jung, S., Edel, C., Emmerling, R., Krogmeier, D., Götz, K.-U., and Fries, R. 2012. Genome-wide association study uncovers four QTL predisposing to supernumerary teats in cattle. Animal Genetics 43: 689-695.

Purcell, S., Neale, B., Todd-Brown, K., Thomas, L., Ferreira, M. A. R., Bender, D., et al. (2007). PLINK: a tool set for whole-genome association and population-based linkage analyses. Am J Hum Genet 81: 559-575.

R Core Team (2015). R: A language and environment for statistical computing. R Foundation for Statistical Computing, Vienna, Austria. https://www.Rproject.org/.

Sahana, G., Guldbrandtsen, B., Thomsen B., Holm, L.-E., Panitz, F., Brøndum, R. F., et al. (2014). Genome-wide association study using high-density single nucleotide polymorphism arrays and whole-genome sequences for clinical mastitis traits in dairy cattle. J Dairy Sci 97: 7258-7275.

Sammeth, M., Foissac, S., and Guigó, R. 2008. A general definition and nomenclature for alternative splicing events. PLoS Comput Biol 4:e1000147.

Schennink, A., W. M. Stoop, M. H. P. W. Visker, J. M. L. Heck, H. Bovenhuis, J. J. Van Der Poel, H. J. F. Van Valenberg, and J. A. M. Van Arendonk. 2007. DGAT1 underlies large genetic variation in milk-fat composition of dairy cows. Anim. Genet. 38:467473.

Schennink, A., J. M. L. Heck, H. Bovenhuis, M. H. P. W. Visker, H. J. F. van Valenberg, and J. A. M. van Arendonk. 2008. Milk fatty acid unsaturation: genetic parameters and effects of Stearoyl-CoA Desaturase (SCD1) and Acyl CoA: Diacylglycerol Acyltransferase 1 (DGAT1). J. Dairy Sci. 91:2135-2143.

Schenk, L., Meinel, D. M., Strässer, K., and Gerber, A. P. 2012. La-motif-dependent mRNA association with SIf1 promotes copper detoxification in yeast. RNA 18: 449461.

Stavraka, C., and Blagden, S. 2015. The la-related proteins, a family with connections to cancer. Biomolecules 5: 2701-2722.

Stoop, W. M., van Arendonk, J. A. M., Heck, J. M. L.,van Valenberg, H. J. F., and Bovenhuis, H. 2008. Genetic parameters for major milk fatty acids and milk production traits of Dutch Holstein-Friesians. J Dairy Sci. 91:385-394.

Tcherkezian, J., Cargnello, M., Romeo, Y., Huttlin, E. L., Lavoie, G., Gygi, S. P., and Roux, P. P. 2014. Proteomic analysis of cap-dependent translation identifies LARP1 as a key regulator of $5^{\prime}$ TOP mRNA translation. Genes and development 28:357371. 
Terwilliger, J. D. 2001. 23 On the resolution and feasibility of genome scanning approaches. Advances in Genetics 42: 351-391.

Venturini, G. C., Cardoso, D. F., Baldi, F., Freitas, A. C., Aspilcueta-Borquis, R. R., Santos, D. J., and Tonhati, H. 2014. Association between single-nucleotide polymorphisms and milk production traits in buffalo. Genetics and molecular research 13:10256.

Weiss, K. M., and Terwilliger, J. D. 2000. How many diseases does it take to map a gene with SNPs? Nature genetics 26:151-158.

Wilmink, J. B. M. 1987. Adjustment of test-day milk, fat and protein yield for age, season and stage of lactation. Livest. Prod. Sci. 16:335-348.

Zhang, B., Jia, J., Yang, M., Yan, C., and Han, Y. 2012. Overexpression of a LAM domain containing RNA-binding protein LARP1c induces precocious leaf senescence in Arabidopsis. Molecules and cells 34:367-374.

Zimin, A. V., A. L. Delcher, L. Florea, D. R. Kelley, M. C. Schatz, D. Puiu, F. Hanrahan, G. Pertea, C. P. Van Tassell, and T. S. Sonstegard. 2009. A whole-genome assembly of the domestic cow, Bos taurus. Genome Biol. 10:R42. 


\subsection{Tables}

Table 4.1 - Phenotypic means (SD), and heritability estimates $\left(h^{2}\right)^{1}$ for individual fatty acids (FA) based on 1,640 winter milk samples and 1,581 summer milk samples

\begin{tabular}{lccccc} 
& \multicolumn{2}{c}{ Winter } & & \multicolumn{2}{c}{ Summer } \\
\cline { 2 - 3 } \cline { 6 - 7 } Individual FA (\% wt/wt) & Mean (SD) & $h^{2}$ & & Mean (SD) & $h^{2}$ \\
\hline C4:0 & $3.51(0.27)$ & 0.47 & & $3.52(0.35)$ & 0.41 \\
C6:0 & $2.23(0.16)$ & 0.46 & & $2.17(0.21)$ & 0.39 \\
C8:0 & $1.36(0.14)$ & 0.59 & & $1.32(0.17)$ & 0.35 \\
C10:0 & $3.02(0.43)$ & 0.73 & & $2.87(0.45)$ & 0.48 \\
C12:0 & $4.12(0.70)$ & 0.62 & & $3.79(0.72)$ & 0.48 \\
C14:0 & $11.62(0.92)$ & 0.62 & & $11.16(1.05)$ & 0.54 \\
\hline
\end{tabular}

${ }^{1} h^{2}=\sigma_{\mathrm{a}}^{2} /\left(\sigma_{\mathrm{a}}^{2}+\sigma_{\mathrm{e}}^{2}\right)$, where $\sigma_{\mathrm{a}}^{2}$ is the additive genetic variance and $\sigma_{\mathrm{e}}^{2}$ is the residual variance. SE between 0.01 and 0.12 for winter samples, and between 0.02 and 0.08 for summer samples.

Table 4.2 - Distribution of the average accuracy of imputation (AR2) stratified per ranges of minor allele frequency (MAF), and the number of markers (as counts and in percentage) for the 45 sequences of Milk Genomics Initiative (MGI) and the 450 sequences of the 1000Bull Genome Consortium (RUN5)

\begin{tabular}{|c|c|c|c|c|c|c|c|c|c|c|}
\hline \multirow[b]{2}{*}{ MAF } & \multirow[b]{2}{*}{ AR2 } & \multicolumn{4}{|c|}{ MGI45 } & \multicolumn{5}{|c|}{ RUN5 } \\
\hline & & AR2 & typed & imputed & $\begin{array}{c}\text { Total } \\
(\%)\end{array}$ & AR2 & typed & imputed & total & $\begin{array}{c}\text { Total } \\
\text { (\%) }\end{array}$ \\
\hline \multirow{2}{*}{0} & all & 0.92 & 64,564 & 614,367 & $58.6 \%$ & 0.00 & 64,564 & 614,367 & 678,931 & $58.6 \%$ \\
\hline & $\geq 0.8$ & 0.97 & 41,601 & 531,552 & $49.5 \%$ & - & 0 & 0 & 0 & $0.0 \%$ \\
\hline \multirow{2}{*}{$0-0.1$} & all & 0.97 & 158,733 & 42,979 & $17.4 \%$ & 0.73 & 158,733 & 42,979 & 201,712 & $17.4 \%$ \\
\hline & $\geq 0.8$ & 0.99 & 154,028 & 37,790 & $16.6 \%$ & 0.94 & 102,738 & 17,003 & 119,741 & $10.3 \%$ \\
\hline \multirow{2}{*}{0.1 .2} & all & 0.98 & 90,821 & 1,549 & $8.0 \%$ & 0.89 & 90,821 & 1,549 & 92,370 & $8.0 \%$ \\
\hline & $\geq 0.8$ & 0.99 & 90,000 & 765 & $7.8 \%$ & 0.96 & 76,582 & 313 & 76,895 & $6.6 \%$ \\
\hline \multirow{2}{*}{$0.2-0.3$} & all & 0.98 & 68,423 & 965 & $6.0 \%$ & 0.91 & 68,423 & 965 & 69,388 & $6.0 \%$ \\
\hline & $\geq 0.8$ & 0.99 & 67,830 & 511 & $5.9 \%$ & 0.97 & 60,442 & 223 & 60,665 & $5.2 \%$ \\
\hline \multirow{2}{*}{$0.3-0.4$} & all & 0.98 & 54,352 & 934 & $4.8 \%$ & 0.92 & 54,352 & 934 & 55,286 & $4.8 \%$ \\
\hline & $\geq 0.8$ & 0.99 & 53,803 & 462 & $4.7 \%$ & 0.97 & 48,559 & 210 & 48,769 & $4.2 \%$ \\
\hline \multirow{2}{*}{$0.4-0.5$} & all & 0.96 & 58,833 & 1,158 & $5.2 \%$ & 0.86 & 58,833 & 1,158 & 59,991 & $5.2 \%$ \\
\hline & $\geq 0.8$ & 0.99 & 56,074 & 426 & $4.9 \%$ & 0.97 & 49,823 & 151 & 49,974 & $4.3 \%$ \\
\hline \multirow{2}{*}{ Total } & all & 0.97 & 495,726 & 661,952 & $100.0 \%$ & 0.72 & 495,726 & 661,952 & $1,157,678$ & $100.0 \%$ \\
\hline & $\geq 0.8$ & 0.99 & 463,336 & 571,506 & $89.4 \%$ & 0.96 & 338,144 & 17,900 & 356,044 & $30.8 \%$ \\
\hline
\end{tabular}


Table 4.3 - Details about candidate genes identified in the QTL region located between 29 and 34 mega base-pairs on BTA17

\begin{tabular}{lccc}
\hline \multicolumn{1}{c}{ Genes } & \multicolumn{1}{c}{ Identifier } & Location & $\begin{array}{c}\text { Numbers of } \\
\text { variants }\end{array}$ \\
\hline C4orf33 & ENSBTAG00000044159 & Chr17:29,105,309-29,116,531 & 2 \\
SLCT1 & ENSBTAG00000013611 & Chr17:29,190,572-29,354,595 & 23 \\
JADE & ENSBTAG00000017493 & Chr17:29,368,416-29,421,827 & 5 \\
PGRMC2 & ENSBTAG00000010843 & Chr17:29,872,406-29,890,867 & 8 \\
LARP1B & ENSBTAG00000012135 & Chr17:29,938,416-30,073,786 & 83 \\
U2 & ENSBTAG00000043806 & Chr17:30,096,344-30,096,524 & 4 \\
C4orf29 & ENSBTAG00000010630 & Chr17:30,106,834-30,143,868 & $11^{*}$ \\
(ABHD18) & ENSBTAG00000042423 & Chr17:30,118,538-30,118,671 & 1 \\
SNORA42 & ENB & $11^{* *}$ \\
MFSD8 & ENSBTAG00000044058 & Chr17:30,144,105-30,181,831 & 4 \\
PLK4 & ENSBTAG00000039552 & Chr17:30,185,756-30,202,777 & 4 \\
SLC25A31 & ENSBTAG00000012826 & Chr17:30,291,318-30,319,495 & 2 \\
INTU & ENSBTAG00000012824 & Chr17:30,324,842-30,404,702 & 3 \\
FAT4 & ENSBTAG00000003345 & Chr17:32,712,712-32,889,849 & 109 \\
\hline
\end{tabular}

*one intron variant of the ABHD18 gene overlaps with the MFSD8 gene, for which it is an upstream gene variant.

**one downstream variant of the MFSD8 gene overlaps with the PLK4 gene, for which it is an downstream gene variant. 


\subsection{Supplementary figures}

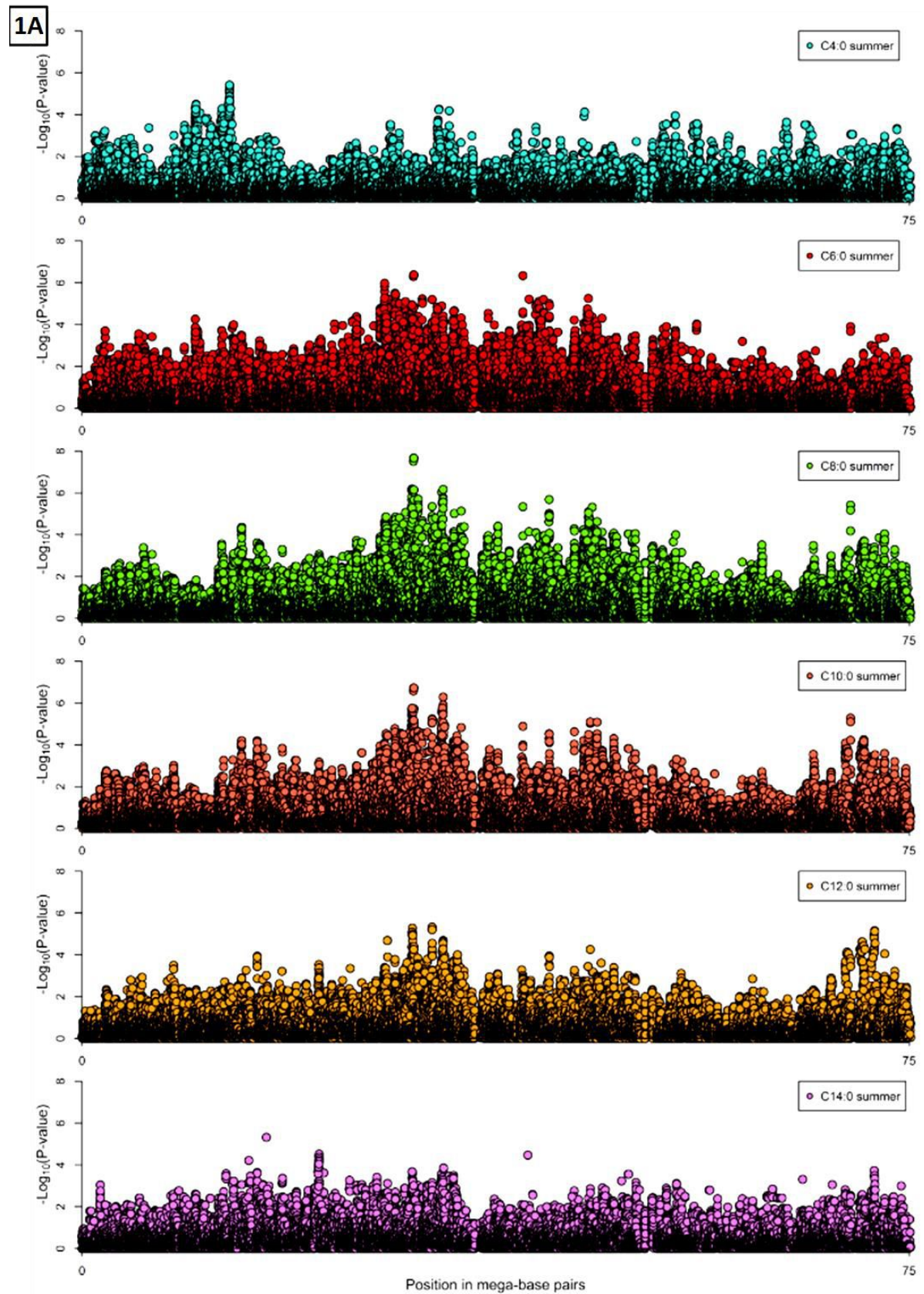

Supplementary Figure 4.1 (A) Fine-mapping of BTA17 with an accuracy of imputation equal and greater than 0.8 (AR2 $\geq 0.8$ ) showing summer milk samples for 6 fatty acids. 

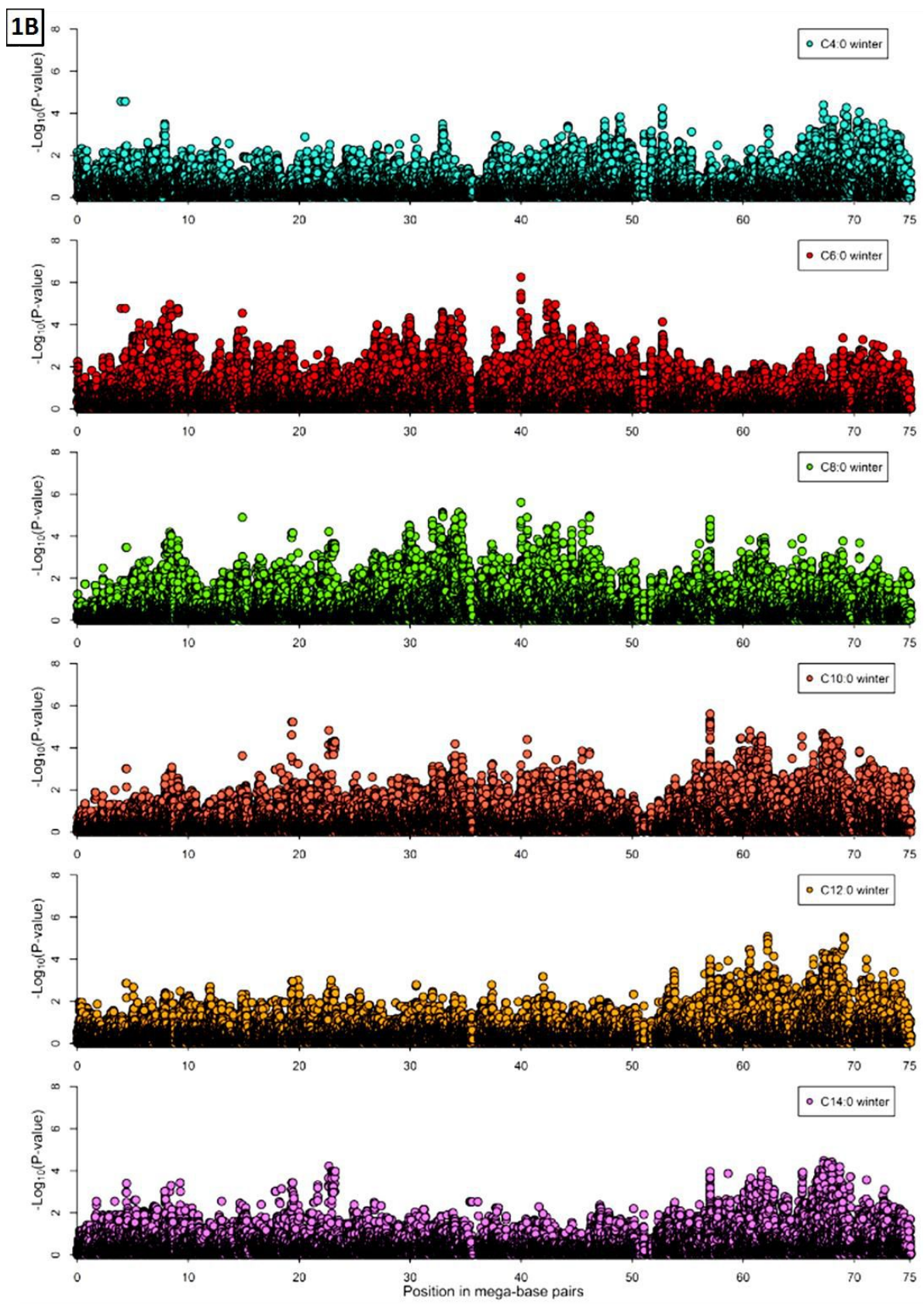

Supplementary Figure 4.1 (B) Fine-mapping of BTA17 with an accuracy of imputation equal and greater than $0.8(A R 2 \geq 0.8)$ showing winter milk samples for 6 fatty acids. 


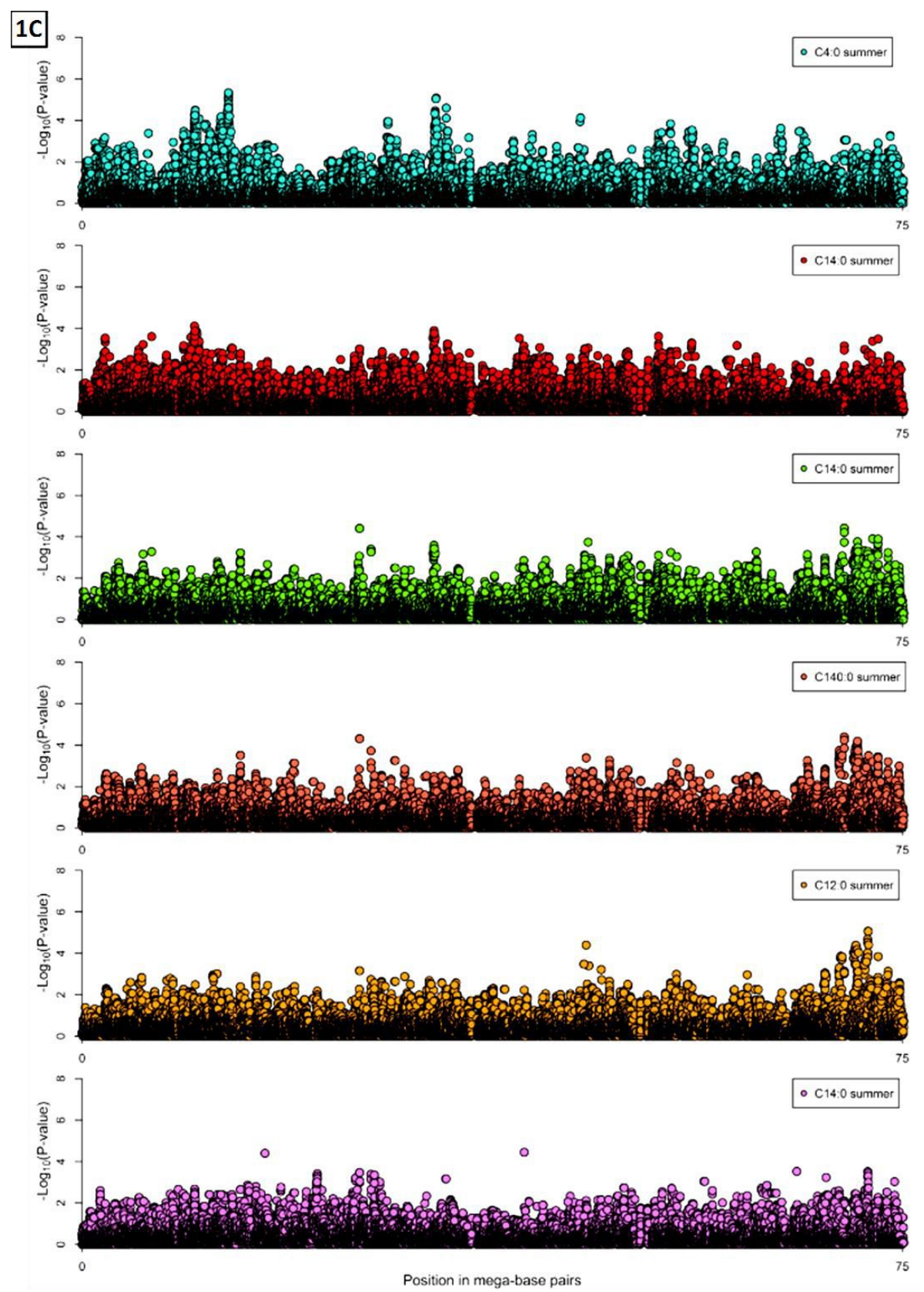

Supplementary Figure 4.1 (C) Fine-mapping of BTA17 with an accuracy of imputation equal and greater than 0.8 (AR2 $\geq 0.8$ ) showing summer milk samples for 6 fatty acids, after fitting the SNP with the highest significance. 


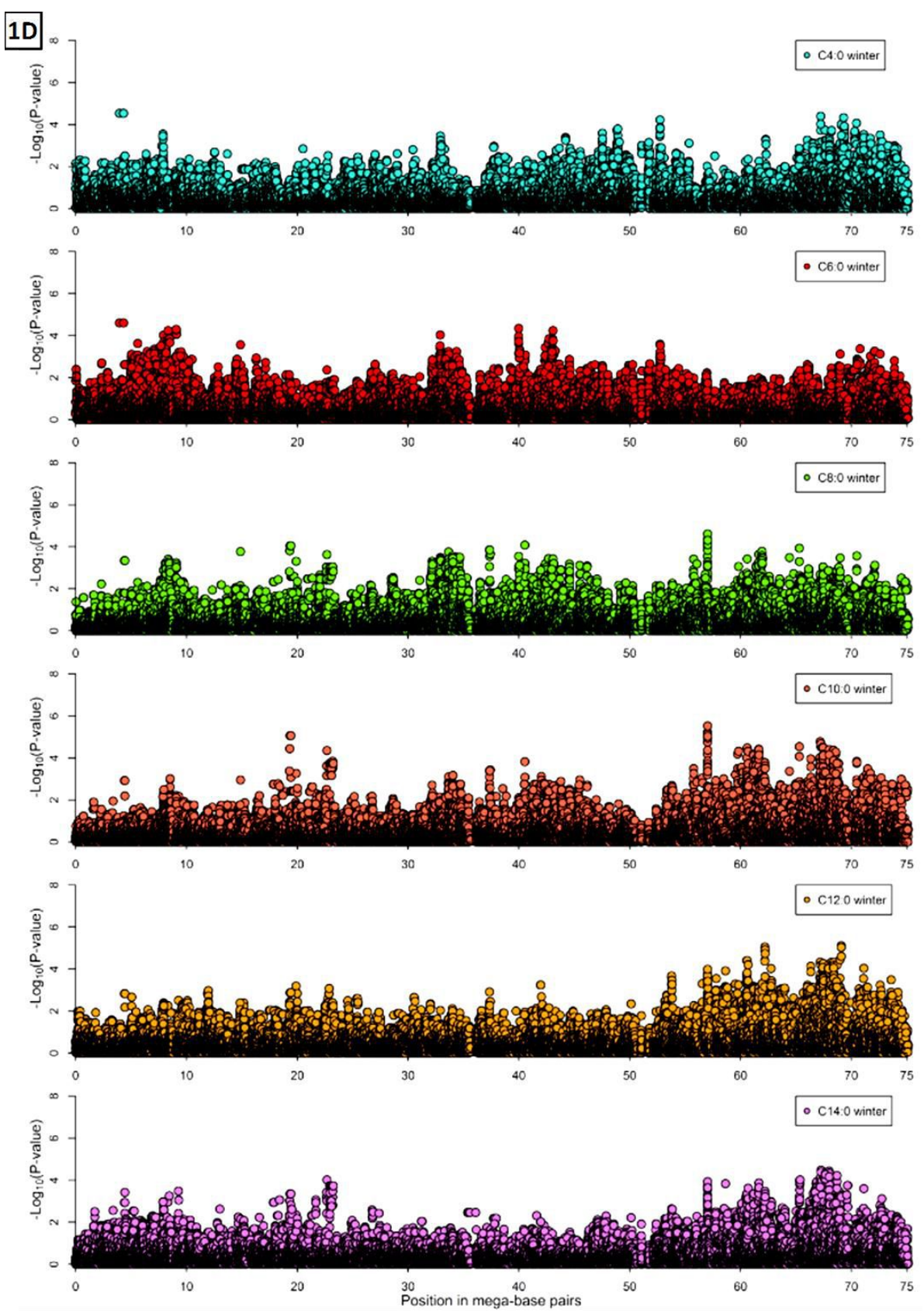

Supplementary Figure 4.1 (D) Fine-mapping of BTA17 with an accuracy of imputation equal and greater than 0.8 (AR2 $\geq 0.8$ ) showing winter milk samples for 6 fatty acids, after fitting the SNP with the highest significance. 



\section{Identification of QTL on chromosome 18 associated with non-coagulating milk in Swedish Red cows}

S.I. Duchemin ${ }^{1,2}$, M. Glantz ${ }^{3}$, D-J. de Koning ${ }^{2}$, M. Paulsson ${ }^{3}$, W.F. Fikse ${ }^{2}$

${ }^{1}$ Animal Breeding and Genomics Centre, Wageningen University, Wageningen, Netherlands; ${ }^{2}$ Department of Animal Breeding and Genetics, Swedish University of Agricultural Sciences, PO box 7023, SE-750 07, Uppsala, Sweden; ${ }^{3}$ Department of

Food Technology, Engineering and Nutrition, Lund University, Lund, Sweden.

Frontiers in Genetics: Livestock Genomics (2016) 7:57. 


\begin{abstract}
Non-coagulating (NC) milk, defined as milk not coagulating within 40 min after rennet-addition, can have a negative influence on cheese production. Its prevalence is estimated at $18 \%$ in the Swedish Red (SR) cow population. Our study aimed at identifying genomic regions and causal variants associated with NC milk in SR cows, by doing a GWAS using 777k SNP genotypes and using imputed sequences to fine map the most promising genomic region. Phenotypes were available from 382 SR cows belonging to 21 herds in the south of Sweden, from which individual morning milk was sampled. NC milk was treated as a binary trait, receiving a score of one in case of non-coagulation within 40 minutes. For all 382 SR cows, 777k SNP genotypes were available as well as the combined genotypes of the genetic variants of $\alpha$ s $1-\beta-\mathrm{k}-$ caseins. In addition, whole-genome sequences from the 1000Bull Genome Consortium (Run 3) were available for 429 animals of 15 different breeds. From these sequences, 33 sequences belonged to SR and Finish Ayrshire bulls with a large impact in the SR cow population. Single-marker analyses were run in ASReml using an animal model. After fitting the casein loci, 14 associations at $-\log _{10}(P$-value $)>6$ identified a promising region located on BTA18. We imputed sequences to the 382 genotyped SR cows using Beagle 4 for half of BTA18, and ran a region-wide association study with imputed sequences. In a 7 mega base-pairs region on BTA18, our strongest association with NC milk explained almost $34 \%$ of the genetic variation in NC milk. Since it is possible that multiple QTL are in strong LD in this region, 59 haplotypes were built, genetically differentiated by means of a phylogenetic tree, and tested in phenotype-genotype association studies. Haplotype analyses support the existence of one QTL underlying NC milk in SR cows. A candidate gene of interest is the VPS35 gene, for which one of our strongest association is an intron SNP in this gene. The VPS35 gene belongs to the mammary gene sets of pre-parturient and of lactating cows.
\end{abstract}

Key words: non-coagulating milk, sequences, dairy, cheese production, haplotypes, VPS35. 


\subsection{Introduction}

Non- or poor-coagulating milk is an undesirable characteristic of milk with a negative influence on cheese production. Non-coagulating (NC) milk is prevalent among several dairy cattle breeds, such as Swedish Red (SR), Finnish Ayrshire (FAY), Holstein-Friesian (HF) and Italian Brown Swiss, to name a few (e.g., Frederiksen et al., 2011; Cecchinato et al., 2011, Gustavsson et al., 2014a). The prevalence of NC milk varies among these breeds ranging from $4 \%$ in Italian Brown Swiss (Cecchinato et al., 2009) up to 13\% in FAY (Ikonen et al., 2004). A recent study has estimated the prevalence of NC milk, defined as milk not coagulating within 40 min after rennetaddition, at $18 \%$ in the SR cow population (Gustavsson et al., 2014a). Targeted research on NC milk can help geneticists develop breeding programs to modify milk composition and technological properties of milk and thus reduce the prevalence of NC milk.

Bittante et al. (2012) suggested that effects of herd have little influence on milk coagulation properties (MCP) including NC milk, although several factors can influence the composition of bovine milk (e.g., breed, a cow's diet, age of a cow, and the stage of lactation; Chilliard et al., 2001). In addition, MCP seem be influenced by many factors, such as SCC (e.g., Ikonen et al., 2004; Cassandro et al., 2008), titratable acidity (e.g., Penasa et al., 2010), casein composition (Okigbo et al., 1985b), pH (Nájera et al., 2003), stage of lactation (Okigbo et al., 1985a; Ostersen et al.,1997), and breed (e.g., Auldist et al., 2004; De Marchi et al., 2007, Bittante et al., 2012), among many other factors. Heritability estimates for MCP and NC milk range from 0.26 in FAY (Ikonen et al., 2004) to 0.45 in SR cows (Gustavsson et al., 2014a). These heritability estimates suggest that breeding could effectively reduce the prevalence of NC milk. In Sweden, the breeding program includes production traits to guarantee the increase in both protein and fat contents (Nordic Cattle Genetic Evaluation, 2013). The negative genetic correlations between NC milk and protein content estimated by Gustavsson et al. (2014a) suggest that breeding for higher protein content in the Swedish Red cows can lead to an increase in the prevalence of NC milk. In Sweden, 41\% of SR cows produce milk for the dairy industry, and more than $30 \%$ of total milk production is used for cheese production (LRF Dairy Sweden, 2015). Since total milk production is about 3 million tons per year (LRF Dairy Sweden, 2015) and the market price of milk produced is about 0.28 euros per $\mathrm{kg}$, the problem of NC milk affects milk with a value of approximately 63 million euros per year. Frederiksen et al. (2011) has estimated in $25 \%$ the proportion of NC milk in a batch of wellcoagulating milk that is sufficient to deteriorate the MCP of well-coagulating milk. 
Van Hooydonk et al. (1986) showed that the addition of calcium would restore coagulation of NC milk but not to the level of well-coagulating milk according to Hallén et al. (2010). Furthermore, addition of calcium above $0.04 \%$ have been reported to produce a bitter flavour (Schwarz and Mumm, 1948) which could be detrimental to cheese production. Therefore, it is important to the Swedish industry to reduce the frequency of NC milk.

It is well established that MCP, including NC milk, are strongly influenced by variable proportions, and genetic variants of milk protein fractions (especially of k-casein (CN); Bittante et al., 2012). In poor- and non-coagulating milk samples of Danish Jerseys and HF cows, Jensen et al. (2012) showed that BB- $A^{2} A^{2}-A A$ was the predominant combined genotype of $\alpha_{\mathrm{S1}^{-}}, \beta-$, and $\mathrm{k}-\mathrm{CN}$ associated with NC milk. Hallén et al. (2007) and Gustavsson et al. (2014b) showed that some of these genotypes (especially $\beta$-, and $k-C N$ genotypes $A^{2} A^{2}-A A$ ) segregate in $S R$ cows. Besides these genetic variants of milk protein fractions in the cattle genome, other undiscovered genes might play a role in the prevalence of NC milk. These genes can be identified by genome-wide association studies (GWAS) using high-density genotyping techniques.

High-density genotyping techniques, such as whole-genome sequences (WGS), can help GWAS increase the power and the precision of quantitative trait loci (QTL) mapping. Whole-genome sequences are expected to contain most of the polymorphisms causing the genetic differences between individuals (Meuwissen and Goddard, 2010). When an entire population is sequenced, WGS are independent of linkage disequilibrium (LD) between polymorphisms and the causal variant (Druet et al., 2014) compared with a lower panel of markers. However, sequencing an entire population can be expensive, and a cost-effective strategy consists of sequencing key ancestors of a population, and imputing to sequence level the rest of this population (Druet et al., 2014). To demonstrate this approach, Daetwyler et al. (2014) imputed dairy cattle populations that were genotyped with 777k SNP (BovineHD) to sequence level using WGS from the 1000 Bull Genome Project. Their study targeted some known genomic regions where QTL affecting milk production and curly coat had previously been identified, and they successfully identified the causal variants underlying these QTL. Therefore, GWAS using imputed sequences could assist in the identification of causal variants.

A recent GWAS on SR cows used BovineHD as genotypes and MCP as phenotypes (Gregersen et al., 2015). However, their GWAS did not include NC milk in the 
analyses. The aim of our study was to identify genomic regions and causal variants associated with NC milk in SR cows. For this purpose, firstly we ran a GWAS using BovineHD genotypes to identify the most promising genomic region associated with NC milk, and secondly we fine-mapped this genomic region using imputed sequences.

\subsection{Material and Methods}

\subsubsection{Animals and phenotypes}

Morning milk samples were retrieved from 382 SR cows belonging to 21 herds in the southern part of Sweden. Cows were kept indoors, were fed according to standard practices, and were milked 2 or 3 times a day. Cows were daughters of 160 sires, and were chosen to be as genetically unrelated as possible. Cows were multiparous, ranging from 1 through 3 parturitions, and were in different lactations stages, ranging from 2.5 through 61 weeks in lactation.

Milk samples were collected in two distinct periods: April through May 2010, and September 2010 through April 2011. Directly after collection, milk samples were cooled and transported to Lund University (Lund, Sweden), where samples were defatted by centrifugation (at 2,000 $\mathrm{g}$ f for $30 \mathrm{~min}$ ) to reduce the number of factors influencing coagulation properties. Fresh skimmed milk samples were preserved by adding bronopol (Sigma-Aldrich, Schnelldorf, Germany) solution of $17 \% \mathrm{wt} / \mathrm{vol}$ $(2 \mu \mathrm{L} / \mathrm{mL})$, as described in Hallén et al. (2007). For rheological measurements, these milk samples were stored at +4 으, but no longer than $3 \mathrm{~d}$. Skimmed milk samples were heated to $32^{\circ} \mathrm{C}$ for $30 \mathrm{~min}$, after which chymosin $(0.44 \mathrm{~mL} / \mathrm{L}$ Chy-Max Plus, 205 international milk clotting units (IMCU)/mL, Chr. Hansen A/S Hørsholm, Denmark) was added, and the resulting solution was gently stirred. The addition of the chymosin represented time zero. Measurements, such as rennet gel strength, rennet coagulation time, and yield stress of rennet-induced gels, were done and described by Gustavsson et al. (2014a). Some samples were unable to coagulate within $40 \mathrm{~min}$ after rennet-addition, and were defined as non-coagulating (NC) milk samples. When observed, NC milk was scored as one, while coagulating milk was scored as zero. Of the 382 cows that had available phenotypes on coagulation properties, $18 \%$ of these cows had NC milk.

\subsubsection{Genotypes}

A blood sample of each of the 382 SR cows was collected for genotyping purposes. These cows were genotyped for 777,963 SNP using the Illumina BovineHD BeadChip 
(Illumina Inc., San Diego, CA). Quality controls of the data were performed using the R-package GenAbel (Aulchenko et al., 2007), and consisted of a minimum of $95 \%$ of non-missing SNP per called genotypes (call rate) and minor allele frequency (MAF) of a minimum of $1 \%$ for a called SNP. All SNP without a map position on the UMD 3.1 genome assembly (Zimin et al., 2009) as well as SNP on the sex chromosome were discarded. After these edits, a total of 624,302 SNP were available for further analyses.

In addition, blood samples were used to extract DNA to genotype all cows for genetic variants of $\alpha s 1-, \beta$ - and $\mathrm{k}$-caseins (CN) using TaqMan SNP genotyping assays (Applied Biosystems, Foster City, CA), as described in Gustavsson et al. (2014b). For these variants, the assays were distinguished among the following: $\alpha$ s1-CN variant $A, B, C$, $D$, and $F ; \beta-C N$ variants $A^{1}, A^{2}, A^{3}, B$ and $I$; and $k-C N$ variants $A, B$ and $E$ ). In their study, combined genotypes were created by combining the genetic variants of $\alpha \mathrm{s} 1-\beta-\mathrm{k}-\mathrm{CN}$. These combined genotypes were used in the present study, and are referred to as "CNcluster".

Whole-genome sequences were available for 428 bulls and for 1 cow from 15 different breeds (Run 3 of the 1000 Bull Genomes consortium; Daetwyler et al., 2014), representing a multi-breed reference population. Among these sequences, 33 belonged to SR and FAY bulls with a large impact in the SR cow population. All positions of the variants on sequences were aligned to the bovine genome assembly UMD3.1 (Zimin et al., 2009). Within this multi-breed reference population, positions containing both a SNP and an indel were excluded because of possible problems with alignment and sequencing.

\subsubsection{GWAS on BovineHD genotypes}

Single-marker analyses were run in ASReml 4.0 (Beta version; Gilmour et al., 2009) using the following animal model:

$$
\begin{gathered}
y=\mu+\text { herd }+ \text { parity }+ \text { wim }+e^{-0.05 * \text { wim }}+\text { CNcluster }+ \text { Marker }+a \\
+e
\end{gathered}
$$

where $y$ is the dependent variable; $\mu$ is the overall mean, herd is the covariate that describes the effect of a cow belonging to a specific herd; parity is the covariate that describes the effect of number of parities per cow; wim is the covariate that describes the effect of weeks in milk, modeled as a Wilmink curve (Wilmink, 1987); CNcluster is the covariate describing the effect of the combined genotypes; Marker 
is the fixed effect of a variant genotype; $a$ is the random effect of animal and is assumed to be distributed as $N \sim\left(0, \boldsymbol{G} \sigma_{a}^{2}\right)$, where $\boldsymbol{G}$ is the genomic relationship matrix based on 382 animals and $\sigma_{a}^{2}$ is the additive genetic variance. We calculated the G-matrix based on the BovineHD genotypes using the software calc_grm (Calus, 2013). $\sigma_{a}^{2}$ was estimated with a model excluding the effect of Marker, and was fixed in model $1 . e$ is the random residual effect and is assumed to be distributed as $N \sim\left(0, I \sigma_{e}^{2}\right)$, where $\mathbf{I}$ is the identity matrix and $\sigma_{e}^{2}$ is the residual variance.

The most promising genomic region with multiple signals at $-\log _{10}(P$-value) $\geq 6$ was imputed from the BovineHD genotypes to sequence level, and a region-wide association study (RWAS) was performed.

\subsubsection{Imputation}

Imputation started by checking the BovineHD against the sequenced reference population for inconsistencies using the Conform-gt software (http://faculty.washington.edu/browning/conform-gt.html). After this check, the 382 cows were imputed from BovineHD genotypes to sequence level for half of a chromosome using Beagle version 4.0 (Browning and Browning, 2007). Beagle version 4 was run with the following settings: 50 for phase iterations, 50 for nthreads, and 100 for imputation iterations. To account for the nature of the different variants, we ran three imputations based on different reference populations. These imputations were named as follows: "Nordic-red-specific", "Dairy-specific", and "Common". For the imputation of the "Nordic-red-specific", the reference population used consisted of the 33 sequences belonging to SR and FAY breeds. For the imputation of the "Dairy-specific", the reference population used consisted of the 284 sequences belonging to dairy breeds ( 8 breeds). For the imputation of the "Common", the reference population used consisted of 429 sequences belonging to Nordic-red, dairy and beef breeds (15 breeds). Following this approach, each variant was imputed three times based on the three different reference populations, which resulted in different imputation accuracies (Beagle allelic-r2, AR2) for each variant. The genotype with the highest imputation accuracy across the three imputations was selected as the best-imputed genotype.

We calculated the average concordance between the imputed genotypes across the three different scenarios of imputation, as implemented in VCFtools version $0.1 .12 \mathrm{~b}$ (Danecek et al., 2011). Subsequently, we combined the best-imputed genotypes into one data set that was used in the RWAS. 


\subsubsection{RWAS on imputed sequences for half a chromosome}

A RWAS with imputed sequence data for the most promising region on half a chromosome was run using model 1 . The imputed sequences were filtered to remove poorly imputed genotypes: only variants that were imputed with an AR2 $\geq$ 0.2 were included in the RWAS. Single-marker analyses were run using model 1 with one modification: the variance of the genetic effect $a$ was assumed to be distributed as $N \sim\left(0, \mathbf{G} \mathbf{1} \sigma_{a^{*}}^{2}\right)$, where $\mathbf{G 1}$ is the genomic relationship matrix based on 382 animals and $\sigma_{a^{*}}^{2}$ is the additive genetic variance. The G1-matrix was calculated using the software calc_grm (Calus, 2013). The BovineHD genotypes of half chromosome that were used in the imputation to sequence level were not included in the G1matrix calculations. $\sigma_{a^{*}}^{2}$ was calculated before the inclusion of Marker, and was fixed in model 1.

The most significant association from the first RWAS (coined TagSNP1) was subsequently included as a fixed effect in model 1 , and a second RWAS was run. For this second RWAS, only the variants with an AR2 $\geq 0.8$ were re-analyzed and considered for further analyses, such as linkage disequilibrium (LD) calculations and haplotype analyses.

\subsubsection{Haplotype analyses}

The construction of haplotypes started by selecting the SNP moderately to highly correlated with TagSNP1 (LD > 0.5). LD was calculated as the squared correlation between TagSNP1 and all other SNP using PLINK version 1.9 (Purcell et al. 2007). An LD plot was produced using the R-package ggplot2 (Wickham, 2009). Next, we combined these correlated SNP into haplotypes.

For the haplotypes, we produced a phylogenetic tree using the molecular evolutionary genetics analysis (MEGA6) software, version 6.0. The MEGA6 software was developed for comparative analyses of DNA and protein sequences that aim at inferring the molecular evolutionary patterns of genes, genomes, and species over time (Kumar et al. 1994; Tamura et al. 2013). To build the phylogenetic tree, we applied the Neighbor-Joining statistical method (Saitou and Nei, 1987) with a substitution model based on the proportion of nucleotide substitutions per site between nucleotides of loaded sequences. Alignment gaps and missing information gaps were accounted for with the partial-deletion option implemented in the software, and gaps were removed when the number of ambiguous sites $\geq 0.95$. 
Subsequently, the phylogenetic tree, all phenotypes and 2 copies of each haplotypes per cow were supplied to TreeScan software, version 1.0 (Templeton et al., 2005). TreeScan uses the phylogenetic tree built from haplotypes in phenotype-genotype association studies. With its iterative approach, TreeScan cuts in two parts a branch of the phylogenetic tree. For part 1, all haplotypes are grouped, and treated as a single allele, say $A$. For part 2, all haplotypes are grouped, and treated as a single allele, say $B$. These alleles allow different combinations of genotypes: $A A, A B$ and $B B$. Subsequently, associations between phenotypes and genotypes ( $A A, A B$ and $B B$ ) are statistically tested with the F-statistics of a one-way ANOVA. This iterative approach is repeated until all the branches of the phylogenetic tree have been tested. The null hypothesis considered for the inference of branches (i.e., haplotypes) is of no association between a partition and the trait of interest, which in our case was NC milk. In addition, the following settings were used in TreeScan: the number of simulations to obtain P-values for the ANOVA tests $p=5,000$; the significance level $\alpha$ $=0.05$, and the minimum number of individuals required in each observed genotypic class $\mathrm{c}=2$. A bipartition was considered as significantly associated to NC milk at Pvalue $<0.05$.

\subsubsection{Bioinformatics and candidate genes}

We used the variant effect predictor (Ve!P) online tool (at http://www.ensembl.org/info/docs/tools/vep/index.html; McLaren et al., 2010) to determine the effect of the variants (SNPs, insertions, deletions, CNVs or structural variants) on genes, transcripts, and protein sequence, as well as regulatory regions.

\subsection{Results}

\subsubsection{GWAS on BovineHD genotypes}

The GWAS on BovineHD genotypes identified many significant SNP associated with NC milk after fitting the casein loci (Supplementary Figures 5.1A, 5.1B, 5.1C, and 5.1D). The accompanying QQ-plot indicated that a small proportion of SNP were deviating from the $x=y$ line. This smaller proportion of SNP represented the most likely associated SNP among the thousands of non-associated SNP with NC milk. In addition, no important deviations from the $x=y$ line were observed, suggesting no obvious signs of population stratification (Supplementary Figure 5.2). Fourteen of the many significant associations had $-\log _{10}$ (Pvalue) larger than 6 , and they are located on BTA11, BTA13 and BTA18 (Table 5.1). The most promising region was located on BTA18, and was distributed over a region of 7 mega base-pairs (MBP). Because BTA18 showed the most significant association with NC milk after fitting the 
casein loci, we focused on this chromosome by running a RWAS using imputed sequence data.

Table 5.1 Most significant SNP from genome-wide association study with NC milk + based on BovineHD genotypes in 382 Swedish Red cows.

\begin{tabular}{cccccc}
\hline $\begin{array}{c}\text { Chromoso } \\
\text { me }\end{array}$ & SNP & position & $-\log _{10}($ Pvalue $)$ & $\sigma_{\text {marker }}^{2}{ }^{\S}$ & $\sigma_{\text {marker }}^{2} / \sigma_{p}^{2}$ \\
\hline 11 & rs136987882 & 55787730 & 6.29 & 0.01 & 0.07 \\
13 & rs136185829 & 47744740 & 6.15 & 0.01 & 0.07 \\
13 & rs109492822 & 47749851 & 6.15 & 0.01 & 0.07 \\
13 & rs134756836 & 47754335 & 6.15 & 0.01 & 0.07 \\
18 & rs137544086 & 9179722 & 6.19 & 0.01 & 0.07 \\
18 & $\mathrm{rs} 11865365$ & 11166809 & 8.77 & 0.01 & 0.09 \\
18 & $\mathrm{rs} 110267892$ & 13136171 & 6.65 & 0.01 & 0.07 \\
18 & $\mathrm{rs} 109208214$ & 13934856 & 10.18 & 0.02 & 0.11 \\
18 & $\mathrm{rs} 135171892$ & 13939170 & 10.18 & 0.02 & 0.11 \\
18 & $\mathrm{rs} 137827420$ & 13943440 & 10.18 & 0.02 & 0.11 \\
18 & $\mathrm{rs} 137429187$ & 13960525 & 10.18 & 0.02 & 0.11 \\
18 & $\mathrm{rs} 132908573$ & 13967910 & 10.18 & 0.02 & 0.11 \\
18 & $\mathrm{rs} 110637786$ & 15017982 & 9.35 & 0.01 & 0.10 \\
18 & $\mathrm{rs} 110615481$ & 15047675 & 6.54 & 0.01 & 0.08 \\
\hline
\end{tabular}

${ }^{\dagger} \mathrm{NC}$ milk as binary trait where $0=$ coagulating milk and $1=$ non-coagulating milk ${ }^{\S} \sigma_{\text {marker }}^{2}=$ marker's variance, computed for each marker as 2 times major allele frequency times minor allele frequency times the square of the allele substitution effect ${ }^{*} \sigma_{\text {marker }}^{2} / \sigma_{p}^{2}=$ proportion of phenotypic variance explained by a marker

\subsubsection{Imputation for half of BTA18}

Before imputation, the inconsistencies between the BovineHD genotypes and the sequence data were strand problems (i.e., 1 for Nordic-red-specific, 815 for Dairyspecific, and 927 for commons), and 7 SNP from the BovineHD genotypes not present in the sequence data. All these inconsistencies were set to missing in the BovineHD data, and imputed.

After imputation, the total number of variants in the region between 0-30 MBP on BTA18 increased from 7,873 SNP on the BovineHD to 562,432 variants on the sequence level, representing an increase of 71 times in the total number of variants. From the 562,432 imputed variants, $69.3 \%$ were monomorphic (MAF=0), 24.5\% were polymorphic and AR2 $\geq 0.2$, and $14.3 \%$ were polymorphic and AR2 $\geq 0.8$ (Table 5.2). After filtering out the monomorphic variants, 137,949 polymorphic variants imputed with an AR2 $\geq 0.2$ were left. This is an increase of more than 17 times in the total number of variants from BovineHD genotypes ( $N=7,873$ SNP) to sequence level ( $\mathrm{N}=137,949$ sites). These 137,949 variants originated from the three scenarios as 
Table 5.2 Distribution of the average accuracy of imputation (AR2) per ranges of minor allele frequency (MAF), and the number of markers (as counts and in percentage) for the three scenarios of imputation

\begin{tabular}{|c|c|c|c|c|c|c|c|c|c|}
\hline \multirow{2}{*}{ MAF } & \multirow{2}{*}{$\mathrm{AR}^{+}$} & \multicolumn{2}{|c|}{ Nordic-red specific } & \multicolumn{2}{|c|}{ Dairy-specific } & \multicolumn{2}{|c|}{ Common } & \multicolumn{2}{|c|}{ Total number of variants } \\
\hline & & average AR2 & $\mathrm{N} 1^{\S}$ & average AR2 & N2* & average AR2 & $\mathrm{N}^{\mathrm{C}}$ & $\mathrm{N}^{*}$ & $(\%)$ \\
\hline \multirow[t]{3}{*}{0} & All & 0.00 & 389,518 & 0.00 & 94 & 0.00 & 54 & 389,666 & $69.3 \%$ \\
\hline & $\geq 0.2$ & - & 0 & 0.31 & 4 & 0.31 & 0 & 4 & $0.0 \%$ \\
\hline & $\geq 0.8$ & - & - & - & - & - & - & - & - \\
\hline \multirow[t]{3}{*}{$0-0.1$} & All & 0.42 & 28,346 & 0.37 & 17,720 & 0.34 & 9,547 & 55,613 & $9.9 \%$ \\
\hline & $\geq 0.2$ & 0.72 & 16,772 & 0.62 & 11,266 & 0.59 & 5,861 & 33,899 & $6.0 \%$ \\
\hline & $\geq 0.8$ & 0.94 & 9,467 & 0.91 & 2,748 & 0.90 & 1,082 & 13,297 & $2.4 \%$ \\
\hline \multirow[t]{3}{*}{$0.1-0.2$} & All & 0.69 & 23,425 & 0.63 & 6,951 & 0.61 & 2,774 & 33,150 & $5.9 \%$ \\
\hline & $\geq 0.2$ & 0.76 & 20,922 & 0.70 & 6,136 & 0.67 & 2,462 & 29,520 & $5.2 \%$ \\
\hline & $\geq 0.8$ & 0.94 & 12,994 & 0.92 & 2,329 & 0.91 & 761 & 16,084 & $2.9 \%$ \\
\hline \multirow[t]{3}{*}{$0.2-0.3$} & All & 0.75 & 22,765 & 0.70 & 4,593 & 0.68 & 1,467 & 28,825 & $5.1 \%$ \\
\hline & $\geq 0.2$ & 0.80 & 21,235 & 0.75 & 4,075 & 0.73 & 1,291 & 26,601 & $4.7 \%$ \\
\hline & $\geq 0.8$ & 0.94 & 14,609 & 0.92 & 2,049 & 0.92 & 412 & 17,070 & $3.0 \%$ \\
\hline \multirow[t]{3}{*}{$0.3-0.4$} & All & 0.78 & 21,900 & 0.74 & 4,422 & 0.71 & 1,205 & 27,527 & $4.9 \%$ \\
\hline & $\geq 0.2$ & 0.83 & 20,429 & 0.80 & 3,759 & 0.78 & 991 & 25,179 & $4.5 \%$ \\
\hline & $\geq 0.8$ & 0.95 & 15,189 & 0.93 & 2,186 & 0.92 & 392 & 17,767 & $3.2 \%$ \\
\hline \multirow[t]{3}{*}{$0.4-0.5$} & All & 0.67 & 22,731 & 0.62 & 3,854 & 0.59 & 1,066 & 27,651 & $4.9 \%$ \\
\hline & $\geq 0.2$ & 0.83 & 18,794 & 0.79 & 3,154 & 0.78 & 798 & 22,746 & $4.0 \%$ \\
\hline & $\geq 0.8$ & 0.95 & 13,937 & 0.93 & 1,779 & 0.92 & 272 & 15,988 & $2.8 \%$ \\
\hline \multirow[t]{3}{*}{ Total } & All & 0.55 & 508,685 & 0.51 & 37,634 & 0.49 & 16,113 & 562,432 & $100.0 \%$ \\
\hline & $\geq 0.2$ & 0.79 & 98,152 & 0.73 & 28,394 & 0.71 & 11,403 & 137,949 & $24.5 \%$ \\
\hline & $\geq 0.8$ & 0.94 & 66,196 & 0.92 & 11,091 & 0.91 & 2,919 & 80,206 & $14.3 \%$ \\
\hline
\end{tabular}

+where: All considers all imputed animals, $\geq 0.2$ considers animals imputed with an AR2 equal and higher than 0.2 , and $\geq 0.8$ con siders animals imputed with an AR2 equal and higher than $0.8 .{ }^{\S} \mathrm{N} 1=$ total number of markers for the Nordic-Red specific scenario. ${ }^{*} \mathrm{~N} 2=$ total number of markers for the Dairy-specific scenario. ${ }^{\varsigma} \mathrm{N} 3=$ total number of markers for the Common scenario. ${ }^{\ddagger} \mathrm{N}=$ sum of markers for all three imputation scenarios $(\mathrm{N} 1+\mathrm{N} 2+\mathrm{N} 3)$. 
follows: 98,152 variants from the Nordic-red-specific scenario, plus 28,394 variants from the Dairy-specific scenario, plus 11,403 variants from the common scenario. In addition, the 98,152 variants from the Nordic-red-specific scenario are composed of 91,363 SNP, 6,753 indels, and 36 multi-allelic variants. The 28,394 variants from the Dairy-specific scenario are composed of 27,113 SNP, 1,253 indels, and 28 multi-allelic variants. The 11,403 variants from the common scenario are composed of 10,989 SNP, 401 indels, and 13 multi-allelic variants.

The average concordance was calculated by comparing genotypes imputed in the three different scenarios, and reported sites were alleles in exact match between files. Results indicated that $97.0 \%$ of the imputed genotypes from the Nordic-redspecific scenario were concordant with the Dairy-specific scenario; $96.8 \%$ of the imputed genotypes from the Nordic-red-specific scenario were concordant with the common scenario; and $98.9 \%$ of the imputed genotypes from the Dairy-specific scenario were concordant with the common scenario.

\subsubsection{RWAS on imputed sequences for half of BTA18}

A RWAS based on imputed sequences was run for half of BTA18, which corresponds to a genomic region of $30 \mathrm{MBP}$ running from position 0 on bovine genome built UMD 3.1. Throughout this region, a total of 205 variants were significantly associated with NC milk at $-\log _{10}$ (Pvalue) $>6$ and imputed with AR2 $\geq 0.8$ (Supplementary Table 5.1). The most significant variants were 1 indel and 2 SNP. The indel was rs385975260 occurring at $15.03 \mathrm{MBP}$, and was imputed with $A R 2=0.87$. The first SNP was rs525335650 located at $15.03 \mathrm{MBP}$, and was imputed with AR2 $=0.87$. The second SNP was rs379827811 located at $15.04 \mathrm{MBP}$, and was imputed with AR2 $=0.42$. These 2 SNP and 1 indel are in perfect LD with each other. We chose rs 525335650 among these three imputed variants, since it was the best imputed variant, and tagged it as TagSNP1 (Figure 5.1A).

After including TagSNP1 as a fixed effect in model 1, a total of 80,206 variants with an $A R 2 \geq 0.8$ were re-analyzed. We re-analyzed these 80,206 imputed variants instead of the 137,949 imputed variants to reduce potential false-positive associations with NC milk caused by imputation errors. After accounting for TagSNP1 in model 1 as fixed effect, no remaining associations were found (Figure 5.1B).

\subsubsection{Haplotype analyses}

A total of 129 SNP plus 17 indels in LD with TagSNP1 (Figure 5.2) were combined into 59 haplotypes. These 59 haplotypes were the basis to build a phylogenetic tree, for 

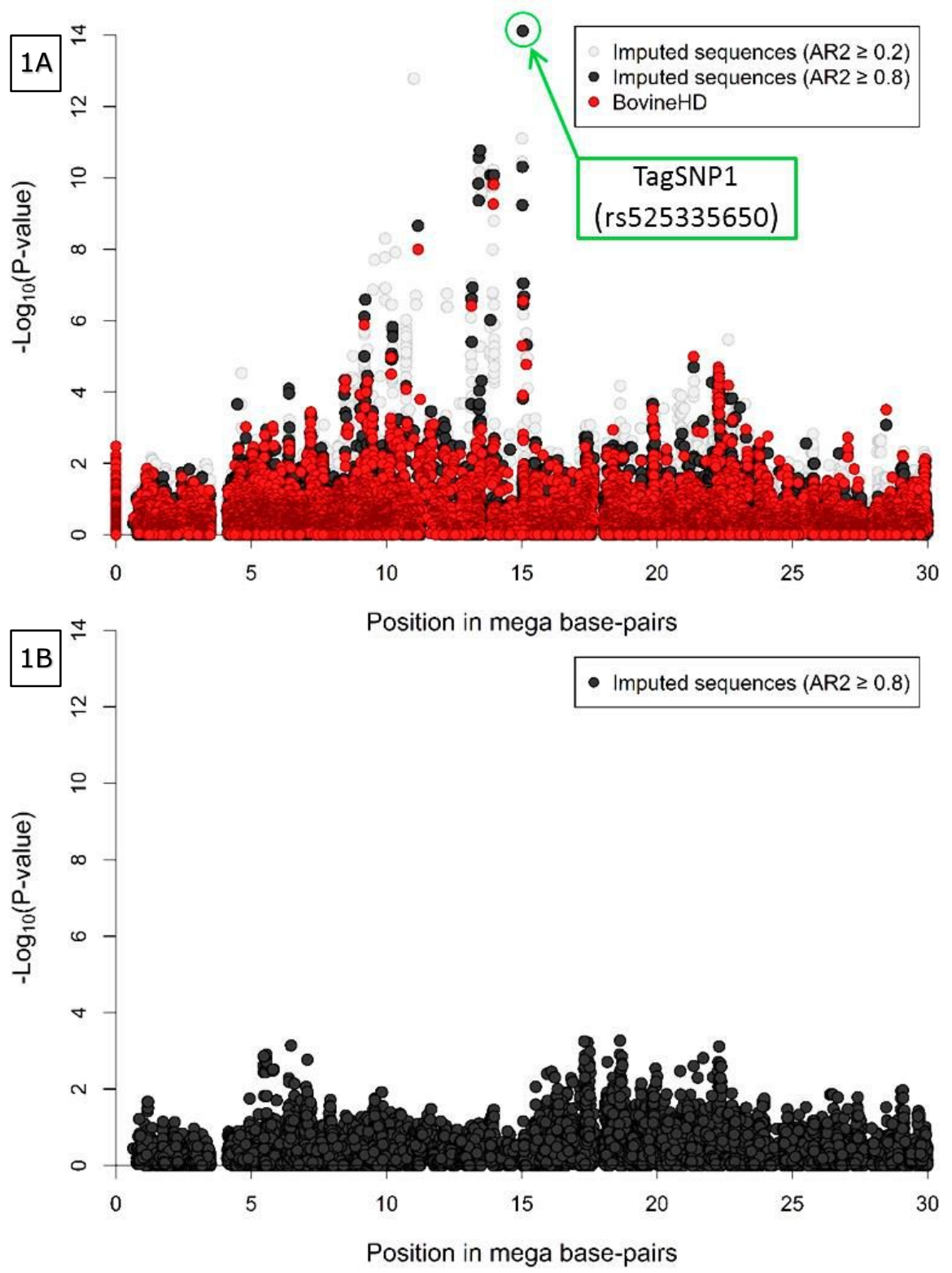

Figure 5.1 Region-wide association study (RWAS) with non-coagulating (NC) milk in 382 Swedish Red cows. Figure 5.1A RWAS based on 137,949 polymorphic imputed variants overlaid with the BovineHD genotypes for half of BTA18. In light gray, imputed variants with accuracy of imputation (AR2) $\geq 0.2$. In black, imputed variants with AR2 $\geq 0.8$. "TagSNP1" as most significant association. Figure 5.1B RWAS after correcting for TagSNP1. In black, imputed variants with $A R 2 \geq 0.8$ ( $N=80,206$ variants). 


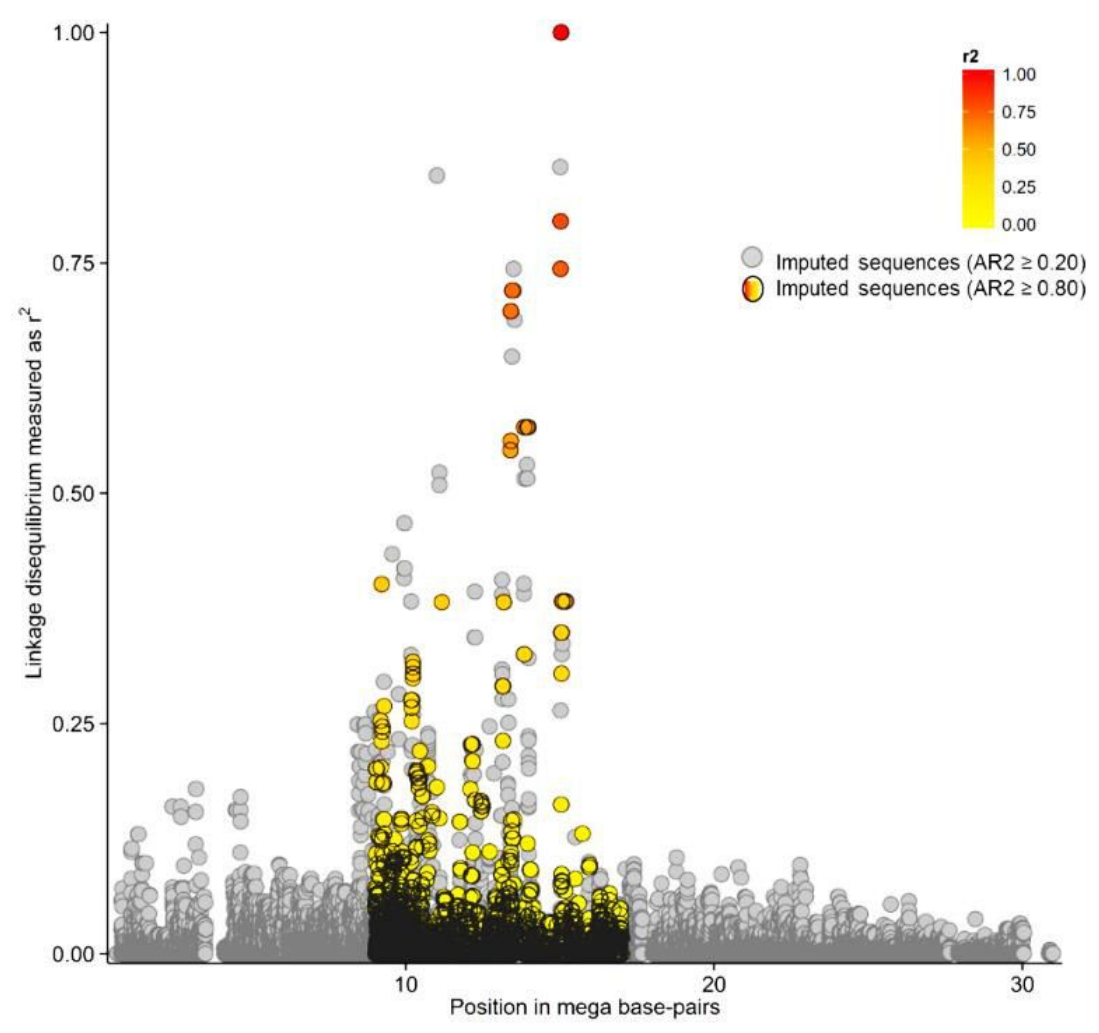

Figure 5.2 Linkage disequilibrium in the QTL region. In the colored region, pairwise linkage disequilibrium as the squared correlation between the most significant association, "TagSNP1", and all other markers. In light gray, imputed variants with accuracy of imputation $(A R 2) \geq 0.2$. In black, imputed variants with $A R 2 \geq 0.8$.

which each branch represented one unique haplotype segregating in the SR cow population (Figure 5.3A). The iterative inference of haplotypes using TreeScan occurred by, for example, cutting the phylogenetic tree in two parts at branch " $\mathrm{A}$ ", where haplotypes 38 and 58 were grouped in one part, while all other haplotypes were grouped in the other part. The parts were then tested against each other. After all branches of the tree were tested, associations with NC milk were: branch " $\mathrm{A}$ " at P-value $=0.002$; haplotype 38 at P-value $=0.03$; and, haplotype 58 at P-value $=0.03$ (Figure 5.3A). Next, we scrutinized in depth the sequences of haplotypes 38 and 58, and we found they have 3 SNP in common. When comparing haplotypes 38 and 58 with haplotypes 13, 20, 29 and 39 (Figure 5.3B), haplotypes 38 and 58 differed from the other haplotypes at these exact same 3 SNP. Interestingly, these 3 SNP shared by haplotypes 38 and 58 are quite close to our TagSNP1 (Figure 5.3B). 


\subsubsection{Bioinformatics and candidate genes}

According to Ve!P, the 129 SNP plus the 17 indels, which included our TagSNP1, were distributed as follows: $32 \%$ of intron variants; $26 \%$ of downstream gene variants, $25 \%$ of upstream gene variants; $12 \%$ of intergenic variants; $4 \%$ of 3'UTR variants; $1 \%$ of synonymous variants, and $1 \%$ of missense variants. In summary, $67 \%$ of these 129 SNP plus 17 indels were synonymous variants without changes to the encoded amino acids. The remaining $33 \%$ were missense variants with changes in one or more bases to the encoded amino acid.

In addition, Ve!P showed that our QTL region on BTA18 contains 7 genes (Table 5.3), of which 1 is a validated gene and 6 are provisional genes. These 7 genes are: validated carbonic anhydrase VA, mitochondrial (CA5A) gene; BTG3 associated nuclear protein (BANP) gene; cytochrome b-245, alpha polypeptide (CYBA) gene; the mevalonate (diphospho) decarboxylase, mRNA (MVD) gene; snail family zinc finger 3 (SNAI3) gene; ring finger protein 166 (RNF166) gene; and, vacuolar protein sorting 35 homolog, mRNA (VPS35) gene. In addition, the CA5A gene is located within a copy number variation.

Table 5.3 Details about candidate genes identified in the QTL region

\begin{tabular}{cccc}
\hline Genes & Identifier & Location & $\begin{array}{c}\text { Numbers } \\
\text { of variants }\end{array}$ \\
\hline CA5A & ENSBTAG00000010151 & chr18:13,356,215-13,445,854 & 8 \\
BANP & ENSBTAG00000023745 & chr18:13,425,303-13,493,366 & 3 \\
CYBA & ENSBTAG00000003895 & chr18:13,931,107-13,938,075 & 40 \\
MVD & ENSBTAG00000012059 & chr18:13,938,827-13,945,489 & $72^{*}$ \\
SNAI3 & ENSBTAG00000017528 & chr18:13,958,995-13,964,622 & $36^{* *}$ \\
RNF166 & ENSBTAG00000020942 & chr18:13,969,303-13,977,633 & 3 \\
VPS35 & ENSBTAG00000002493 & chr18:15,038,821-15,066,463 & 2 \\
\hline
\end{tabular}

*40 of these 72 variants in the MVD gene overlap with variants in the CYBA gene. These are: 26 downstream variants in the MVD gene corresponding to 16 introns, 1 synonymous, and 9 upstream variants in the CYBA gene; and seven 3' UTR, 1 synonymous, 5 intron, and 1 missense variants in the $M V D$ gene corresponding to upstream variants in the CYBA gene.

**5 of these 36 hits are downstream gene variants in the SNAI3 gene that correspond to upstream gene variants in the RNF166 gene. 
The genomic position of the 3 strongest associations with NC milk on BTA18 are shown in Supplementary Figure 5.3A. Of these associations, rs379827811 is an intron variant in the VPS35 gene. According to Ve!P, rs379827811 is upstream to 14 missense variants, 1 synonymous variant, 1 stop gained variant and 1 splice region variant (Supplementary Figure 5.3B).

The 3 SNP shared by haplotypes 38 and 58 identified in the haplotype analyses are intergenic variants located between 20.5 and 31.2 kilo base-pairs (kbp) downstream to the VPS35 gene.

\subsection{Discussion}

In the present study, we used the same phenotypes and BovineHD genotypes as in Gustavsson et al. (2014a) to perform a GWAS with NC milk, and we further finemapped a genomic region on half of BTA18 using imputed sequences. This genomic region is distributed over $7 \mathrm{MBP}$ on $\mathrm{BTA} 18$, and is strongly associated with NC milk. At least one QTL could be fine-mapped using imputed sequences. In addition, we conducted haplotype analyses to disentangle the occurrence of multiple QTL in strong LD within this region. At last, we identified potential candidate genes within this QTL region.

\subsubsection{GWAS on BovineHD genotypes}

The GWAS on BovineHD genotypes showed significant associations with NC milk distributed over 7 mega base-pairs (MBP) on BTA18 (Table 5.1). These 7 MBP explain large fractions of the phenotypic variation in NC milk, ranging from $7 \%$ to $11 \%$. Tyrisevä et al. (2008) performed a genome scan to map non-coagulation of milk in 477 genotyped FAY cows. Their study used microsatellite markers and identified a QTL located around $17 \mathrm{MBP}$ on BTA18. Their QTL is very close to the $7 \mathrm{MBP}$ region identified in our study. The methodology used by Tyrisevä et al. (2008) is different from the present study. It is important to note that the study by Tyrisevä et al. (2008) is based on a linkage study within sire families with pooled DNA of cows with extreme phenotypes, and our study is based on an association analysis of genotyped cows with scored phenotypes. Both methodologies have the common goal of pointing out the potential candidate genes associated with a trait of interest, and, despite the differences between both studies, a similar genomic region was associated with NC milk. 
3A

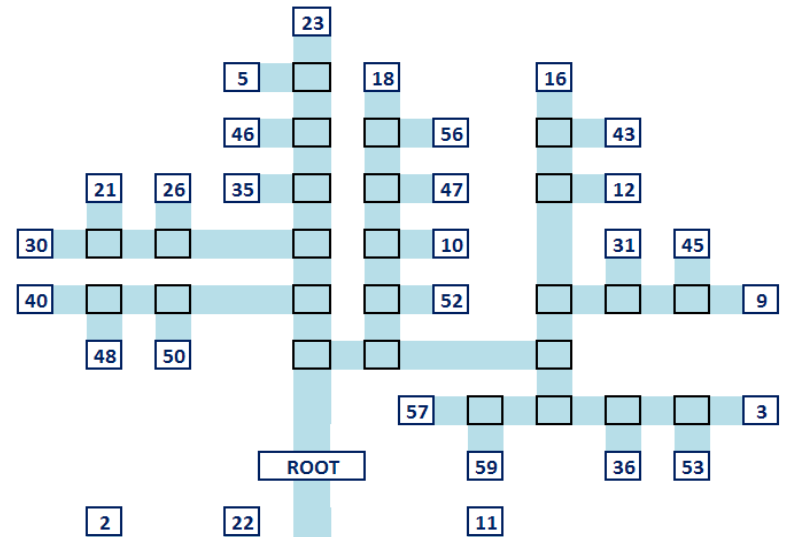

25

$\quad 19$
$28 \quad \square$

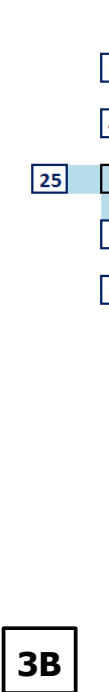

10

$51 \square$

\begin{tabular}{ll|l|l|}
6 & $\square$ & 8 & 7
\end{tabular}

$17 \square$

55

27

$54 \square \square$

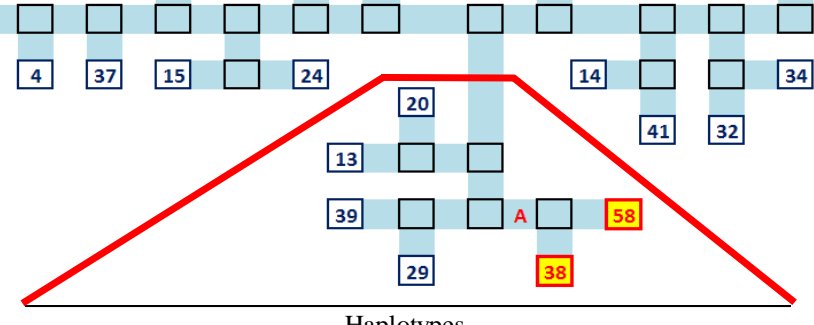

Haplotypes

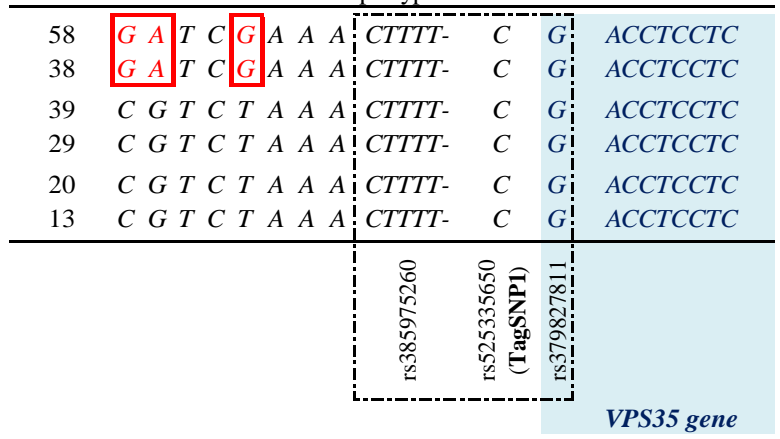

Figure 5.3 Haplotypes analyses characterizing the QTL region in SR cows. Figure 5.3A Phylogenetic tree of the 59 unique haplotypes, numbered in blue. In light blue, a branch of the tree. In black borders, bipartitions. In red and yellow, significant haplotypes at P-value $<0.05$. Figure 5. 3B relevant part of the sequences of significant versus other haplotypes. In red, differences between haplotypes. Dashed in black, strongest associations including TagSNP1. In light blue, the VPS35 gene. 
Eleven significant associations found by our GWAS were in agreement with associations found by the GWAS of Gregersen et al. (2015), who studied MCP properties but not NC milk. This agreement occurred with the following two traits: rennet gel strength measured 30 minutes after chymosin addition ( $\left.\mathbf{G}^{\mathbf{3}} \mathbf{3 0}\right)$, and rennet coagulation time (CTrennet). For G'30, associations agreed on BTA1, BTA13, BTA18, and BTA22. More specifically, these associations were: 4 SNP located between 70.75 and 70.90 MBP on BTA1; 5 SNP located between 58.10 and 58.14 MBP on BTA13; 1 SNP at 13.13MBP on BTA18; and 1 SNP located at 19.35 MBP on BTA22. The strong negative genetic correlation between NC milk and G'30 (-0.82; Gustavsson et al., 2014a) is likely to explain the agreement of results between both studies regarding G'30. For CTrennet, associations agreed on BTA18, and these were: 1 SNP located at 11.16 MBP, and 1 SNP located at 11.65 MBP. Gregersen et al. (2015) used (logtransformed) CTrennet in their GWAS, whereas we analyzed NC milk, a trait derived from CTrennet. Despite the use of different but CTrennet-related traits, it was unexpected to find only two associations in agreement between both studies. A reason for this little agreement might be caused by our approach to analyze NC milk, which dealt with the right-censored nature of coagulation time in a more suitable way (Cecchinato and Carnier, 2011).

An important aspect of our GWAS on BovineHD genotypes was the analyses of NC milk as a normally distributed trait despite its binary nature. Cecchinato and Carnier (2011) were the first authors to suggest this approach because NC milk samples have been consistently excluded from most analyses when observed (e.g., Ikonen et al., 2004; Gregersen et al., 2015). Cecchinato and Carnier (2011) showed that statistical models have difficulties to correctly account for NC milk, and suggested to score NC milk as a binary trait and include it as a normally distributed trait in linear mixed models. This option allows for analyses of NC milk without the exclusion of information. Following this approach, Gustavsson et al. (2014a) included NC milk as a binary trait in their analyses, and estimated genetic parameters for rennet-induced coagulation properties in SR cows. In addition, the inclusion of NC milk as a binary trait in our study could be one of the reasons why little overlap was found with the study by Gregersen et al. (2015) regarding CTrennet.

Besides their GWAS, Gregersen et al. (2015) found a suggestive QTL for the logtransformed G'30 trait by haplotypes analyses. This suggestive QTL was found in the interval located between 11.65 and 22.34 MBP on BTA18. Although not significant in their study, this suggestive QTL interval is in agreement with 9 out of 10 of our most significant SNP associated with NC milk on BTA18 (Table 5.1). In addition, the top 
SNP indicated by Gregersen et al. (2015) at 11.16 MBP is among our most significant SNP associated with NC milk.

Breeding for higher protein content in SR cows might lead to problems in the foreseeable future, suggested by the moderate, yet unfavorable genetic correlation between NC milk and protein content (Gustavsson et al., 2014a). Our main goal was to disentangle the effects of genetic variants of milk protein fractions from other genetic variants associated with NC milk. For this reason, we included a multi-locus genotype that combined the genetic variants of the main milk protein fractions (i.e., as1- $\beta-\mathrm{k-CN}$; "CNcluster") in our model. Bittante et al. (2012) reviewed the most important genetic factors that affect $\mathrm{MCP}$, indicating that $\mathrm{MCP}$, including $\mathrm{NC}$ milk, are strongly influenced by variable proportions, and genetic variants of milk protein fractions (especially of $\mathrm{k}-\mathrm{CN}$ ). These milk protein fractions, mainly representing caseins, are encoded on BTA6 and thus, the recombination among alleles is small (Bittante et al., 2012). In contrast, Tyrisevä et al. (2008) did not find significant associations between NC milk and the casein loci. In the present study, the casein loci were included as part of the design of our GWAS with NC milk, resulting in significant associations that are independent from the casein loci. This means that genes found by our study represent a new set of genes compared with the genes of the casein loci known to influence the prevalence of NC milk (e.g., Jensen et al., 2012; Gustavsson et al., 2014b).

\subsubsection{Imputation}

Imputation of SR cows was quite challenging because most of the variants were poorly imputed at sequence level when directly using the 429 WGS as reference population. As pointed out by Bouwman and Veerkamp (2014), breed-specific variants are best imputed by using a large single-breed reference population. This suggestion would mean that only 33 out of the 429 WGS would be of interest to impute our 382 SR cows to sequence level. The challenge of imputing a small breed like SR was overcome by running three different scenarios of imputation, and each time with a different reference population. The genotype that had the best imputation accuracy across the three scenarios was selected as the best-imputed genotype. The average accuracies of imputation using our approach were 0.79 for variants imputed with $A R 2 \geq 0.2$, and 0.93 for variants imputed with $A R 2 \geq 0.8$. While this is a slightly ad-hoc approach, there was good concordance between the three imputation scenarios and our subsequent focus on variants with AR2 $\geq 0.8$ adds further rigor to our analyses. 


\subsubsection{RWAS on imputed sequences for half of BTA18}

The RWAS on imputed sequences for half of BTA18 revealed many significant associations with NC milk (Supplementary Table 5.1). One of our three strongest associations, TagSNP1, explained almost $34 \%$ of the genetic variation and $14 \%$ of the phenotypic variance in NC milk (Figures 5.1A and 5.1B). This large fraction of genetic variance explained by TagSNP1 is independent of the casein loci on located on BTA6. Altogether, these findings strongly suggest the existence of at least one causal variant in our focus region distributed over $7 \mathrm{MBP}$ associated with NC milk. It might be plausible that one causal variant, i.e., 1 QTL is associated with NC milk in our focus region, although we cannot exclude the presence of multiple QTL in strong LD associated with NC milk in our focus region. Similar findings were found by Daetwyler et al. (2014) and Sahana et al. (2014). In their GWAS with imputed sequences, the considerable number of significant variants closely linked to each other increased the complexity of identifying a causal variant. In our study, we performed haplotype analyses to answer whether one or multiple QTL were present in the $7 \mathrm{MBP}$.

\subsubsection{Haplotype analyses}

Among the many advantages of haplotype over single-variant analyses (Balding, 2006), two of them are: a) haplotype analyses naturally account for the correlated structure between variants because all the genetic variation in a population is transmitted from parent to offspring through haplotypes (Clark, 2004); and b) haplotype analyses reduce the number of parameters tested in association studies as compared with single-variant analyses (e.g., Clark, 2004; Balding, 2006). In contrast, a "tagging" strategy would reduce the power gained from using haplotypes per se (Balding, 2006). In our study, this limitation was dealt with by using the TreeScan approach (Templeton et al., 2005). TreeScan considered two aspects simultaneously: the correlated structure of variants closely linked to each other, and the origin of this haplotype in the population through a phylogenetic tree. Using the TreeScan approach, 2 out of the 59 haplotypes were found to be associated with NC milk in our QTL region (Figure 5.3A). The two significant haplotypes had 3 SNP in common, and these SNP are located from 13.7 to $24.4 \mathrm{kbp}$ apart from TagSNP1 (Figure 5.3B). These findings support the presence of one QTL influencing NC milk in our focus region. Nonetheless, the task of identifying the causal variant remains challenging. According to Vasemägi and Primmer (2005), when an association between TagSNP1 and the causal variant is found, other linked associations can be responsible for the variation in the trait of interest. This might be our case since TagSNP1 was one out of three closely linked variants strongly associated with NC milk. 


\subsubsection{Bioinformatics and candidate genes}

Our three strongest association with NC milk are composed of 1 indel and 2 SNP. One of the 2 SNP ( $r$ 379827811) is an intron variant located between 15.04 MBP within the VPS35 gene (Figures 5.3B, Supplementary Figure 5.3A, and Supplementary Figure $5.3 \mathrm{~B})$. In humans, the VPS35 gene is a component of the retromer complex that mediates endosome-to-Golgi retrieval of membrane proteins such as the cationindependent mannose 6-phosphate receptor. According to Malik et al. (2015), cargoselective sorting is important for the correct sub-cellular destination of membrane proteins. The retromer complex mediated by VPS35 gene seems to promote the recycling of specific membrane proteins, such as $\beta 2$-adrenergic receptor and the glucose transporter GLUT1, directly back to plasma membrane (Seaman et al., 2013). It is important to mention that GLUT1 is the major glucose transporter in the basal membrane of epithelial cells and, in the mice mammary gland, its expression was increased when greater demand for glucose for the synthesis of lactose was needed (Anderson et al., 2007). If the recycling mechanism of the retromer complex is defective, it is possible that not enough membrane proteins are recycled, and in turn, are not available for milk synthesis.

A mutation in the VPS35 gene has been associated with Parkinson's disease (Zavodszky et al., 2014). In mice-models for Parkinson's disease, a VPS35 deficiency could contribute to retinal ganglion neuro-degeneration, leading to the blindness of many retinal degenerative disorders (Liu et al., 2014). In addition, Lemay et al. (2013) shows that the VPS35 gene is expressed throughout lactation in humans, which include colostrum, transitional, and mature milk, after they sequenced the mRNA found in milk fat layer. In Arabidopsis, the VPS35 gene has been associated with protein sorting and is involved in the plant growth and leaf senescence (Yamazaki et al., 2008). In addition, Munch et al. (2015) shows that a dysfunction in the VPS35 gene can contribute to immune-associated cell death in Arabidopsis. In cattle, Lemay et al. (2009) classified the mammary gene sets according to their condition and their developmental specific-stage, and showed that the VPS35 gene belonged to the mammary gene sets of pre-parturient and of lactating cows. The VPS35 gene has not been associated to non-coagulating milk yet.

\subsection{Conclusions}

The GWAS on BovineHD genotypes found significant associations with NC milk distributed over 7 MBP on BTA18 for SR cows. These 7 MBP contained 14 SNP that 
explained from $7 \%$ to $11 \%$ of phenotypic variation in NC milk. This large proportion of explained phenotypic variance is independent of the casein loci. To further characterize these $7 \mathrm{MBP}$, we ran a region-wide association study with imputed sequences. The significance of the associations increased from $-\log _{10}(P$-value $)$ $=10.18$ on BovineHD genotypes to $-\log _{10}($ Pvalue $)=14.12$ on imputed sequences. NC milk in SR cows was influenced by at least one QTL within these 7 MBP. A haplotype analyses identified 2 haplotypes that differed from the other 57 haplotypes at 3 SNP. These 3 SNP were located near to the strongest association identified by the regionwide association study with imputed sequences. For BTA18, haplotype analyses support the existence of one QTL underlying NC milk in SR cows. A candidate gene of interest is the VPS35 gene, for which one of our strongest association is an intronic SNP in this gene. It has been suggested that the VPS35 gene is involved in the recycling of specific membrane proteins, such as $\beta 2$ - adrenergic receptor and the glucose transporter GLUT1. The VPS35 gene belongs to the mammary gene sets of pre-parturient and of lactating cows, and has not been associated to NC milk yet.

\subsection{Author Contributions}

MG and MP coordinated the data collection and analysis of milk samples. MG, MP, WFF \& DJK designed and supervised the study. SID, DJK \& WFF analyzed the data and interpreted the results. SID, MG, DJK, MP, WFF wrote the manuscript. All authors revised and accepted the final version of the manuscript.

\subsection{List of abbreviations}

AR2 - beagle's accuracy of imputation;

BovineHD - 777,963 SNP genotypes

BTA - Bos taurus autosome

$\mathrm{CN}$ - caseins

CTrennet - rennet coagulation time

FAY - Finnish Ayrshire

G'30 - rennet gel strength measured 30 minutes after chymosin addition

GWAS - genome-wide association study

LD - linkage disequilibrium

$\mathrm{MAF}$ - minor allele frequency

$\mathrm{MBP}$ - mega base-pair

MCP - milk coagulation properties 
$\mathrm{NC}$ - non-coagulating

QTL - quantitative trait loci

RWAS - region-wide association study

SR - Swedish Red

TagSNP1- most significant association retrieved from RWAS

Ve!P - variant effect predictor

WGS - whole-genome sequences

\subsection{Acknowledgements}

SID currently benefits from a joint-grant from the European Commission [within the framework of the Erasmus-Mundus joint doctorate "EGS-ABG" (Paris, France) and Breed4Food (a public-private partnership in the domain of animal breeding and genomics and CRV]. Further, the authors wish to thank the Swedish Farmer's Foundation for Agricultural Research (SLF), Stockholm, Sweden for financial support as well as Dr. Frida Gustavsson, Lund University, Sweden for milk collection and analyses of coagulation data. DJK \& WFF acknowledges Mistra Biotech, a research program financed by Mistra - Stiftelsen för miljoöstrategisk forskning and SLU.

\subsection{Conflict of Interest Statement}

The authors declare that the research was conducted in the absence of any commercial or financial relationships that could be construed as a potential conflict of interest.

\subsection{References}

Anderson, S. M., Rudolph, M. C., McManaman, J. L., and Neville, M. C. (2007). Secretory activation in the mammary gland: it's not just about milk protein synthesis. Breast Cancer Res 9:204-217. doi:10.1186/bcr1653.

Auldist, M. J., Johnston, K. A., White, N. J., Fitzsimons, W. P., and Boland, M. J. (2004). A comparison of the composition, coagulation characteristics and cheesemaking capacity of milk from Friesian and Jersey dairy cows. J Dairy Res 71:51-57.

Aulchenko, Y. S., Ripke, S., Isaacs, A., and Van Duijn, C. M. (2007). GenABEL: an R library for genome-wide association analysis. Bioinformatics 23, 1294-1296. doi:10.1093/bioinformatics/btm108. 
Balding, D. J. (2006). A tutorial on statistical methods for population associationstudies. Nature Rev Genet 7, 781-791.

Bittante, G., Penasa, M., and Cecchinato, A. (2012). Invited review: Genetics and modeling of milk coagulation properties. J Dairy Sci 95, 6843-6870. doi:10.3168/jds.2012-5507.

Browning, S. R., and Browning, B. L. (2007). Rapid and accurate haplotype phasing and missing-data inference for whole-genome association studies by use of localized haplotype clustering. Am J Hum Genet 81, 1084-1097. doi:10.1086/521987.

Bouwman, A. C., and Veerkamp, R. F. (2014). Consequences of splitting wholegenome sequencing effort over multiple breeds on imputation accuracy. BMC genet 15, 105. doi:10.1186/s12863-014-0105-8.

Calus, M. P. L. (2013). Calc_grm-A programme to compute pedigree, genomic, and combined relationship matrices. Animal Breeding and Genomics Centre, Wageningen UR Livestock Research, Wageningen, Netherlands.

Cassandro, M., Comin, A., Ojala, M., Dal Zotto, R., De Marchi, M., Gallo, L., et al. (2008). Genetic parameters of milk coagulation properties and their relationships with milk yield and quality traits in Italian Holstein cows. J Dairy Sci 91:371-376.

Cecchinato, A., De Marchi, M., Gallo, L., Bittante, G., and Carnier, P. (2009). Midinfrared spectroscopy predictions as indicator traits in breeding programs for enhanced coagulation properties of milk. J Dairy Sci 92, 5304-5313. doi:10.3168/jds.2009-2246.

Cecchinato, A., and Carnier, P. (2011). Short communication: statistical models for the analysis of coagulation traits using coagulating and noncoagulating milk information. J Dairy Sci 94, 4214-4219. doi:10.3168/jds.2010-3911.

Cecchinato, A., Penasa, M., De Marchi, M., Gallo, L., Bittante, G., and Carnier, P. (2011). Genetic parameters of coagulation properties, milk yield, quality, and acidity: estimated using coagulating milk and noncoagulating information in Brown Swiss and Holstein cows. J Dairy Sci 94, 4205-4213. doi:10.3168/jds.2010-3913.

Chilliard, Y., Ferlay, A., and Doreau, M. (2001). Effect of different types of forages, animal fat or marine oils in cow's diet on milk fat secretion and composition, especially conjugated linoleic acid (CLA) and polyunsaturated fatty acids. Livest Prod Sci 70, 31-48. doi:10.1016/S0301-6226(01)00196-8.

Clark, A. G. (2004). The role of haplotypes in candidate-gene studies. Genet Epidemiol 27, 321-333.

Danecek, P., Auton, A., Abecasis, G., Albers, C. A., Banks, E., DePristo, M. A., et al. (2011). The variant call format and VCFtools. Bioinformatics 27, 2156-2158. doi:10.1093/bioinformatics/btr330 
Daetwyler, H. D., Capitan, A., Pausch, H., Stothard, P., van Binsbergen, R., Brøndum, R. F., et al. (2014). Whole-genome sequencing of 234 bulls facilitates mapping of monogenic and complex traits in cattle. Nat Genet 46, 858-865. doi:10.1038/ng.3034.

De Marchi, M., Dal Zotto, R., Cassandro, M., and Bittante, G. (2007). Milk coagulation ability of five dairy cattle breeds. J Dairy Sci 90, 3986-3992. doi:10.3168/jds.2006627.

Druet, T., Macleod, I. M., and Hayes, B. J. (2014). Toward genomic prediction from whole-genome sequence data: impact of sequencing design on genotype imputation and accuracy of predictions. Heredity (Edinb) 112, 39-47. doi:10.1038/hdy.2013.13.

Frederiksen, P. D., Andersen, K. K., Hammershøj, M., Poulsen, H. D., Sørensen, J., Bakman, M., et al. (2011). Composition and effect of blending of noncoagulating, poorly coagulating, and well-coagulating bovine milk from individual Danish Holstein cows. J Dairy Sci 94, 4787-4799. doi:10.3168/jds.2011-4343.

Gilmour, A. R., Gogel, B., Cullis, B., and Thompson, R. (2009). ASReml user guide, release 3.0. VSN International Ltd., Hemel Hempstead, UK.

Gregersen, V. R., Gustavsson, F., Glantz, M., Christensen, O. F., Stålhammar, H., Andrén, A., et al. (2015). Bovine chromosomal regions affecting rheological traits in rennet-induced skim milk gels. J Dairy Sci 98, 1261-1272. doi:10.3168/jds.20148136.

Gustavsson, F., Glantz, M., Poulsen, N. A., Wadsö, L., Stålhammar, H., Andrén, A., et al. (2014a). Genetic parameters for rennet- and acid-induced coagulation properties in milk from Swedish Red dairy cows. J Dairy Sci 97, 5219-5229. doi:10.3168/jds.2014-7996.

Gustavsson, F., Buitenhuis, A. J., Glantz, M., Stålhammar, H., Lindmark-Månsson, H., Poulsen, N. A., et al. (2014b). Impact of genetic variants of milk proteins on chymosin-induced gelation properties of milk from individual cows of Swedish Red dairy cattle. Int Dairy J 39, 102-107. doi:10.1016/j.idairyj.2014.05.007.

Hallén, E., Allmere, T., Näslund, J., Andrén, A., and Lundén, A. (2007). Effect of genetic polymorphism of milk proteins on rheology of chymosin-induced milk gels. Int Dairy J 17, 791-799. doi:10.1016/j.idairyj.2006.09.011.

Hallén, E., Lundén, A., Tyrisevä, A. M., Westerlind, M., and Andrén, A. (2010). Composition of poorly and non-coagulating bovine milk and effect of calcium addition. J Dairy Res 77:398-403.

Ikonen, T., Morri, S., Tyrisevä, A-M., Ruottinen, O., and Ojala, M. (2004). Genetic and phenotypic correlations between milk coagulation properties, milk production traits, somatic cell count, casein content, and pH of milk. J Dairy Sci 87, 458-467. 
Jensen, H. B., Poulsen, N. A, Andersen, K. K., Hammershøj, M., Poulsen, H. D., and Larsen, L. B. (2012). Distinct composition of bovine milk from Jersey and HolsteinFriesian cows with good, poor, or noncoagulation properties as reflected in protein genetic variants and isoforms. J Dairy Sci 95, 6905-17. doi:10.3168/jds.2012-5675. Kumar, S., Tamura, K., and Nei, M. (1994). MEGA: Molecular Evolutionary Genetics Analysis software for microcomputers. Comput Appl Biosci 10, 189-191. doi:10.1093/bioinformatics/10.2.189.

LRF Dairy Sweden. 2015. http://www.Irf.se/globalassets/dokument/omIrf/branscher/Irf-mjolk/statistik/milk_key_figures_sweden.pdf, accessed on Nov 3rd, 2015.

Lemay, D. G., Ballard, O. A., Hughes, M. A., Morrow, A. L., Horseman, N. D., and Nommsen-Rivers, L. A. (2013). RNA sequencing of the human milk fat layer transcriptome reveals distinct gene expression profiles at three stages of lactation. PLoS One 8, e67531. doi:10.1371/journal.pone.0067531.

Lemay, D. G., Lynn, D. J., Martin, W. F., Neville, M. C., Casey, T. M., Rincon, G., et al. (2009). The bovine lactation genome: insights into the evolution of mammalian milk. Genome Biol 10, R43. doi:10.1186/gb-2009-10-4-r43.

Liu, W., Tang, F., Erion, J., and Xiao, H. (2014). VPS35 haploinsufficiency results in degenerative-like deficit in mouse retinal ganglion neurons and impairment of optic nerve injury-induced gliosis. Mol Brain 7, 1-11.

Malik, B. R., Godena, V. K., and Whitworth, A. J. (2015). VPS35 pathogenic mutations confer no dominant toxicity but partial loss of function in Drosophila and genetically interact with parkin. Hum Mol Genet 24:6106-6117. 10.1093/hmg/ddv322

McLaren, W., Pritchard, B., Rios, D., Chen, Y., Flicek, P., and Cunningham, F. (2010). Deriving the consequences of genomic variants with the Ensembl API and SNP Effect Predictor. Bioinformatics 26, 2069-2070. doi:10.1093/bioinformatics/btq330.

Meuwissen, T., and Goddard, M. (2010). Accurate prediction of genetic values for complex traits by whole-genome resequencing. Genetics 185, 623-631. doi:10.1534/genetics.110.116590.

Munch, D., Teh, O.-K., Malinovsky, F. G., Liu, Q., Vetukuri, R. R., El Kasmi, F., et al. (2015). Retromer contributes to immunity-associated cell death in Arabidopsis. Plant Cell Online 27,463-479. tpc.114.132043. doi:10.1105/tpc.114.132043.

Nájera, A. I., De Renobales, M., and Barron, L. J. R. (2003). Effects of pH, temperature, $\mathrm{CaCl} 2$ and enzyme concentrations on the rennet-clotting properties of milk: a multifactorial study. Food Chem 80:345-352. doi:10.1016/S0308-8146(02)002704. 
Nordic Cattle Genetic Evaluation, 2013.NAV - routine genetic evaluation of dairy cattle - data and genetic models. Available online at: http://www.nordicebv.info/wp-content/uploads/2015/04/General-description from-old-homepage 06052015.pdf.

Okigbo, L. M., Richardson, G. H., Brown, R. J., and Ernstrom, C. A. (1985a). Variation in Coagulation Properties of Milk from Individual Cows 1, 2. J Dairy Sci 68:822-828. doi:10.3168/jds.S0022-0302(85)80899-7.

Okigbo, L. M., Richardson, G. H., Brown, R. J., and Ernstrom, C. A. (1985b). Casein composition of cow's milk of different chymosin coagulation properties. J Dairy Sci 68:1887-1892. doi:10.3168/jds.S0022-0302(85)81045-6.

Ostersen, S., Foldager, J., and Hermansen, J. E. (1997). Effects of stage of lactation, milk protein genotype and body condition at calving on protein composition and renneting properties of bovine milk. J Dairy Res 64 :207-219.

Penasa, M., Cassandro, M., Pretto, D., De Marchi, M., Comin, A., Chessa, S., et al. (2010). Short communication: Influence of composite casein genotypes on additive genetic variation of milk production traits and coagulation properties in Holstein-Friesian cows. J Dairy Sci 93:3346-3349. doi:10.3168/jds.2010-3164.

Purcell, S., Neale, B., Todd-Brown, K., Thomas, L., Ferreira, M. A. R., Bender, D., et al. (2007). PLINK: a tool set for whole-genome association and population-based linkage analyses. Am J Hum Genet 81, 559-575. doi:10.1086/519795.

Sahana, G., Guldbrandtsen, B., Thomsen B., Holm, L.-E., Panitz, F., Brøndum, R. F., et al. (2014). Genome-wide association study using high-density single nucleotide polymorphism arrays and whole-genome sequences for clinical mastitis traits in dairy cattle. J Dairy Sci 97, 7258-7275. doi:10.3168/jds.2014-8141.

Saitou, N., and Nei, M. (1987).The neighbor-joining method: a new method for reconstructing phylogenetic trees. Mol Biol Evol 4, 406-425.

Seaman, M. N., Gautreau, A., \& Billadeau, D. D. (2013). Retromer-mediated endosomal protein sorting: all WASHed up! Trends Cell Biol 23:522-528. 10.1016/j.tcb.2013.04.010

Schwarz, G., and Mumm, H. (1948). The effects of adding calcium chloride potassium nitrate or sodium nitrate to the cheese milk during Tilsit cheese making. Süddeutsche Molkereizeitung, 69:160-161.

Tamura, K., Stecher, G., Peterson, D., Filipski, A., and Kumar, S. (2013). MEGA6: Molecular evolutionary genetics analysis version 6.0. Mol Biol Evol 30, 2725-2729. doi:10.1093/molbev/mst197.

Templeton, A. R., Maxwell, T., Posada, D., Stengård, J. H., Boerwinkle, E., and Sing, C. F. (2005). Tree scanning: A method for using haplotype trees in 
phenotype/genotype association studies. Genetics 169, 441-453. doi:10.1534/genetics.104.030080.

Tyrisevä, A. M., Elo, K., Kuusipuro, A., Vilva, V., Jänönen, I., Karjalainen, H., et al. (2008). Chromosomal regions underlying noncoagulation of milk in Finnish Ayrshire cows. Genetics 180, 1211-1220. doi:10.1534/genetics.107.083964.

Van Hooydonk, A. C. M., Hagedoorn, H. G., and Boerrigter, I. J. (1986). The effect of various cations on the renneting of milk. Neth Milk Dairy J 40:369-390.

Vasemägi, A., and Primmer, C. R. (2005). Invited review - Challenges for identifying functionally important genetic variation:the promise of combining complementary research strategies. Mol Ecol 14, 3623-3642. doi: 10.1111/j.1365294X.2005.02690.x.

Wickham, H. (2009). Ggplot2: elegant graphics for data analysis. Springer Science \& Business Media, New York, USA.

Wilmink, J. B. M. (1987). Adjustment of test-day milk, fat and protein yield for age, season and stage of lactation. Livest Prod Sci 16, 335-348. doi:10.1016/03016226(87)90003-0.

Yamazaki, M., Shimada, T., Takahashi, H., Tamura, K., Kondo, M., Nishimura, M., et al. (2008). Arabidopsis VPS35, a retromer component, is required for vacuolar protein sorting and involved in plant growth and leaf senescence. Plant Cell Physiol 49, 142-156. doi:10.1093/pcp/pcn006.

Zavodszky, E., Seaman, M. N. J., Moreau, K., Jimenez-Sanchez, M., Breusegem, S. Y., Harbour, M. E., et al. (2014). Mutation in VPS35 associated with Parkinson's disease impairs WASH complex association and inhibits autophagy. Nat Commun 5, 3828. doi:10.1038/ncomms4828.

Zimin, A. V., Delcher, A. L., Florea, L., Kelley, D. R., Schatz, M. C., Puiu, D., et al. (2009). A whole-genome assembly of the domestic cow, Bos taurus. Genome Biol 10, R42. doi:10.1186/gb-2009-10-4-r42. 


\subsection{Supplementary Files}

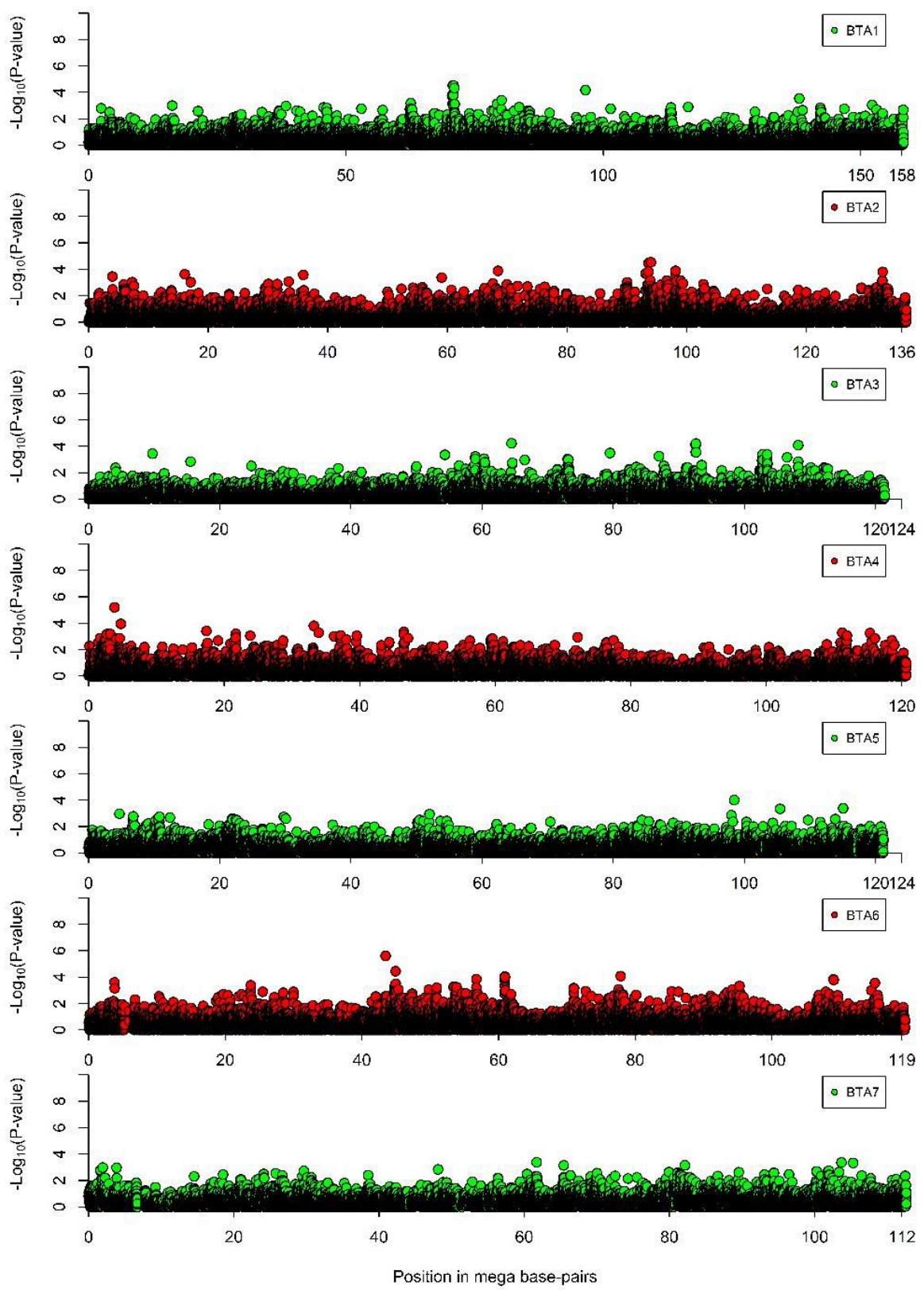

Supplementary Figure 5.1 A Genome-wide association study using 777,963 SNP genotypes affecting non-coagulating milk in Swedish Red cows for BTA1 through BTA7 


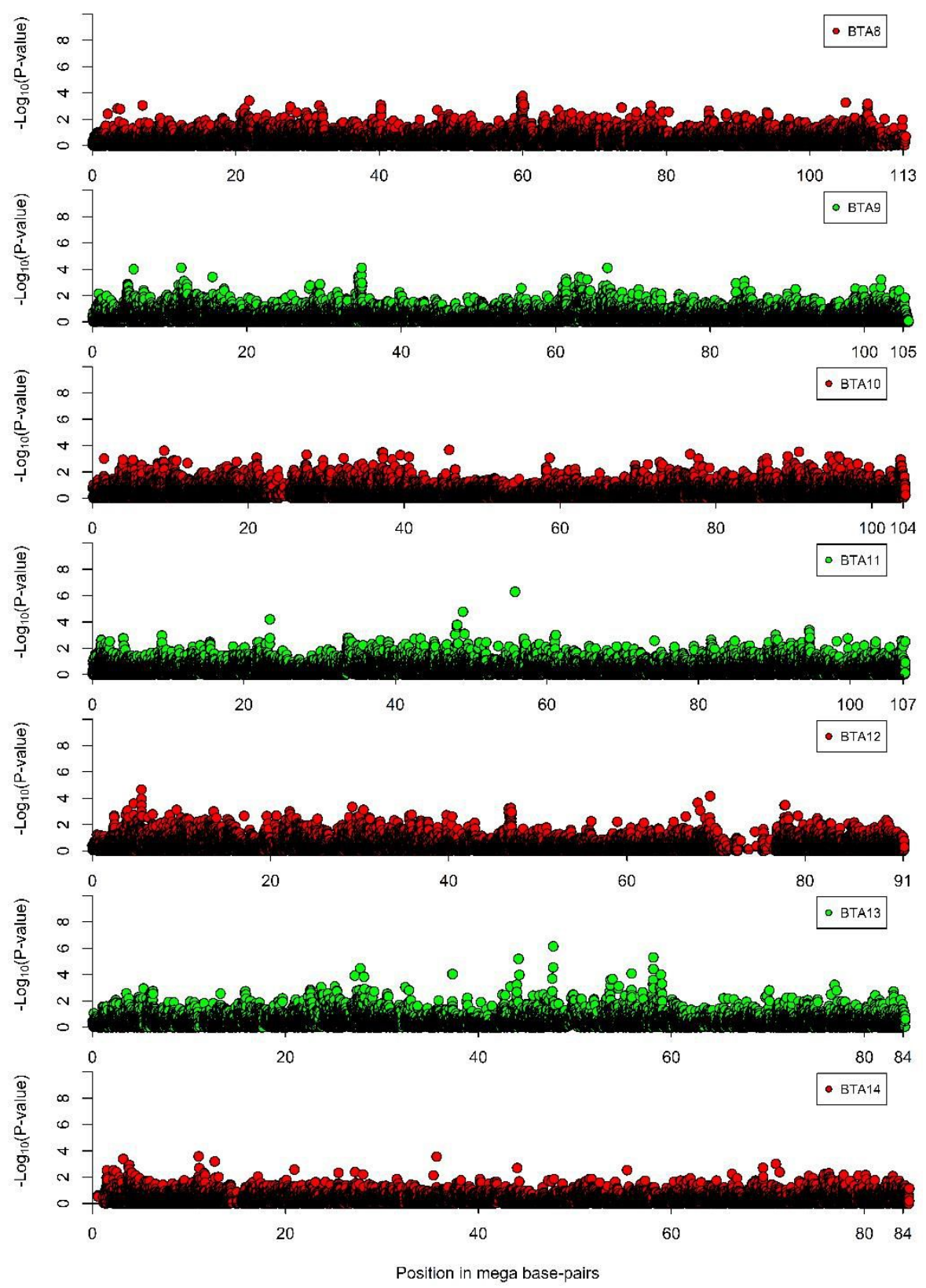

Supplementary Figure 5.1 B Genome-wide association study using 777,963 SNP genotypes affecting non-coagulating milk in Swedish Red cows for BTA8 through BTA14. 


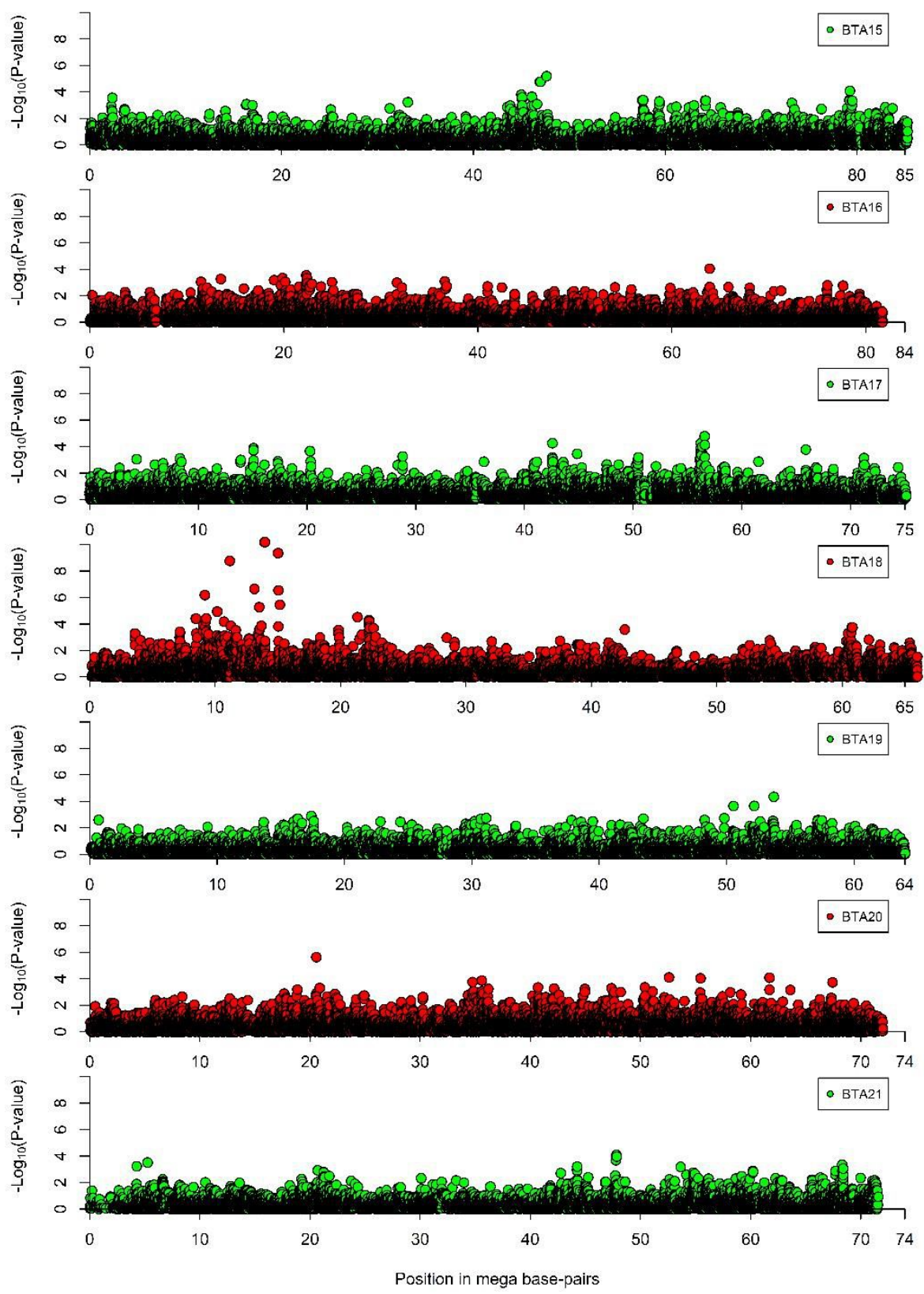

Supplementary Figure 5.1 C Genome-wide association study using 777,963 SNP genotypes affecting non-coagulating milk in Swedish Red cows for BTA15 through BTA21. 


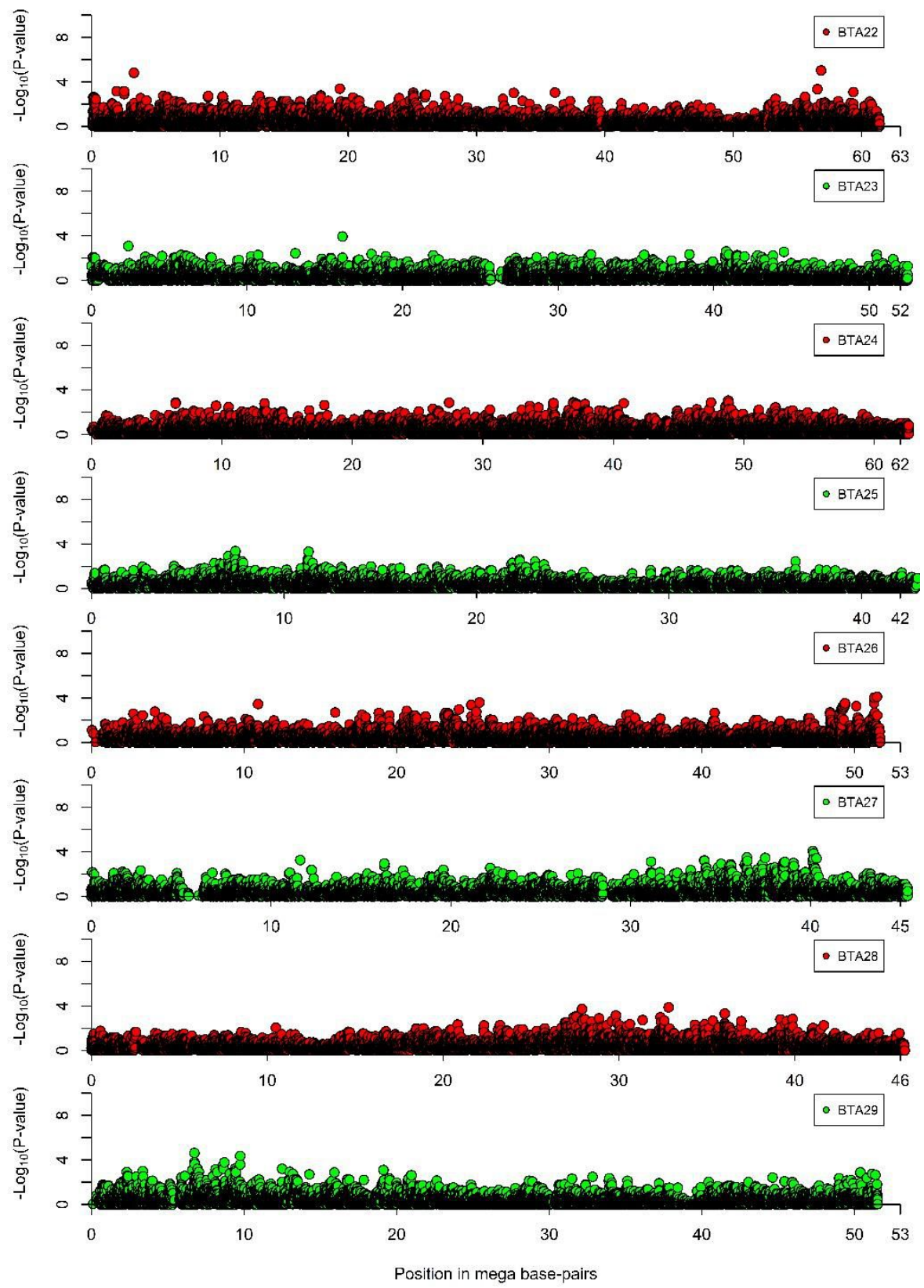

Supplementary Figure 5.1 D Genome-wide association study using 777,963 SNP genotypes affecting non-coagulating milk in Swedish Red cows for BTA22 through BTA29. 


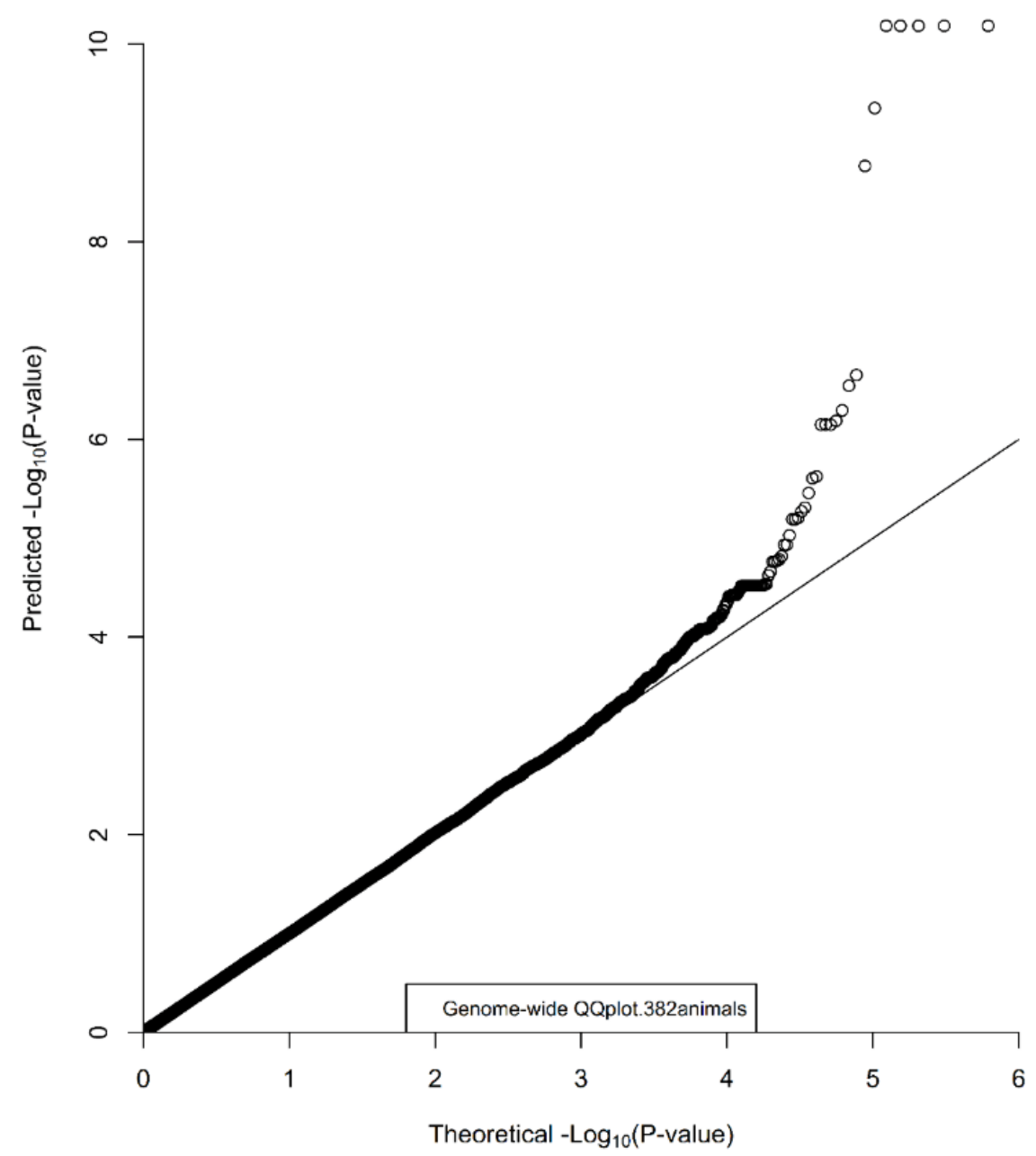

Supplementary Figure 5.2 Genome-wide QQ-Plot for the GWAS with NC milk based on 777,963 SNP genotypes and 382 Swedish Red Cows. 


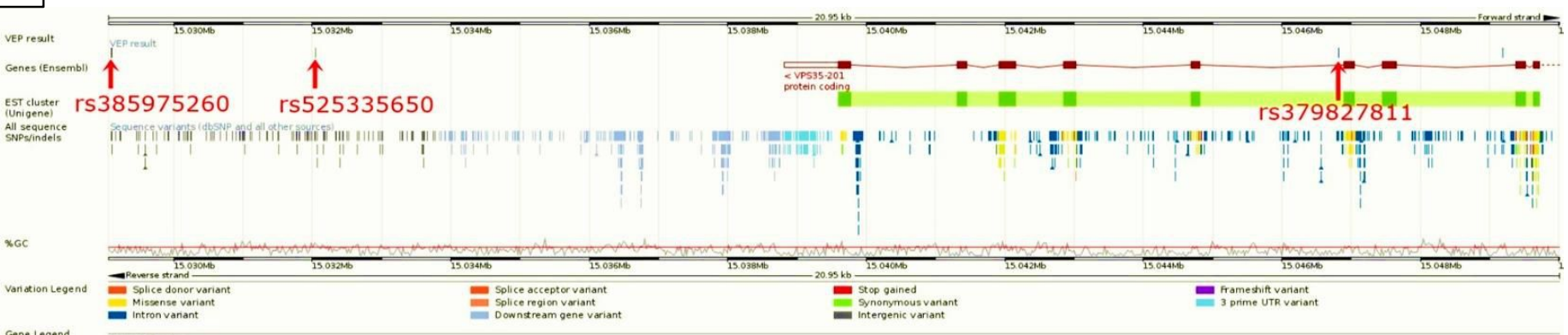

Protein Coding

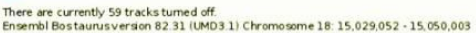

VEP res Genes IEnsem

EST cluster
[Unigenel

variontegent

Variation Legen

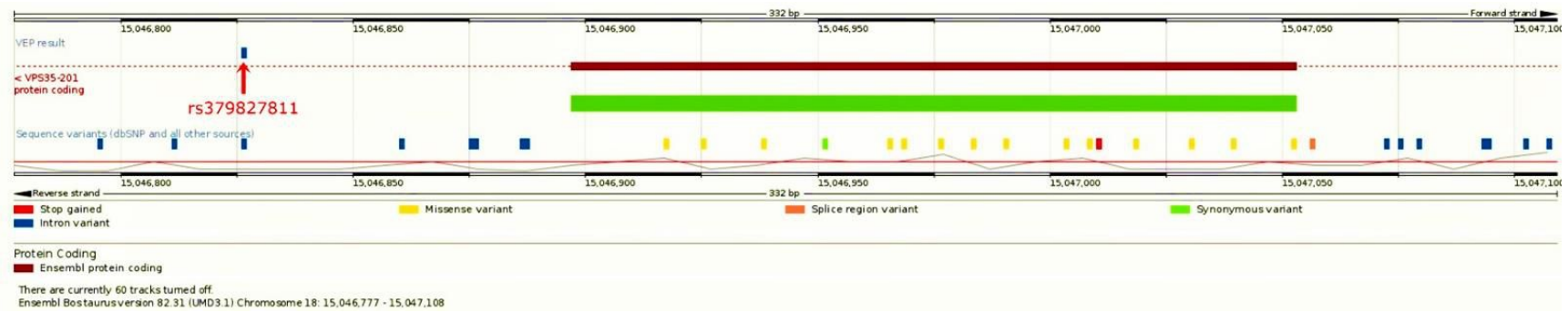

Supplementary Figure 5.3. Views from Ensembl (http://www.ensembl.org) of strongest associations. (A) Genomic location of rs385975260, rs525335650 (TagSNP1), and rs379827811. (B) rs379827811 as intron variant to the VPS35 gene. 
Supplementary Table 5.1. Region-wide association study: list of most significant variants associated with non-coagulating (NC) ${ }^{\dagger}$ milk in Swedish Red cows

\begin{tabular}{|c|c|c|c|c|c|}
\hline Chromosome & $\begin{array}{l}\text { Name of } \\
\text { variant }\end{array}$ & $\begin{array}{l}-\log _{10} \\
\text { (Pvalue) }\end{array}$ & $\mathrm{AR} 2^{\S}$ & $\sigma_{\text {marker }}^{2}$ & $\sigma_{\text {marker }}^{2} / \sigma_{p}^{2}$ \\
\hline 18 & $18: 9179338$ & 6.11 & 0.80 & 0.01 & 0.07 \\
\hline 18 & 18:9179437 & 6.11 & 0.82 & 0.01 & 0.07 \\
\hline 18 & 18:9179455 & 6.11 & 0.83 & 0.01 & 0.07 \\
\hline 18 & 18:9179462 & 6.11 & 0.83 & 0.01 & 0.07 \\
\hline 18 & 18:9179471 & 6.11 & 0.81 & 0.01 & 0.07 \\
\hline 18 & 18:9179491 & 6.11 & 0.82 & 0.01 & 0.06 \\
\hline 18 & $18: 9179500$ & 6.11 & 0.82 & 0.01 & 0.06 \\
\hline 18 & 18:9179561 & 6.11 & 0.91 & 0.01 & 0.06 \\
\hline 18 & $18: 9179563$ & 6.11 & 0.91 & 0.01 & 0.06 \\
\hline 18 & 18:9179722 & 6.11 & 1.00 & 0.01 & 0.07 \\
\hline 18 & 18:9179819 & 6.11 & 0.99 & 0.01 & 0.07 \\
\hline 18 & 18:9179826 & 6.11 & 1.00 & 0.01 & 0.07 \\
\hline 18 & 18:9179834 & 6.11 & 1.00 & 0.01 & 0.07 \\
\hline 18 & 18:9180145 & 6.11 & 0.99 & 0.01 & 0.07 \\
\hline 18 & 18:9180426 & 6.11 & 0.99 & 0.01 & 0.07 \\
\hline 18 & 18:9180513 & 6.11 & 0.99 & 0.01 & 0.07 \\
\hline 18 & 18:9180543 & 6.11 & 0.99 & 0.01 & 0.07 \\
\hline 18 & 18:9180617 & 6.11 & 0.99 & 0.01 & 0.07 \\
\hline 18 & 18:9180637 & 6.11 & 0.99 & 0.01 & 0.07 \\
\hline 18 & $18: 9181238$ & 6.11 & 0.99 & 0.01 & 0.07 \\
\hline 18 & 18:9181315 & 6.11 & 0.99 & 0.01 & 0.07 \\
\hline 18 & 18:9181629 & 6.11 & 0.99 & 0.01 & 0.07 \\
\hline 18 & 18:9181646 & 6.11 & 0.99 & 0.01 & 0.07 \\
\hline 18 & 18:9182405 & 6.11 & 0.81 & 0.01 & 0.08 \\
\hline 18 & $18: 9214353$ & 6.59 & 0.85 & 0.01 & 0.08 \\
\hline 18 & 18:9215169 & 6.59 & 0.96 & 0.01 & 0.07 \\
\hline 18 & 18:9215335 & 6.59 & 0.86 & 0.01 & 0.08 \\
\hline 18 & 18:9215376 & 6.59 & 0.96 & 0.01 & 0.07 \\
\hline 18 & 18:9215787 & 6.59 & 0.96 & 0.01 & 0.07 \\
\hline 18 & $18: 9215948$ & 6.59 & 0.96 & 0.01 & 0.07 \\
\hline
\end{tabular}




\begin{tabular}{|c|c|c|c|c|c|}
\hline Chromosome & $\begin{array}{c}\text { Name of } \\
\text { variant }\end{array}$ & $\begin{array}{c}-\log _{10} \\
\text { (Pvalue) }\end{array}$ & $\mathrm{AR} 2^{\S}$ & $\sigma_{\text {marker }}^{2}$ & $\sigma_{\text {marker }}^{2} / \sigma_{p}^{2}$ \\
\hline 18 & 18:9216194 & 6.59 & 0.96 & 0.01 & 0.07 \\
\hline 18 & 18:11166809 & 8.66 & 1.00 & 0.01 & 0.09 \\
\hline 18 & $18: 13136070$ & 6.61 & 0.83 & 0.01 & 0.07 \\
\hline 18 & 18:13136171 & 6.61 & 1.00 & 0.01 & 0.07 \\
\hline 18 & $18: 13137293$ & 6.61 & 0.95 & 0.01 & 0.07 \\
\hline 18 & $18: 13138676$ & 6.61 & 0.95 & 0.01 & 0.07 \\
\hline 18 & $18: 13142955$ & 6.61 & 0.90 & 0.01 & 0.07 \\
\hline 18 & $18: 13145923$ & 6.61 & 0.90 & 0.01 & 0.07 \\
\hline 18 & $18: 13146013$ & 6.61 & 0.90 & 0.01 & 0.07 \\
\hline 18 & $18: 13146020$ & 6.61 & 0.90 & 0.01 & 0.07 \\
\hline 18 & 18:13146999 & 6.61 & 0.90 & 0.01 & 0.07 \\
\hline 18 & 18:13147063 & 6.61 & 0.90 & 0.01 & 0.07 \\
\hline 18 & $18: 13147747$ & 6.61 & 0.90 & 0.01 & 0.07 \\
\hline 18 & 18:13149017 & 6.61 & 0.90 & 0.01 & 0.07 \\
\hline 18 & 18:13149305 & 6.61 & 0.90 & 0.01 & 0.07 \\
\hline 18 & $18: 13151402$ & 6.61 & 0.86 & 0.01 & 0.07 \\
\hline 18 & 18:13151967 & 6.61 & 0.86 & 0.01 & 0.07 \\
\hline 18 & $18: 13152843$ & 6.61 & 0.86 & 0.01 & 0.07 \\
\hline 18 & 18:13155943 & 6.61 & 0.83 & 0.01 & 0.07 \\
\hline 18 & $18: 13175633$ & 6.93 & 0.90 & 0.01 & 0.07 \\
\hline 18 & $18: 13175950$ & 6.93 & 0.89 & 0.01 & 0.07 \\
\hline 18 & 18:13391752 & 9.84 & 0.83 & 0.02 & 0.11 \\
\hline 18 & 18:13391841 & 9.84 & 0.83 & 0.02 & 0.11 \\
\hline 18 & 18:13393733 & 9.84 & 0.85 & 0.01 & 0.11 \\
\hline 18 & $18: 13403337$ & 10.57 & 0.83 & 0.02 & 0.11 \\
\hline 18 & $18: 13403968$ & 9.37 & 0.87 & 0.01 & 0.10 \\
\hline 18 & $18: 13405460$ & 9.37 & 0.87 & 0.01 & 0.10 \\
\hline 18 & $18: 13408106$ & 10.57 & 0.85 & 0.02 & 0.11 \\
\hline 18 & 18:13409996 & 10.57 & 0.84 & 0.01 & 0.10 \\
\hline 18 & $18: 13450556$ & 10.77 & 0.80 & 0.02 & 0.11 \\
\hline 18 & $18: 13453819$ & 10.77 & 0.82 & 0.01 & 0.10 \\
\hline
\end{tabular}


(continuation)

\begin{tabular}{|c|c|c|c|c|c|}
\hline Chromosome & $\begin{array}{l}\text { Name of } \\
\text { variant }\end{array}$ & $\begin{array}{c}-\log _{10} \\
\text { (Pvalue) }\end{array}$ & $\mathrm{AR} 2^{\S}$ & $\sigma_{\text {marker }}^{2}$ & $\sigma_{\text {marker }}^{2} / \sigma_{p}^{2}$ \\
\hline 18 & $18: 13454607$ & 10.77 & 0.95 & 0.02 & 0.11 \\
\hline 18 & $18: 13839520$ & 10.08 & 0.80 & 0.01 & 0.09 \\
\hline 18 & $18: 13840950$ & 6.02 & 0.86 & 0.01 & 0.07 \\
\hline 18 & $18: 13934348$ & 10.08 & 0.84 & 0.02 & 0.11 \\
\hline 18 & $18: 13934429$ & 10.08 & 0.82 & 0.01 & 0.10 \\
\hline 18 & 18:13934546 & 10.08 & 0.87 & 0.02 & 0.11 \\
\hline 18 & 18:13934657 & 10.08 & 0.93 & 0.01 & 0.10 \\
\hline 18 & $18: 13934670$ & 10.08 & 0.95 & 0.02 & 0.11 \\
\hline 18 & $18: 13934856$ & 10.08 & 1.00 & 0.01 & 0.11 \\
\hline 18 & 18:13934858 & 10.08 & 0.97 & 0.02 & 0.11 \\
\hline 18 & 18:13934872 & 10.08 & 0.97 & 0.01 & 0.11 \\
\hline 18 & 18:13934903 & 10.08 & 0.94 & 0.02 & 0.11 \\
\hline 18 & 18:13934926 & 10.08 & 0.95 & 0.02 & 0.11 \\
\hline 18 & 18:13935065 & 10.08 & 0.95 & 0.02 & 0.11 \\
\hline 18 & 18:13935102 & 10.08 & 0.94 & 0.02 & 0.11 \\
\hline 18 & 18:13935106 & 10.08 & 0.94 & 0.02 & 0.11 \\
\hline 18 & 18:13935269 & 10.08 & 0.92 & 0.01 & 0.10 \\
\hline 18 & $18: 13935300$ & 10.08 & 0.93 & 0.01 & 0.11 \\
\hline 18 & 18:13935356 & 10.08 & 0.84 & 0.01 & 0.11 \\
\hline 18 & $18: 13935590$ & 10.08 & 0.90 & 0.02 & 0.11 \\
\hline 18 & 18:13938211 & 10.08 & 0.86 & 0.02 & 0.11 \\
\hline 18 & 18:13938277 & 10.08 & 0.90 & 0.01 & 0.10 \\
\hline 18 & $18: 13938283$ & 10.08 & 0.90 & 0.01 & 0.10 \\
\hline 18 & 18:13938291 & 10.08 & 0.91 & 0.01 & 0.10 \\
\hline 18 & 18:13938461 & 10.08 & 0.85 & 0.01 & 0.09 \\
\hline 18 & 18:13938602 & 10.08 & 0.99 & 0.02 & 0.11 \\
\hline 18 & $18: 13938614$ & 10.08 & 0.99 & 0.02 & 0.11 \\
\hline 18 & $18: 13938680$ & 10.08 & 0.99 & 0.02 & 0.11 \\
\hline 18 & 18:13938708 & 10.08 & 0.95 & 0.01 & 0.10 \\
\hline 18 & 18:13938871 & 10.08 & 0.99 & 0.02 & 0.11 \\
\hline 18 & 18:13938963 & 10.08 & 1.00 & 0.02 & 0.11 \\
\hline
\end{tabular}




\begin{tabular}{|c|c|c|c|c|c|}
\hline Chromosome & $\begin{array}{c}\text { Name of } \\
\text { variant }\end{array}$ & $\begin{array}{c}-\log _{10} \\
\text { (Pvalue) }\end{array}$ & $\mathrm{AR} 2^{\S}$ & $\sigma_{\text {marker }}^{2}$ & $\sigma_{\text {marker }}^{2} / \sigma_{p}^{2}$ \\
\hline 18 & 18:13939032 & 10.08 & 0.95 & 0.01 & 0.10 \\
\hline 18 & 18:13939085 & 10.08 & 0.91 & 0.01 & 0.10 \\
\hline 18 & 18:13939109 & 10.08 & 0.96 & 0.01 & 0.10 \\
\hline 18 & $18: 13939170$ & 10.08 & 1.00 & 0.01 & 0.11 \\
\hline 18 & $18: 13939213$ & 10.08 & 0.96 & 0.01 & 0.10 \\
\hline 18 & 18:13939414 & 10.08 & 1.00 & 0.01 & 0.11 \\
\hline 18 & 18:13939492 & 10.08 & 0.96 & 0.01 & 0.10 \\
\hline 18 & 18:13939541 & 10.08 & 0.89 & 0.01 & 0.10 \\
\hline 18 & $18: 13940296$ & 10.08 & 0.96 & 0.02 & 0.11 \\
\hline 18 & $18: 13941584$ & 10.08 & 0.89 & 0.01 & 0.10 \\
\hline 18 & 18:13941841 & 10.08 & 0.91 & 0.01 & 0.11 \\
\hline 18 & 18:13942012 & 10.08 & 0.90 & 0.01 & 0.10 \\
\hline 18 & $18: 13943200$ & 10.08 & 0.93 & 0.02 & 0.11 \\
\hline 18 & $18: 13943440$ & 10.08 & 1.00 & 0.01 & 0.11 \\
\hline 18 & 18:13944067 & 10.08 & 0.95 & 0.01 & 0.11 \\
\hline 18 & 18:13944341 & 10.08 & 0.95 & 0.01 & 0.11 \\
\hline 18 & 18:13944359 & 10.08 & 0.95 & 0.01 & 0.11 \\
\hline 18 & 18:13944405 & 10.08 & 0.95 & 0.01 & 0.11 \\
\hline 18 & $18: 13944426$ & 10.08 & 0.94 & 0.01 & 0.11 \\
\hline 18 & 18:13944487 & 10.08 & 0.94 & 0.01 & 0.11 \\
\hline 18 & $18: 13944678$ & 10.08 & 0.94 & 0.02 & 0.11 \\
\hline 18 & 18:13944759 & 10.08 & 0.93 & 0.01 & 0.11 \\
\hline 18 & 18:13944979 & 10.08 & 0.97 & 0.02 & 0.11 \\
\hline 18 & 18:13945037 & 10.08 & 0.92 & 0.01 & 0.11 \\
\hline 18 & 18:13945704 & 10.08 & 0.88 & 0.02 & 0.12 \\
\hline 18 & $18: 13945860$ & 10.08 & 0.85 & 0.02 & 0.11 \\
\hline 18 & 18:13945962 & 10.08 & 0.86 & 0.02 & 0.12 \\
\hline 18 & $18: 13946128$ & 10.08 & 0.88 & 0.02 & 0.11 \\
\hline 18 & 18:13946143 & 10.08 & 0.87 & 0.02 & 0.11 \\
\hline 18 & $18: 13946439$ & 10.08 & 0.85 & 0.01 & 0.10 \\
\hline 18 & $18: 13947029$ & 10.08 & 0.84 & 0.02 & 0.12 \\
\hline
\end{tabular}


(continuation)

\begin{tabular}{|c|c|c|c|c|c|}
\hline Chromosome & $\begin{array}{l}\text { Name of } \\
\text { variant }\end{array}$ & $\begin{array}{c}-\log _{10} \\
\text { (Pvalue) }\end{array}$ & $\mathrm{AR} 2^{\S}$ & $\sigma_{\text {marker }}^{2}$ & $\sigma_{\text {marker }}^{2} / \sigma_{p}^{2}$ \\
\hline 18 & $18: 13947133$ & 10.08 & 0.84 & 0.02 & 0.12 \\
\hline 18 & 18:13947135 & 10.08 & 0.84 & 0.02 & 0.12 \\
\hline 18 & 18:13947191 & 10.08 & 0.84 & 0.02 & 0.12 \\
\hline 18 & $18: 13947229$ & 10.08 & 0.83 & 0.02 & 0.12 \\
\hline 18 & 18:13948757 & 10.08 & 0.86 & 0.02 & 0.11 \\
\hline 18 & 18:13949676 & 10.08 & 0.83 & 0.02 & 0.11 \\
\hline 18 & 18:13949754 & 10.08 & 0.85 & 0.02 & 0.11 \\
\hline 18 & $18: 13949853$ & 10.08 & 0.85 & 0.02 & 0.12 \\
\hline 18 & $18: 13949912$ & 10.08 & 0.85 & 0.02 & 0.12 \\
\hline 18 & $18: 13950098$ & 10.08 & 0.85 & 0.02 & 0.12 \\
\hline 18 & 18:13950100 & 10.08 & 0.85 & 0.02 & 0.12 \\
\hline 18 & 18:13950384 & 10.08 & 0.85 & 0.02 & 0.12 \\
\hline 18 & 18:13950481 & 10.08 & 0.85 & 0.02 & 0.12 \\
\hline 18 & $18: 13950512$ & 10.08 & 0.85 & 0.02 & 0.12 \\
\hline 18 & $18: 13950714$ & 10.08 & 0.86 & 0.02 & 0.12 \\
\hline 18 & 18:13951417 & 10.08 & 0.90 & 0.02 & 0.11 \\
\hline 18 & $18: 13951454$ & 10.08 & 0.90 & 0.02 & 0.11 \\
\hline 18 & $18: 13951584$ & 10.08 & 0.83 & 0.02 & 0.12 \\
\hline 18 & $18: 13952060$ & 10.08 & 0.90 & 0.02 & 0.11 \\
\hline 18 & $18: 13952858$ & 10.08 & 0.90 & 0.02 & 0.11 \\
\hline 18 & $18: 13953290$ & 10.08 & 0.87 & 0.02 & 0.12 \\
\hline 18 & $18: 13953846$ & 10.08 & 0.86 & 0.02 & 0.12 \\
\hline 18 & $18: 13953980$ & 10.08 & 0.86 & 0.02 & 0.12 \\
\hline 18 & 18:13954496 & 10.08 & 0.90 & 0.02 & 0.11 \\
\hline 18 & $18: 13955270$ & 10.08 & 0.91 & 0.01 & 0.10 \\
\hline 18 & 18:13955479 & 10.08 & 0.87 & 0.02 & 0.12 \\
\hline 18 & $18: 13956152$ & 10.08 & 0.87 & 0.02 & 0.12 \\
\hline 18 & $18: 13956601$ & 10.08 & 0.90 & 0.02 & 0.11 \\
\hline 18 & 18:13956677 & 10.08 & 0.90 & 0.01 & 0.11 \\
\hline 18 & $18: 13956796$ & 10.08 & 0.90 & 0.02 & 0.11 \\
\hline 18 & 18:13956954 & 10.08 & 0.90 & 0.02 & 0.11 \\
\hline
\end{tabular}


(continuation)

\begin{tabular}{|c|c|c|c|c|c|}
\hline Chromosome & $\begin{array}{c}\text { Name of } \\
\text { variant }\end{array}$ & $\begin{array}{c}-\log _{10} \\
\text { (Pvalue) }\end{array}$ & $\mathrm{AR} 2^{\S}$ & $\sigma_{\text {marker }}^{2}$ & $\sigma_{\text {marker }}^{2} / \sigma_{p}^{2}$ \\
\hline 18 & $18: 13957123$ & 10.08 & 0.90 & 0.02 & 0.11 \\
\hline 18 & $18: 13957548$ & 10.08 & 0.86 & 0.02 & 0.12 \\
\hline 18 & 18:13957651 & 10.08 & 0.90 & 0.02 & 0.11 \\
\hline 18 & 18:13957672 & 10.08 & 0.87 & 0.02 & 0.12 \\
\hline 18 & $18: 13958100$ & 10.08 & 0.86 & 0.02 & 0.12 \\
\hline 18 & 18:13958151 & 10.08 & 0.84 & 0.02 & 0.12 \\
\hline 18 & 18:13958362 & 10.08 & 0.91 & 0.02 & 0.11 \\
\hline 18 & $18: 13958364$ & 10.08 & 0.91 & 0.02 & 0.11 \\
\hline 18 & 18:13958689 & 10.08 & 0.92 & 0.02 & 0.11 \\
\hline 18 & $18: 13958726$ & 10.08 & 0.92 & 0.02 & 0.11 \\
\hline 18 & 18:13959429 & 10.08 & 0.92 & 0.02 & 0.11 \\
\hline 18 & 18:13959552 & 10.08 & 0.92 & 0.02 & 0.11 \\
\hline 18 & 18:13959862 & 10.08 & 0.92 & 0.02 & 0.11 \\
\hline 18 & 18:13959864 & 10.08 & 0.92 & 0.02 & 0.11 \\
\hline 18 & 18:13960117 & 10.08 & 0.93 & 0.02 & 0.11 \\
\hline 18 & 18:13960334 & 10.08 & 0.94 & 0.02 & 0.11 \\
\hline 18 & $18: 13960525$ & 10.08 & 1.00 & 0.01 & 0.11 \\
\hline 18 & 18:13961532 & 10.08 & 0.91 & 0.01 & 0.11 \\
\hline 18 & $18: 13962136$ & 10.08 & 0.97 & 0.02 & 0.11 \\
\hline 18 & $18: 13962696$ & 10.08 & 0.96 & 0.02 & 0.11 \\
\hline 18 & $18: 13962940$ & 10.08 & 0.96 & 0.02 & 0.11 \\
\hline 18 & $18: 13962990$ & 10.08 & 0.93 & 0.01 & 0.11 \\
\hline 18 & $18: 13963215$ & 10.08 & 0.96 & 0.02 & 0.11 \\
\hline 18 & $18: 13964657$ & 10.08 & 0.88 & 0.01 & 0.11 \\
\hline 18 & 18:13965595 & 10.08 & 0.93 & 0.02 & 0.11 \\
\hline 18 & $18: 13967836$ & 10.08 & 0.94 & 0.02 & 0.11 \\
\hline 18 & $18: 13967910$ & 10.08 & 1.00 & 0.01 & 0.11 \\
\hline 18 & $18: 13968028$ & 10.08 & 0.93 & 0.02 & 0.11 \\
\hline 18 & 18:13970606 & 10.08 & 0.80 & 0.02 & 0.12 \\
\hline 18 & 18:13970771 & 10.08 & 0.80 & 0.01 & 0.10 \\
\hline 18 & $18: 13971413$ & 10.08 & 0.86 & 0.02 & 0.11 \\
\hline
\end{tabular}




\begin{tabular}{|c|c|c|c|c|c|}
\hline Chromosome & $\begin{array}{l}\text { Name of } \\
\text { variant }\end{array}$ & $\begin{array}{c}-\log _{10} \\
\text { (Pvalue) }\end{array}$ & $\mathrm{AR} 2^{\S}$ & $\sigma_{\text {marker }}^{2}$ & $\sigma_{\text {marker }}^{2} / \sigma_{p}^{2}$ \\
\hline 18 & 18:15017933 & 10.31 & 0.99 & 0.01 & 0.11 \\
\hline 18 & 18:15017982 & 9.24 & 1.00 & 0.01 & 0.10 \\
\hline 18 & $18: 15018610$ & 9.24 & 0.99 & 0.01 & 0.10 \\
\hline 18 & 18:15019735 & 10.31 & 0.99 & 0.01 & 0.11 \\
\hline 18 & $18: 15024959$ & 10.31 & 0.83 & 0.01 & 0.10 \\
\hline 18 & 18:15029101 & 14.12 & 0.88 & 0.02 & 0.14 \\
\hline 18 & $18: 15032047$ & 14.12 & 0.88 & 0.02 & 0.14 \\
\hline 18 & $18: 15038074$ & 7.05 & 0.85 & 0.01 & 0.07 \\
\hline 18 & 18:15046094 & 7.05 & 0.89 & 0.01 & 0.07 \\
\hline 18 & $18: 15047436$ & 6.46 & 0.99 & 0.01 & 0.07 \\
\hline 18 & $18: 15047675$ & 6.46 & 1.00 & 0.01 & 0.07 \\
\hline 18 & 18:15047877 & 6.46 & 0.99 & 0.01 & 0.07 \\
\hline 18 & 18:15047927 & 6.46 & 0.99 & 0.01 & 0.07 \\
\hline 18 & 18:15049190 & 7.05 & 0.84 & 0.01 & 0.08 \\
\hline 18 & 18:15051124 & 7.05 & 0.86 & 0.01 & 0.08 \\
\hline 18 & $18: 15055682$ & 7.05 & 0.84 & 0.01 & 0.08 \\
\hline 18 & $18: 15056537$ & 7.05 & 0.87 & 0.01 & 0.08 \\
\hline 18 & $18: 15064047$ & 6.68 & 0.89 & 0.01 & 0.08 \\
\hline 18 & $18: 15081850$ & 6.68 & 0.96 & 0.01 & 0.08 \\
\hline 18 & $18: 15083765$ & 6.68 & 0.96 & 0.01 & 0.08 \\
\hline
\end{tabular}

${ }^{+} \mathrm{NC}$ milk as binary trait where $0=$ coagulating and $1=$ non-coagulating ${ }^{\S} \mathrm{AR} 2$ =accuracy of imputation obtained from Beagle 4.0 ${ }^{`} \sigma_{\text {marker }}^{2}=$ marker's variance, computed for each marker as 2 times major allele frequency times minor allele frequency times allele substitution effect ${ }^{*} \sigma_{\text {marker }}^{2} / \sigma_{p}^{2}=$ phenotypic variance explained by a marker 



\section{6}

General discussion 



\subsection{Introduction}

In this thesis, the genetic backgrounds of milk-fat composition and of noncoagulation of milk have been explored. Firstly, for bovine milk-fat composition, we investigated how genetic differences between winter and summer milk contributed to the observed phenotypic differences (Chapter 2). We showed that winter and summer milk-fat composition are largely genetically the same trait. Phenotypic differences between winter and summer milk-fat composition were mainly caused by dietary differences rather than by genetic differences. Furthermore, for most fatty acids (FA), no significant DGAT1 and $S C D 1$ by season interactions were found. In case significant interactions were present, we showed that these interactions were likely caused by the scaling of the genotype effects. Secondly, for bovine milk-fat composition and for non-coagulation (NC) of milk, we explored their genetic variation by means of genome-wide association studies (GWAS). Through GWAS (in Chapters 3 and 5), we characterized promising chromosomal regions associated with the phenotypes. Subsequently, in Chapters 3, 4 and 5, these promising regions were fine-mapped with imputed 777k SNP genotypes and imputed sequence data. The fine-mappings refined the location of quantitative trait loci (QTL), and contributed to the identification of candidate genes for these QTLs.

In this general discussion, I discuss different perspectives regarding gene discovery in cattle. I had the opportunity to use a substantial number of genetic markers for gene discovery, and encountered some challenges. Therefore, firstly, I discuss the challenges with respect to high-density genotypes for gene discovery. Secondly, I discuss future possibilities to expand gene discovery studies, and I propose some alternatives to identify causal variants underlying complex traits in cattle.

\subsection{Challenges with high-density genotypes for gene discovery}

The two main challenges for gene discovery were the imputation to high-density genotypes and the annotation of the cattle genome. In general, the attainment of high-density genotypes (and herein, I include sequences as high-density genotypes) requires several expensive steps, such as genotyping DNA samples in laboratories, using bioinformatic tools plus programmers to handle the huge data sets, and storing data. In recent years in cattle, imputation has been used to reduce costs and to accelerate the attainment of these high-density genotypes for large groups of 
animals. A recognized imputation strategy consists in genotyping influential ancestors in a population, and imputing the rest of the population to a higher density of genetic markers (e.g., Druet et al., 2014). After using imputation in Chapters 3, 4 and 5 , the density of genetic markers increased while the distance between genetic markers decreased. Regarding the distance between genetic markers, it was reduced from 10 mega base-pairs (bp) with 50k SNP to \pm 4 mega bp with (imputed) 777k SNP genotypes (Chapter 3), and to a few kilo bp with (imputed) sequences (Chapters 4 and 5). GWAS and fine-mapping using these imputed genotypes resulted in a substantial increase in the number of significant associations (in the thousands) with the phenotypes (Chapters 4 and 5). As a consequence, it became more difficult to identify among the thousands of significant associations which one is the causal mutation.

After finding thousands of significant associations with the phenotypes, the next step consisted in identifying candidate genes underlying these phenotypes. For this purpose, the annotation of the cattle genome is an important tool to pin-point candidate genes. The annotation of genomes including cattle is a dynamic process, hence, constantly changing over time. Currently, important developments regarding the assembly and the annotation of genomes including cattle are on their way. These developments, more specifically the FAANG Consortium (Andersson et al., 2015), will contribute to identify candidate genes and regulatory elements more efficiently than at present.

I will discuss in more detail the two challenges for gene discovery: imputation to high-density genotypes and the annotation of the cattle genome.

\subsubsection{Imputation of high-density genotypes}

A key feature in using GWAS with imputed high-density genotypes is the accurate imputation of genotypes. According to Marchini and Howie (2010), genotype imputation is a statistical method of predicting (i.e., imputing) genotypes in a sample based on a reference population (RefPop). The sample is a representation of a population, typically genotyped for a lower density of genetic markers (e.g., 50k SNP genotypes), and this sample has not been assayed for a higher density of genetic markers (e.g., 777k SNP genotypes). The RefPop consists of individuals that are related to the sampled population and that have been genotyped for a higher density of genetic markers (e.g., 777k SNP genotypes). Based on the RefPop, the sampled population is imputed to a higher density of genetic markers (see figure 6.1). The accuracies of the resulting imputed genotypes range from 0 (poorly imputed) to 1 
(correctly imputed). In most cases, genotypes are imputed at accuracies lower than 1. Imputation accuracy is influenced by factors, such as the size of the RefPop, the genetic distance between the sampled population and the RefPop, the minor allele frequency (MAF), and the linkage disequilibrium (LD) between genetic markers (e.g., Zhang and Druet, 2010; Van Raden et al., 2013; Pausch et al., 2013; and Uemoto et al., 2015).

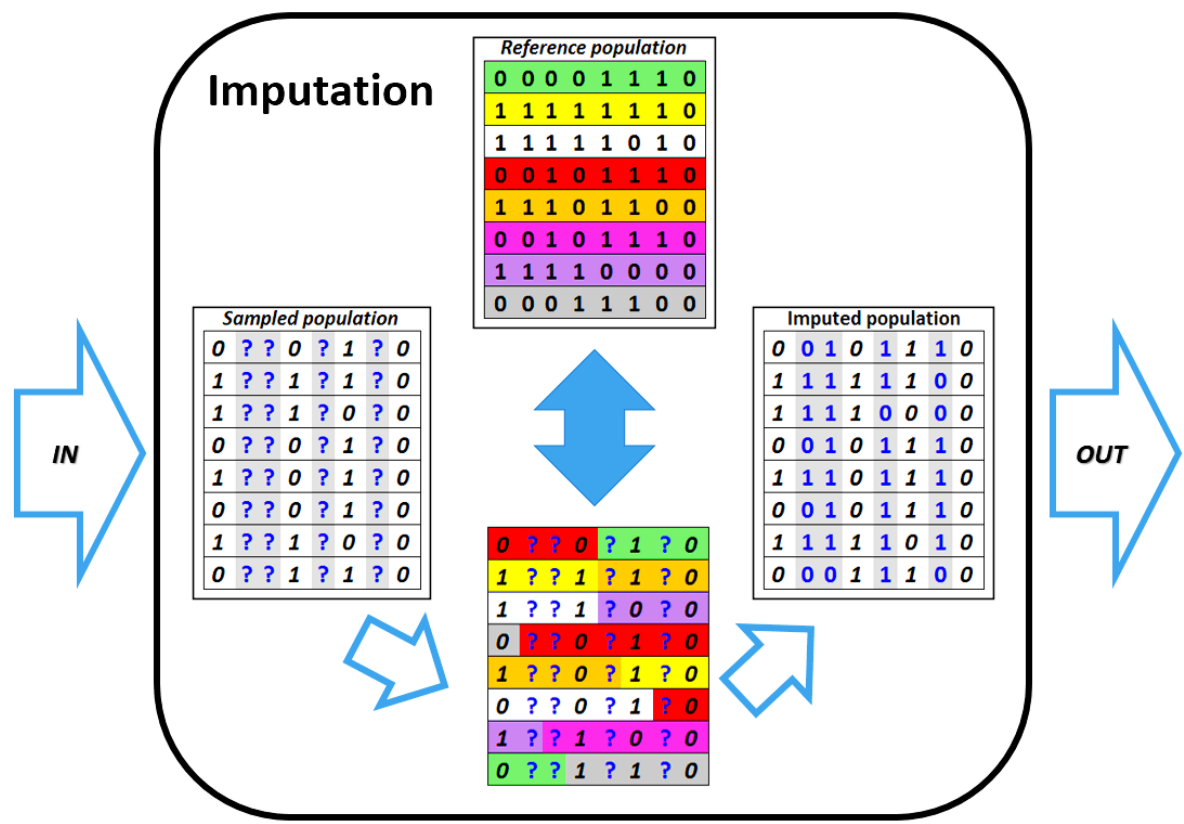

Figure 6.1 - Schematic representation of how imputation works. The sampled population is genotyped at a lower density of genetic markers. The reference population (RefPop) contains individuals related with the sampled population that are genotyped at a higher density of genetic markers. Based on the RefPop, the sampled population is imputed to a higher marker density.

Size of the reference population and the genetic distance between the sampled and the reference population. The 1000 Bulls Genome Consortium (Daetwyler et al., 2014) is a world-wide collaborative initiative that aims at sequencing animals from the cattle population, and at creating a multi-breed RefPop. Using this multi-breed RefPop, a substantial increase in the density of genetic markers is currently available for imputation giving the opportunity to impute genotypes to whole-genome sequences (WGS). The WGS are available for more than 15 breeds, and each breed is represented by a number of key sequenced influential ancestors. Recently the 1,000 Bull Genome Consortium increased the 
number of sequenced animals, and has included sequences of influential cows in this multi-breed RefPop. By accounting for influential cows and bulls, more relationships between the sampled population and the RefPop are considered. Consequently, the accuracy of imputed genotypes should increase.In this multi-breed RefPop, the Hostein-Friesian (HF) breed is well represented with $450 \mathrm{HF}$ sequenced ancestors (the latest Run5). In contrast, the Swedish Red (SR) breed is represented with 16 SR sequenced ancestors and the Finnish Ayrshire (FAY) breed is represented with 17 FAY sequenced ancestors.

In Chapter 4, we aimed at imputing the imputed 777k SNP genotypes of HF cows to WGS level. Therefore, only HF sequences $(\mathrm{N}=450)$ from the multi-breed RefPop were used to impute genotypes to WGS level, and due to the size of the RefPop, at high accuracies (> 0.9). In contrast, in Chapter 5, a rather limited number $(\mathrm{N}=33)$ of sequenced SR and FAY were available for the imputation to WGS level. The 33 sequenced SR and FAY bulls have a large impact in the SR cow population. To make the best possible use of the multi-breed RefPop, our approach in Chapter 5 consisted of imputing a variant three times, each time with a different RefPop (33 SR and FAY sequences, 284 dairy-breeds sequences, and 429 beef- and dairy-breeds sequences). Subsequently, we were able to impute the genotypes of SR cow population to WGS. Based on the findings of Chapter 5 , the accuracies of imputed genotypes in smaller breeds (e.g., SR) will only improve if the addition of sequenced animals in the multibreed RefPop is tailored toward smaller breeds.

Minor Allele Frequency. According to Daetwyler et al. (2014) imputation errors for low MAF (<0.05) genetic markers are high when imputing a cow population to WGS level. If an allele segregates at low MAF, then there is a relatively small number of sequenced ancestors in the RefPop carrying this low MAF variant. Hence, the imputation of this low MAF variant in the sampled population will be more difficult, and there is a high probability that this variant will be poorly imputed. Therefore, the interpretation of GWAS findings needs more caution when significant associations concern imputed low MAF variants. GWAS detects QTL with genetic markers at a certain power. This detection occurs under the assumption that a genetic marker is correlated with the QTL. MAF at the QTL is an important determinant of power because the heritability of a QTL is directly proportional to the frequencies of the alleles at the QTL locus (Sham and Purcell, 2014). In this context, the power of detecting a QTL segregating at low MAF is low. In addition, the power of detecting this QTL becomes even lower when using imputed low MAF variants, especially if their imputation accuracy is low. If a variant has low MAF, low imputation accuracy 
and is strongly correlated with the QTL, this implies that QTL effect size needs to be sufficiently high to be detected by GWAS. In Chapter 4, the 8 strongest associations with milk-fat composition segregate at a MAF $=0.44$. For the findings of Chapter 4 , the imputation accuracy of low MAF variants was not an important issue. In Chapter 5 , the 3 strongest associations with $\mathrm{NC}$ milk were segregating at a MAF=0.03 and explained more than $10 \%$ of the phenotypic variance. This strong signal, which was first detected in SR cows genotyped for 777k SNP genotypes, can be explained by a large QTL effect of more 1 phenotypic standard deviation. This illustrates that rare variants should not by default be considered sequencing errors and therefore excluded from GWAS.

The inclusion of pedigree information can improve the accuracy of imputation of low MAF genetic markers. This approach focuses on imputing identical-by-descent genetic markers that segregate from parents to offspring instead of using information on LD between genetic markers. However, this approach is computationally time-consuming. Some examples of softwares with implemented algorithm that account for simple pedigree information (i.e., duos and trios) are Beagle, fastPHASE, and Fimpute. Recently, a method that imputes SNP combining LD and identical-by-descent information has been proposed (iBLUP, Yang et al., 2014). In general, accounting for pedigree information is expected to impute low MAF genetic markers more accurately than without pedigree information.

Linkage disequilibrium. The non-random association between two loci is defined as LD. Two sampling processes cause LD to arise in a population according to Hill and Weir (1980). First, the sampling of gametes from parents to offspring, and this process depends on the effective population size. Second, the number of individuals sampled from a finite population. In the case of cattle, crossbreeding, mutation, drift, and small population size are events that create LD. Imputation uses LD present in the RefPop to impute the genotypes of the sampled population. One of the problems is that LD can exist between an (imputed) marker and QTL in one family but not in other families (Goddard and Hayes, 2012). For Chapters 3 and 4, the sires of the sampled population of HF cows were included in the RefPop, and in Chapter 5, this was also the case with the 33 sequenced ancestors of SR and FAY. However, in Chapter 5, we also used two other imputation scenarios that included different breeds, for which the sequenced SR and FAY have no common ancestors. In this case, LD in SR and FAY breeds can be different than LD in other breeds. LD across-breeds is expected to be smaller than LD within a breed because more recombination events separate individuals from different breeds (De Roos et al., 2008). Therefore, 
imputation accuracy is probably influenced by the differences in LD within- and across- breeds, which might result in lower imputation accuracies for genotypes in small breeds compared with large breeds.

In both cases, for milk-fat composition and for NC milk, imputation to high-density genotypes was challenging. The factors affecting imputation and their consequences on the interpretation of GWAS and fine-mapping results cannot be solved with the data at hand. Only through validation studies it will be possible to confirm the findings reported in this thesis. Validation studies would further help to ascertain if the strongest associations identified in Chapters 3, 4 and 5, and thus the most likely candidate genes, can be confirmed. If a validation study would be based on multiple breeds and these associations persist across breeds, the genetic markers are likely to be very close to the QTL, because of the limited extent of LD across-breeds (e.g., De Roos et al., 2008; Goddard and Hayes, 2012). However, we cannot exclude the possibility that the QTL might not segregate in other breeds (Goddard and Hayes, 2012). Nonetheless, by attempting to validate our associations, it would lead us closer to the identification of the causal variants for the QTL identified in Chapters 3 , 4 and 5 .

\subsubsection{Annotation of the cattle genome}

The second major challenge encountered in Chapters 3, 4 and 5 was the limited, hence, incomplete annotation of the cattle genome. The cattle genome contains the genetic information organized in chromosomes, which include the genes for the protein coding regions, and the DNA sequences for the non-protein coding regions. The genome annotation attaches to these genes and DNA sequences the biological information of an organism (Stein, 2001). In Chapter 3, the QTL region located between 29 and 34 mega bp on BTA17 contained 29 genes. A total of 18 out of the 29 genes had not been annotated yet. Among these 18 genes, the non-annotated LOC515517 was the gene closest to our strongest association on BTA17, and was pointed out as a suggestive candidate gene in Chapter 3. LOC515517 was assigned this symbol because the investigation of all orthologs for this gene was incomplete. Orthologs are genes in different species that evolved from a common ancestral gene by speciation. The full determination of orthologs assist in the annotation of a gene. Two years later, this QTL region was re-analyzed with imputed sequences (Chapter $4)$. In these two years, the non-annotated LOC515517 has been annotated as the $\angle A R P 1 B$ gene in the cattle genome. In Chapter 4 , the LARP1B gene became our primary candidate gene because 6 out of the 8 strongest associations were located in this gene. In two years, a clear improvement has been made on the annotation of 
genes and their biological functions, at least for BTA17. The lesson taken from Chapters 3 and 4 is that the limited annotation of the cattle genome should not be a reason to discard suggestive candidate genes.

The annotation of the genome of domesticated animal species is a slow and complex process. In the last decade, the annotation of the genome of domesticated animal species has been extrapolated from the annotation of the human genome, through actions such as the encyclopedia of DNA elements (ENCODE). ENCODE is a global initiative to identify functional variants in high-quality sequences of humans. It is the aim of ENCODE to improve the annotation of structural and regulatory variants as well as non-coding genes in humans. The ENCODE initiative has been very successful in humans, and was expanded to other species like mouse (Shen et al., 2012; Yue et al., 2014). However, the idea of extrapolating gene-expression and its regulation network from human to mouse was not successful because of substantial divergence between these two species (Yue et al., 2014). This genetic diversity between species contributes to the complexity and the slow annotation of the domesticated animal species genomes.

The genetic diversity of domesticated animal species is the focus of the recently started functional annotation of the animal genomes (FAANG) consortium. The FAANG consortium aims at identifying all functional elements in the genome of domesticated animal species (Andersson et al., 2015), and involves a collaboration between several research groups worldwide. In a first stage, many different tissues across domesticated animal species will be sampled, such as skeletal muscle, adipose and liver tissues, and in addition, samples of reproductive, immune and nervous systems will be collected. These sampled tissues and systems are necessary to perform functional studies. These studies enable the prediction of the function encoded in sequences. Andersson et al. (2015) argue that filling the genotype-tophenotype gap requires functional genome annotation of species with substantial phenotype information. The FAANG initiative aims at improving the annotation of the genome of domesticated animal species by creating standardized protocols for sampling, storing, and analyzing the information among the participating research groups (Clarke et al., 2015). The samples will be analyzed by some of the following protocols: transcribed loci (using RNA sequencing), chromatin accessibility and architecture (the link between gene-expression and nuclear organization of cells), and histone modification marks (to identify regulatory elements; Andersson et al., 2015). In a second stage, other tissues will be sampled, such as rumen tissues from ruminant species, mammary tissue from mammals, among others (Andersson et al., 
2015). As pointed out by Zhou et al. (2015), the genomes of chicken, cow and pig have been assembled, but limited information is available on the enhancers, promoters, and other elements of the genome of these species. The identification of these elements and their biological roles will improve the annotation of these three genomes. I expect that it will take some time ( $>5$ years) to gather and analyze all this information, in order to produce a comprehensive and better annotated genome for each of the domesticated animal species, including cattle. Therefore, the identification of candidate genes will be more efficient in the near future.

\subsection{From GWAS to causal variants}

The typical outcomes of GWAS are large chromosomal regions, and many polymorphisms that are statistically associated with phenotypes. In Chapter 3, GWAS with imputed 777k SNP genotypes identified a QTL region covering 5 mega bp that contained 29 genes. Subsequent fine-mapping with imputed sequences (Chapter 4) refined the QTL region and reduced the number of candidate genes from 29 to 14 . Although this characterization of chromosomal regions associated with our phenotypes (Chapters 3, 4 and 5) was successful, what remains unclear from GWAS and subsequent fine-mapping is whether a polymorphism is the actual causal variant. For complex traits, such as bovine milk composition, it would be interesting to identify causal variants. It would increase biological knowledge, and specifically, help to understand how these causal variants influence our phenotypes. Consequently, it would be possible to predict potential pleiotropic effects on non(routinely) recorded traits with consequences on the selection of the nextgeneration of cows. According to Falconer and Mackay (1996), quantitative genetic theory will become more realistic when the numbers and the properties of genes are known because it would improve the methods to studying complex traits. If this is the case, we need to find causal variants to confirm that the identified genes influence the phenotypes. Therefore, in this section, I propose several possibilities to identify causal variants. In more detail, I explore the possibilities of using targeted gene-expression studies, gene-editing, and gene knockouts in livestock to identify causal variants.

\subsubsection{Exploring alternatives to identify causal variants}

As indicated by Das et al. (2011), the causality of a polymorphism is difficult to be determined by GWAS and fine-mapping. In practice, when GWAS and fine-mapping identify significant associations with the phenotype, the associated variants can be located within protein-coding regions. When this happens, the gene is declared a 
candidate gene and the polymorphism might be a causal variant. If the variant is causal, it is possible to predict changes to the encoded-protein, thus predicting functional changes to the phenotype (e.g., Freedman et al., 2011). Consequences on the phenotype can be straightforward for monogenic diseases in humans, such as the Duchenne muscular dystrophy. This disease is caused by large deletions of one or more exon(s) in the dystrophin gene causing severe muscular dystrophy in about $60 \%$ of male infants (Hoffman et al., 1987). However, consequences on complex traits are more difficult to interpret than for monogenic diseases. In Chapters 4 and 5, many associations with milk FA composition and with NC milk were identified within and outside protein-coding regions. In Chapters 4 and 5, the LARP1B and the VPS35 genes were nominated as positional candidate genes, after these genes were found expressed in bovine mammary tissue (Bionaz et al., 2012), and during different stages of lactation in humans (Lemay et al., 2013). Figure 6.2 (A and B) illustrates the strongest associations with milk FA composition in the LARP1B gene and with NC milk in the VPS35 gene. Although we limited the number of candidate genes to only 2 , the interpretation of possible functional changes of these 2 genes on milk FA composition and on NC milk are unclear.

Furthermore, two other complications arise. First, the strongest identified associations with milk FA composition and with NC milk are in strong LD (figure 6.2$A$ and $B$ ). Hence, we cannot disentangle which of these associations would promote changes to the phenotypes. Second, some of these correlated associations are intron variants in these candidate genes (figures 6.2 A and B). Particularly in livestock species, there might be a bias in declaring candidate genes toward well-annotated genes (Tasan et al., 2015) because non-coding protein regions still need to be characterized (Andersson et al., 2015). Consequently, associations identified in nonprotein coding regions are often ignored. To understand the possible changes to the phenotypes, I hypothesize that the causal variants are among one of the significant associations with the LARP1B and VPS35 genes. If this is the case, this hypothesis can serve as research question for further studies, such as targeted gene-expression studies.

\subsubsection{Targeted gene-expression studies}

Gene-expression is the process by which functional gene products are formed. Gene products have been studied in many species including mice, rats and humans, and in different cell types (e.g., de Koning et al., 2007; Civelek and Lusis, 2014). Gene 

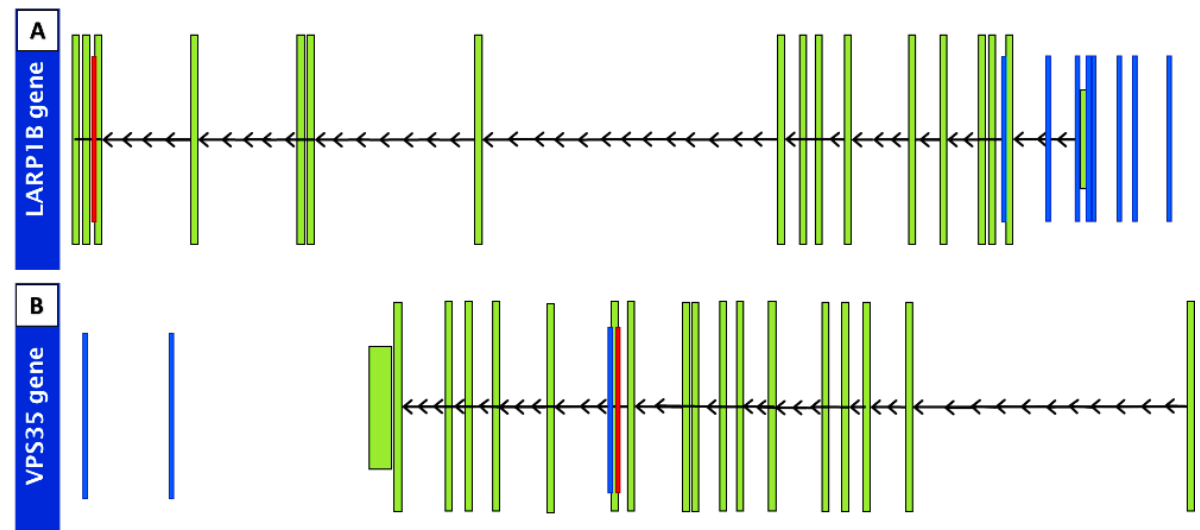

Figure 6.2 - Schematic view of the LARP1B and the VPS35 genes. The green boxes represent the exons connected by a black line and small arrows showing the protein coding direction of the genes. Blue boxes represent the location of the strongest associations, and the red boxes represent the splice region variants. (A) The $L A R P 1 B$ gene, and its eight strongest associations with multiple fatty acids on Bos Taurus Autosome (BTA) 17 [at $-\log 10$ (P-value) $=7.66$, and linkage disequilibrium between the eight markers = 1]. $(B)$ The VPS35 gene, and its three strongest associations with non-coagulation of milk on BTA18 [at -log10 (P-value) $=14.12$, and linkage disequilibrium between the three markers $=1]$.

products can be transcripts of genes (mRNA) but equally protein abundance and metabolite levels. The most often analyzed gene products are mRNA rather than protein abundance or metabolite levels (e.g., Albert and Kruglyak, 2015). Typically, the mRNA expression is constantly changing over time (e.g., Jiang et al., 2013). After establishing that most genes are quantitatively expressed, Jansen and Nap (2001) proposed the "genetical genomics" approach. Genetical genomics combines the (quantitative) gene-expression and the genetic variation from related individuals in segregating populations (as a representation of genetic markers).

In genetical genomics (or its equivalent genome-wide association of gene-expression studies - eQTL ), the mRNA abundance is treated as the quantitative phenotype, and the genomic regions influencing gene-expression result in the detection of eQTL (e.g., Jansen and Nap, 2001; Jansen, 2003). According to Jansen and Nap (2001), the eQTLs can act in two ways: a) in cis by influencing the expression of the closest gene nearby (also known as locale QTL); or b) in trans by influencing the expression of genes in other parts of the genome (also known as distant eQTL). In animal breeding, Kadarmideen et al. (2006) indicated that eQTLs contribute to the refinement of the identified traditional QTL, candidate gene and SNP discovery. Furthermore, de Koning et al. (2007) combined eQTL and fine-mapping to reduce the confidence 
interval of functional trait loci in poultry. As a consequence, the chromosomal region under investigation and the number of candidate genes were reduced. This targeted eQTL approach allows the identification of cis-acting eQTL rather than trans-eQTL. Targeted eQTL are especially important when there is no obvious biological reason supporting a significant association with the phenotypes. The reason being that eQTL can provide further insights into the function, regulation and pathways of genes underlying a complex trait (e.g., Jansen, 2003; de Koning et al., 2007; Lowe and Reddy, 2015). For instance, the LARP1B and the VPS35 genes have not been associated to bovine milk composition before the present thesis. Further insights into the function, regulation and pathways would clarify the functional role of the $\angle A R P 1 B$ and the VPS35 genes in relation to their respective phenotypes.

According to Hassan and Saeij (2014), if a genetic variant influences the mRNA abundance of a nearby gene, which in turn modulates a complex trait, this cis-eQTL can co-localize with the QTL identified by traditional GWAS. When a common chromosomal region identified by cis-eQTL co-localizes with the QTL from traditional GWAS at the same genetic variant, it provide strong evidence that the underlying candidate gene is correctly identified (Schadt et al., 2005). In addition, this colocalization (if observed) would suggest that the causal variant is associated with the gene-expression and with the phenotype simultaneously (Schadt et al., 2005). Based on these findings, targeted eQTL focused on the expression of the LARP1B and the VPS35 genes would help confirm that the candidate genes were correctly assigned, and help determine the most likely causal variants for these phenotypes.

Nonetheless, targeted eQTL on the expression of LARP1B and VPS35 genes can point out variants in regulatory elements. In humans, some studies have suggested that multiple correlated associations can influence the activity of multiple enhancers (regulatory elements). When the activity of these regulatory elements is coordinated, their effects can alter gene-expression (e.g., Corrandin et al., 2014; Lowe and Reddy, 2015). Albert and Kruglyak (2015) indicated that many polymorphisms identified in human GWAS are over-represented in regulatory regions. In addition, Parikshak et al. (2015) indicated that these regulatory elements are located in non-protein coding regions of the genome. In our case, multiple significant associations with the LARP1B and the VPS35 genes are in strong LD and are located in non-protein coding regions (figure 6.2 A and B). I would investigate if the co-localization of the cis-eQTL with the QTL from a traditional GWAS would occur at one of the variants located in the non-protein coding regions of LARP1B and VPS35 genes. If this would happen, the position of the regulatory element showing the cis- 
eQTL effect could be accurately determined based on the sequence data. One limitation, however, is that the regulatory elements of the cattle genome are not annotated yet. In summary, it is possible that the significant associations in strong LD for the LARP1B and the VPS35 genes are regulatory elements.

A step further from targeted eQTL would be to investigate the proteins encoded by the genes directly. This approach would be interesting because of a highly regulated mechanism known as alternative splicing (Hassan and Saeij, 2014). Through this process, introns and exons in genes are re-arranged creating the opportunity for mRNA to synthesize different protein variants (isoforms) that may have different cellular functions (Wang et al., 2008). This process occurs at a specific site known as splice junction (or splice variant). Interestingly, the LARP1B and the VPS35 genes contain splice-region variants (figure $6.2 \mathrm{~A}$ and $\mathrm{B}$ ). Using RNA-sequencing technology, it is possible to distinguish between the transcript abundance from alternative splicing and regular transcript abundance (Trapnell et al., 2010). According to Wickramasinghe et al. (2014), RNA-sequencing technology is the method of choice for studying RNA transcripts, and this technology shows great ability in studying allele-specific expression and non-coding RNA. In a further study, it might be worth investigating the different isoforms resulting from the splicevariants found in the $L A R P 1 B$ and the VPS35 genes with RNA-sequencing.

The contribution of RNA-sequencing is not limited to studying gene-expression. RNAsequencing can also be used for SNP and gene discovery, as well as gene ontology and pathway analysis. The RNA-sequencing approach is different than genetical genomics. Using RNA-sequencing and gene-expression of bovine milk retrieved from somatic cells, the different isoforms of interesting genes are tested for associations directly with the phenotypes. When a significant association is identified, if this association is identified within the isoforms, then SNP and candidate genes can be identified. Several studies have used this approach to identify candidate genes associated with bovine milk composition (e.g., Cánovas et al.,2010; Wickramasinghe et al., 2012; and Cánovas et al., 2013). It is important to acknowledge the substantial contribution of the RNA sequencing technology for studying bovine milk composition.

\subsubsection{Gene-editing and gene knockouts in livestock}

A complementary approach to gene-expression studies is targeting genes in mouse models. Targeting a gene in mouse models means to disrupt a specific gene in the genome of a mouse, thus creating a knockout mouse for that specific gene. In the 
last 50 years, gene targeting by means of homologous recombination combined with the refinement of protocols (e.g., microinjection of purified DNA, electroporation, and positive selection enrichments) and the subsequent transmission to mouse germlines have led to knockout more than 7,000 genes in transgenic mouse models (Capecchi, 2005). The "principles for introducing specific gene modifications in mice by the use of embryonic stem cells" have made Dr. Capecchi, Dr. Evans and Dr. Oliver winners of the Nobel Prizes in Physiology or Medicine in 2007. This refinement of methods and protocols has substantially accelerated the biological knowledge of genes, and has led to the development of gene-editing.

Gene-editing. Although gene targeting has required the introgression of exogenous DNA into the genome of a mouse, gene-editing with site-specific nucleases is an alternative to target specific genes without the introgression of exogenous DNA (e.g., Capecchi, 2005; Carlson et al., 2014). According to Cappechi (2005), the use of these site-specific nucleases allow to target a series of alleles in the same gene, thus manipulating any chosen allele in mouse models. There are at least three known sitespecific nucleases: the zinc-finger nucleases (Kim et al., 1996), the transcription activator-like effector nucleases (Boch et al., 2009; Moscou and Bogdanove, 2009), and the clustered regularly interspaced short palindromic repeats associated endonuclease cas9 (CRISPR/Cas9; Cong et al., 2013; Mali et al., 2013). My focus will be on the most recent, the CRISPR/Cas9 system.

The CRISPR/Cas9 system is part of the protection mechanism against viruses that has been identified from the immune system of bacteria. The CRISPR/Cas9 was first described by Cong et al. (2013) and by Mali et al. (2013), as a RNA-guided site-specific DNA cleavage technique. According to Cong et al. (2013), the Cas9 nuclease can direct short RNAs to induce precise cleavage at DNA loci, facilitating the knockout of targeted genes. Initially, the CRISPR/Cas9 technique was intended to understand genes, their regulation and their biological functions because of its easiness of programmability and of usage (Cong et al., 2013). Gene-editing has the potential of targeting a single gene as well as multiple genes simultaneously. Gene-editing can be used to obtain cell-specific knockdown (one copy of the gene inactivated) or knockout (both copies of a gene inactivated) as well as gene specific mutations using rodent models (Shalem et al., 2015). For this reason, it has become an important ally to study genes underlying complex traits, such as bovine milk composition. For bovine milk composition, gene-editing has the potential to accelerate knowledge discovery (about genes, their biological function, and their influence at the 
phenotypic level). On this regard, gene-editing is substantially contributing to improve the annotation of domesticated animal species genomes, including cattle.

Gene knockouts in livestock. With gene-editing, some gene knockouts in livestock have been successfully produced. With the zinc-finger nuclease, the knockout of the PPARY gene in pigs (Yang et al., 2011) and of the $\beta-L G$ gene in cattle (Yu et al., 2011) was possible. However, Carlson et al. (2014) indicated that proprietary algorithms were responsible for impeding the use of this zinc-finger nuclease. With the transcription activator-like effector nucleases, Proudfoot et al. (2015) reports the gene-editing of the myostatin (MSTS) gene in sheep and in cattle with successful results. In the future, using gene-editing with the CRISPR/Cas9 technique, knockout cows are likely to be produced. The resulting (functional) changes will be interpretable at the phenotypic level. It would be useful to understand the extent of changes from one or multiple genes on bovine milk composition, but also on the important physiologic changes faced by cows at parturition. For phenotypes such as bovine milk, I foresee in the coming future gene knockout cows being widely produced, kept and challenged in a commercial environment. I can also foresee the knockdown of one or multiple alleles in the LARP1B and the VPS35 genes, as well as the knockout of these genes in gene-edited cows.

While gene-editing with the CRISPR/Cas9 technique will become widely used in the future, functional changes in bovine milk composition can already be studied using a lactating bovine mammary epithelial cell (bMEC) model. Zhao et al. (2010) and Jedrzejczak and Szatkowska (2014) indicated that bMEC models are suitable to study bovine milk synthesis. Instead of using bMEC sampled from tissues through biopsy, Boutinaud et al. (2002) isolated mRNA directly from somatic cells, which are naturally released in milk during lactation. Using RNA sequencing, Medrano et al. (2010) and Cánovas et al. (2014), both concluded the viability of using milk somatic cells and milk fat globules to study mammary gland expression. For bovine milk composition, functional changes to be phenotypes can already be assessed by studying the gene-expression of LARP1B and the VPS35 genes directly from milk samples. In addition, it is also a possibility to target one or multiple alleles in a single gene (e.g., the LARP1B and the VPS35 genes) using bMEC models.

In summary, there are many opportunities to transform the significant associations identified from traditional GWAS and fine-mapping in research questions for further studies. All the approaches discussed in this section would, a priori, help to identify causal variants underlying complex traits such as bovine milk composition, and a 
posteriori, help to understand the function of genes and their biological role in bovine milk.

\subsection{References}

Albert, F. W., and Kruglyak, L. 2015. The role of regulatory variation in complex traits and disease. Nature Rev Genet 16: 197-212.

L. Andersson, Archibald, A. L., Bottema, C.D., Brauning, R., Burgess, S.C., Burt, D.W., et al. 2015. Coordinated international action to accelerate genome-to-phenome with FAANG, the Functional Annotation of Animal Genomes project. Genome Biol $16: 57$

Bionaz, M., K. Periasamy, S. L. Rodriguez-Zas, W. L. Hurley, and Loor, J. J. 2012. A novel dynamic impact approach DIA for functional analysis of time-course omics studies: validation using the bovine mammary transcriptome. PLoS ONE.7: e32455

Boch, J., Scholze, H., Schornack, S., Landgraf, A., Hahn, S., Kay, S., Lahaye, T., Nickstadt, A., and Bonas, U. 2009. Breaking the code of DNA binding specificity of TAL-type III effectors. Science 326: 1509-12. doi:10.1126/science.1178811.

Boutinaud, M., and Jammes, H. 2002. Potential uses of milk epithelial cells: a review. Reprod Nutr Dev 42:133-147.

Cánovas, A., Rincon, G., Islas-Trejo, A., Wickramasinghe, S., and Medrano, J. F. 2010. SNP discovery in the bovine milk transcriptome using RNA-Seq technology. Mamm genome 21: 592-598.

Cánovas, A., Rincón, G., Islas-Trejo, A., Jimenez-Flores, R., Laubscher, A., and Medrano, J. F. 2013. RNA sequencing to study gene expression and single nucleotide polymorphism variation associated with citrate content in cow milk. J Dairy Sci 96: 2637-2648.

Cánovas, A., Rincón, G., Bevilacqua, C., Islas-Trejo, A., Brenaut, P., Hovey, R. C., et al. 2014. Comparison of five different RNA sources to examine the lactating bovine mammary gland transcriptome using RNA-Sequencing. Sci Rep 4. doi:10.1038/srep05297

Capecchi, M. R. 2005. Gene targeting in mice: functional analysis of the mammalian genome for the twenty-first century. Nat Rev Genet 6: 507-512.

Carlson, D. F., Tan, W., Hackett, P. B., and Fahrenkrug, S. C. 2014. Editing livestock genomes with site-specific nucleases. Reprod Fertil Dev 26: 74-82.

Civelek, M., and Lusis, A. J. 2014. Systems genetics approaches to understand complex traits. Nat Rev Genet 15:34-48. 
Clarke, L, Archibald, A. L.,Flicek, P., Burt, D. ,Hume, D., Vernimmen, D., et al. 2015. The functional annotation of animal genomes, data standards, annotation and sharing. In Plant and Animal Genome XXIII Conference. Plant and Animal Genome.

Cong, L., Ran, F. A., Cox, D., Lin, S., Barretto, R., Habib, N., et al. 2013. Multiplex genome engineering using CRISPR/Cas systems. Science 339:819-823.

Corradin, O., Saiakhova, A., Akhtar-Zaidi, B., Myeroff, L., Willis, J., Cowper-Sal lari, R., et al. 2014. Combinatorial effects of multiple enhancer variants in linkage disequilibrium dictate levels of gene expression to confer susceptibility to common traits. Genome Res 24: 1-13.

Daetwyler, H. D., Capitan, A., Pausch, H., Stothard, P., van Binsbergen, R., Brøndum, R. F., et al. 2014. Whole-genome sequencing of 234 bulls facilitates mapping of monogenic and complex traits in cattle. Nat Genet 46, 858-865. doi:10.1038/ng.3034.

Das, S. K., and Sharma, N. K. 2014. Expression quantitative trait analyses to identify causal genetic variants for type 2 diabetes susceptibility. World J Diabetes 5:97114.

de Koning, D. J., Cabrera, C. P., and Haley, C. S. 2007. Genetical genomics: combining gene expression with marker genotypes in poultry. Poultry Sci 86:1501-1509.

De Roos, A. P. W., Hayes, B. J., Spelman, R. J., and Goddard, M. E. 2008. Linkage disequilibrium and persistence of phase in Holstein-Friesian, Jersey and Angus cattle. Genetics 179:1503-1512.

Druet, T., Macleod, I. M., and Hayes, B. J. 2014. Toward genomic prediction from whole-genome sequence data: impact of sequencing design on genotype imputation and accuracy of predictions. Heredity 112:39-47.

Falconer, D. S., and Mackay, T. F. C. 1996. Introduction to Quantitative Genetics. Correlated characters: genotype-environment interaction. Pages 321-325. Fourth edition, ed. Longman Greens, Harlow, Essex, UK.

Freedman, M. L., Monteiro, A. N., Gayther, S. A., Coetzee, G. A., Risch, A., Plass, C., et al. 2011. Principles for the post-GWAS functional characterization of cancer risk loci. Nat genet 43:513-518.

Goddard, M. E., and Hayes, B. J. 2012. Bovine Genomics. Linkage disequilibrium in cattle. Pages 192-210. Ed. John Wiley and Sons, Inc. West Sussex, UK.

Hassan, M. A., and Saeij, J. P. 2014. Incorporating alternative splicing and mRNA editing into the genetic analysis of complex traits. BioEssays, 36:1032-1040.

Weir, B. S., and Hill, W. G. 1980. Effect of mating structure on variation in linkage disequilibrium. Genetics 95:477-488.

Hoffman, E. P., Brown, R. H., and Kunkel, L. M. 1987. Dystrophin: the protein product of the Duchenne muscular dystrophy locus. Cell, 51:919-928. 
Jansen, R. C., and Nap, J. P. 2001. Genetical genomics: the added value from segregation. Trends Genet 17:388-391.

Jansen, R. C. 2003. Studying complex biological systems using multifactorial perturbation. Nat Rev Genet 4: 145-151.

Jedrzejczak, M., and Szatkowska, I. 2014. Bovine mammary epithelial cell cultures for the study of mammary gland functions. In Vitro Cell Dev Biol Anim 50: 389-398.

Jiang, J., Cui, W., Vongsangnak, W., Hu, G., and Shen, B. 2013. Post genome-wide association studies functional characterization of prostate cancer risk loci. BMC genomics 14:S9.

Kadarmideen, H. N., von Rohr, P., and L. L. Janss. 2006. From genetical genomics to systems genetics: potential applications in quantitative genomics and animal breeding. Mamm Genome 17:548-564.

Kim, Y. G., Cha, J., and Chandrasegaran, S. 1996. Hybrid restriction enzymes: zinc finger fusions to Fok I cleavage domain. Proc. Natl Acad. Sci. USA 93:1156-1160. doi:10.1073/PNAS.93.3.1156

Lemay, D. G., Ballard, O. A., Hughes, M. A., Morrow, A. L., Horseman, N. D., and Nommsen-Rivers, L. A. 2013. RNA sequencing of the human milk fat layer transcriptome reveals distinct gene expression profiles at three stages of lactation. PloS one 8:e67531.

Lowe, W. L., and Reddy, T. E. 2015. Genomic approaches for understanding the genetics of complex disease. Genom Res 25:1432-1441.

Mali, P., Yang, L., Esvelt, K. M., Aach, J., Guell, M., DiCarlo, J. E., et al. 2013. RNAguided human genome engineering via Cas9. Science 339:823-826.

Marchini, J., and Howie, B. 2010. Genotype imputation for genome-wide association studies. Nat Rev Genet 11:499-511.

Medrano, J.F., Rincon, G.,and Islas-Trejo, A. 2010. Comparative analysis of bovine milk and mammary gland transcriptome using RNA-Seq. In: 9th World congress on genetics applied to livestock production, Leipzig, Germany, August 1-6, 2010, Paper no 0852.

Moscou, M. J., and Bogdanove, A. J. 2009. A simple cipher governs DNA recognition by TAL effectors. Science 326:1501-1501.

Parikshak, N. N., Gandal, M. J., and Geschwind, D. H. 2015. Systems biology and gene networks in neurodevelopmental and neurodegenerative disorders. Nat Rev Genet 16:441-458.

Pausch, H., Aigner, B., Emmerling, R., Edel, C., Götz, K. U., and Fries, R. 2013. Imputation of high-density genotypes in the Fleckvieh cattle population. Genet Sel Evol 45:10-1186. 
Proudfoot, C., Carlson, D. F., Huddart, R., Long, C. R., Pryor, J. H., and King, T. J., et al. 2015. Genome edited sheep and cattle. Transgenic Res 24:147-153.

Schadt, E. E., Lamb, J., Yang, X., Zhu, J., Edwards, S., GuhaThakurta, D., et al. 2005. An integrative genomics approach to infer causal associations between gene expression and disease. Nat Genet 37:710-717.

Shalem, O., Sanjana, N. E., and Zhang, F. 2015. High-throughput functional genomics using CRISPR-Cas9. Nat Rev Genet 16:299-311.

Sham, P. C., and Purcell, S. M. 2014. Statistical power and significance testing in largescale genetic studies. Nat Rev Genet, 15:335-346.

Shen, Y., Yue, F., McCleary, D. F., Ye, Z., Edsall, L., Kuan, S., et al. 2012. A map of the cis-regulatory sequences in the mouse genome. Nature 488:116-120.

Stein, L. 2001. Genome annotation: from sequence to biology. Nat Rev Genet 2:493503.

Taşan, M., Musso, G., Hao, T., Vidal, M., MacRae, C. A., and Roth, F. P. 2015. Selecting causal genes from genome-wide association studies via functionally coherent subnetworks. Nat Methods, 12:154-159.

Trapnell, C., Williams, B. A., Pertea, G., Mortazavi, A., Kwan, G., van Baren, M. J., et al. 2010. Transcript assembly and abundance estimation from RNA-Seq reveals thousands of new transcripts and switching among isoforms. Nat Biotechnol 28: 511-515.

Uemoto, Y., Sasaki, S., Sugimoto, Y., and Watanabe, T. 2015. Accuracy of high-density genotype imputation in Japanese Black cattle. Anim Genet 46: 388-394.

VanRaden, P. M., Null, D. J., Sargolzaei, M., Wiggans, G. R., Tooker, M. E., Cole, J. B., et al. 2013. Genomic imputation and evaluation using high-density Holstein genotypes. J Dairy Sci 96:668-678.

Wang, E. T., Sandberg, R., Luo, S., Khrebtukova, I., Zhang, L., Mayr, C., et al. 2008. Alternative isoform regulation in human tissue transcriptomes. Nature 456:470476.

Wickramasinghe, S., Rincon, G., Islas-Trejo, A., and J. F. Medrano. 2012. Transcriptional profiling of bovine milk using RNA sequencing. BMC genomics 13:1 Wickramasinghe, S., Cánovas, A., Rincón, G., and Medrano, J. F. 2014. RNAsequencing: a tool to explore new frontiers in animal genetics. Livest Sci, 166: 206216.

Yang, D., Yang, H., Li, W., Zhao, B., Ouyang, Z., Liu, Z., et al. 2011. Generation of PPARY mono-allelic knockout pigs via zinc-finger nucleases and nuclear transfer cloning. Cell Res 21:979. 
Yang, Y., Wang, Q., Chen, Q., Liao, R., Zhang, X., Yang, H., et al. 2014. A new genotype imputation method with tolerance to high missing rate and rare variants. PloS one 9:e101025.

Yu, S., Luo, J., Song, Z., Ding, F., Dai, Y., and Li, N. 2011. Highly efficient modification of beta-lactoglobulin (BLG) gene via zinc-finger nucleases in cattle. Cell Res. 21:1638-1640. doi:10.1038/CR.2011.153

Yue, F., Cheng, Y., Breschi, A., Vierstra, J., Wu, W., Ryba, T, et al. 2014. A comparative encyclopedia of DNA elements in the mouse genome. Nature 515:355-364.

Zhang, Z., and Druet, T. 2010. Marker imputation with low-density marker panels in Dutch Holstein cattle. J Dairy Sci 93:5487-5494.

Zhao, K., Liu, H. Y., Zhou, M. M., and Liu, J. X. 2010. Establishment and characterization of a lactating bovine mammary epithelial cell model for the study of milk synthesis. Cell Biol Int 34: 717-721.

Zhou, H., Ross, P.J., Korf, I., Delany, M. E., Cheng, H., Medrano, J. F., et al. 2015. Annotation of functional regulatory elements in livestock species. In ADSA-ASAS 2015 Midwest Meeting. Asas. 

Summary 



\section{Summary}

The present thesis aims at unraveling the genetic background of bovine milk composition by finding genes associated with milk-fat composition and noncoagulation of milk. The fine-mapping was realized by increasing the number of genotypes analyzed in the targeted chromosomal regions. This allowed to increase the resolution for these genomic regions and pin-point candidate genes associated with bovine milk composition.

In Chapter 2, we analyzed milk fat composition in winter and summer and estimated in both seasons' genetic parameters, the effects of acyl-CoA: diacylglycerol acyltransferase1 (DGAT1) K232A and stearoyl-CoA desaturase1 (SCD1) A293V polymorphisms. Furthermore, we estimated genetic correlations between winter and summer milk fatty acids and tested for genotype by season interactions of DGAT1 K232A and SCD1 A293V polymorphisms. Phenotypes consisted of gas chromatography measurements $(\% \mathrm{w} / \% \mathrm{w})$ of seventeen individual fatty acids (C4:0 to C18:0, C10:1 to C18:1cis-9, C18:1trans-11, C18:2cis-9,trans-11 (CLA), C18:2cis9,12 and C18:3cis-9,12,15), groups of fatty acids (saturated FA (SFA), unsaturated FA (UFA) and the ratio SFA to UFA), and six unsaturation indices (C10 index - CLAindex). These phenotypes were available for 2,001 cows in winter and in summer milk samples. We showed that the genetic correlations between winter and summer milk FA were very high, and these indicated that milk-fat composition in winter and in summer can largely be considered as genetically the same trait. We showed that effects of DGAT1 K232A and SCD1 A293V polymorphism were very similar in winter and in summer milk for most FA. At last, we tested for genotype by season interactions, and demonstrated significant DGAT1 K232A by season interaction for some FA. A SCD1 A293V by season interaction was only found for C18:1trans-11. These genotype by season interactions were due to scaling of genotype effects.

In Chapter 3 and in Chapter 4, we used a subset of the fatty acids analyzed in Chapter 2. This subset consisted of six individual FA (C4:0 - C14:0) were available for winter and for summer milk samples.

In Chapter 3, a quantitative trait locus (QTL) on Bos taurus autosome (BTA) 17 explaining a large proportion of the genetic variation in de novo synthesized milk FA was fine-mapped. This QTL region has been identified previously using 50k SNP genotypes. We fine-mapped this QTL region with imputed 777k single nucleotide polymorphism (SNP) genotypes to identify candidate genes associated with milk FA composition. Single-SNP analyses showed that several SNP in a region located 
between 29.0 and 34.0 mega base-pairs were in strong association with C6:0, C8:0, and C10:0. This region was further characterized based on haplotypes, and these analyses suggested the presence of one causal variant. Although many genes are present in this QTL region on BTA17, the strongest association was found close to the progesterone receptor membrane component 2 (PGRMC2) gene. This gene has not been associated previously to milk FA composition.

In Chapter 4, the chromosomal region associated with de novo synthesized milk FA on BTA17 was further re-fined using imputed whole-genome sequences (WGS). WGS were available for 450 Holstein-Friesian (HF) animals (the 1000 bull genome consortium (Run5) and $45 \mathrm{HF}$ sequenced animals from the Dutch Milk Genomics Initiative. Based on these $495 \mathrm{HF}$ sequences, all cows were imputed from (imputed) 777k SNP genotypes to sequence level. Single-marker analyses identified many significant associations (in the thousands) with c6:0, c8:0, c10:0, c12:0 and c14:0. Most significant associations were detected in a region covering 5 mega base-pairs and in this region a total of 14 genes could be identified. Six out of the 8 SNP that showed the strongest associations were located in the LA ribonucleoprotein domain family, member 1B (LARP1B) gene. This candidate gene has not been associated with milk-fat composition before.

In Chapter 5, firstly, we performed a GWAS using 777k SNP genotypes to identify the most promising genomic regions associated with non-coagulation (NC) of milk in Swedish Red cows. Secondly, we fine-mapped the most promising genomic region using imputed sequences. Individual morning milk samples were available for the 382 Swedish Red cows that were also genotyped using a 777k SNP array. Using 429 sequences from the 1000 bull genome consortium (Run 3), all cows were imputed from $777 \mathrm{k}$ to sequence level. Single-marker analyses identified 14 associations with NC milk in a 7 mega base-pairs region on BTA18. For this region, our strongest association explained almost $34 \%$ of the genetic variation in NC milk. Haplotypes were built, genetically differentiated by means of a phylogenetic tree, and tested in phenotype-genotype association studies. A candidate gene is the vacuolar protein sorting 35 homolog, mRNA (VPS35) gene, for which one of our strongest association is an intron SNP in this gene. The VPS35 gene belongs to the mammary gene sets of pre-parturient and of lactating cows, and has not been associated to milk composition yet.

In Chapter 6, the general discussion is presented. Firstly, I discuss the imputation to high-density genotypes and the annotation of the cattle genome. I discuss what 
imputation is, the factors which affect imputation accuracy, and the consequences of using imputed genotypes for GWAS and fine-mapping studies. Regarding the annotation of the cattle genome, I discuss the major difficulties in finding candidate genes with the current annotation, and discuss future initiatives that will contribute for a better annotation of genomes in the future.

Secondly, the future possibilities to expand gene discovery are discussed. In this section, the discussion starts with the importance of identifying causal variants underlying complex traits. The discussion continues by exploring possibilities, such as targeted gene-expression studies, eQTL, gene editing and knockout cows, to identify the causal variants underlying complex traits 

Training and education 

Training and Supervision Plan

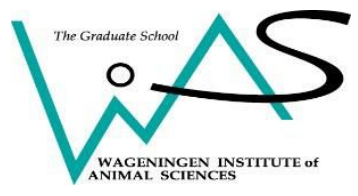

\begin{tabular}{|c|c|c|}
\hline The Basic Package (9 ECTS) & year & credits* \\
\hline Welcome to EGS-ABG & 2011 & 2.0 \\
\hline WIAS Introduction Course & 2011 & 1.5 \\
\hline Course on philosophy of science and/or ethics & 2011 & 1.5 \\
\hline EGS-ABG Summer Research School Aarhus/Denmark & 2012 & 2.0 \\
\hline EGS-ABG Summer Research School SLU/Sweden & 2014 & 2.0 \\
\hline Scientific Exposure (13.0 ECTS) & year & credits* \\
\hline \multicolumn{3}{|l|}{ International conferences (4.5 ECTS) } \\
\hline 63th EAAP Annual Meeting, Bratislava, Slovak Republic & 2012 & 1.2 \\
\hline \multicolumn{3}{|l|}{ 9th International Symposium on Milk Genomics and } \\
\hline Human Health, Wageningen, Netherlands & 2012 & 0.6 \\
\hline \multicolumn{3}{|l|}{ 11th World Conference in Animal Breeding and } \\
\hline Genetics, Vancouver, Canadá & 2014 & 1.5 \\
\hline 66th EAAP Annual Meeting, Warsaw, Poland & 2015 & 1.2 \\
\hline \multicolumn{3}{|l|}{ Seminars and workshops (4.0 ECTS) } \\
\hline Nutrition and fat metabolism in dairy cattle & 2011 & 0.3 \\
\hline WIAS Science Day $(2012,2013,2016)$ & 2012 & 0.9 \\
\hline Workshop on Techniques for Measuring Milk & & \\
\hline Phenotypes & 2012 & 0.6 \\
\hline WIAS Seminar: Aspects of sow and piglet performance & 2013 & 0.3 \\
\hline \multicolumn{3}{|l|}{ Symposium Genetics of Social Life: Agriculture Meets } \\
\hline Evolutionary Biology & 2013 & 0.3 \\
\hline Mini-symposium: How to write a world-class paper & 2013 & 0.3 \\
\hline WIAS Seminar Genomic selection for novel traits & 2013 & 0.3 \\
\hline Seminar series HGEN at SLU, Uppsala, Sweden & 2014 & 1.0 \\
\hline \multicolumn{3}{|l|}{ Presentations (6.0 ECTS) } \\
\hline $\begin{array}{l}\text { WIAS Science day2012, Wageningen, Netherlands - } \\
\text { poster }\end{array}$ & 2012 & 1.0 \\
\hline
\end{tabular}




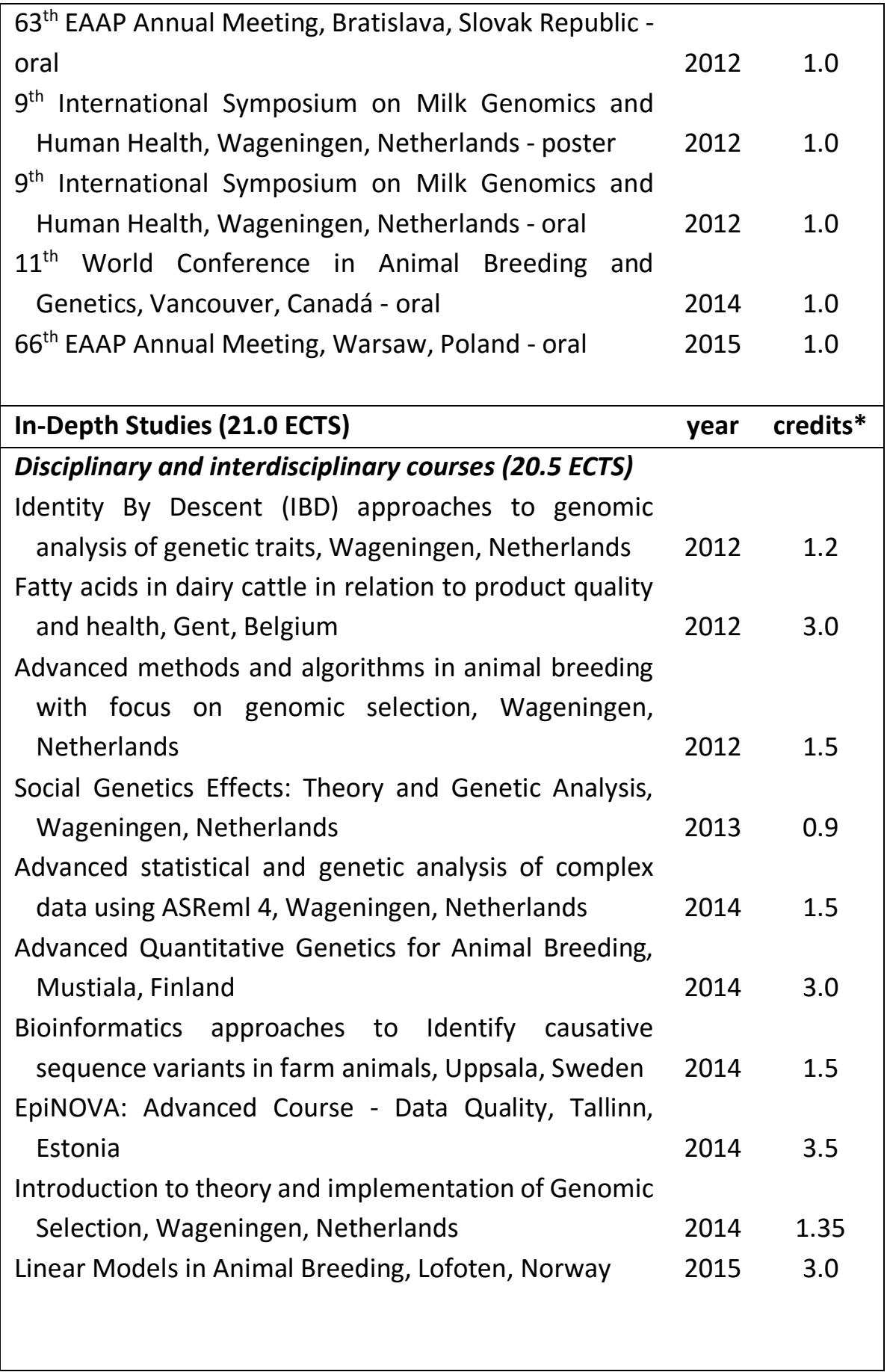




\begin{tabular}{|c|c|c|}
\hline $\begin{array}{l}\text { PhD students' discussion groups (1 ECTS) } \\
\text { Quantitative Genetic Discussion Group (2011-2013, } \\
\text { 2015) }\end{array}$ & 2011 & 1.0 \\
\hline Professional Skills Support Courses (9.0 ECTS) & year & credits* \\
\hline Techniques for Writing and presenting a Scientific Paper & 2012 & 1.2 \\
\hline Course Supervising MSc thesis work & 2012 & 1.0 \\
\hline Project and Time Management & 2013 & 1.5 \\
\hline Scientific Writing & 2013 & 1.8 \\
\hline Writing Grant Proposals & 2015 & 2.0 \\
\hline Social Dutch for employees & 2013 & 1.8 \\
\hline Research Skills Training (2.0 ECTS) & year & credits* \\
\hline External training period at SLU, Sweden & 2014 & 2.0 \\
\hline Management Skills Training (6 ECTS) & year & credits* \\
\hline \multicolumn{3}{|l|}{ Organization of seminars and courses (2.0 ECTS) } \\
\hline \multicolumn{3}{|l|}{ Advanced methods and algorithms in animal breeding } \\
\hline \multicolumn{3}{|l|}{ Membership of boards and committees (4.0 ECTS) } \\
\hline WAPS council member (2012-2013) & 2012 & 2.0 \\
\hline EGS-ABG student representative (2011-2013) & 2011 & 2.0 \\
\hline
\end{tabular}

* one ECTS credit equals a study load of approximately 28 hours 

Curriculum vitae 



\section{About the author}

Sandrine Isolde Duchemin is born on the $4^{\text {th }}$ August 1975 in Vendôme, France. When she was 5 years old, her family emigrated to Brazil. She obtained her first bachelor in Economic Sciences at Pontifícia Universidade Católica do Rio de Janeiro (PUC-RJ) in 1998. After a few years, she changed her career orientation and, in 2009, Sandrine became Doctor in Veterinary Medicine (DVM). Her bachelor thesis was entitled "Utilização de embriões F1 produzidos in vitro em rebanhos leiteiros comerciais e em rebanho controlado". In August 2009, she started the European Masters in Animal Breeding and Genetics (EM-ABG). This program gave her the opportunity to stay one year in the Netherlands, and one year in France. During these two years, she wrote two major theses. The first major thesis was written in the Netherlands, entitled "Effects of polymorphisms in DGAT1 and SCD1 on milk-fat composition of summer milk samples", and the second major thesis was written in France, entitled "Genomic selection in Lacaune dairy sheep". In August 2011, she received her double-degree Masters in Animal Breeding and Genetics. In September 2011, she started her $\mathrm{PhD}$, which is part of the European Graduate School in Animal Breeding and Genetics (EGS-ABG). While most of her PhD was done at Wageningen (Netherlands), she had the opportunity to spend one year at Uppsala (Sweden). The results of her PhD are presented in this thesis entitled "Mapping and fine-mapping of genetic factors affecting bovine milk composition." 


\section{Peer-reviewed publications}

Duchemin, S. I., Colombani, C., Legarra, A., Baloche, G., Larroque, H., Astruc, J.-M., Barillet, F., Robert-Granié, C., and E. Manfredi. 2012. Genomic selection in the French Lacaune dairy sheep breed. J Dairy Sci 95:2723-2733.

Duchemin, S. , H. Bovenhuis, W. M. Stoop, A. C. Bouwman, J. A. M. van Arendonk, and M. H. P. W. Visker. 2013. Genetic correlation between composition of bovine milk fat in winter and summer, and DGAT1 and SCD1 by season interactions. J Dairy Sci 96:592-604.

Duchemin, S. I., Visker, M.H.P.W., Van Arendonk, J.A.M., and Bovenhuis, H. 2014. A quantitative trait locus on Bos taurus autosome 17 explains a large proportion of the genetic variation in de novo synthesized milk fatty acids. J Dairy Sci 97: 72767285 .

Duchemin, S. I., Glantz, M., de Koning, D-J., Paulsson, M., and W.F. Fikse. 2016. Identification of QTL on chromosome 18 associated with non-coagulating milk in Swedish Red cows. Front Genet 7:57. doi: 10.3389/fgene.2016.00057.

\section{Manuscripts in preparation}

Duchemin, S. I., Bovenhuis, H., Megens, H-J., Van Arendonk, J. A. M., and M. H. P. W. Visker. Fine-mapping of BTA17 using imputed sequences for associations with de novo synthesized fatty acids in bovine milk.

\section{Conference papers}

Robert-Granié, C., Duchemin, S., Larroque, H., Baloche, G., Barillet , F., MorenoRomieux, C., Legarra, A., and E. Manfredi. A comparison of various methods for the computation of genomic breeding values in French Lacaune dairy sheep breed. In: 62th Annual Meeting of the European Federation of Animal Science (EAAP), Stavanger, Norway in August 2011.

Duchemin, S. I., Bovenhuis, H., Stoop, W. M., Bouwman, A. C., van Arendonk, J. A. M., and Visker, M. H. P. W. Genetic relation between composition of bovine milk fat in winter and summer. The $9^{\text {th }}$ International Symposium Milk Genomics and Human Health, Wageningen, The Netherlands, October 2012. 
Duchemin, S.I., Visker, M. H. P. W., Van Arendonk, J. A. M., and Bovenhuis, H. Finemapping of a chromosomal region on BTA17 associated with milk-fat composition. In: 64th Annual Meeting of the European Federation of Animal Science (EAAP), Nantes, France in August 2013.

Duchemin, S. I., Visker, M. H. P. W., Van Arendonk, J. A. M., and Bovenhuis, H. Finemapping of a candidate region associated with milk-fat composition on Bos taurus autosome 17. Proceedings of 10th World Congress on Genetics Applied to Livestock Production (WCGALP), Vancouver, Canadá in August 2014.

Duchemin, S. I., Glantz, M., de Koning, D-J, Paulsson, M., and Fikse, W. F. Finemapping of a QTL region on BTA18 affecting non-coagulating milk in Swedish Red cows. In: 66th Annual Meeting of the European Federation of Animal Science (EAAP), Warsaw, Poland in September 2015.

Duchemin, S. I., Glantz, M., de Koning, D-J, Paulsson, M., and Fikse, W. F. Finemapping of non-coagulating milk in Swedish Red cows using sequences. In: IDF parallel symposia, Dublin, Ireland in April 2016. 

Acknowledgements 



\section{Acknowledgements}

To God: Thank you for this third opportunity.

To my friends and colleagues: Acknowledgements are always a very difficult task to write. And throughout this PhD, lots of people have contributed directly and indirectly to this achievement. I would like to say thank you to each and every one of you who contributed, but in a different way.

This is the year 2009 and I am decided to make some changes. Yet, I have no idea what is to come. Guided by my will, this idea grows stronger and stronger inside my heart. After a few clicks and a directed search on the internet, I find EM-ABG. The advertisement seem too good to be true. Never mind: I subscribe. The road ahead is unknown, and one of the most important journeys of my life is about to start.

Exactly three days after I subscribed, I receive an e-mail from the captain of ABGC, Johan Van Arendonk, asking me if I would like to apply for a scholarship that would cover my living expenses while on board. I will never forget that I really thought it was a phishing attempt. After successfully getting the scholarship, I travel to this far distant new world called the Netherlands. In my luggage, some pieces of clothes and a heart full of hope and eager for adventure. After 26 hours of travel, I finally arrive to this beautiful place called Wageningen Bay.

What an exciting first view! Beyond the main deck of $A B G C$, I can see Forum Building as the harbor that connects all the other ships. The joy and the excitement are suddenly cut by the voice of the captain: "You have the opportunity and the privilege to be part of this diverse and multicultural team. Enjoy the training, the trip, and have fun!". After a few introductions, EM-ABG are sent to the hold of ABGC ship, where during two years, me and my colleagues will struggle with codes, cleaning data and learning all aspects of the genetic architecture of traits in Animal Breeding and Genetics. As final exam, I am challenged to sail across these beautiful and calm waters of Wageningen Bay. The final result is priceless! After two unforgettable years, the training is completed.

I would like to kindly thank Johan, Dieuwertje, Patricia, Marleen, Aniek, Ada, Gerda, Piet, Eduardo, Christelle, Andrés, Guillaume and all the teachers for their support, guidance and friendship during EM-ABG. I would kindly thank the Koepon family for the amazing opportunity that they offered me.

This is the year 2011, and new challenges have been announced: there is a possibility of subscribing to EGS-ABG. The catchy advertisement comes with a difficult mission: sailing to the North in the open sea. Without hesitation, I subscribe. :-) .All on 
board", shouts Captain Johan! EGS-ABG gathers together for the first time. The main deck is a huge promotion for most of us. Some came with more experience than others, and the group is very diverse. At first sight, this is going to be challenging. The main deck is indeed a huge responsibility. But we are not alone, at least we think so! All PhD receive specific jobs, but our destination remains unknown. Only the captain and his crew know the direction ABGC ship is heading for. The sails are lifted, and in no time, we leave the quiet and calm waters of Wageningen Bay!

Under the supervision of Colonel Henk and Major Marleen, I happily start my task. After a few months at sea, the excitement has been replaced by a tedious and continuous routine. Asreml, Excel, Linux and $\mathrm{R}$ are just part of the job, which is complemented with endless meetings with Colonel Henk and Major Marleen. To keep the spirit alive, some strategic stops are planned, like harbors Pub-Quiz, WEday and ABGC day-outs. Ahead of us, the first storm in sight: the huge storm coined "Paper One". Paper One Storm soon brings lots of bumpy waves and strong winds. Winds from the North and South reviewers that seemed to battle endlessly with us on the main desk. I almost was thrown out of the main deck. Colonel Henk shouting endless orders, followed by obedient Major Marleen, and a beaten up PhD Sandrine. "Pull the sails down!" shouts Colonel Henk, "The reviewers are angry", he continues. "We need to hold ourselves, 'cause these winds are too strong!!!!". Milk Genomics meetings, presentations, minutes, discussions, posters, endless shift hours, few sets of brilliant ideas, a list of new suggestions, and frustration stepping in at high speed. These were unusual times for me, and all my expectations changed. Would I be able to continue? At these times, the excellent team of PhDs is like an island of comfort in these troubled waters. After discussing and sharing our deepest fears and frustrations, the morale of the PhDs substantially improves. Motivated as I have never been before, I think: "Let's go through this storm, let's do this!". Welcome meetings, presentations, minutes, discussions, posters, QDG, TLMs! Finally, Paper One Storm has passed; and I remember thinking: "OUF, I survived!".

I would like to kindly thank Johan, Henk and Marleen for their guidance and support throughout the PhD. Yes, I do not come with a manual, but neither do you. (-). I would kindly thank CRV for their financial support for the last year of my PhD. I would kindly say thank you to Erik Mullaart for your constant interest in my work, Daylan, Elsa, Kasper, and Hein for the nice discussions within Milk Genomics. I would like to say thank you to Mahlet, Marzieh, Yogesh, Hooiling, Troncg, Susan, Ewa, Katrijn, Naomi, Gabriel, Marcos, Hamed, Mirte, Bert, Kimberly, Sabine, Tessa, Jovana, Sonia, Maria, Zih-Hua, Anoop, Maulik, Vinicius, Coralia, Amabel, Mathijs, Claudia, Kasper, Saskia, Mathieu, Floor, Qiuyu, Mandy, Wosseni, Robert, Haibo, Shuwen, Yvonne, Esther, Ilse, 
Anouk, Aniek, Jérémie, Alex, Rosilde and Maya. I would also like to say thank you to Pim, Henry, Jan, Piter, Liesbeth, John, Richard, Martin, and all the other staff members for all the discussions at QDG and at lunch breaks.

In subsequent years, ABGC ship came across some other important storms. I can say Paper One Storm prepared me for the next storms that were still to come. However, nothing was as frightening as in 2013 when the sea started shaking so much that I was sea-sick. This has never happened before. After receiving a lot of help from my good friend Marshall Dieuwertje, I discover that I have to go back to Rio de Janeiro Bay and stay some time recovering while on land. Before I left, Captain Johan was very supportive "Sandrine", he said, "Take your time, health is more important than anything. When you are fully recovered you come back." How grateful I am to have this kind of support. I leave ABGC ship thinking: "I will be back before you know it".

A few months later, I return to $A B G C$ ship. A part of me is excited. I miss being at $A B G C$, I miss the EGS-ABG gang, all the other PhDs, I miss the Marshalls, the nice friends and colleagues, and I miss the blue Sea of Knowledge that lies in front of ABGC ship. The other part of me is different. I have deeply changed after the sickness, and things do not look the same. It seems that time has continued for everyone, and it has stopped for me. Caught in my thoughts, I hear this voice behind me, "Oh dear, don't be sad, everything is going to be fine". I look back, and see Marshall Ada. She continues: "Your program has been upgraded. You just need time to get used to it. All will be fine at the end. You will see, relax, and no worries". I am so grateful to be hearing this. And Marshall Lisette adds a little more: "No worries, we, 1975 are the best! I am sure you will recover in no time. Hey girl, we are "75s! Uh-u!". My heart is feeling lighter again, and I think proudly to myself: "Yes, 'mam. I am a '75s. Go for it!".

Dieuwertje, I will never forget how much you helped me. Thank you! For all the support and help on this difficult phase, I acknowledge Dr. Cafure and his family, my family, Johan, Marleen, and Henk. I would like to say thank you for the amazing support and hard work that Ada and Lisette did. "Lieve Dames, dank jullie wel!"

This is the year 2014, and on this very sunny day, Captain Johan, Colonel Henk and Major Marleen altogether announce my final destination: "Sandrine", said captain Johan, "You are going to the North Pole. There, you will spend some time in a ship called SLU. The captain is a good friend of mine and you can learn lots of things from him and his crew. I argued back: "Captain, my Captain! These are dangerous waters. I am going to freeze to death!" "Naja", says Captain Johan, "You just need some good clothes, then it will be OK!". Colonel Henk watching me worried, says "Sandrine, keep 
an eye on polar bears. Beware of sliding bears! They can swipe you out of the deck!". "Safe trip! "said Major Marleen. After waving goodbye to all colleagues and friends, and gathering nice tips from my fellow PhD Dianne, my puzzlement was replaced by the eagerness of discovering this new boat, place and crew.

It is on a summer sunny day when I finally reach ship SLU. This boat was somewhat surprising; the main deck was round. I was a little lost at first, especially because so many people around me were saying "Fiiiikka!". I could not stop thinking: "What a strange language!". "AH, AH", says this voice at the far end of the deck. "You made it! Welcome, welcome to the main deck of the SLU ship. By the way, I am Captain DJ and this is my crew: Major Freddy, Lieutenants Fernando and Lisa. You also know Nancy and André!". It was so nice to see these familiar faces. Very supportive PhDs Nancy and André helped me settling in very fast. In no time, the round deck became a very familiar place. But there was that dark side of the deck. I turn to André, and ask: "Hey bro, what is on that dark side of the deck?". "Sandrine, follow me", he said. In no time, we step into the dark side, and André says: "Meet the SLU Mafia!". "Hey, bro! Who is THAT? You are not supposed to bring strange people in." says this PhD to André. She turns to me and says: "My name is Agnese, and I am sort of the leader of the SLU mafia! And these are Merina, Chrissy, Bingjie, Ahmed, Thu, Shizhi, Xiaowei, and all the others! This is where all the PhD gather and organize many parties and all sorts of activities! You are most welcome to join! By the way, Fiiiiikkka." I thought "And here we go again". :-

It was mid-October 2014 and strong winds were bringing very dark clouds that marked the beginning of the winter. The forecast was announcing light snow for the evening, and at the main deck, I noticed that the days were getting shorter quite rapidly. Captain DJ in his usual good shoes was sort of inspired: "Sandrine, the weather is not an issue, we are inside the ship. For some months, the main deck will remain closed, and we will be stuck in the North Pole until spring, next year." I say: "WHAT????? Spring is in April, we are gonna die!" Major Freddy and Lieutenant Fernando started their usual jokes "Ah, Ah, we are gonna die indoors, so we will go out to ski, ice-skate and all sorts of nice things! It will be fun! You will see!". The next morning the weatherman announces: "Yesterday, it only snowed one meter of snow." "Whow, this winter is gonna be promising", I thought.

I would like to say thank DJ and Freddy for all the support that you gave me while in Sweden and afterwards. Thank you Maria and Marie for all the nice comments. A special thank you to Lisa because you let me stay two months in your house, and I am really grateful for this. Fernando, Karl and Cano thanks for keeping me smiling. A 
special thank you to the SLU Mafia. Thank you for all the amazing stuff we did together: "Guys, you rock!". Thanks Sofia, Kim, Emilie, Thomas, Eva and Valentina for the nice discussions.

Thank you Dianne for the tips before I went to Sweden, especially the one to go to Kiruna! It was fantastic! Nancy and André: Hey you two! I shall never forget you! After a PhD, we shared so many moments! I can only say: thanks for everything.

This is the year 2015 and spring makes its way in this rather dark room. This new ship ABGC 2.0 is located in the middle of this rather dark forest. A change that I notice, especially after spending sometime at the North Pole. This is the last chapter of this tremendous adventure called EGS-ABG to me. I have experienced so much, and many $\mathrm{PhD}$ have harvested their thesis already. The direction set for me now is towards the sun. I am heading full speed towards the final stage of every training: the Aula. This period of time is intense, and everything has to be ready before spring 2016. Courses have to be finalized, all the Storm Papers are mastered by now, and the final challenge makes its entrance in no time: Hurricane General Discussion. Winds much stronger than expected and waves just look like mountains of waters in front of ABGC 2.0 ship. Everything is so dark, and suddenly caught off guards, I fell in the sea. "Woman at Sea", shouts the Captain. I am safe and sound. I am quite lucky because new EGS-ABG and PhDs have started their training.

So nice to meet them with their high spirits and hearts full of determination. The nice and quiet main deck is suddenly taken by their voices, bringing a new sense of hope. They do not realize, but they came to the rescue right on ... "DRING, DRING", I am immediately transposed at the computer behind my desk at Radix building. "DRING, DRING", insists the phone. "Bonjour Maman, Bonjour Papa!"...

Para minha Família: Merci Maman et Papa! Merci pour tous ce que vous avez fait pour moi et de m'avoir enseignée ce que l'amour inconditionnel est. Je vous aime! Merci Yvan et Stéphane, pour les visites, voyages et vos soucis. Obrigada MariaClaudia e Sophia pelo carinho. Obrigada à tia Carmen, tio Reimar, Alexandra, Simão, Felipe, Mariana, Fernando e à falecida tia Margitte por todo o carinho, interesse e apoio.

Afinal, um PhD não é fruto de coincidências. É fruto de muito trabalho, e dedicação. Por isso, estendo os meus agradeçimentos a todos os meus professores da FAAValença/RJ, e em especial à minha amiga Aparecida e ao meu amigo Generoso. 

Colophon 


\section{Colophon}

The work performed in Chapters 2, 3 and 4 are part of the Dutch Milk Genomics Initiative, funded by Wageningen University, the Dutch Dairy Association (NZO), Cooperative Cattle Improvement Organization (CRV; Arnhem, the Netherlands), and the Dutch Technology Foundation (STW). The work performed in Chapter 5 was financed by the Swedish Farmer's Foundation for Agricultural Research (SLF), Stockholm, Sweden.

The author was supported by the European Commission (within the framework of the Erasmus-Mundus joint doctorate "EGS-ABG") and Breed4Food (a public-private partnership in the domain of animal breeding and genomics and CRV).

The cover of this thesis was designed by Sandrine I. Duchemin.

The thesis was printed by Digiforce | Proefschriftmaken.nl, De Limiet 26, 4131NC, Vianen, the Netherlands. 